\title{
An Engineering and Cost Comparison of Three Different All-Dry Cooling Systems
}

by

Brent C. Fryer

Daniel J. Braun

David J. Braun

Duane W. Faletti

Lawrence E. Wiles

September 1976

Prepared for the Energy Research and Development Administration under Contract $\mathrm{E}(45-1)-1830$ 
NOTICE

This report was prepared as an account of work sponsored by the United States Government. Neither the United States nor the Energy Research and Development Administration, nor any of their employeas, nor any of their contractors, subcontractors, or their employees, makes any warranty, express or impled, or assumes any legal liability or rasponsibility for the accuracy, completeness or usefulness of any information, apparatus, product or process disclosed, or represents that its use would not infringe privately owned rights.

\author{
PACIFIC NORTHWEST LABORATORY \\ operated by \\ BATTELLE \\ for the \\ ENERCY RESEARCH AND DEVELOPMENT ADMINISTRATIDN \\ Under Contract EY-76-C-06-7830
}
Printec in the United States or America
Available from
National Technical information Service
U.S. Department of Commerce
5285 Po: Royal Road
Springfizid, Virginia 2215

Price: Printed Copy 5

$\therefore$ Microfiche $\$ 3.00$

$\begin{array}{lc}\text { *Pages } & \text { Selling Price } \\ 001-025 & 54.50 \\ 026-050 & 55.00 \\ 051-075 & 55.50 \\ 076-100 & 56.00 \\ 101-125 & 56.50 \\ 126-150 & 57.00 \\ 151-775 & 57.75 \\ 176-200 & 58.50 \\ 201-225 & 58.75 \\ 226-250 & 55.00 \\ 251-275 & 51000 \\ 27-300 & 57025\end{array}$


by

Brent C. Fryer

Daniel J. Braun

David J. Braun

Lawrence E. Wiles

Duane W. Faletti

September 1976

BATTELLE

Pacific Northwest Laboratories

Richland, Washington 99352 



\section{FOREWORD}

The Dry Cooling Tower Development Program at Battelle, Pacific Northwest Laboratory was initiated with a program scope that included the following near-term and ultimate emphases.

Near-Term Objectives:

- Develop economic and performance models for cost optimization of total heat rejection systems using dry cooling.

- Analyses of, and dissemination of experience on, existing drycooled plant performance.

- Demonstrate certain features of existing technology equipment to provide confidence for specification by utilities.

Ultimate Objective:

- Promote water conservation through industry use of dry cooling by developing and demonstrating the reliability of lower-cost systems. The development of advanced dry/wet systems is also considered to be within this scope.

Over the past two years the following documents have been issued, reporting the results of the work toward these objectives.

Cost optimization of dry-cooled heat rejection systems:

A REVIEW AND ASSESSMENT OF ENGINEERING ECONOMIC STUDIES OF DRY COOLED ELECTRICAL GENERATING PLANTS. B. C. Fryer, BNWL-1976, March 1976.

HEAT TRANSFER AND PRESSURE DROP CHARACTERISTICS OF DRY TOWER EXTENDED SURFACES. PART I: HEAT TRANSFER AND PRESSURE DROP DATA. PFR Engineering Systems, Inc., PFR 7-100, March 1976.

HEAT TRANSFER AND PRESSURE DROP CHARACTERISTICS OF DRY TOWER EXTENDED SURFACES. PART II : DATA ANALYSIS AND CORRELATION. PFR Engineering Systems, Inc., PFR 7-102, June 1976. 
Analysis of performance of existing dry-cooled plants:

DRY COOLING TOWER PROGRAM: RESULTS OF INDUSTRIAL CONTACTS THROUGH AUGUST 1974. BNWL-1878, November 1, 1974.

A SURVEY OF MATERIALS AND CORROSION PERFORMANCE IN DRY COOLING APPLICATIONS. A. B. Johnson, Jr., D. R. Pratt and G. E. Zima, BNWL-1958, March 1976.

EUROPEAN DRY COOLING TOWER OPERATING EXPERIENCE. J. G. DeSteese and K. Simhan, BNWL-1995, March 1976.

MATHEMATICAL AND EXPERIMENTAL INVESTIGATIONS ON DISPERSION AND RECIRCULATION OF PLUMES FROM DRY COOLING TOWERS AT WYODAK POWER PLANT IN WYOMING. Y. Onishi and D. S. Trent, BNWL-1982, February 1976.

Advanced dry (dry/wet) cooled systems:

PREL IMINARY EVALUATION OF WET/DRY COOLING CONCEPTS FOR POWER PLANTS. W. V. Loscutoff, BNWL-1969.

COMPATIBILITY OF AMMONIA WITH CANDIDATE DRY COOLING SYSTEM MATERIALS. D. R. Pratt, BNWL-1992, Apri1 1976.

SCALE FORMATION IN DELUGED DRY COOLING SYSTEMS. D. R. Pratt, BNWL-2060, March 1976.

AMMONIA AS AN INTERMEDIATE HEAT EXCHANGE FLUID FOR DRY COOLED TOWERS. R. T. Allemann, B. M. Johnson and G. C. Smith, BNWL-SA-5997, September 1976.

A group of reports (including this report) has recently been issued. This group serves the dual purpose of developing cost optimization models for dry cooling systems based on available technology and comparing the results of analyzing the costs of these systems with the projected cost of several advanced dry and dry/wet systems. Included in this group are:

AN ENGINEERING AND COST COMPARISON OF THREE DIFFERENT ALL-DRY COOLING SYSTEMS. B. C. Fryer, D. W. Faletti, Dan J. Braun, David J. Braun and L. E. Wiles, BNWL-2121, September 1976.

A STUDY OF THE COMPARATIVE COSTS OF FIVE WET/DRY COOLING TOWER CONCEPTS. F. R. Zaloudek, R. T. Allemann, D. W. Faletti, B. M. Johnson, H. L. Parry, G. C. Smith, R. D. Tokarz, and R. A. Wa1ter, BNWL-2122, September 1976. 
DRY COOLING OF POWER GENERATING STATIONS A SUMMARY OF THE ECONOMIC EVALUATION OF SEVERAL ADVANCED CONCEPTS VIA A DESIGN OPT IMIZATION STUDY AND A CONCEPTUAL DESIGN AND COST EST IMATE. B. M. Johinson, R. T. Allemann, D. W. Faletti, B. C. Fryer and F. R. Zaloudek, BNWL-2120, September 1976.

COSTS AND COST ALGORITHMS FOR DRY COOLING TOWER SYSTEMS. P. A. Ard, C. H. Henager, D. R. Pratt and L. E. Wiles, BNWL-2123, September 1976.

A USER'S MANUAL FOR THE BNW-I OPTIMIZATION CODE FOR DRY-COOLED POWER PLANTS. David J. Braun, Dan J. Braun, Warren V. De Mier, D. W. Faletti and L. E. Wiles, BNWL-2180, January 1977. 


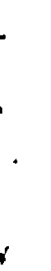

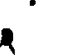




\section{ACKNOWLEDGMENTS}

This report contains an account of the work sponsored by the Division of Nuclear Research and Applications of ERDA under the Dry Cooling Tower Program at Battelle, Pacific Northwest Laboratory (PNL). The project was completed under the direction of Ira Helms, Project Officer; W. F. Savage, Manager of the Advanced Concepts Evaluation Branch, ERDA Division of Nuclear Research and Applications; and B. M. Johnson, Manager of the Dry Cooling Tower Project at PNL.

In addition to the authors, the following personnel at PNL contributed to completion of the work: P. A. Ard, Daniel J. Braun, David J. Braun, B. C. Fryer, C. H. Henager, L. E. Wiles and A. J. Currie (Technical Editor).

The information provided by Dott. Ing. Carlo Rocco and Vincenzio Leonelli of Italimpianti, Genoa, Italy, and by Professor Carlo Roma of the University of Rome on the natural draft system currently under development by Italimpianti was of invaluable assistance in our evaluation of the induced draft PLASTIC system.

Acknowledgments are due to S. F. Anderson of the Public Service of New Mexico for the information on the conditions and general cooling system requirements for the Famington, New Mexico, site used as the baseline for the comparative conceptual design study of dry/wet cooling system alternatives.

Acknowledgments are also due to the following cooling tower manufacturers and their representatives for their interest during this study: M. Larinoff and E. C. Smith of Hudson Products, and R. Landon and R. Cates of Marley Company.

Many manufacturers of components for cooling tower systems were contacted during the conduct of this study and provided essential cost information that was incorporated into the cost algorithms and estimates. This information is the basis of the comparisons made herein. We acknowledge this vital contribution to the study, although any mistakes in interpretation and formalization of this information are the responsibility of PNL. 


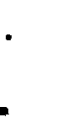

. 


\section{CONTENTS}

FOREWORD.

ACKNOWLEDGMENTS

$i \mathrm{i}$

LIST OF FIGURES

vij

LIST OF TABLES

xiij

LIST OF TABLES

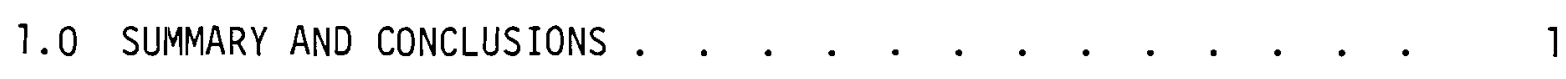

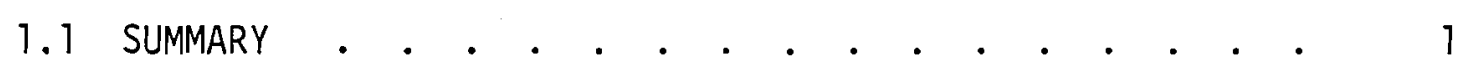

1.2 CONCLUSIONS . . . . . . . . . . . . . . . . . . . 5

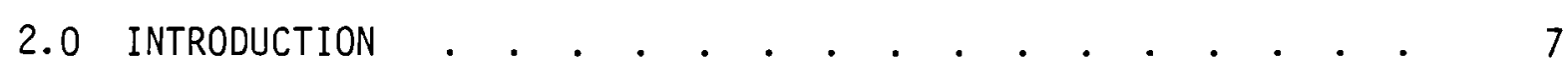

2.1 SCOPE OF REPORT . . . . . . . . . . . . . . . . . 7

2.2 BACKGROUND . . . . . . . . . . . . . . . . . 8

2.3 PROBLEM DEFINITION . . . . . . . . . . . . . . 10

3.0 METHODOLOGY . . . . . . . . . . . . . . . . . . . . . .

3.1 SYSTEM CONSIDERATIONS . . . . . . . . . . . . . 13

3.2 COSTING APPROACH . . . . . . . . . . . . . . 19

3.3 OPTIMIZATION . . . . . . . . . . . . . . . . . . . . 21

3.4 COMPUTER PROGRAM . . . . . . . . . . . . . . . . 25

3.5 DEVELOPMENT OF COST MODELS . . . . . . . . . . . 26

4.0 COOLING SYSTEM DESIGN BASES . . . . . . . . . . . . . 27

4.1 GENERAL DESIGN BASIS . . . . . . . . . . . . . 27

4.2 AdDITIONAL DESIGN BASES LimitationS . . . . . . . 28

5.0 PHYSICAL DESCRIPTION AND COST COMPARISON OF THE

THREE COOLING SYSTEMS . . . . . . . . . . . . . . . . . 31

5.1 SOA COOLING SYSTEM . . . . . . . . . . . . . . 31

5.1.1 Condenser . . . . . . . . . . . . . . . 31

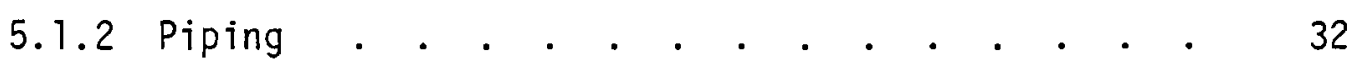

5.1.3 Cooling Tower . . . . . . . . . . . . 32 
5.2 PLASTIC HEAT EXCHANGER COOLING SYSTEM . • • • • • • 33

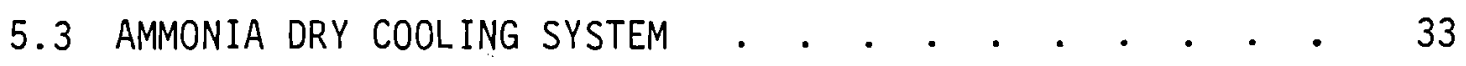

5.3.1 Condenser/Reboiler . . . . . . . . . . 34

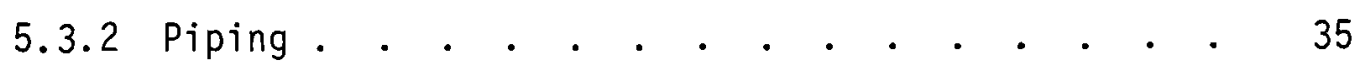

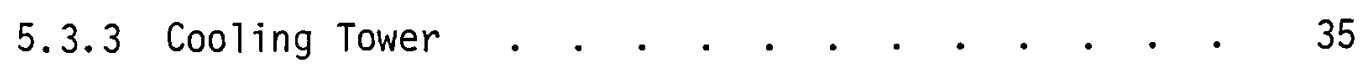

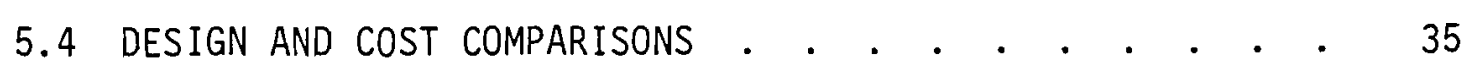

5.4.1 Incremental Energy Costs . . . . . . . . . 42

5.4 .2 Cooling Tower, Fans, Heat Exchangers and
Louvers. . . . . . . . . . . . . . . . 44

5.4.3 Condensers and Condenser/Reboiler. . . . . . 49

5.4.4 Piping and Pumps . . . . . . . . . . . . 49

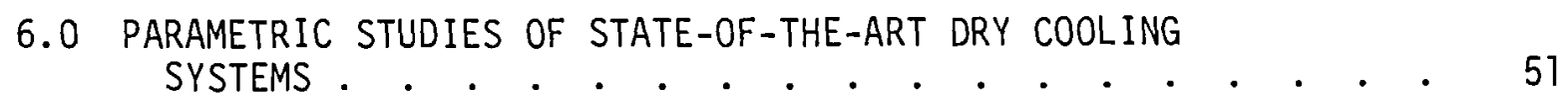

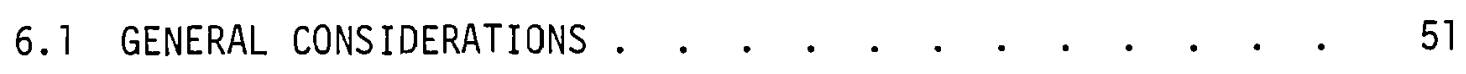

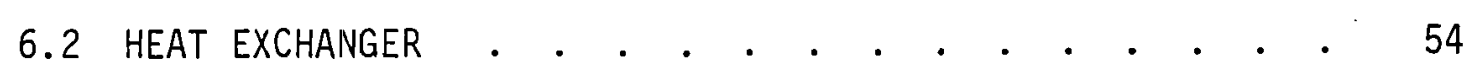

6.2.1 Unit Geometry . . . . . . . . . . . . 56

6.2.2 Heat Exchanger Configuration . . . . . . . 59

6.2.3 Fin Type/Manufacturing Method . . . . . . . 62

6.2 .4 Liner Material . . . . . . . . . . . . 63

6.2 .5 Number of Passes . . . . . . . . . . . 64

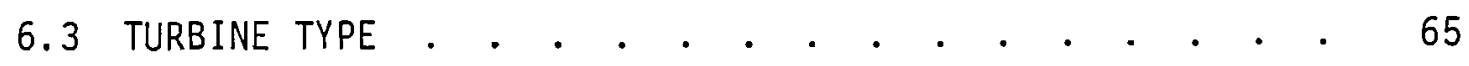

6.3 .1 Turbine Descriptions . . . . . . . . . . 67

6.3 .2 Turbine Optimization Analysis . . . . . . . 69

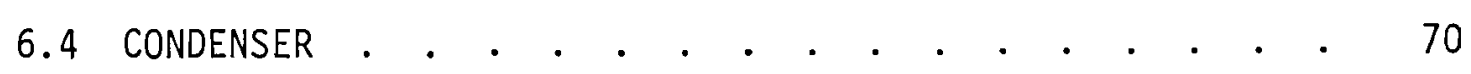

6.4 .1 Condenser Deisgn Parameters . . . . . . . . 73

6.4.2 Parametric Study of TTD . . . . . . . . . 74 
6.5 PIPING SYSTEM WATER DESIGN VELOCITY . . . . . . . . 77

6.6 TOWER CONFIGURATION . . . . . . . . . . . . . . . . 79

6.6.1 Circular Versus Rectilinear Towers. . . . . 81

6.7 FAN SYSTEM . . . . . . . . . . . . . . . . 82

6.7.1 Fan Type . . . . . . . . . . . . . . . 82

6.7.2 Packing Factor . . . . . . . . . . . 84

6.7.3 Diffusers and Delta Arrangements . . . . . 86

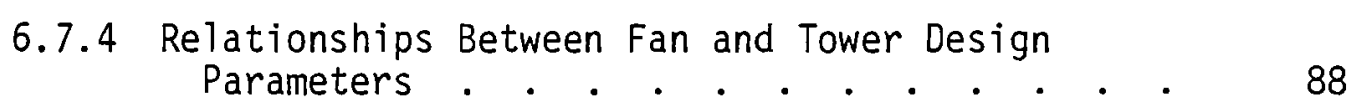

6.8 METEOROLOGY .

6.8.1 ITD . . . . . . . . . . . . . . . . . . . . . . 92

6.8.2 Capacity Cost. . . . . . . . . . . . 92

6.8.3 Energy Cost . . . . . . . . . . . . 93

6.8.4 Evaluation of Five Site Meteorologies. . . . 93

6.8.5 Design Temperature . . . . . . . . . . . . . 98

7.0 PARAMETRIC STUDIES OF PLASTIC TUBE HEAT EXCHANGER

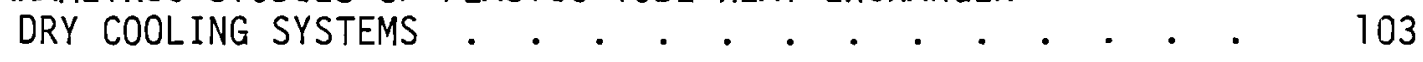

7.1 GENERAL CONSIDERATIONS . . . . . . . . . . . 103

7.2 TOWER ARRANGEMENTS . . . . . . . . . . . . . . 105

7.3 HEAT EXCHANGER . . . . . . . . . . . . . . 108

7.3.1 Staggered Tube Arrangement . . . . . . . 109

7.3.2 Inl ine Tube Arrangement . . . . . . . . 110

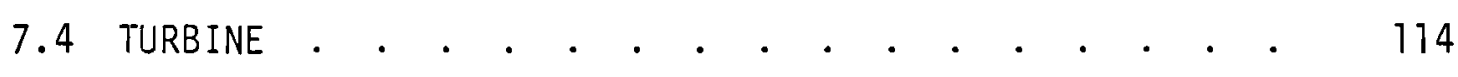

7.5 PIPING SYSTEM WATER DESIGN VELOCITY . . . . . . . . 118

7.6 CONDENSER .

7.7 GeNERAL COMMENTS . . . . . . . . . . . . . . . 120

7.7.1 Circular versus Rectilinear Towers. . . . 120 
8.0 PARAMETRIC STUDIES OF AMMONIA LOOP COOLING SYSTEM $\quad$ • $\quad$ • $\quad$ • 121

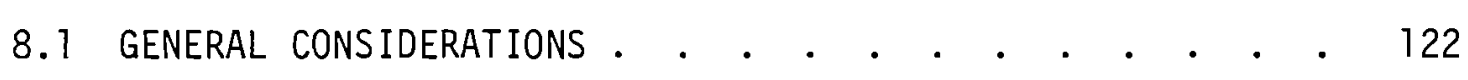

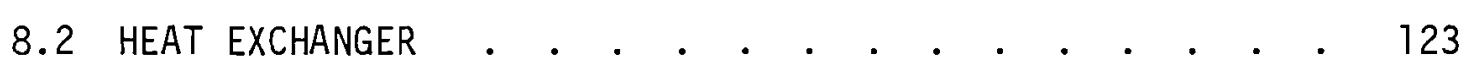

8.2.1 Heat Exchanger Configuration . . . . . . . 124

8.2.2 Fin Type or Manufacturing Method and Linear Materials........... . . 124

8.3 TURBINE TYPE

8.4 CONDENSER/REBOILER $\quad$ •

8.5 PIPING SYSTEM DESIGN VELOCITIES • • • • • • • • • • • • 129

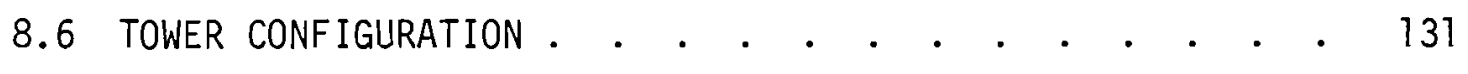

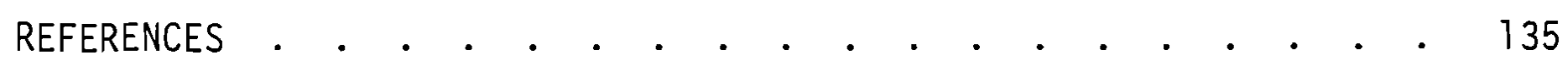

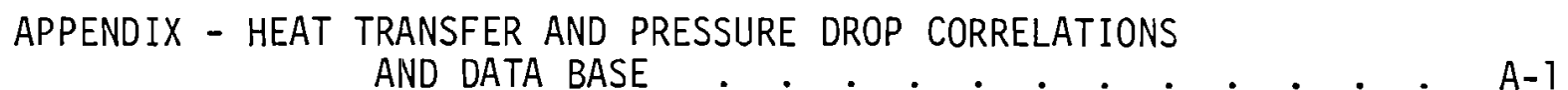




\section{FIGURES}

1-1 Comparison if Incremental Power Production Costs . . . 3

3-1 General Dry Cooled Plant Interactions . . . . . . 13

3-2 Detailed Dry Cooled Plant Interactions . . . . . . 15

3-3 Direct Dry Cooling System with Mechanical Draft Tower . 17

3-4 Indirect Dry Cooling System with Direct Contact Condenser and Natural Draft Tower . . . . . 17

3-5 Indirect Dry Cooling System with Surface Condenser and Mechanical Draft Tower . . . . . . . . 18

3-6 Ammonia Coolant Dry Cooling System . . . . . . . 18

3-7 Dry Cooling System Computer Optimization . • • • • • 26

5-1 Temperature Relationships for SOA and Plastic Heat Exchanger Cooling Systems... . . . . . . 32

5-2 Temperature Relationships for Ammonia Coolant Dry Cooling System . . . . . . . . . . . . .

5-3 State-cine-Art Al1-Dry Cooling System, Expensive Finneo Tube . . . . . . . . . . . . 36

5-4 State-of-the-Art A11-Dry Cooling System, Inexpensive

Finned Tube . . . . . . . . . . . . . 37

5-5 PLASTIC A11-Dry Cooling System . . . . . . . . 38

5-6 Ammonia A17-Dry Cooling System . . . . . . . . . 39

5-7 All-Dry Cooled Plant Performance . . . . . . . . 41

6-1 Finned Tube Unit Geometry and Tube Pitch Parameters . 57

6-2 Incremental Cost Versus Root Diameter and Fin Height . 58

6-3 Incremental Cost Versus Fin Parameters . . . . . . 58

6-4 Incremental Cost, Tube Rows In Depth and Air-Side

Friction Factor Versus Equilateral Fin Tip

Clearance. . . . . . . . . . . . 60 
6-5 Normalized Heat Rate Versus Turbine Back

6-6 Normalized Heat Rate Versus Turbine Back Pressure - Nuclear . . . . . . . . . . 66

6-7 Incremental Cost Versus Condenser TTD for the Three Turbine Types - Fossil . . . . . . . . . 74

6-8 Incremental Cost Versus Condenser TTD for the Three Turbine Types - Nuclear . . . . . . . . . 75

6-9 Incremental Cost, Pump Power, and Piping System Cost Versus Water Design Velocity . . . . . . . 78

6-10 Incremental Cost, Optimized Tube Rows in Depth and Tower Diameter Versus the Number of Circular Towers

6-11 Cumulative Temperature Distribution Taken from

Ten-Year Average for Five Site Meteorologies with Site Elevation in Parentheses . . . . . .

6-12 Cost Parameters Versus Design Temperature . . . . . 100

6-13 Plant Output Versus Turbine Back Pressure for Two Design Temperatures

Incremental Costs Versus Fan Packing Factor for the PLASTIC System . . . . . . . . . . 106

7-2 Incremental Costs and Tower Diameter Versus Number of Circular Towers for the PLASTIC System. . . . 108

7-3 Incremental Costs Versus Tube Outside Diameter for PLASTIC System with Staggered Tube Arrangement . . . 110

7-4 Incremental Costs Versus Transverse Pitch for PLASTIC System with Staggered Tube Arrangement . . • . . . 111

7-5 Incremental Costs Versus Tube Outside Diameter for PLASTIC System with Inline Tube Arrangement . • . . 112

7-6 Incremental Costs Versus Transverse Pitch for PLASTIC System with Inl ine Tube Arrangement

7-7 Incremental Costs Versus Longitudinal Pitch for PLASTIC System with Inl ine Tube Arrangement 
7-8 Incremental Costs Versus maximum Turbine Back Pressure for the PLASTIC System . . . . . . . . . . 115

7-9 Incremental Costs, Pump Power, and Piping System Cost Versus Piping Design Velocity for the PLASTIC System . 119

7-10 Incremental Costs Versus Piping Design Velocity for the PLASTIC System . . . . . . . . . . . . . . 119

8-1 Incremental Costs Versus Piping Design Velocities

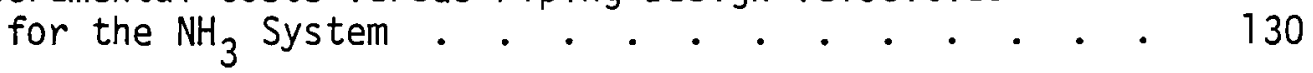

8-2 Incremental Costs Versus Packing Factor for the

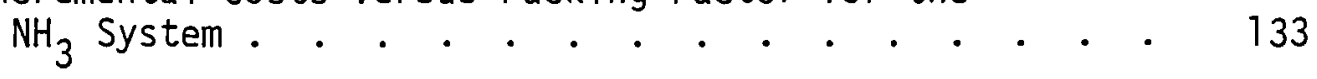

8-3 Incremental Costs Versus Number of Circular Towers for the $\mathrm{NH}_{3}$ System. . . . . . . . . 133 


\section{TABLES}

1-1 Incremental and Total Power Production Cost Reductions . . . . . . . . . . . . . 4

3-1 Computer Analysis - Major Cooling System Parameters and Options . . . . . . . . .

5-1 Comparison of Design and Operating Parameters for Near-Optimum Designs. . . . . . . . . . 40

5-2 Cost Comparison of Near Optimum Designs . . . . . 43

5-3 Cooling System Capital Costs . . . . . . . . . 45

6-1 Additional Design Basis Variables for SOA Dry Cooling Systems . . . . . . . . . . 52

6-2 Incremental Costs for Cooling System Designs Using Different Fin Types and Liner Materials . . . . .

6-3 Differences in Fossil and Nuclear Design and Cost Input . . . . . . . . . . . . . .

6-4 Comparison of Optimized Design and Cost Data for Al1-Dry Cooling Systems Using the Three Turbine Types - Fossil . . . . . . . . . . .

6-5 Comparison of Optimized Design and Cost Data for A11-Dry Cooling Systems Using the Three Turbine Types - Nuclear.

6-6 Comparison of Optimized Cooling Designs for Two Condenser TTD Values . . . . . . . . . . 76

6-7 Fan Diameter and Incremental Power Production Cost . .

6-8 Incremental Power Production Costs as a Function of Packing Factor and Design Options . . . . . .

6-9 Incremental Power Production Costs for Fossil-Fueled Turbine-Generators for the Five Site Meteorologies and the Three Turbine Types . . . . . . .

6-10 Incremental Power Production Costs for Nuclear-Fueled Turbine-Generators for the Five Site Meteorologies and the Three Turbine Types . . . . . . . .

6-11 Parameters and Costs of Wyodak, Miami, and Phoenix for the Modified Conventional Turbine - Fossil 
6-12 Parameters and Costs for Wyodak, Miami and Phoenix for the Modified Conventional Turbine - Nuclear . .

6-13 Two Designs for the Wyodak Meteorology With Different Elevation Above Sea Level . .

6-14 Comparison of Optimized Designs for Two Design Temperature . . . . . . . . . . 101

7-1 Comparison of Optimized Design and Cost Data for PLASTIC All-Dry Cooling Systems Using the Three Turbine Types - Fossil . . . . . . . .

8-1 Comparison of Optimized Design and Cost Data for Al1-Dry Cooling Systems Using Three Different Tubes in the Tower................

8-2 Comparison of Optimized Design and Cost Data for A11-Dry Cooling Systems Using the Three Turbine Types - Fossil . . . . . . . . . . . . . .

8-3 Comparison of Optimized Design and Cost Data for Al1-Dry Cooling Systems Using Four Different Materials in the Condenser/Reboiler . . . . . .

8-4 Comparison of Incremental Costs of SOA, PLASTIC, and Ammonia Systems . . . . . . . . . . . 


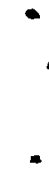

.

, 


\section{AN ENGINEERING AND COST COMPARISON OF THREE DIFFERENT}

ALL-DRY COOLING SYSTEMS

\subsection{SUMMARY AND CONCLUSIONS}

\subsection{SUMMARY}

The use of dry cooling in power plants could have a major impact on conserving the quantity and quality of water resources in the U.S. However, the increased power production costs assessed to dry cooling systems currently offered by domestic and foreign vendors have precluded its selection when compared to wet systems for most power plants planned for the future.

This report describes the results of a detailed engineering and cost study of three different all-dry cooling systems to assess the potential for reducing the cost of all-dry cooling for steam electric power plants. The three types of cooling systems considered were:

1. state-of-the-art dry cooling systems using metal finned tubes (SOA);

2. an advanced dry cooling system utilizing heat exchangers made of plastic tubes (PLASTIC); and,

3. an advanced dry cooling system utilizing ammonia as the coolant $\left(\mathrm{NH}_{3}\right)$.

The SOA system uses a conventional surface condenser. Water used to condense the steam is passed through an induced mechanical draft, metal finned tube cooling tower.

The PLASTIC system differs from the SOA system in that bare (unfinned) polyethylene tubes are substituted for the metal finned tubes in the cooling tower.

The $\mathrm{NH}_{3}$ system differs from the SOA system in that ammonia is substituted for water as the intermediate fluid. Steam from the turbine is condensed by boiling ammonia in a condenser/reboiler; the ammonia vapor is condensed in an induced draft, metal finned tube heat exchanger and returned to the condenser/reboiler. 
These three systems were selected for the following reasons. For SOA systems it was unclear to nonvendor dry cooling investigators that systems offered by vendors were optimum in unit geometry, heat exchanger configuration, operating parameters, etc.

Natural draft plastic systems are under active investigation by Italimpianti in Italy. Preliminary assessments of the data provided by Italimpianti indicated that further analysis was warranted for mechanical draft systems using fabrication techniques applicable to the U.S. construction practices. This mechanical draft americanized version is referred to as the PLASTIC system. However, the differences between the PLASTIC mechanical draft and the Italimpianti natural draft system are sufficiently great that it is not possible to predict the competitiveness of the Italimpianti system by using the results shown here for the PLASTIC system.

Preliminary investigations of the $\mathrm{NH}_{3}$ system indicated certain generic characteristics which could possibly result in significant cost savings.

The results for the SOA, PLASTIC, and $\mathrm{NH}_{3}$ systems are shown in Figure 1-1 in terms of incremental power production cost for a 1000-MWe fossil plant. Incremental power production cost is the increased cost of producing power with dry cooling when compared to a reference plant. The reference plant employs a zero-cost cooling system and a turbine operating at a constant back pressure of $3.5 \mathrm{in.} \mathrm{Hga.}$

The costs given for the ammonia system are based upon use of aluminum tubes with enhanced heat transfer surfaces for boiling and condensing in the condenser/ reboiler. The ammonia system's incremental cost increases significantly if other tube materials or nonenhanced surfaces are used.

SOA systems with expensive and inexpensive finned tubes are presented in Figure 1-1. Using the expensive finned tube SOA system as a base and a nominal power production cost of $22 \mathrm{mi} 1 \mathrm{~s} / \mathrm{kWh}$ for the reference plant, the potential for cost savings are shown in Table 1-1.

The optimized SOA designs resulting from this study are not significantly different from what would be expected to be offered by vendors under the 


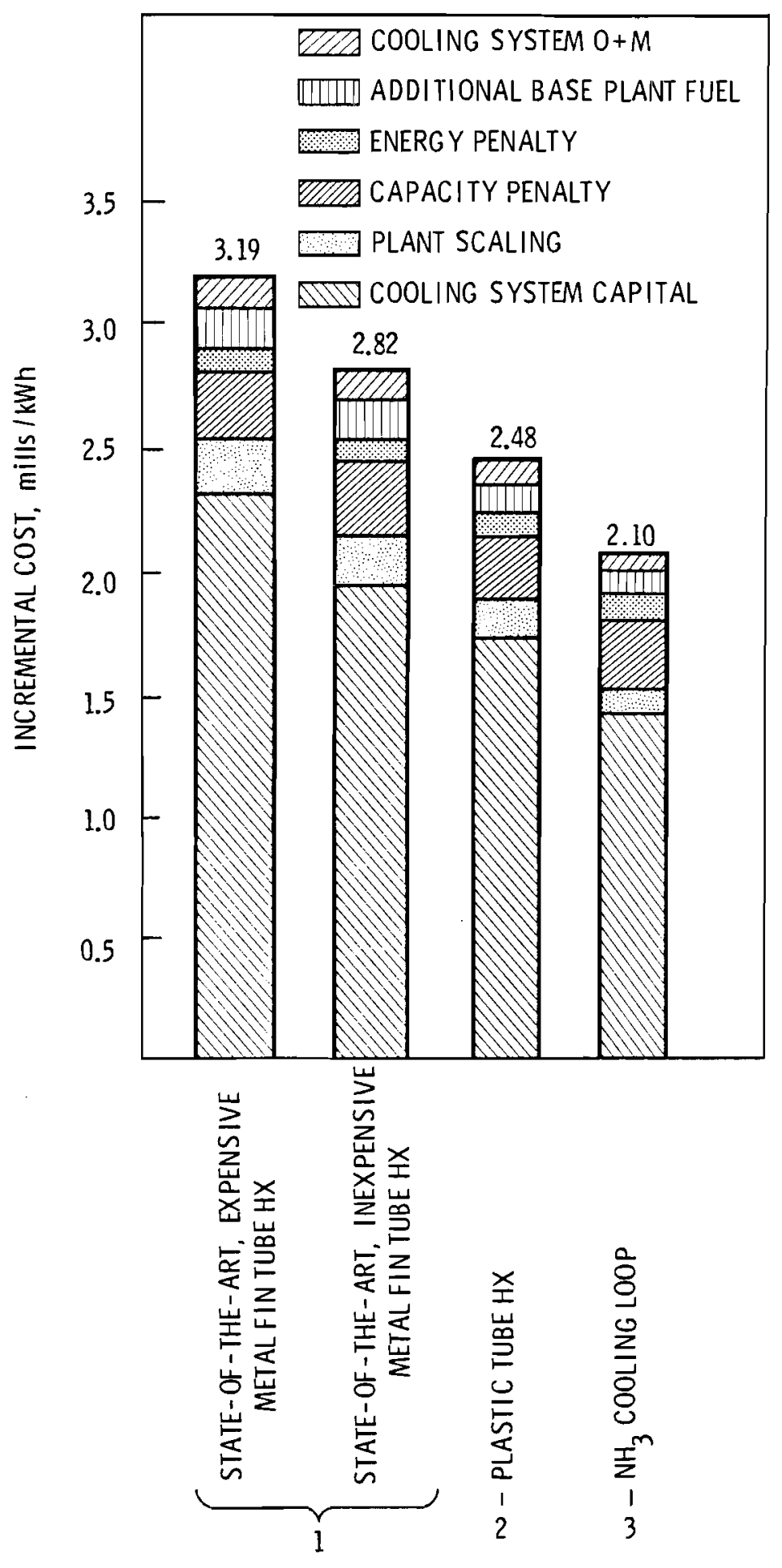

FIGURE 1-1. Comparison of Incremental Power Production Costs 
TABLE 1-1. Incremental and Total Power Production Cost Reductions

\begin{tabular}{|c|c|c|}
\hline Cooling System & $\begin{array}{l}\text { Percent Reduction } \\
\text { in Incremental Power } \\
\text { Production Cost }\end{array}$ & $\begin{array}{l}\text { Percent Reduction } \\
\text { in Total Power } \\
\text { Production Cost } \\
\end{array}$ \\
\hline SOA (expensive) & 0 & 0 \\
\hline SOA (inexpensive) & 11.9 & 1.5 \\
\hline PLASTIC & 22.2 & 2.8 \\
\hline $\mathrm{NH}_{3}$ & 34.2 & 4.1 \\
\hline
\end{tabular}

same design bases. The costs of vendor offerings could thus be expected to lie somewhere between the expensive and inexpensive finned tube SOA systems. Selection of the expensive or inexpensive finned tubes depends primarily on corrosion considerations, and involves specifying fin manufacturing method, the liner material, and the, liner thickness. Vendors routinely consider coolant loop water quality, circulation system materials compatability, downtime procedures, and the air-side environment in making the finned tube selection.

This investigation indicates little (if any) potential for reducing costs for SOA systems relative to vendor offerings.

The potential for reducing incremental power production costs of dry cooling using $\mathrm{NH}_{3}$ (34 percent) and/or PLASTIC (22 percent) in comparison to SOA systems is significant (Table 1-1). However, the apparent impact on the total power production costs appears at first to be quite smal1. On the other hand, it can represent a tremendous saving in absolute dollars when the total amount of energy to be generated by new plants in the future is considered. This situation is not without precedent in the power industry. Significant amounts of time, manpower and finances have been expended by the electric power industry over the years in attempts to make small percentage reductions in power production costs. Where the reduction has occurred it has been well worth the investment. Such could be the case with investments made to advance dry cooling technology. 


\subsection{CONCLUSIONS}

Two major conclusions drawn from this study are:

1. SOA systems offered by vendors are near optimum in terms of heat exchanger unit geometry and configuration. Therefore, there is little, if any, cost advantage to be gained by further study of SOA systems using wrap-on or extruded finned tubes other than in the selection of tube materials, materials compatibility, water quality control, or fin manufacturing methods. These are all routinely considered by vendors for each particular installation.

2. Significant savings (34 percent) in incremental power production costs appear to be obtainable using $\mathrm{NH}_{3}$ systems. Considerable savings (22 percent) can also be obtained with PLASTIC systems. 


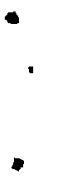




\subsection{INTRODUCTION}

The study described in this report was performed as part of the Energy Research and Development Administration's Dry Cooling Tower (DCT) Program. The objective of the study was to define the potential for reducing the high costs associated with all-dry cooling of steam electric power plants through comparison of three cooling system concepts on an engineering and cost basis.

\subsection{SCOPE OF REPORT}

This report documents the detailed engineering and cost comparison of three a11-dry cooling systems:

- state-of-the-art (SOA) dry cooling systems using metal finned tubes;

- an advanced dry cooling system using plastic tubes as the heat exchange surface (PLASTIC); and

- an advanced dry cooling system utilizing ammonia as the intermediate heat transfer fluid $\left(\mathrm{NH}_{3}\right)$.

The three systems were selected for the following reasons:

- For SOA systems, it was important to determine whether systems offered by vendors were optimum in terms of unit geometry, heat exchanger configuration, operating parameters, etc. Inclusion of SOA systems provided a reference base from which to compare the advanced concepts, i.e., PLASTIC and $\mathrm{NH}_{3}$.

- Natural draft plastic systems are under active investigation by Italimpianti in Italy. Pilot plant studies have been completed and the demonstration of a 75-MWe unit is planned. Italimpianti supplied PNL considerable information about their system. A review of this information indicated that the use of plastic heat exchangers offered promise. However, U.S. construction practices indicated that certain design modifications would make the plastic 
system more competitive in the U.S. Moreover, U.S. utilities have generally found mechanical draft systems more economical than natural draft systems. Therefore, PNL chose to investigate a mechanical draft plastic system using the americanized design; this system is referred to as the PLASTIC system. The PLASTIC system differs so much from the Italimpianti system that it is not possible to predict the competitiveness of the Italimpianti system from the results obtained for the PLASTIC system.

- Preliminary investigation of the $\mathrm{NH}_{3}$ system indicated certain generic characteristics could possibly result in significant cost savings.

The methodology and its justification are presented in Section 3; the design basis is presented in Section 4 .

Section 5 presents a detailed design and cost comparison of the three systems. Several design limitations, which had negligible effect upon the final costs, were placed on all three systems to arrive at "optimal" designs, allowing the reader to obtain a feel for the similarities and differences in the physical and cost attributes of the three systems.

Sections 6, 7, and 8 present the results of parametric studies of the three systems. These sections should be of particular interest to those seeking an in-depth understanding of the effects of design parameters on cost.

\subsection{BACKGROUND}

Except for two small all-dry cooled generating units at Wyodak, Wyoming, $(1,2)$ all steam electric plants in the U.S. currently use evaporative or once-through cooling. These methods, which can be referred to as wet cooling, contribute significantly to waste heat management problems because of the resulting consumption and pollution of water resources. Dry cooling of future steam electric plants would considerably reduce the demands to be imposed on this country's rapidly diminishing water resources. However, U.S. dry cooling 
studies conducted between 1970 and 1975 indicate that power production costs are always higher for plants using SOA dry cooling technology than for wet cooled plants. In some cases, the costs were as much as 21 percent higher with dry cooling. Hence, only two future power generating facilities in the U.S.--the 330-MWe Wyodak plant ${ }^{(1)}$ and the 85-MWe Braintree, Massachusetts, plant ${ }^{(3)}$-will utilize all-dry cooling systems. Increased cost is the primary deterrent to using dry cooling. This was confirmed by a 1974 survey of utilities, architect engineering firms and turbine and cooling equipment vendors.

It appears that U.S. utility acceptance of available SOA dry cooling systems will result only from one of two conditions:

- a power plant site with little or no water;

- regulation based on environmental concerns.

In either case, the power production costs can be expected to increase and be subsequently passed on to electric power consumers.

A more efficient use of capital, energy, manpower and, ultimately, U.S. water resources would be to work toward technological advances to reduce the costs associated with dry cooling. Cost reductions will bring about earlier utilization of dry cooling, thus prolonging availability of water resources for other beneficial uses.

To develop the technology leading to cost reductions and to subsequently demonstrate the resulting cooling equipment reliability, the U.S. Atomic Energy Commission initiated the Dry Cooling Tower Program in 1974. The DCT program, currently conducted under the auspices of the Energy Research and Development Administration (ERDA), is described in Reference 4 as initially conceived. This program has changed its goals to keep pace with the developing dry cooling market.

The description of design and costing aspects of all-dry cooling systems, reported herein and in Reference 5 , is one of several tasks of the Dry Cooling Tower Program, Other supporting program work is documented in References 6 through 12. 


\subsection{PROBLEM DEFINITION}

The multiplicity of parameters requiring consideration complicates the task of identifying means to reduce the costs of dry cooling. Even for state-of-the-art (SOA) systems, one of the most difficult aspects of the problem is determining a starting point amidst the multitude of detailed cooling system design and operating parameters, options, physical arrangements, and system types. In addition, the balance of plant design and operating options, and the interface options between the utility system and the dry cooled plant, should be considered. These, in turn, should be coupled to external factors imposed on the analysis, such as site meteorology, fuel costs, fixed charge rates, and capacity factors.

Constantly changing costs of equipment, labor, material and interest, as well as changing inflation rates, only add to the difficulties. Even with these items fixed, the problems of defining cost models for the manufacture and installation of particular components are difficult, due to the proprietary nature of cost information in competitive industries.

When advanced technology is being considered, the problems above are compounded because of a lack of adequate cost and physical data. Without adequate physical data, system performance and design cannot be satisfactorily defined. Without the design and performance specifications, the costs cannot be determined. Yet without determining the potential for a significant cost saving, it is difficult to justify the experimental work to obtain the physical data.

A similar situation can exist in obtaining adequate cost data. If a large plant cooling system were actually going to be built, then vendors would be more responsive to requests for realistic cost information. There is little incentive for vendors to supply cost data for analytical studies which have long-term national payoffs but no short-term return to the vendor.

A review of previous studies on dry cooling ${ }^{(5)}$ indicated the following.

Most previous studies of dry cooled plants were based on predesigned vendor-offered cooling tower equipment using metal finned tube heat exchangers 
with water as the coolant. The studies have optimized the econonic trade-offs between the size of the cooling tower, type of condenser, and turbine type. Previous studies have also considered such items as natural versus mechanical draft, and have defined the effect of such factors as site meteorology, fuel costs, and other economic parameters. The resulting dry cooling systems have subsequently been compared to various wet cooling systems. In a11 cases, power production costs from the resulting dry cooled generating plants have always been significantly higher than for wet cooled plants. The result has been extremely limited use of dry cooling for steam electric generating plants in the U.S.

As indicated above, most previous studies have not considered detailed optimization of cooling system design and operating parameters, for either SOA systems or advanced concepts. The studies which have attempted detajled analysis have unfortunately been based on inadequate physical and cost data.

Reference 5 indicates that significant reductions in the cost of dry cooling would only come through technological advances. These advances would include changes in the detailed design of SOA systems and/or major conceptual changes in the cooling system. Detailed design changes, for example, could include such simple things as making finned tubes with more fins/inch than are currently considered. Conceptual changes, on the other hand, might include such things as using mercury as the coolant in a dry cooling spray pond system. Whether the changes are cost effective, result in a functional and reliable system, and are environmentally acceptable requires various levels of evaluation. Other examples of design alternatives that lead to complicated analyses follow.

Consider two finned tubes, identical in construction except that the fins of one are serrated. Suppose the tubes also cost the same. Serrations tend to increase the heat transfer coefficient, but they also increase the friction factor. If incorporated into the dry tower heat exchangers of an optimized dry cooling system, which tube will result in the lowest power production costs? 
Consider yet another example. Polyethylene plastic tubes (smooth unfinned) are suggested as an alternative to metal finned tubes. What is the optimum cooling system design (i.e., tube diameter, wall thickness, and tube length, etc.) employing plastic tubes? Does the plastic tube offer potential cost savings?

Additional questions which may be asked about each of these proposed ideas deal with some of the questions already asked, and answered, in studies based on predesigned dry cooling equipment done to date. They include the following: Which turbine type is most economical? How do the conclusions change from one meterological site to another? In most cases, it seems that these do not have simple answers, but require comprehensive analysis due to the complex intercoupling of design and operating parameters, system options and physical arrangements, capital and operating costs, balance of plant, and utility system interfaces. In addition, the comparisons must be made on an optimized basis to draw a meaningful conclusion. 


\subsection{METHODOLOGY}

The methodology used to define and/or optimize dry cooling systems is a subject of much concern to active investigators of dry cooling systems. Before discussing the costing approach and optimization methods used, an overview of the engineering and economic aspects of dry cooling as they relate to interactions with the utility system, the power plant and the dry cooling system will be given.

\subsection{SYSTEM CONSIDERATIONS}

A prerequisite to identifying improvements which will reduce the power production costs of dry cooled electrical power plants (and subsequently lead to successful demonstration of the performance and reliability of the improved cooling system) is a very detailed and comprehensive understanding of the engineering and economic aspects of three interacting levels in the power system. These levels are shown in Figure 3-1.

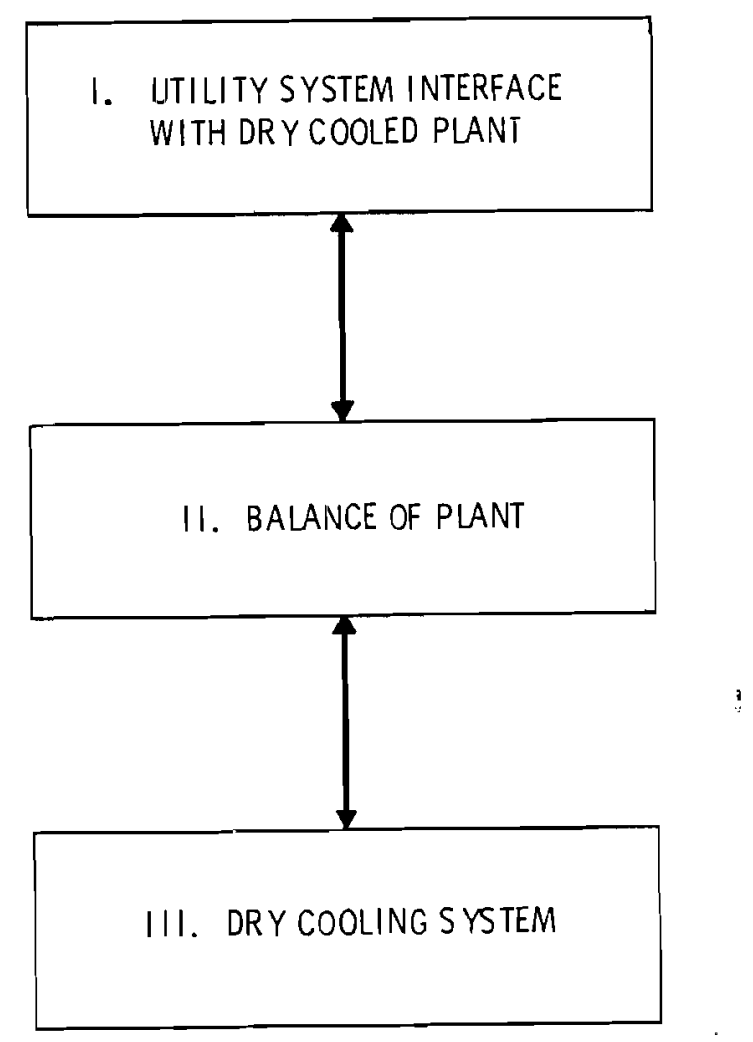

FIGURE 3-1. General Dry Cooled Plant Interactions 
The first level involves interactions of the cooling system design and operating parameters and basic cooling system options. The second level encompasses the interaction of the cooling system and the balance of the plant. The third level is the interaction of the dry cooled plant with the utility system. The third level is very important because the capacity of the dry cooled plant drops with increased ambient air temperature and some means must be provided within the utility system to accommodate this characteristic. It must also be accounted for in engineering and cost analyses. In some studies the cost of this lost performance in terms of capacity and energy penalities has accounted for over two-thirds of the costs assessed to dry cooling. Considerable progress has been made in previous studies in attempts to describe the interaction of these three levels. However, many detailed aspects, which could be a means of reducing cost, have not been adequately investigated.

To provide the investigator newly acquainted with dry cooling some perspective regarding the complexity of the engineering and economic aspects of dry cooling, Figure 3-2 is included. It contains a list of 1) utility system interface options, 2) balance of plant design and operating options, and 3) cooling system design and operating parameter options, physical arrangements, and system types. Examples of options include:

- mechanical versus natural draft, forced versus induced draft - circular versus rectilinear tower arrangement

- horizontal versus vertical versus " $A$ "-frame orientation of heat exchange bundles

- contact condensers versus surface condensers versus direct condensation.

Schematics of the major state-of-the-art dry cooling system types are presented in Figures 3-3 through 3-5. The PLASTIC dry cooling system and the SOA system considered in this study are represented by Figure 3-5. Figure 3-6 illustrates the ammonia coolant all-dry cooling system also investigated in this study. 


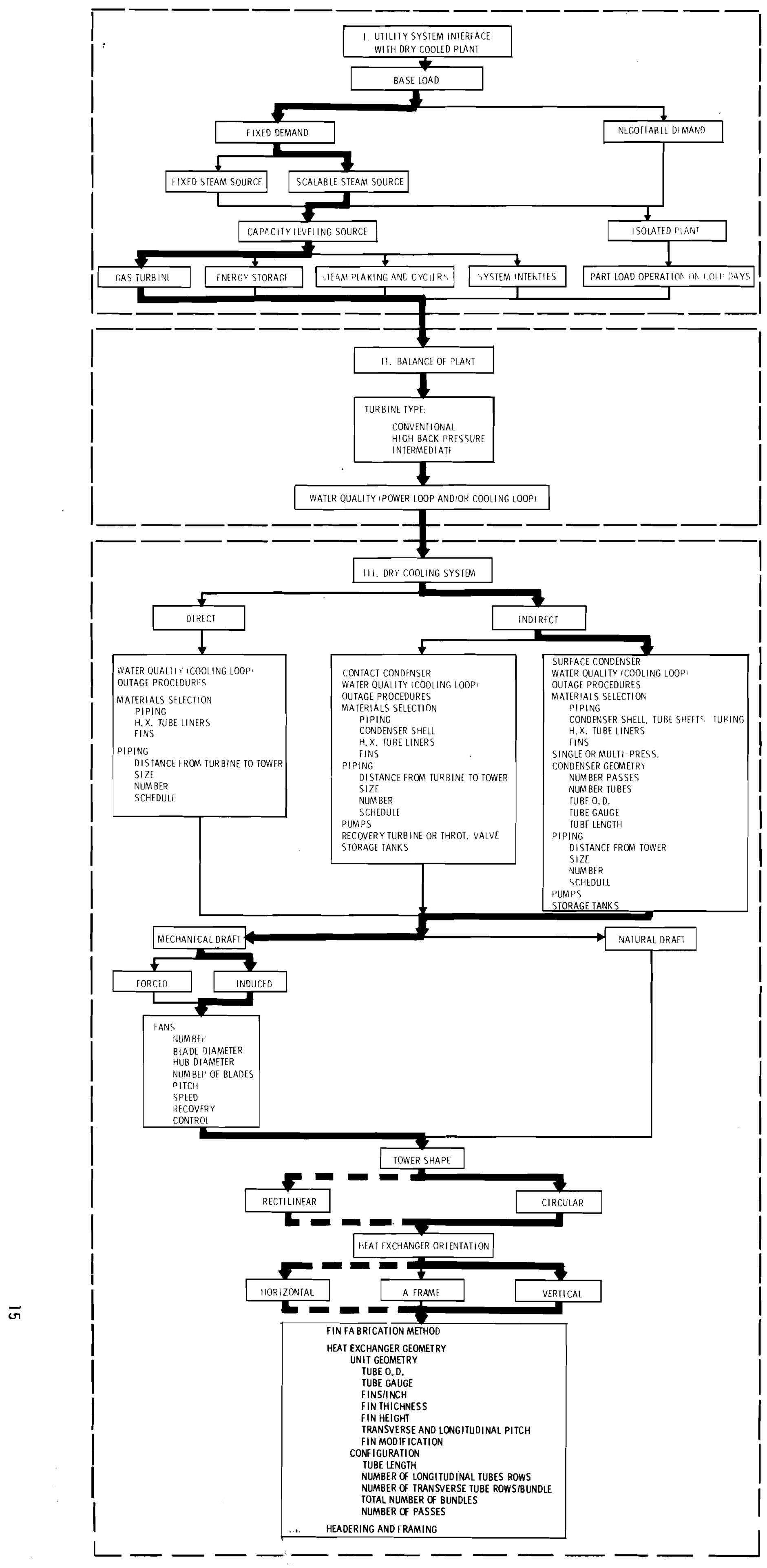




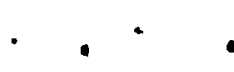


DIRECT, DRY COOLING SYSTEM

WITH MECHANICAL DRAFT TOWER

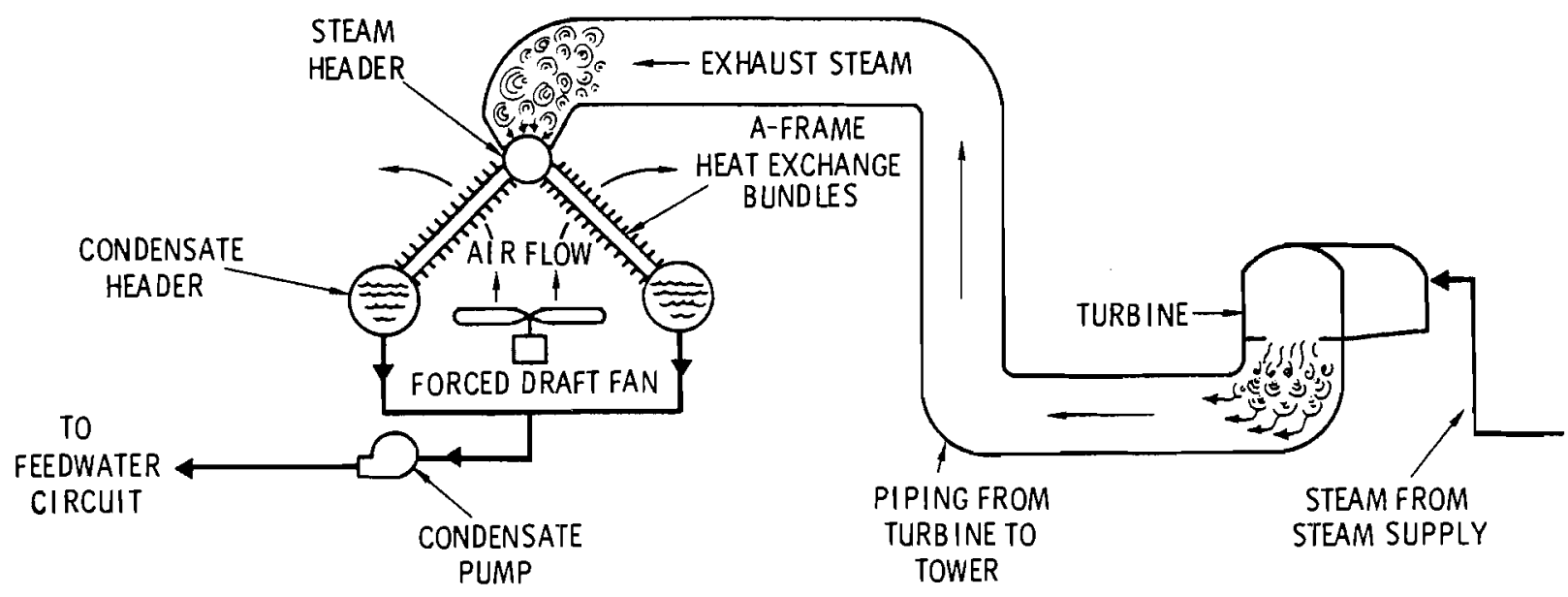

FIGURE 3-3. Direct Dry Cooling System with Mechanical Draft Tower

INDIRECT, DRY COOLING SYSTEM WITH NATURAL

DRAFT TOWER

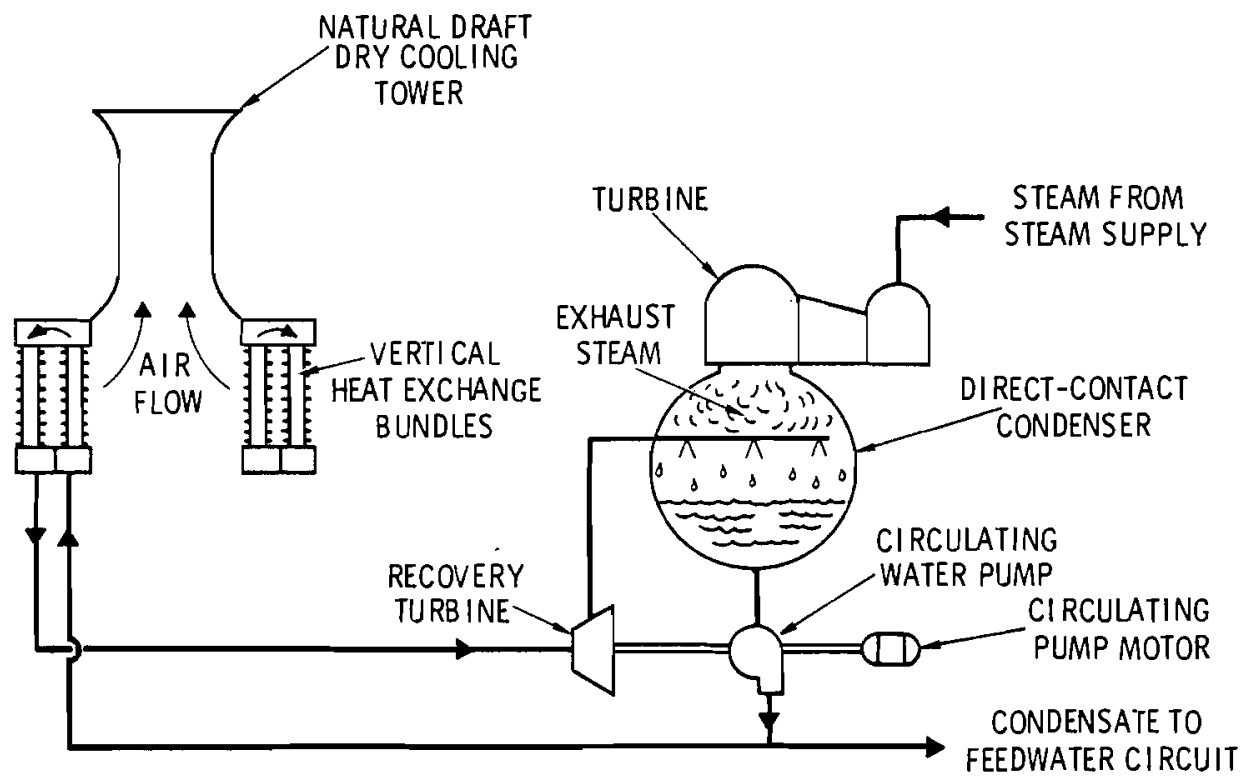

FIGURE 3-4. Indirect Dry Cooling System with Direct Contact Condenser and Natural Draft Tower 
INDIRECT, DRY COOLING SYSTEM WITH SURFACE CONDENSER AND MECHANICAL DRAFT TOWER

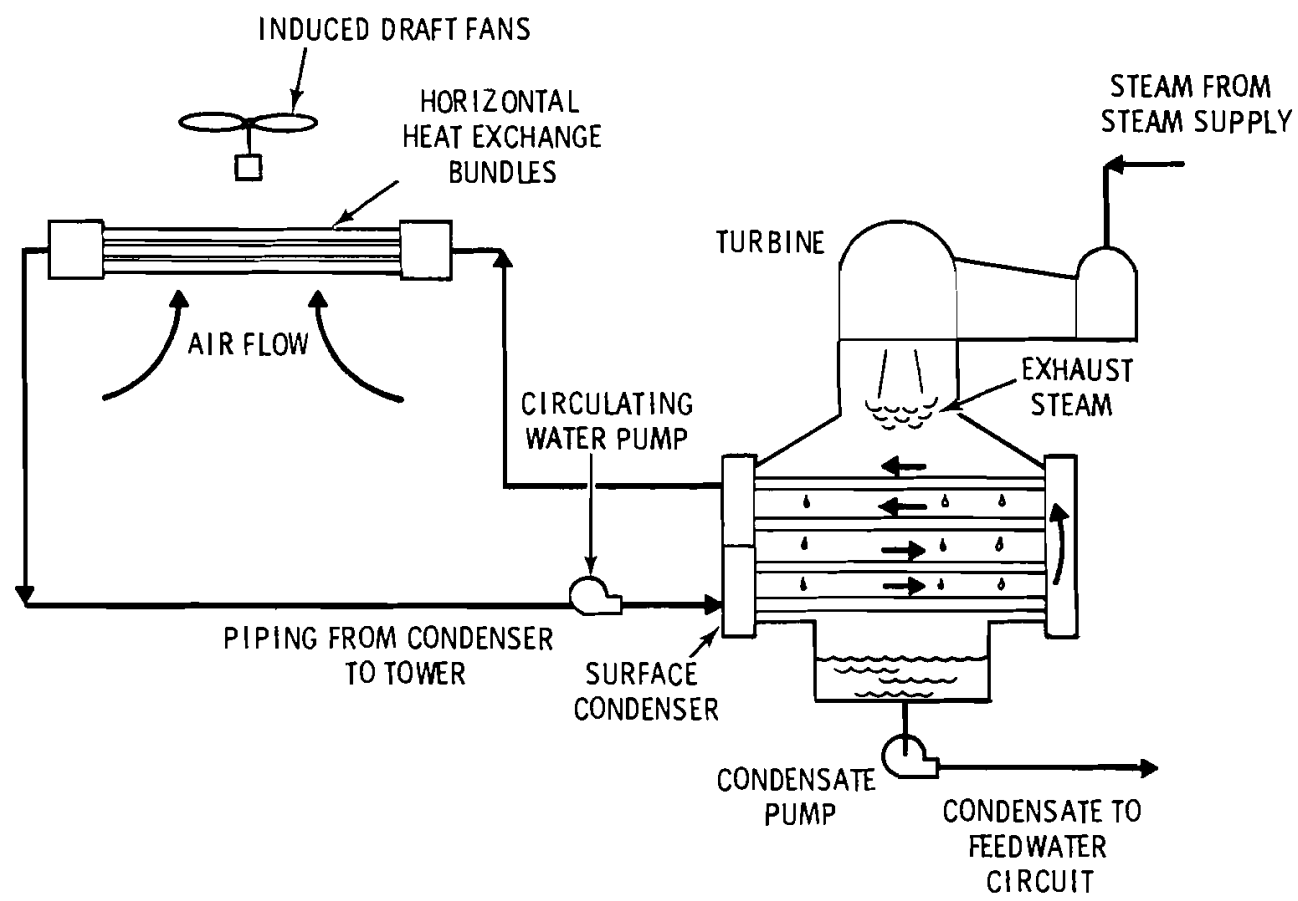

FIGURE 3-5. Indirect Dry Cooling System with Surface Condenser and Mechanical Draft Tower

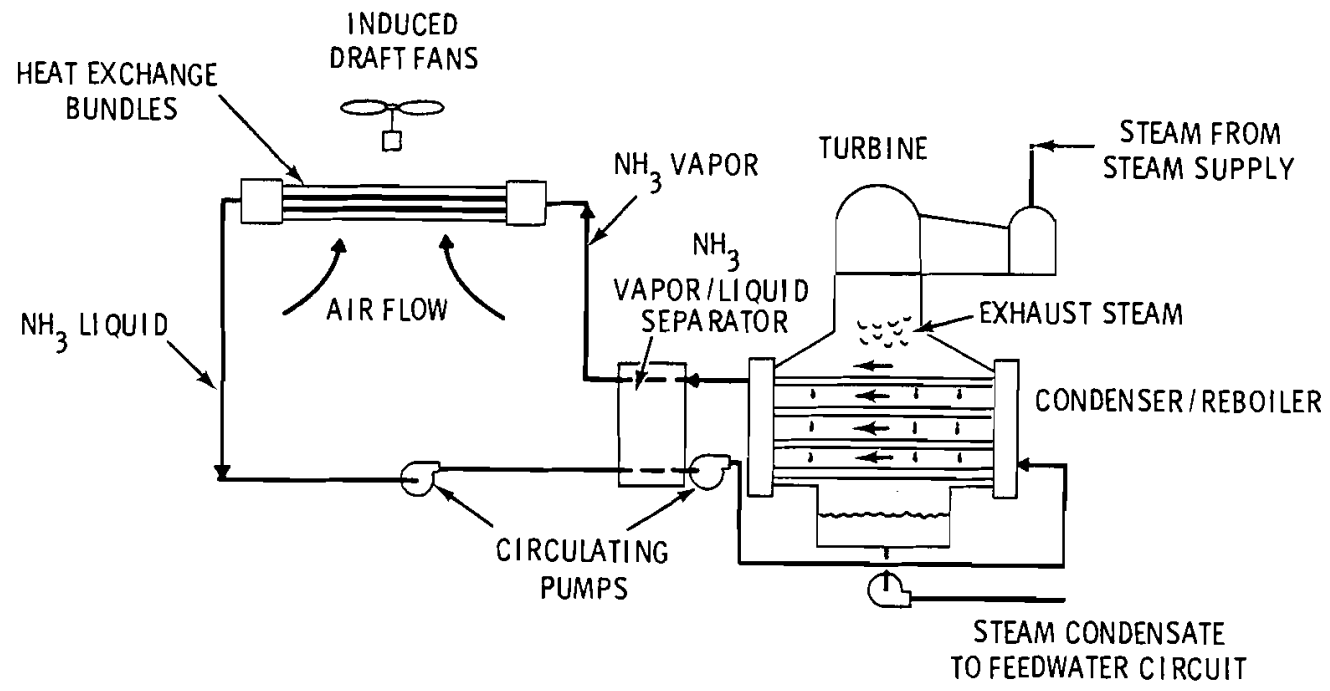

FIGURE 3-6. Ammonia Coolant Dry Cooling System 
No published engineering and economic studies provide detailed coverage of all options presented in Figure 3-2. In fact, no study adequately details any one component and option path of Figure 3-2 from the utility system, through the balance of the plant, and on through the cooling system.

This study has attempted to accomplish a detailed treatment of the option path indicated by the heavy wide line in Figure 3-2 for SOA systems. Exploratory investigations of the rectilinear tower arrangement with horizontal heat exchangers (dotted heavy line) were also conducted. Similar option paths were also investigated for PLASTIC systems. Investigation of the $\mathrm{NH}_{3}$ concept was limited to the circular tower option with appropriate modifications for generic differences.

\subsection{COSTING APPROACH}

The costing of all-dry cooling is based on the following considerations:

a. The dry cooling system is optimized in such a way as to minimize the power production costs of the utility system incorporating a dry cooled plant. (This is of particular importance in relation to lost performance of any dry cooled plants.) This would seem to be a fundamental basis from which to conduct optimization and/ or comparative studies of different cooling systems; however, it has not been the basis in many studies conducted to date. For a discussion of "lost performance", Reference 5 is suggested. The approach to accommodating lost performance in effect follows the suggested method summarized in that reference on pages 64-68.

Because of this approach, the reader should note that the absolute value of the incremental power production costs and percentage increases in total power production costs reported in this transmittal are significantly less than reported in many studies to date. The approach pursued may not affect the relative ranking of competitive systems, but it can definitely have a major impact upon the absolute costs attributed to a particular cooling system. 
b. The "cost" of dry cooling is defined as an incremental increase in power production costs compared to the cost of producing power with a plant having a zero cost cooling system and a conventional turbine operating at $3.5 \mathrm{in.} \mathrm{Hga.}$

c. The incremental cost due to dry cooling consists of:

1. cooling system equipment and installation costs (including indirect costs),

2. power and energy costs for fans and pumps in increased plant size and fuel costs,

3. costs for increased steam supply system, base plant scaling, and associated additional base plant fuel due to increased turbine heat rate at high back pressure, and

4. certain utility system interface costs in capacity and energy penalties (currently these particular interface costs are handled by assuming that gas turbines would be used to make up a certain amount of the lost capacity and energy of the dry cooled plant during high temperature hours. The balance is made up through Step 3 . The split is obtained through an optimization procedure.)

d. Items and related costs not included within this analysis are:

1. cover gas system

2. land costs

3. cooling system instrumentation costs

4. cooling loop water treatment costs.

One of the major capital cost items is the piping system. Only steel pipe has been considered in analysis thus far. Concrete and fiberglass pipe may be cost effective; however, their impact is only now undergoing preliminary investigation and the results are not included in this report. 
e. A11 costs are in January 1976 dollars. Interest during construction and inflation prior to or during construction are not considered. Effects of the dry cooling systems' construction schedules and their impact on the balance of plant construction schedule are also not considered. The uncertainty involved in defining these items appears to outweigh any additional understanding obtained by including them in a comparative analysis.

\subsection{OPTIMIZATION}

Optimization of a dry cooling system involves:

a. determining a set of independent parameters which fix the design, after which all other dependent parameters can then be calculated; and

b. defining which combination of this set results in the lowest incremental power production costs.

At PNL, a computerized approach is used to optimize dry cooling systems. The computer optimization involves four types of parameters:

1. internally optimized independent parameters

2. internally optimized dependent parameters

3. externally optimized independent parameters

4. external fixed parameters.

A list of the major parameters and options in each of the above groups is given in Table 3-1.

The external fixed parameters are those which are imposed on the analysis. They are generally fixed at a given site for a particular plant. However, the investigator may vary these "fixed" parameters when comparing the cost of dry cooling for nuclear plants with coal plants, or evaluating cost differences at different sites. The effect of changes in fuel costs, capacity factors, etc., can also be investigated by varying these parameters. 

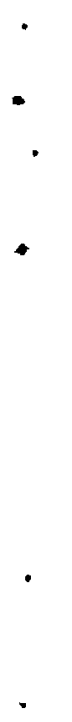
TABLE 3-1. Computer Analysis - Major Cooling System Parameters and 0ptions

1 HEf $\because$ EXCHANGER

II FAN SYSTEM

III TOMER

IV PIPING AND PUMP

$\checkmark$ CONDENSER (SOA AND PLASTIC)
1. TERMINAL TEMPERATURE DIFFERENCE $\left(\mathrm{NH}_{3}\right)$

1. TUBE NUMBER

2. BLADE DIAMETER *

3. BLADE ANGLE*

4. NUMBER OF BLADES *

5. FAN POWER

1. NUMBER* (CIRCULAR)

2. DIAMETER (CIRCULAR)

1. PUMP POWER

2. PIPE LENGTHS

1. TUBE LENGTH

2. TUBE NUMBER

1. DESIGN TURBINE EXHAUST

TEMPERATURE*

1. CAPACITY RATIO (WATER/AIR)

1. AIR MASS FLOW RATE (RANGE OF AIR)

2. RANGE OF WATER*

3. RANGE OF $A I R\left(\mathrm{NH}_{3}\right)$

2. WATER MASS FLOW RATE

3. TOWER INITIAL

TEMPERATURE DIFFERENCE (ITD)*
EXTERNALLY OPTIMIZED INDEPENDENT

1. UNIT GEOMETRY (TLIBE OD, TUBE PITCH, FIN PITCH, FIN HEIGHT, STAGGERED VS IN-LINE, ETCI

2. TUBE AND FIN MATERIAL

3. FIN TYPE

4. SPACER MATERIAL AND

TYPE

5. HEADER TYPE

1. VELOCITY RECOVERY VS NO VELOCITY RECOVERY
1. DESIGN VELOCITY

2. PIPE WALL THICKNESS

3. PIPING TEMPERATURE

1. TERMINAL TEMPERATURE DIFFERENCE

2. TUBE MATERIAL

3. TUBE DIAMETER

4. DESIGN VELOCITY

1. TUBE LENGTH

2. TUBE MATERIAL

3. TUBE DIAMETER

4. TUBE TYPE

5. EXIT QUALITY

EXTERNAL F IXE[ I

1. TURBINE TYPE

1. RATIO OF TOWER ROOF AREA TO FAN SWEPT AREA

2. DESIGN AMBIENT TEMPERATURE

3. DELTA VRS NON-DELTA HEAT EXCHANGER

4. CIRCULAR VRS RECTILINEAR TOWER ARRANGE

VIII BA.IE PLANT

1. FUEL COST

2. PLANT COST

3. HEAT RATE

4. CAPACITYFAC OR

5. FIXED CHARGE RATE

6. SIZE

1. ENERGY PENALTY CHARGES

2. CAPACITY PENALTY CHARGES

1. METEOROLOGY

\section{$X$ SIIE}


The externally optimized independent parameters or options are those which are optimized by changing one or more parameters or options at a time and observing the resultant changes in costs and cooling system design. This includes simple factors such as the effect of fin spacing, as well as more complex elements such as delta heat exchanger arrangements.

For a given set of external parameters, there are only five internally optimized independent parameters. Once these five independent parameters are specified, all other system design and operating dependent parameters can be calculated. Several different combinations of five parameters could have been used in lieu of those in Table 3-1. However, combinations shown in Table 3-1 are those used in the MIT studies $(13-15)$ which served as one reference for the work described herein.

This particular set of parameters makes solving for the dependent parameters rather straightforward with a minimum of time-consuming iterative implicit calculations. However, this approach results in heat exchanger designs with a non-integer number of tube rows in the direction of air flow. Usually, this can be circumvented by applying constraints to the optimization analysis. However, difficulties can still result when attempting to arrive at optimized cooling systems having an integer number of tube rows. For continuous matrix heat exchangers, the non-integer tube row problem does not exist. However, SOA, PLASTIC, and $\mathrm{NH}_{3}$ systems investigated in this study employ integer tube row heat exchangers. This is particularly important in the case of SOA systems utilizing two-pass heat exchangers where exchangers of interest are 2, 4, or 6 rows deep, resulting in relatively large discrete changes in the number of tube rows. In single-pass $\mathrm{NH}_{3}$ systems, the problem is less severe. In PLASTIC systems, the problem is insignificant because exchangers with as many as 30 tube rows are typical.

\subsection{COMPUTER PROGRAM}

The optimization process involves many repetitive calculations, requiring use of a computer. The computer program consists of equations describing 
costs as a function of design and operating parameters, and of physical models describing the interaction between the physical design and operating parameters. In addition, the program contains an optimization technique to determine which combination of internal dependent parameters results in the minimum incremental power production costs associated with dry cooling. The input to the program is illustrated in Figure 3-7. General output information is also indicated.

\subsection{DEVELOPMENT OF COST MODELS}

Considerable effort has been made as part of the DCT program to develop cost models in addition to physical models for the cooling system. These extremely important cost models are described in a companion report, Reference 16.

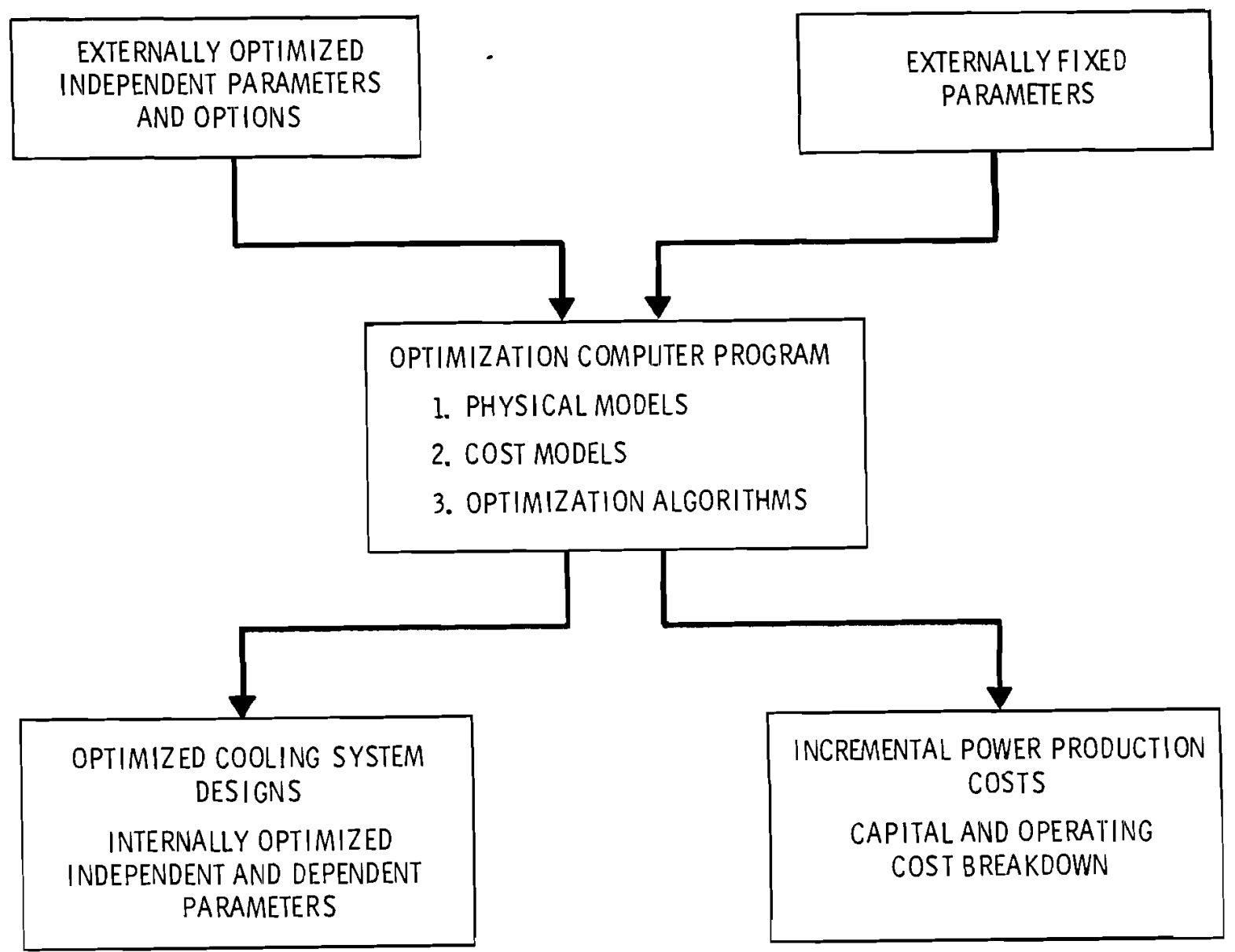

FIGURE 3-7. Dry Cooling System Computer Optimization 


\subsection{COOLING SYSTEM DESIGN BASES}

The general design bases and limitations used in this study are described in this section.

\subsection{GENERAL DESIGN BASIS}

The primary purpose of this study was to compare three different cooling systems in terms of incremental power production costs. An objective comparison requires that the systems be optimized, and that the bases for the cooling system design be equitable for each system. The following parameters, system options, and limitations were selected as the design bases for the studies presented within tḧis report. Certain qualifications and alterations will be subsequently discussed.

Plant Type
Plant Size
Nominal Heat Rejection
Reference Base Plant Cost
Base Plant Fuel Cost
Base Plant Incremental
Steam Supply Cost
Capacity Charge
Energy Charge
Capacity Factor
Fixed Charge Rate
Cooling System Annual 0\&M
Meteorological Site
Turbine Type (a)

Design Temperature (a)

Condenser Type

Tower Arrangement

Heat Exchanger Orientation

Cooling System Type
Fossil

1000 MWe

$5.1 \times 10^{9} \mathrm{Btu} / \mathrm{hr}$

$440 \$ / k W \cdot e$

$81 \$ / 10^{6}$ Btu

$146 \$ / \mathrm{kWe}$

$121 \$ / \mathrm{kWe}$

2. $4 \$ / \mathrm{kWh}$

$65 \%$

$17.4 \%$

Arinual cost equals 1\% of cooling system capital cost

Wyodak, Wyoming

Modified Conventiona

(Maximum Back Pressure 8 in. Hga.)

$50^{\circ} \mathrm{r}^{-}$

Surface - Single Pressure

Circular

Vertica 1

Indirect Mechanical Draft

(a) Choice of item was based upon results of parametric studies (Sections 6 through 8 ). 
Fan Draft

Fan Discharge

Ratio: Tower Roof Area/

Fan Swept Area

Plant Operating Condition
Induced

Recovery Stacks

Packing Factor 2.0(a)

Full Load; Valve Wide Open

Comparison of the three competitive systems and the parametric analysis of each individual system were based upon the conditions given above. However, to determine if the bases were equitable for each system, and to perform additional parametric analysis for each individual system, the effect of varying these general design bases was investigated.

The three dry cooling systems were evaluated under nuclear plant conditions, different meteorological sites, rectilinear tower arrangements with horizontal heat exchanger orientation, with different turbines, different fan/roof area packing factors, and without velocity recovery stacks.

The effect of these factors is discussed in Sections 6 through 8, which indicate the above to be an equitable general comparative base.

\subsection{ADDITIONAL DESIGN BASES LIMITATIONS}

The comparison of the three systems presented in Section 5 is greatly simplified if some design and operating parameters of the resulting optimized cooling system are the same or nearly so. This allows the investigator to concentrate on the major differences, and to readily determine which systems are generically better and why. Analys is indicates that placing the following limits on the three different systems will still permit determination of near optimum designs: $(b)$

(a) Choice of item was based upon results of parametric studies (Sections 6 through 8 ).

(b) Less than 1 percent increase in incremental power production cost except for a 3 percent increase for the SOA - expensive metal fin system. 
Tower Diameter $\quad 195 \pm 10$

Heat Exchanger

Tube length

80 feet

Fan Diameter

28 feet

Heat Exchanger

Depth $\left(\mathrm{NH}_{3}\right.$ only) $\geq 4$ rows

In comparing one system to another, these limits were used. However, in the general parametric studies of the individual systems (Sections 6, 7 and 8 ), these limits were not imposed. 


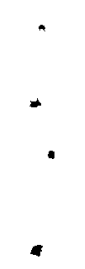




\subsection{PHYSICAL DESCRIPTION AND COST COMPARISON \\ OF THE THREE COOLING SYSTEMS}

General descriptions of the SOA, PLASTIC, and $\mathrm{NH}_{3}$ c001ing systems are provided in Sections 5.1 through 5.3. The descriptions assume each system is operating steady-state at full load. Startup, shutdown, load change, and system operational changes to accommodate meteorological changes for various plant operating modes are not considered.

The incremental energy costs and the system capital costs are discussed in Section 5.4 .

\subsection{SOA COOLING SYSTEM}

The SOA cooling system considered in this study is illustrated in Figure 3-5. It is an indirect system with induced mechanical draft and a single pressure surface condenser. The cooling process is best described with the aid of the temperature relationship diagram in Figure 5-1. Turbine exhaust steam is condensed at constant temperature on the outside of the condenser tubes. Water entering the condenser tubes is heated, then carried through the supply piping to the cooling tower. The increase in water temperature is termed the RANGE Water. The water approaches the steam saturation temperature, with the difference being termed the terminal temperature difference, or TTD. At the cooling tower, the water cools while simultaneously heating the air as it passes over the finned tubes in the tower. The change in air temperature is termed the RANGE ${ }_{A i r}$. The cooled water is then returned via return piping to the condenser inlet. The heated air is discharged to the environment via the induced draft fans. A short description of the components within the cooling system will now be presented.

\subsubsection{Condenser}

The condenser considered for this study is a single pressure surface condenser. It consists of one-inch 00 admiralty tubes of $18 \mathrm{BWG}$. Other tube materials, diameters, and wall thicknesses can be investigated with the 


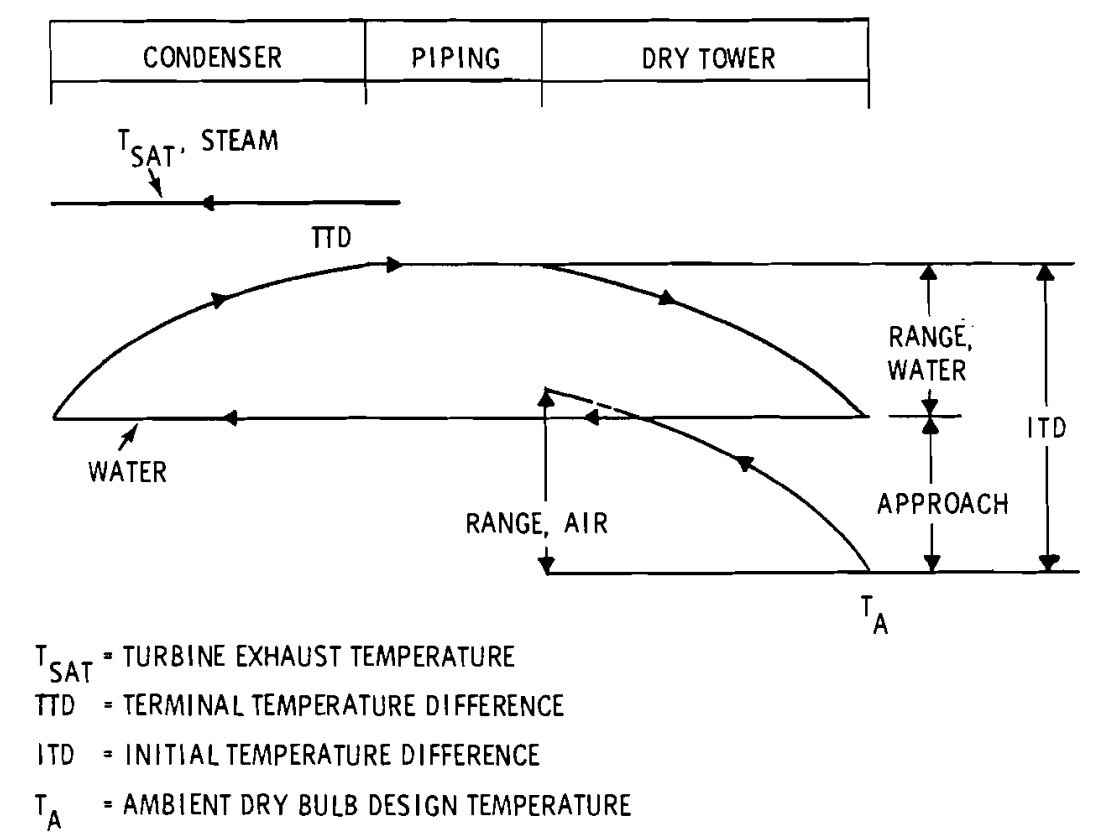

\section{FIGURE 5-1. Temperature Relationships for SOA and Plastic Heat Exchanger Cooling Systems}

computer program described in Section 3; however, at this date they have not been studied. Investigation of multipressure surface condensers has not been made, and would require modification to the computer program.

\section{1 .2 Piping}

The pipina consists of main supply and return lines, tower distribution lines, headers, and pump station pipina. Carbon steel pipina and fittings were considered in this study. Concrete and fiberalass are under preliminary investiqation, but no conclusions have been reached reaardina their competitive rankina relative to steel pipe. The main supply and return pipina and the tower distribution lines are considered to be below ground. The headers are considered to be above ground. The vertical inline pumps draw water from an open reservoir. A complete description of the piping layouts and algorithms is presented in Reference 16.

\subsubsection{Cooling Tower}

The cooling towers are circular with vertical heat exchangers (i.e., tubes are vertical, fins horizontal) and induced draft fans. Louvers are 
provided for air flow control and hail protection. The fan system consists of the fans, motors, gear boxes, and electrical wiring. The fan blades are fiberglass. The gear boxes are single-speed bevel gear type. The fans have manually adjustable pitch blades.

Rectangular cooling towers with horizontally oriented heat exchanger bundles were also investigated. The details are discussed in Section 6.

SOA cooling systems with and without fan diffuser stacks were investigated. Marginal cost savings were shown for diffuser stacks. However, the stacks are energy conservative, and this factor may result in their economic application as the relative costs of items assessed to dry cooling change in the future. For these reasons, the stacks were selected as the optimum system.

\subsection{PLASTIC HEAT EXCHANGER COOLING SYSTEM}

The plastic heat exchanger cooling system is basically the same as the SOA system with the metal finned tubes replaced with plastic tubes. Details of plastic heat exchanger fabrication may be found in References 16 and 17.

Because of the larger frontal area found to be optimum with the PLASTIC system vis-a-vis the SOA and the $\mathrm{NH}_{3}$ systems, the PLASTIC system made use of a configuration in which the heat exchanger bundles were located in $60^{\circ}$ deltas about the periphery of the towers.

\subsection{AMMONIA DRY COOLING SYSTEM}

The ammonia dry cooling system, illustrated in Figure 3-6, differs from SOA systems in two ways. First, ammonia replaces water as the coolant. Second, a condenser/reboiler is used in place of the standard condenser. The cooling process can be explained by referring to Figures 3-6 and 5-2. Turbine exhaust steam is condensed at constant temperature on the outside of the condenser/reboiler tubes. Slightly subcooled liquid ammonia entering the condenser/reboiler tubes is first heated to saturation temperature, then partially boiled at constant temperature as it traverses the length of the tubes. A mixture of liquid and vapor ammonia (typically 


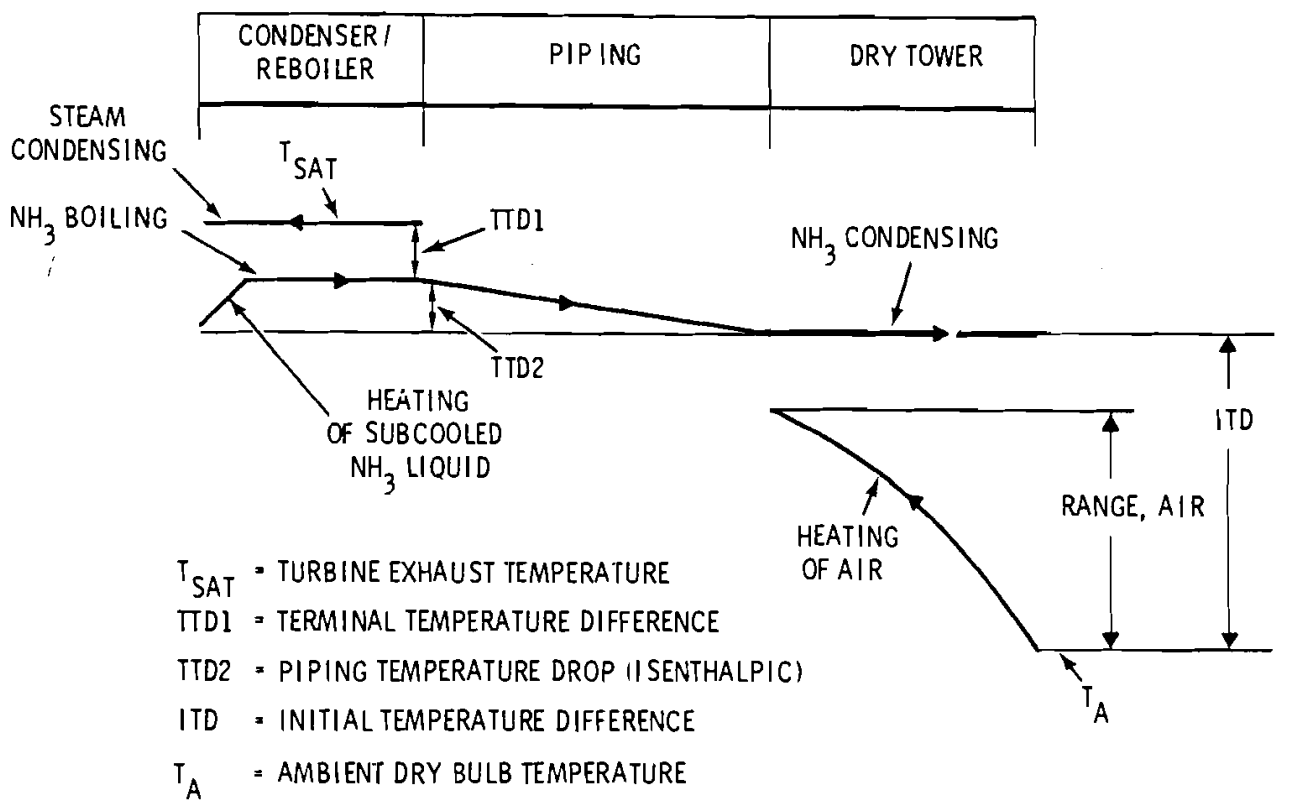

FIGURE 5-2. Temperature Relationships for Ammonia Coolant Dry Cooling System

50 to 80 percent quality, depending on the design) enters the separator where the vapor is routed to the tower supply piping, and the liquid is collected for recirculation to the condenser/reboiler. The vapor flows through the supply piping at near-saturation conditions. However, there is a pressure drop in the piping system from frictional effects. Because of the physical characteristics of ammonia vapor, this pressure drop is accompanied by a drop in temperature. At the tower, the vapor is condensed inside the metal finned tubes at constant temperature. The condensed ammonia is then collected and returned to the condenser/reboiler. The basic terminology remains the same as for the SOA system except that the parameter, RANGE water, is eliminated and replaced by the vapor supply piping temperature drop, TTD2. Because of the economic trade-offs, the RANGE ${ }_{A}$ ir is larger for the ammonia system than for SOA or PLASTIC systems.

\subsubsection{Condenser/Reboiler}

The condenser/reboiler considered in this study is essentially similar to the SOA condenser in general appearance. However, water boxes would be replaced with high pressure headers and tube sheets would be much thicker. 
Tubes would be of two types: conventional smooth tubes of aluminum or stainless steel, or enhanced tubes which improve steam and ammonia-side heat transfer processes. With the enhanced tubes, the size of the condenser/ reboiler would be about the same as for a conventional condenser. For conventional tubes the condenser/reboiler is significantly larger. Only horizontal tube arrangements with ammonia on the tube side have been considered. Other arrangements, including vertical tubes and/or ammonia on the shell side, are optional possibilities that have not been evaluated.

\subsubsection{Piping}

The piping in the ammonia system is considerably different from the water systems. First, the diameter is typically smaller, particularly in the return line. Second, for a given diameter, the ammonia piping must be considerably thicker to accommodate the higher pressure (neglecting corrosion allowances).

\subsubsection{Cooling Tower}

The ammonia cooling system considered consists of vertical one-pass heat exchangers. Ammonia vapor enters the top of the heat exchangers, and condenses as it flows down the inside of the finned tubes. This is in contrast to the two-pass SOA and PLASTIC systems in which water enters and exits the heat exchangers at the bottom of the vertical heat exchanger. Other arrangements have been considered for the $\mathrm{NH}_{3}$ system. One, involving countercurrent vapor/liquid flow with vertical heat exchangers, could result in cost savings. However, questions regarding the "flooding" phenomena discussed in the appendix have yet to be resolved before the arrangement can be pursued.

\subsection{DESIGN AND COST COMPARISONS}

The cooling system layouts and some important design details of each of the systems are illustrated in Figures 5-3 through 5-6; design and operating parameters are presented in Tab7e 5-1. Net power output of the dry cooled plant over the meteorological cycle is identical for each system as illustrated in Figure 5-7. As described in Section 4.2, 1imits were 


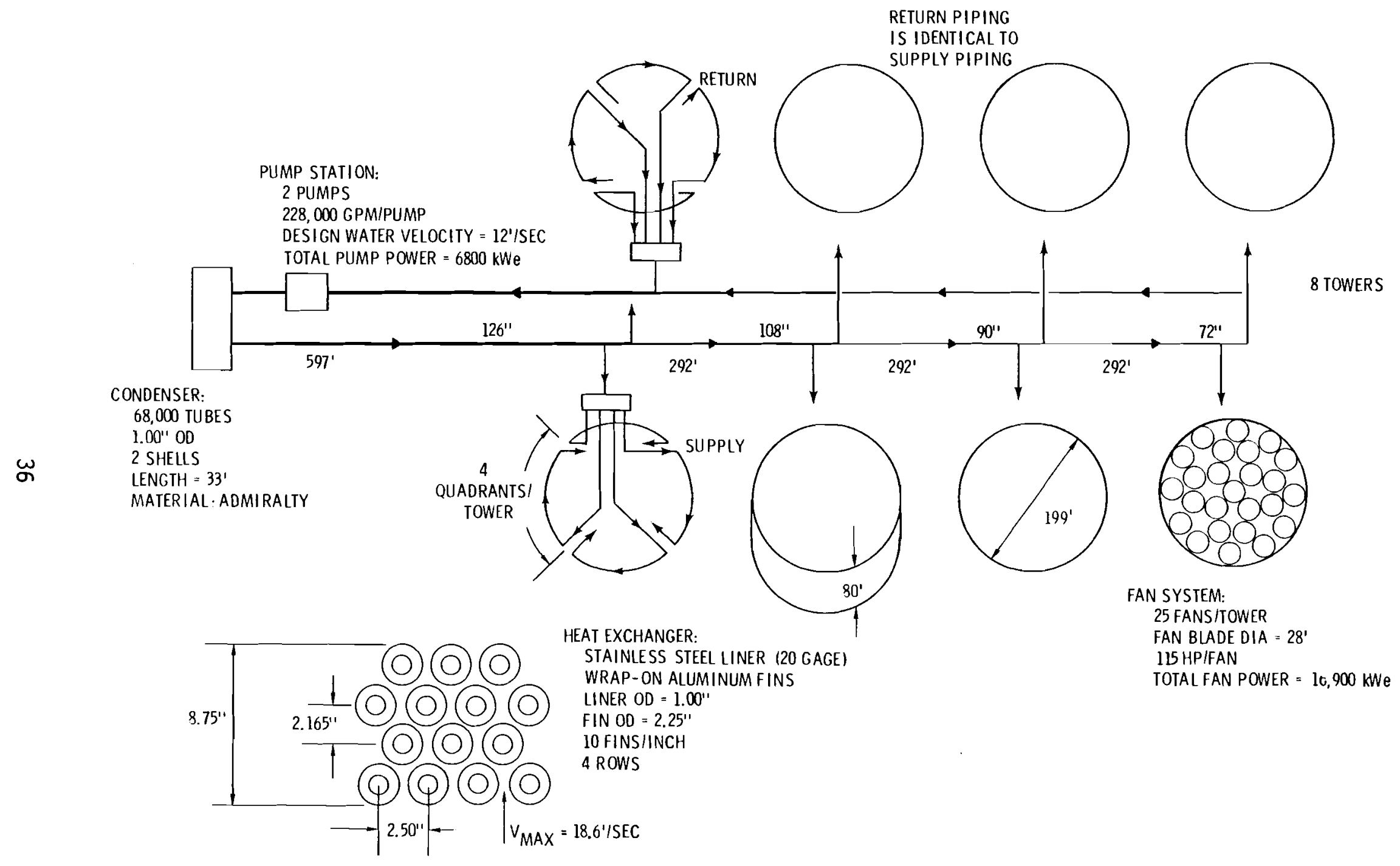

FIGURE 5-3. State-of-the-Art A17-Dry Cooling System, Expensive Finned Tube 


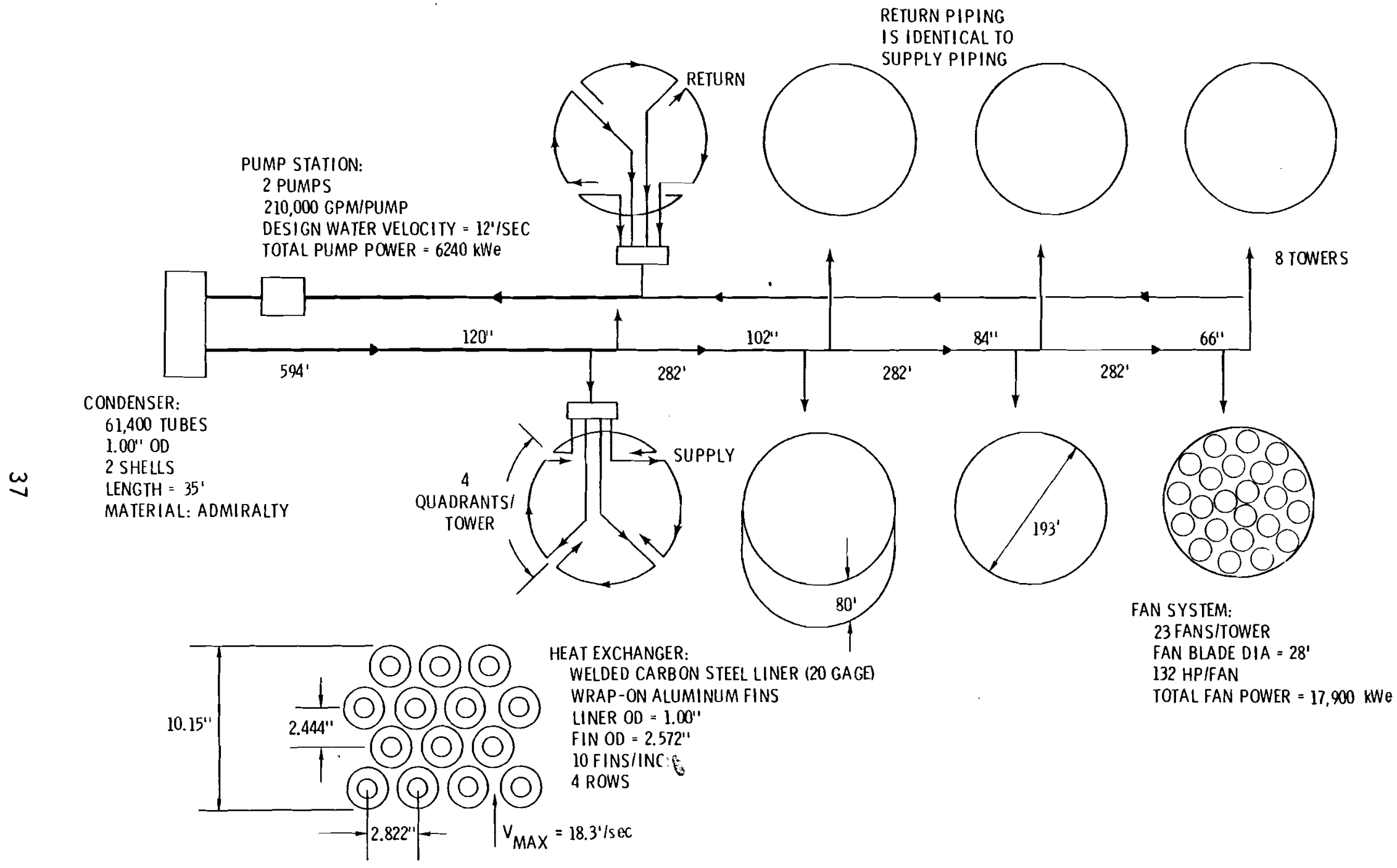

FIGURE 5-4. State-of-the-Art A11-Dry Cooling System, Inexpensive Finned Tube 


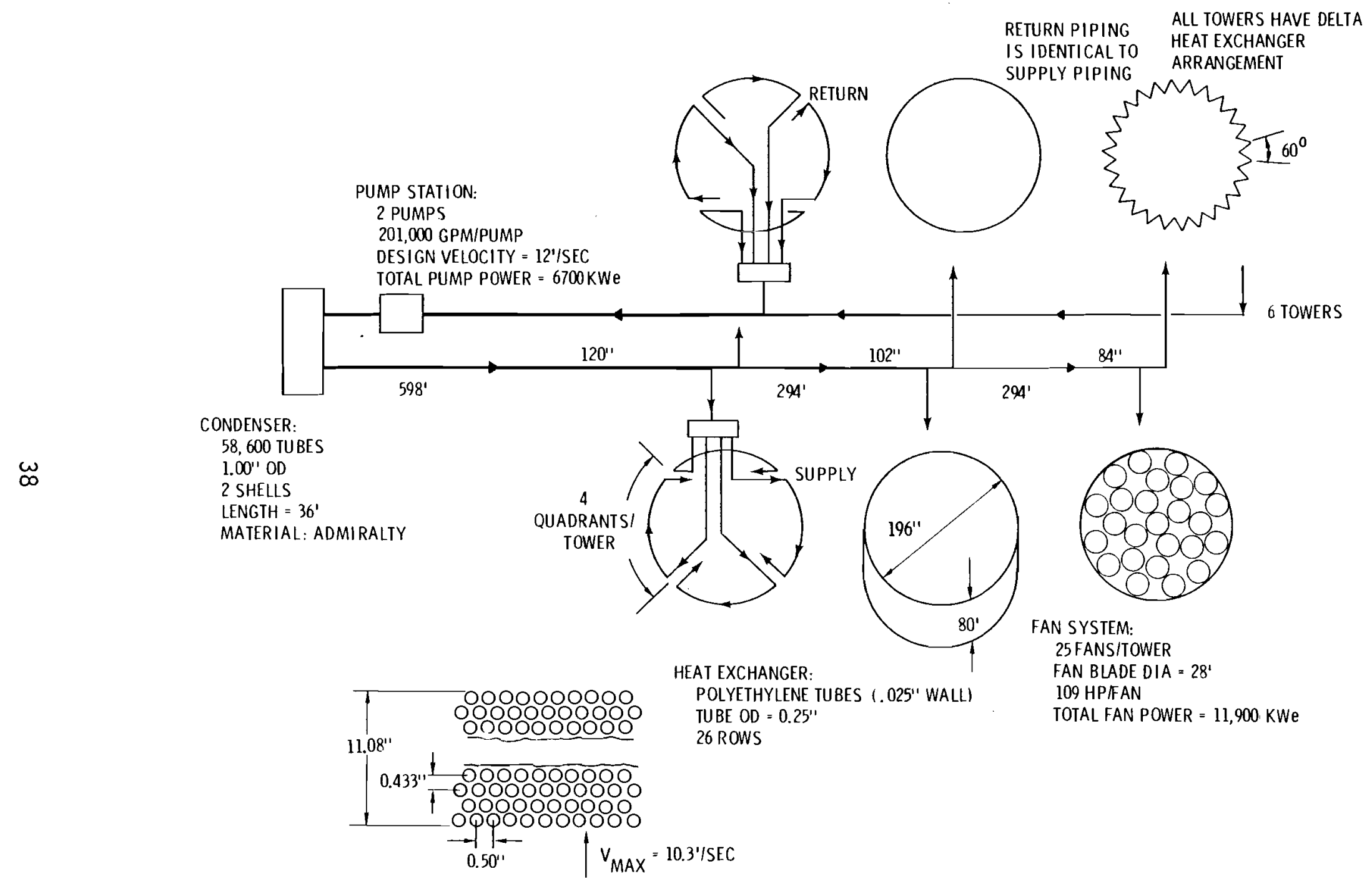

FIGURE 5-5. PLASTIC A11-Dry Cooling System 


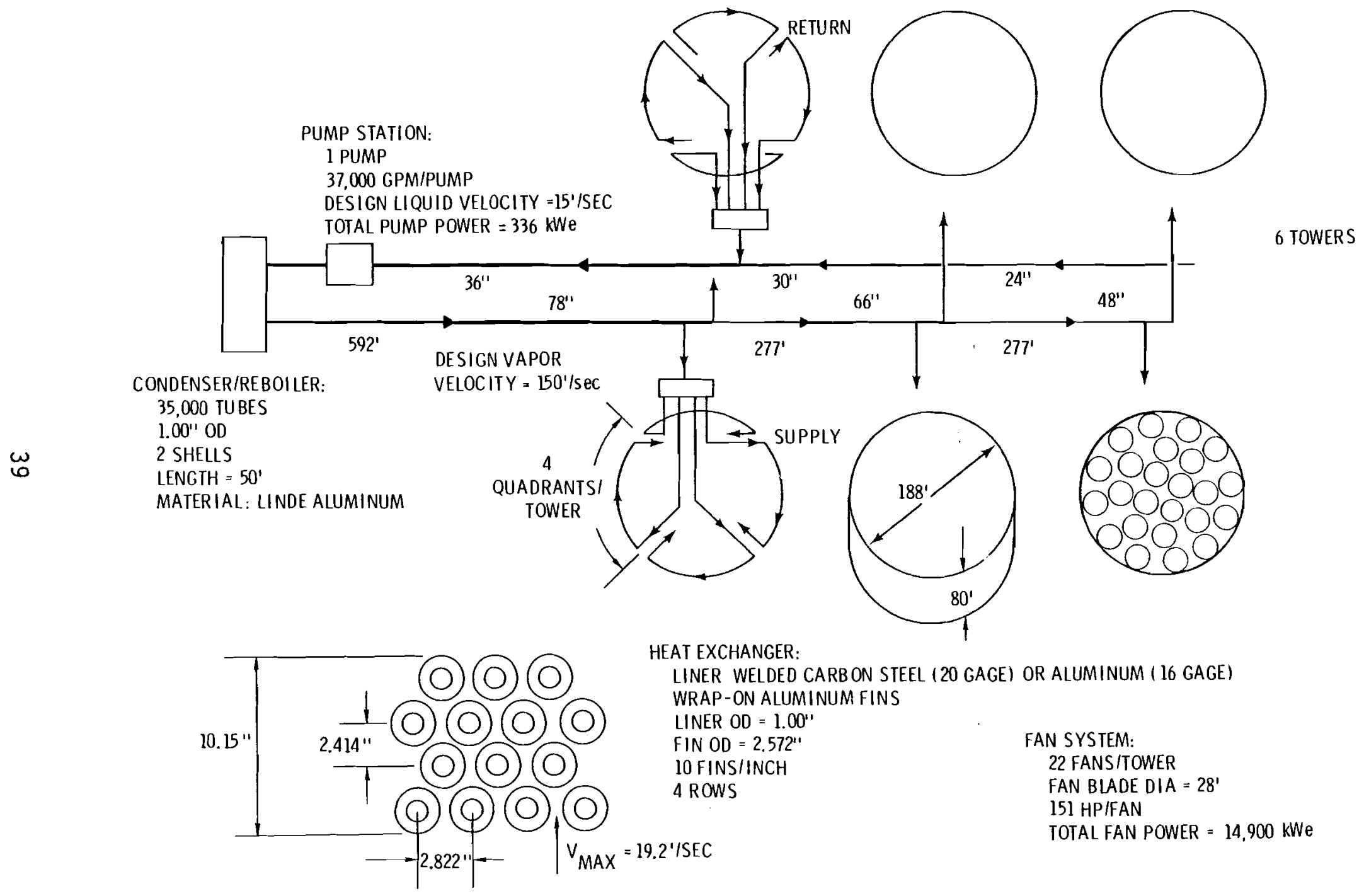

FIGURE 5-6. Ammonia A11-Dry Cooling System 


\section{TABLE 5-1. Comparison of Design and Operating Parameters, Near-Optimum Designs}

\section{Temperatures}

TTD1, ${ }^{\circ} \mathrm{F}$ (Condenser)

TTO2, ( $\mathrm{NH}_{3}$ Supply Pipe)

ITD, ${ }^{\circ} \mathrm{F}$

LMTD, ${ }^{\circ} \mathrm{F}$

Range $_{\text {i } r}$, ${ }^{\circ} \mathrm{F}$

Range $_{\mathrm{H}_{2} \mathrm{O}},{ }^{\circ} \mathrm{F}$

\begin{tabular}{|c|c|c|c|}
\hline $\begin{array}{l}\text { SOA } \\
\text { (Exp } \\
\text { tube) }\end{array}$ & $\begin{array}{c}\text { SOA } \\
\text { (Inexp. } \\
\text { tube) }\end{array}$ & Plastic & $\mathrm{NH}_{3}$ \\
\hline
\end{tabular}

Velocities

$V_{\text {air max. }}, \mathrm{ft} / \mathrm{sec}$

$V_{\mathrm{H}_{2} \mathrm{O}}$ H.X. ft/sec

$V_{\mathrm{NH}_{3}} \mathrm{H} . X . \mathrm{ft} / \mathrm{sec}$

$\begin{array}{cccc}5 & 5 & 5 & 4.3 \\ -- & -- & -- & 3.6 \\ 45.6 & 45.6 & 45.6 & 45.0 \\ 21.3 & 20.6 & 17.4 & 24.8 \\ 26.1 & 25.4 & 30.6 & 33.1 \\ 22.5 & 24.5 & 25.5 & --\end{array}$

Heat Transfer Coefficients

U, Btu/hr-ft ${ }^{2}-{ }^{\circ} \mathrm{F}$

$\mathrm{h}_{\mathrm{H}_{2} \mathrm{O}}, \mathrm{Btu} / \mathrm{hr}-\mathrm{ft}{ }^{2}-{ }^{\circ} \mathrm{F}$

$\mathrm{h}_{\mathrm{NH} 3}, \mathrm{Btu} / \mathrm{hr}-\mathrm{ft}^{2}-^{\circ} \mathrm{F}$

$h_{\text {air }}$, Btu/hr-ft ${ }^{2}-{ }^{\circ} \mathrm{F}$

$\begin{array}{cccc}8.6 & 18.3 & 10.3 & 19.2 \\ 4.6 & 4.9 & 1.8 & -- \\ -- & -- & -- & 16.7\end{array}$

Heat Exchanger Dimensions

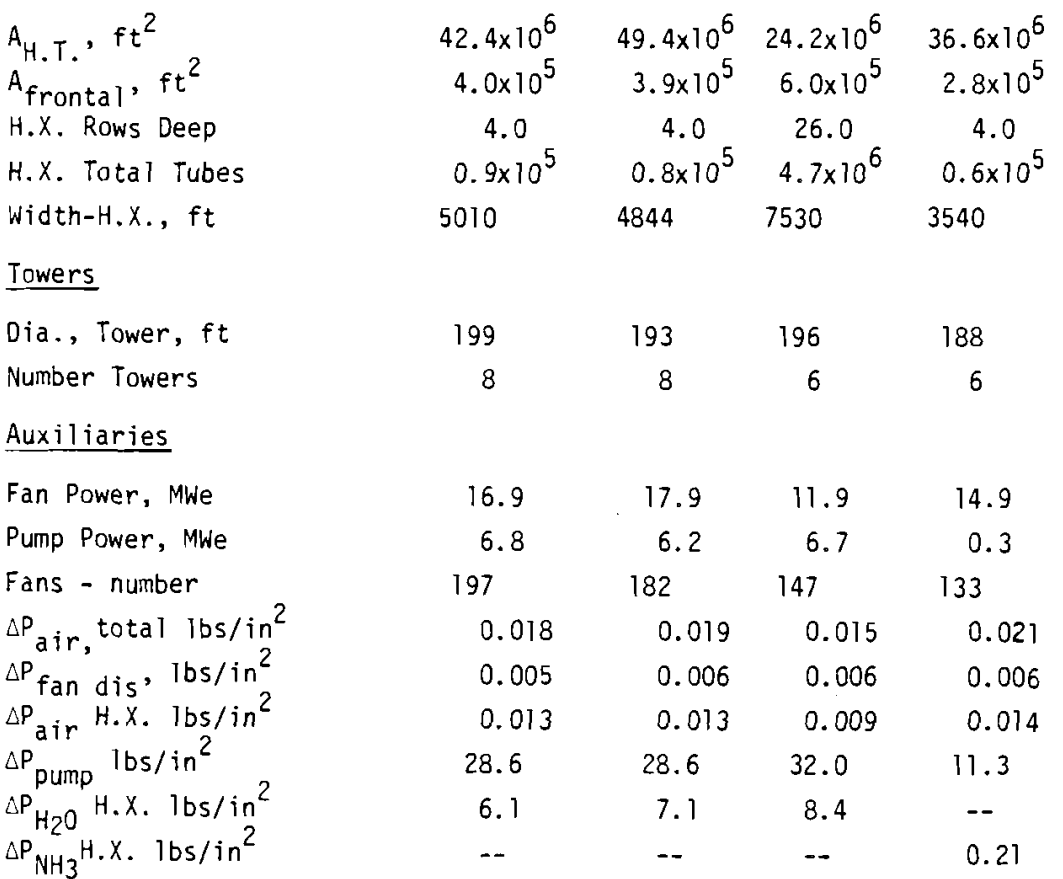

$\begin{array}{cccc}6.1 & 5.4 & 13.6 & 5.7 \\ 1094 & 1170 & 713 & -- \\ -- & -- & -- & 1304 \\ 8.0 & 7.5 & 15.7 & 8.0\end{array}$



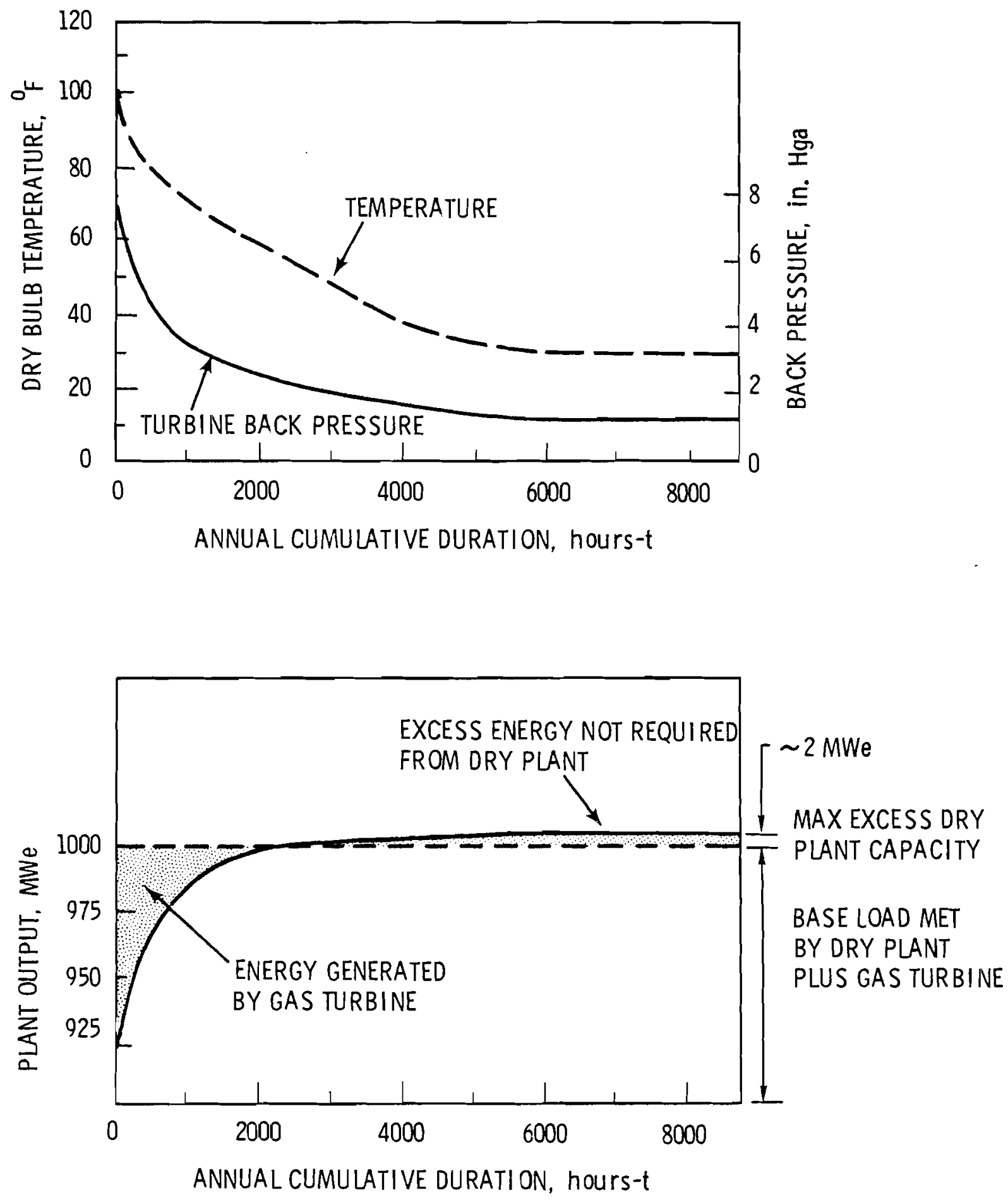

FIGURE 5-7. A11-Dry Cooled Plant Performance 
placed on tower diameter, heat exchanger tube length, fan diameter and heat exchanger depth to make comparisons between the systems easier. Thus, "near-optimum" systems were arrived at with incremental costs less than one percent more expensive than the optimum systems described in Sections 6 through 8 except for the expensive SOA system which was 3 percent more expensive (still a negligible difference).

The SOA and PLASTIC systens operated at a turbine back pressure of 2.0 in. Hga whereas the $\mathrm{NH}_{3}$ system operated at a back pressure of 2.1 in. Hga at the design temperature of $50^{\circ} \mathrm{F}$ (the maximum ambient temperature at which plant net power production remained at 1000 MWe). Thus all systems had essentially identical design point heat rates.

With this background, the incremental energy costs will be presented prior to comparing the designs and costs of the components.

\subsubsection{Incremental Energy Costs}

The incremental energy costs, normalized to unit power output, are presented in Table 5-2. The SOA system using expensive fin tubes is the most expensive followed by the SOA system with inexpensive tubes (11.9 percent cheaper), the PLASTIC system (22.2 percent cheaper) and finally the $\mathrm{NH}_{3}$ system (34.2 percent cheaper).

An examination of the operating conditions (Table 5-1) in terms of air and water flow rates and the associated change in air and water temperatures shows that they are typical of what would be specified by the dry cooling tower industry for the design basis considered (e.g., the change in water and the change in air temperature is typically about 0.4 to 0.4 of the ITD). Thus, the costs of vendor offerings could be expected to lie somewhere between the expensive and inexpensive finned tube SOA systems.

This investigation indicates little, if any, potential for reducing costs for SOA systems relative to vendor offerings.

On the other hand, the $\mathrm{NH}_{3}$ and PLASTIC systems show significant reductions in incremental costs even if corrosion considerations permit the use of the inexpensive finned tube SOA system. 
TABLE 5-2. Cost Comparison of Near Optimum Designs

\begin{tabular}{lcl}
\multicolumn{3}{c}{ Energy Costs, mills/kWh } \\
\hline SOA & SOA \\
(Exp. & $\begin{array}{c}\text { (Inexp } \\
\text { tube) } \quad \text { Plastic }\end{array}$ \\
&
\end{tabular}

Unit

\begin{tabular}{|c|c|c|c|c|}
\hline Cooling System Capital & 2.33 & 1.96 & 1.76 & 1.45 \\
\hline O\&M & 0.13 & 0.11 & 0.10 & 0.08 \\
\hline Base Plant Scaling & 0.22 & 0.23 & 0.15 & 0.12 \\
\hline $\begin{array}{l}\text { Additional Base } \\
\text { Plant Fuel }\end{array}$ & 0.15 & 0.16 & 0.12 & 0.10 \\
\hline Capacity Penalty & 0.27 & 0.27 & 0.27 & 0.26 \\
\hline Energy Penalty & $\underline{0.09}$ & $\underline{0.09}$ & $\underline{0.09}$ & $\underline{0.09}$ \\
\hline $\begin{array}{l}\text { Total Incremental Power } \\
\text { Production Costs }\end{array}$ & 3.19 & 2.82 & 2.49 & 2.10 \\
\hline
\end{tabular}

The incremental costs associated with the cooling system capital costs differ the greatest. These costs were $0.88 \mathrm{mills} / \mathrm{kWh}$ higher for the expensive SOA system than for the $\mathrm{NH}_{3}$ system.

Because operation and maintenance costs (0\&M) are assessed as one percent per year of the capital costs, they are proportional to and equal to 6 percent of the incremental costs associated with capital costs. As a result, the O\&M cost for the expensive SOA system is $0.05 \mathrm{mills} / \mathrm{kWh}$ higher than that of the $\mathrm{NH}_{3}$ system.

The differences in the base plant scaling and additional base plant fuel result, for the most part, from differences in the amount of auxiliary power required by the systems. The PLASTIC system requires less fan power, whereas the $\mathrm{NH}_{3}$ system requires somewhat less fan power and negligible pumping power than the SOA system. As a result, the sum of the costs due to base plant scaling and to additional base plant fuel range from 0.37 to $0.39 \mathrm{mills} / \mathrm{kWh}$ for the two SOA systems, to $0.27 \mathrm{mills} / \mathrm{kWh}$ for the PLASTIC system and $0.22 \mathrm{mills} / \mathrm{kWh}$ for the $\mathrm{NH}_{3}$ system. 
The costs associated with providing replacement power from gas turbines are essentially the same for all systems--0.27 mills/kWh for gas turbine capacity and $0.09 \mathrm{mi} 11 \mathrm{~s} / \mathrm{kWh}$ for gas turbine fuel.

The capital costs and design feature of the systen components shall now be discussed in some detail.

\subsubsection{Cooling Towers, Fans, Heat Exchangers and Louvers}

Cooling Towers. $\mathrm{NH}_{3}$ and PLASTIC cooling systems have only six towers compared to eight of comparable size for the SOA systems. This results in a direct reduction in structure, foundation and plenum costs (Table 5-3). However, to accomplish this with PLASTIC, the heat exchangers must be arranged in a delta orientation, allowing more heat exchanger bundles to be packed into a given peripheral distance. For the PLASTIC system, delta orientation results in significant cost savings. However, for $\mathrm{NH}_{3}$ and SOA, only marginal savings result from the use of deltas. The difference lies in the fact that the PLASTIC system uses a heat exchange system with a considerably larger frontal area than either the SOA or the $\mathrm{NH}_{3}$ system. This allows use of the delta orientation for PLASTIC without putting undue constraint on the fan system.

Maldistribution of the air flow has been observed with the use of the delta heat exchanger arrangement. The impact of these maldistributions on operating performance should be evaluated. If necessary, methods for avoiding maldistributions, such as nonuniform number of rows across the bundles, should be developed if the delta arrangement is pursued.

Fans. The fan diameter for all systems was fixed at 28 feet. As shown, the number of fans per tower is essentially the same (22 to 25 fans/tower). There are significant differences in total fan power; the SOA systems require about 15 to 50 percent more fan power than the $\mathrm{NH}_{3}$ and PLASTIC systems. Consequently, the $\mathrm{NH}_{3}$ and PLASTIC systems require fewer fans. This results in a capital cost savings of about $\$ 3,000,000$ for the fan systems. Also, because less fan power is required for the $\mathrm{NH}_{3}$ and for the PLASTIC systems, the base plant scaling and additional base plant fuel requirements are reduced. 
TABLE 5-3. Cooling System Capital Costs

(Millions of dollars)

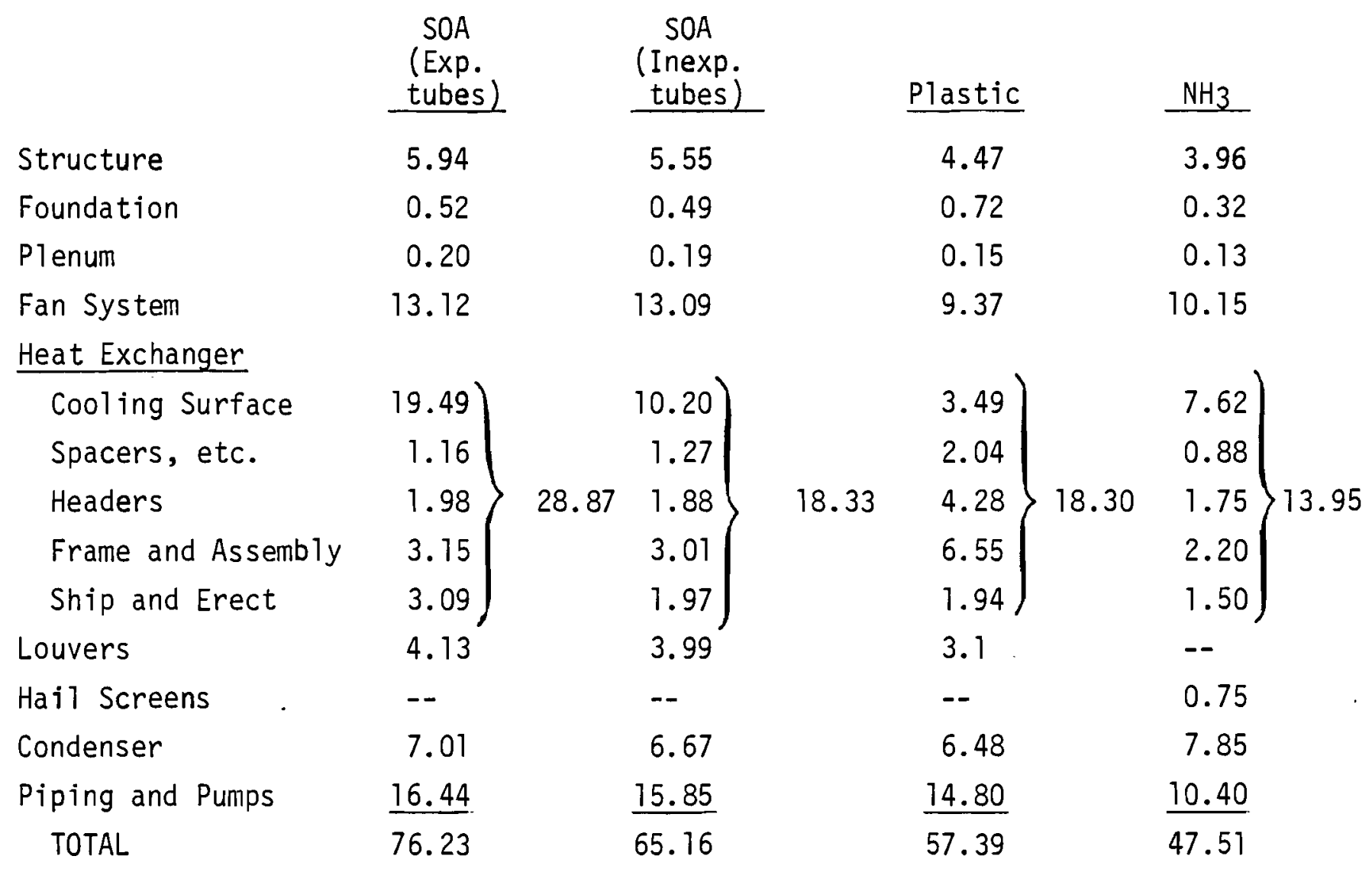

Heat Exchange Surfaces. The $\mathrm{SOA}$ and $\mathrm{NH}_{3}$ systems both employ metal finned tubes. The finned tube unit geometry and heat exchanger configuration shown in Figures 5-3, 5-4 and 5-6 are typical of what vendors would be expected to offer for SOA systems.

The inexpensive finned tube used in SOA analysis has 3/4-inch high wrap-on fins on a 20 gage welded carbon steel liner. The expensive finned tube has $5 / 8$-inch high wrap-on fins on a 20 gage stainless steel liner. The finned tubes used in the study of the ammonia system have wrap-on fins on a 20 gage welded carbon steel or aluminum 1 iner. A11 fins are aluminum.

Corrosion aspects must be carefully dealt with before these inexpensive finned tubes could be expected to perform reliably throughout the life of a 
typical power plant, particularly for SOA systems. This would include consideration of suitable water quality, materials compatibility in the balance of the circulation system, downtime procedures, and demonstration of reliability under particular site air-side environments. This is particularly true for the carbon steel liner employing a wrap-on fin.

Materials compatibility with the circulation system piping and condenser tubing imposes some limitations on liner material selection. The aluminum liner in combination with the $\mathrm{NH}_{3}$ system would appear to involve the least uncertainty. There are unanswered questions regarding the compatibility of aluminum liners and copper-based alloys in the condenser in the SOA system. However, use of proper inhibitors may allow the use of this materials combination, although further evaluation would be required. The use of aluminum in the condenser would be acceptable, provided potential steam erosion problems are circumvented. Stainless steel is compatible with aluminum. However, its increased cost over copper-based condenser tube alloys would somewhat offset the advantage of using the cheaper 1 iner in the cooling tower. In summary, there are cost savings to be obtained by using the inexpensive tubes. However, there are questions to be resolved before they can be assured to function reliably, particularly in the case of SOA systems.

Many tubes could be considered expensive due to the materials, finning method used, and the unit geometry. Expensive finned tubes may or may not be free of corrosion problems, depending again on water quality control, downtime procedures, materials compatibility and air-side environment. The expensive finned tube has a stainless steel liner and a wrap-on fin; this unit geometry is typical for process plant or electric power industry applications. It would require minimal water treatment and be compatible with most standard circulation system materials. It would not be considered to be corrosion-prone and therefore would not require replacement during the life of the plant. Extruded fins on admiralty tubing is also an expensive tube (for the same unit geometry) with minimal potential corrosion problems. 
The most distinctive difference evident in the design of the PLASTIC heat exchanger compared to the $\mathrm{SOA}$ and $\mathrm{NH}_{3}$ heat exchangers is the large number of smal1 diameter plastic heat exchanger tubes. Larger diameter PLASTIC tubes must be thick-walled to avoid creep rupture failure. A large quantity of plastic is therefore required for a given amount of heat transfer surface area. Other factors enter the economic trade-offs required to arrive at an optimum diameter. The tube diameter/thickness relationship, however, is a major consideration. Another significant difference is the high overall heat transfer coefficient compared to finned tubes (14 versus $\left.6 \mathrm{Btu} / \mathrm{hr}-\mathrm{ft}^{2}-{ }^{\circ} \mathrm{F}\right)$. This results in a smaller amount of actual heat transfer area than would be required with a metal finned tube system for the same mean temperature difference. Another distinctive feature is the large number of tube rows in the direction of air flow compared to metal finned tubes. The reader should also note that the PLASTIC system has much less heat transfer area/volume. This results in a heat exchanger with a much larger frontal area than the SOA system, but the same heat exchanger depth. This occurs in spite of the increased overall heat transfer coefficient. Although the plastic heat exchanger is significantly different from the other systems, the total cost of the heat exchanger is comparable to the inexpensive metal finried tube SOA system.

The PLASTIC system is unconventional in its choice of materials and in the very large number of tubes employed. Two questions which arise are:

- What would be the effect on the competitiveness of the PLASTIC system of increased plastic costs resulting from increased oil prices?

- What would be the effect on the competitiveness of the PLASTIC system if the cost algorithms for constructing the PLASTIC system heat exchanger bundles are in error?

The plastic tubes and spacers cost a total of $\$ 5.5$ million (Table 5-3). If the price of these materials were to double (in 1976 dollars), the total incremental power production cost of the PLASTIC system would increase by 
$0.17 \mathrm{mi} 11 \mathrm{~s} / \mathrm{kWh}$ to $2.67 \mathrm{mi} 11 \mathrm{~s} / \mathrm{kWh}$. This is still cheaper than the SOA system, assuming no increase in the cost of metal finned tubes, an unlikely event if oil prices were to increase.

The cost of assembling a plastic bundle using the techniques described in Reference 16 cannot be determined until the feasibility of the techniques is demonstrated. Assuming that it is feasible to assemble heat exchanger bundles in the manner anticipated, an estimate of the cost uncertainty can be made as follows. The cost of "frame and assembly" given in Table 5-3 for the PLASTIC system can be viewed as being made up of two components. The first component is that portion which is analogous to the SOA system (e.g., the cost of supporting steel); this portion can be costed out with the same accuracy as the algorithms used in the SOA system (indeed, in essence the same algorithms are used). The remaining component is made up of the costs associated with those portions of the assembly process which are unique to the PLASTIC system and which are unproven. This second component, which amounts to about one-fourth of the total frame and assembly costs, is the only one that need be considered. Assume that the true cost of this portion is double that used in Table 5.3. The frame and assembly costs would increase by 25 percent or $\$ 1,640,000$, resulting in an increase in incremental costs of only $0.04 \mathrm{mills} / \mathrm{kWh}$.

Thus it can be concluded that the competitiveness of the PLASTIC system is not likely to be endangered by future increases in oil prices. Further, if the proposed assembly techniques are mechanically feasible, the competitiveness is not likely to be affected by uncertainties in the assembly cost al gorithms.

Louvers and Hail Screens. The SOA and PLASTIC systems incur a significant expense because they require louvers for air flow control to protect from freezing. These also provide hail protection. The $\mathrm{NH}_{3}$ system does not require flow control louvers. Far less expensive hail screens are used for protection against hail storms. 


\subsubsection{Condensers and Condenser/Reboiler}

The condensers for the SOA and PLASTIC systems are essentially the same in design (Figures 5-3 through 5-6) and cost (Table 5-3). The condenser/reboiler for the $\mathrm{NH}_{3}$ system has slightly less total heat transfer area and the number of tubes and tube length are different. It should be noted that a significant portion of the cost advantage shown by the $\mathrm{NH}_{3}$ system is dependent on the cost and performance data for an enhanced aluminum surface developed by LINDE. (a) If smooth tubes or enhanced stainless steel were required for some yet undetermined reason, the cost margin would decrease substantially, as discussed in Section 8 , and the optimum size of the condenser/reboiler would increase.

\subsubsection{Piping and Pumps}

The two SOA piping systems are essentially identical. The PLASTIC piping system is similar to the SOA in terms of pipe diameters. However, the main circulation system is less costly for the PLASTIC system due to the reduction in towers. This is partially offset, however, by the additional piping required per tower to accommodate the delta heat exchanger orientation.

The $\mathrm{NH}_{3}$ system is significantly different from the SOA and PLASTIC systems. The major differences are much smaller diameter piping, particularly for the liquid return line, and less piping due to the smaller number of towers when compared to SOA systems. On the other hand, the piping must have a thicker wall. However, the net piping costs are significantly lower than SOA systems.

(a)LINDE Division of Union Carbide Co., New York, NY. 


\subsection{PARAMETRIC STUDIES OF STATE-OF-THE-ART DRY COOLING SYSTEMS}

The principal component establishing an all dry cooling system as state-of-the-art is the metal finned tube heat exchanger. Waste heat from the power plant is rejected to the environment by the transfer of heat from water flowing inside the finned tubes to air flowing over the outside finned surface. Variations in design parameters such as direct or indirect heat rejection, forced or induced mechanical draft, and natural or mechanical draft are discussed in Section 2 of this report. The design basis for most of the state-of-the-art analysis is presented in Section 4.1 . Some of the parameters composing the design basis, such as plant type, turbine type, and meteorology, have been varied to determine their impact on the cost of dry cooling. Several other important cooling system parameters have aiso been evaluated. The method of evaluation is presented in Section 3 . It involves the use of a computer code that determines the least cost cooling system design and operational parameters for any given set of external variables. The computer code will be referred to here as the economics code or the optimization code.

\subsection{GENERAL CONSIDERATIONS}

In this section, the parametric study methodology and some general comments will be presented to assist the reader in sections that follow.

All the variables forming the design basis could be externally evaluated. (a) Several other variables that were externally studied are listed in Table 6-1. The values given for these variables form the design basis for the state-of-the-art analysis, in addition to the design basis parameters presented in Section 4.1 .

The method by which any one parameter was evaluated was to fix all the other variables according to the design basis values. Then, this one parameter was varied over its entire range. The impact of each variable was determined in this fashion. Some internal variables, including heat

(a) See Section 3 regarding internal and external variables. 
exchanger depth, number of towers, and the fan system, could be externally controlled. The design basis condition, however, was to allow the code to internally optimize these parameters.

TABLE 6-1. Additional Design Basis Variables for SOA Dry Cooling Systens

\begin{tabular}{|c|c|}
\hline Liner Diameter & $1.00 \mathrm{in.}$ \\
\hline Root Diameter & 1.072 in. \\
\hline Liner Material & Welded Carbon Steel (20 Gage) \\
\hline Fin Material & Aluminum \\
\hline Fin Type & Double-Footed Wrap-on \\
\hline Fin Height & 0.75 in. (maximum) \\
\hline Fin Thickness & $0.018 \mathrm{in}$. \\
\hline Fins/inch & 10 \\
\hline $\begin{array}{l}\text { Heat Exchanger Tube } \\
\text { Length }\end{array}$ & $80 \mathrm{ft}$ \\
\hline Heat Exchanger Depth & Optimized \\
\hline Tube Pitch & $\begin{array}{l}\text { Equilateral w/Fin Tips in } \\
\text { Contact }\end{array}$ \\
\hline Condenser TTD & $5^{\circ} \mathrm{F}$ \\
\hline $\begin{array}{l}\text { Piping System Water } \\
\text { Design Velocity }\end{array}$ & $12 \mathrm{ft} / \mathrm{sec}$ \\
\hline Number of Towers & Optimized \\
\hline Fan System & Optimized \\
\hline $\begin{array}{l}\text { NTU Relation for } \\
\text { Heat Exchanger }\end{array}$ & $\begin{array}{l}\text { 2-Pass Counter-Crossflow, } \\
\text { Water-Side Mixed Between } \\
\text { Passes }\end{array}$ \\
\hline
\end{tabular}


The purpose of this parametric study was to evaluate the relative economics of different state-of-the-art al1-dry cooling systems. To do this most effectively would require the same degree of conservatism in a 11 the cost models, physical models, assumptions, and correlations used to design and cost the cooling system. It is not realistic to expect that this could be done. Instead, the best available models were used with the hope that the conservatism in any one model was not sufficiently unbalanced to significantiy affect the identification of the optimum. If the cost of any single item is increased relative to the other cooling system components, then the optimization code will generally optimize at a design that uses less of that item. In addition, the incremental power production costs will always be higher.

The following sections present considerable discussion regarding the trade-offs. The trade-offs refer to the scheme by which the optimization code determines the least cost cooling system design. For a given set of external variables which include the design basis parameters, the tradeoffs will determine the combination of internally optimized parameters resulting in the lowest overall costs.

To support some of the discussion, different optimized designs are presented for comparison. The tabulated information supplies the important design and operational parameters as well as a cost summary. The costs are given in terms of unit energy costs. The unit energy cost of the capita 1 cost items is determined from

$$
\text { Unit Energy Cost }=\frac{\text { Capital Cost } * \text { Fixed Charge Rate }}{\text { Plant Size * Capacity Factor * Hours per year }}
$$

The capital cost items include the cooling system, the capacity charge, and the base plant scaling. The cooling system includes the condenser, the piping system and pumps, and the cooling tower. The capacity cost is the capital cost of the gas turbines required to make up lost performance on the hottest day. Base plant scaling refers to the cost of adjusting the plant size to account for turbine back pressure and heat rate effects. Scaling also includes the cost of increasing the plant size to provide power for the fans and pumps. The energy cost is the cost of fuel for the 
gas turbines. The base fuel cost is the cost of the additional fuel needed to provide auxiliary power to the fans and pumps and to account for turbine heat rate effects. The annual operation and maintenance cost, designated O\&M, is one percent of the cooling system capital. It is calculated on a unit energy cost basis except that the fixed charge rate is not included.

\subsection{HEAT EXCHANGER}

Many capital cost components and assembly costs are included in the construction of the heat exchanger. These include finned tubes, tube spacers, tube bundle frames, headers and tube end preparation. Consequently, the heat exchanger is the single most costly item in the cooling system. While using the least expensive to the most expensive finned tube the heat exchanger represents from 25 percent to 33 percent of the capital costs incurred by the optimized cooling system design.

The finned tube is the biggest cost item in the heat exchanger. It can be from 35 percent to 45 percent of the heat exchanger cost. Tota 1 costs for the finned tubes range from seven to fourteen million dollars for a 1000-MWe dry cooled power plant. Because of its high cost the specification of the finned tube can have a tremendous impact on the trade-offs that determine the design of the entire cooling system. An expensive finned tube forces the design to a lower heat transfer area. To maintain the heat rejection capability of the heat exchanger the heat transfer coefficient must be increased. This requires increased air velocities through the heat exchanger. The heat transfer coefficient increases approximately with the 0.7 power of velocity. The extent to which the velocity can be increased is dependent upon the fan power requirement, which is proportional to the product of the friction factor, the tube rows in the direction of air flow, and the cube of the air velocity. The friction factor is a slightly negative function of velocity. To maintain a reasonable value of fan power in spite of the push to higher velocities, the tube rows in depth must be decreased. This increases the width of the heat exchanger, which reflects itself in the number and size of the circular cooling towers. Thus, the cost of the finned tube affects the cooling system design in many ways. 
In addition to significantly affecting the cost trade-offs, the specification of the finned tube is particularly important to heat exchanger performance. Two different finned tubes may exhibit significantly different performance characteristics. A finned tube having a naturally high heat transfer coefficient will result in a design having less heat transfer area and/or less air flow. The air flow could be decreased at a slight sacrifice of heat transfer coefficient while the fan power would decrease significantly. In this case the heat transfer area would not decrease. A finned tube having a low friction factor will result in a design that trades off slightly increased air flow to obtain a lower heat transfer area. Thus, the finned tube performance characteristics are also significant to the cooling system design.

The ideal finned tube not only has a high heat transfer coefficient and low friction factor; it also must be low cost. In general, a finned tube having a high heat transfer coefficient will also have a higher friction factor. The cheapest finned tubes, based on the cost per square foot of heat transfer area, will have a maximum number of fins per inch, a maximum fin height and a minimum fin thickness. However, too many fins per inch can actually increase the friction factor while decreasing the heat transfer coefficient. A higher fin has reduced efficiency. Also, building a higher fin may require using a thicker fin. However, the fin efficiency is proportional to the fin thickness. Another cost factor is reliability. The more expensive finned tubes, e.g., an extruded fin on a stainless stee 1 liner, are typically more reliable with respect to corrosion. However, the cheapest finned tube with adequate reliability will be the most cost effective surface. The finned tube associated with the least cost cooling system will be determined by the trade-offs between these performance and cost factors.

The heat transfer coefficient and friction factor are caiculated from correlations developed by PFR Engineering Systems, Inc. (18) The data base and the development of these correlations are discussed in detail in the Appendix. 
The correlations are important because they determine the performance characteristics of the finned tube unit geometries evaluated in this analysis. From the discussion above one can appreciate the problems a designer would have if the performance prediction were off by as little as ten percent. The only way to get an accurate, reliable performance prediction is to actually test the finned tube in an environment identical to that of its intended application. Therefore, the parametric analys is done in this study can only indicate the cost incentive for further evaluation of a particular surface.

\subsubsection{Unit Geometry}

The unit geometry parameters that were parametrically studied are defined in Figure 6-1. They include the root diameter, $D_{r}$, the fin height, 1 , the fin thickness, $t$, and the fin spacing, $s$. The fins per inch, or fin pitch, was also evaluated. The fin pitch is determined by the fin thickness and spacing. The fin diameter, $D_{f}$, was not evaluated independently of the root diameter and fin height.

The results of the parametric study are presented in Figures 6-2 and 6-3. As each unit geometry parameter was varied over its range, all the other variables, including the remaining unit geometry parameters, were fixed at their design basis values described in Section 6.1. The results show that the unit geometry typically offered by industrial vendors in the U.S. is very near to the optimum; i.e., root diameter $=1.0$ inch, fin height $=0.6$ inches, 10 fins per inch, and a fin thickness of about 0.02 inches. It appears that there may be some cost incentive to further evaluate smaller diameter liners. There are limitations on fin height for a given fin thickness and liner diameter. (16) However, there is no incentive to push this limit according to the cost models used in this analysis. The fin thickness should be as low as possible. Apparently the savings in material outweigh the loss in fin efficiency by going to thinner fins. Manufacturing limits on fin thickness, however, must be considered. (16) The durability of the fins is also dependent upon thickness. 

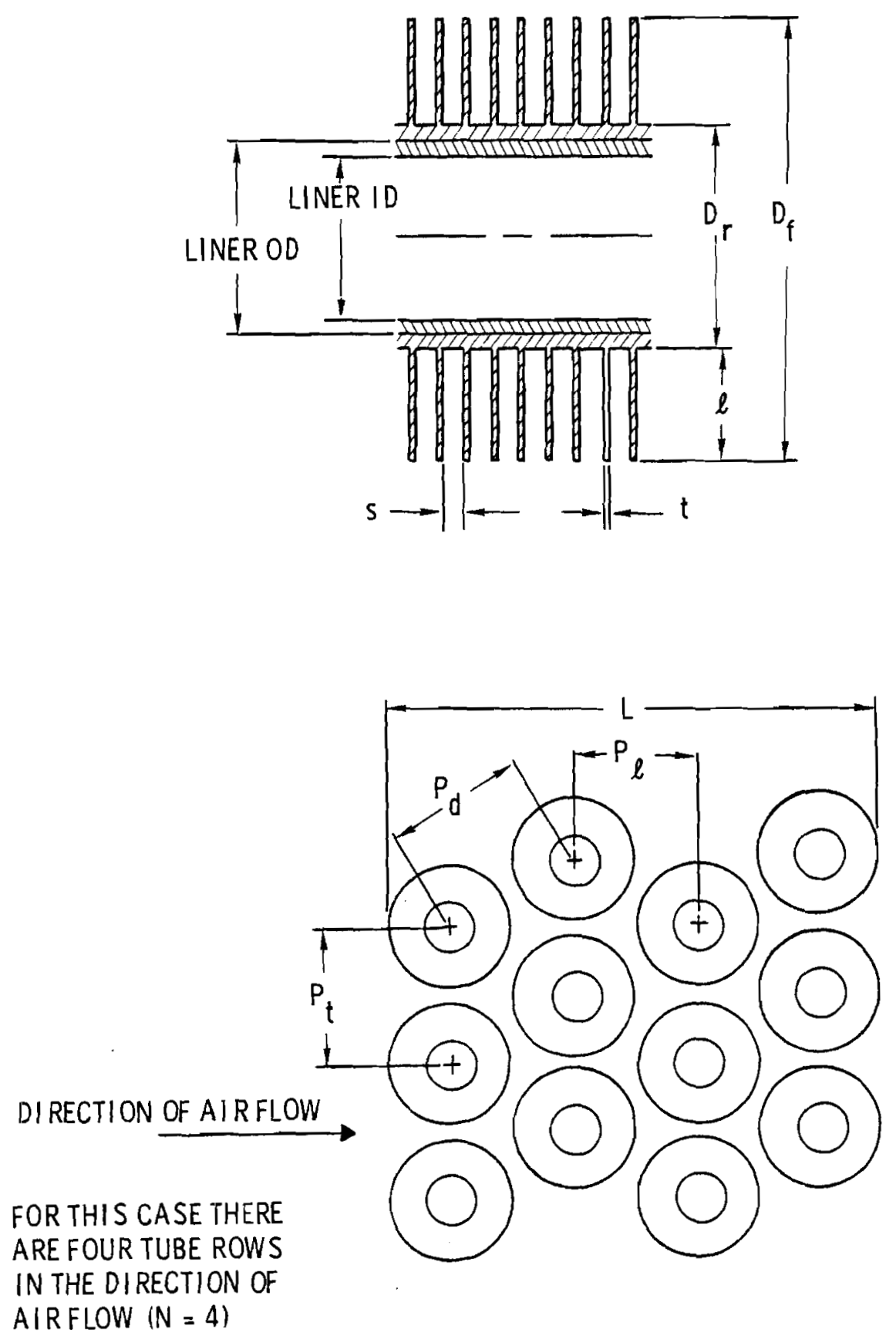

FIGURE 6-1. Finned Tube Unit Geometry and Tube Pitch Parameters 


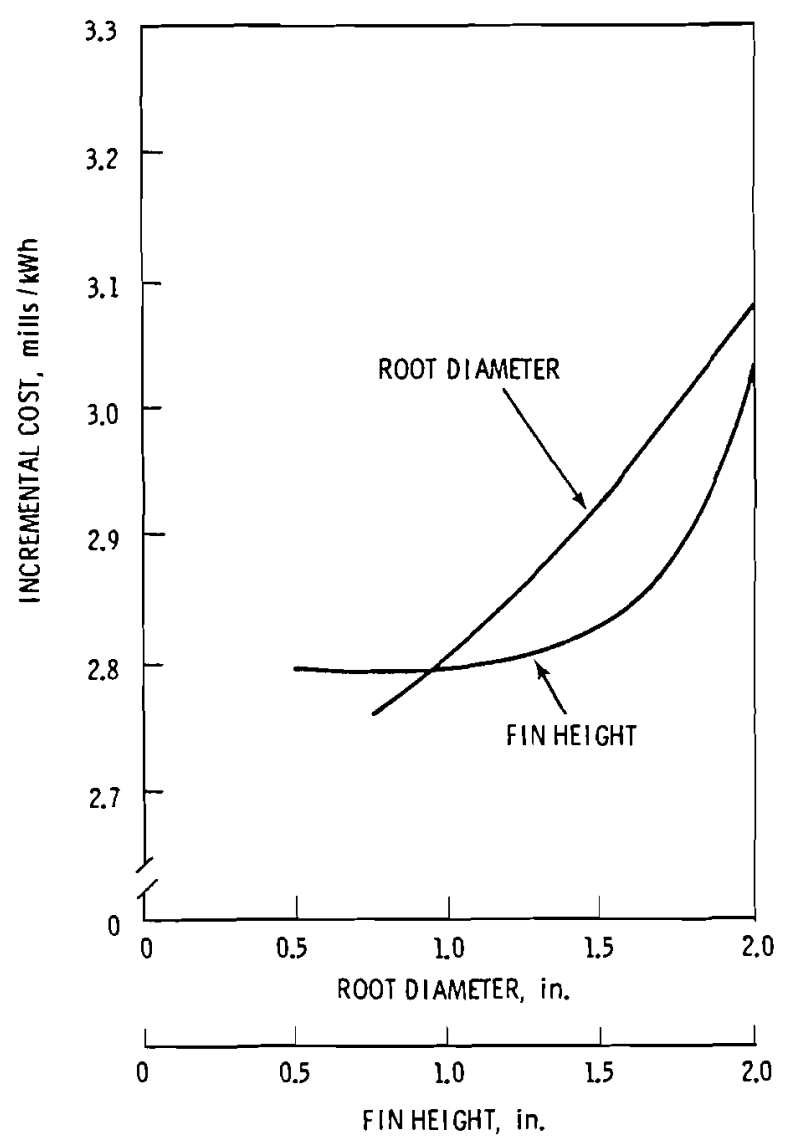

FIGURE 6-2. Incremental Cost Versus Root Diameter and Fin Height

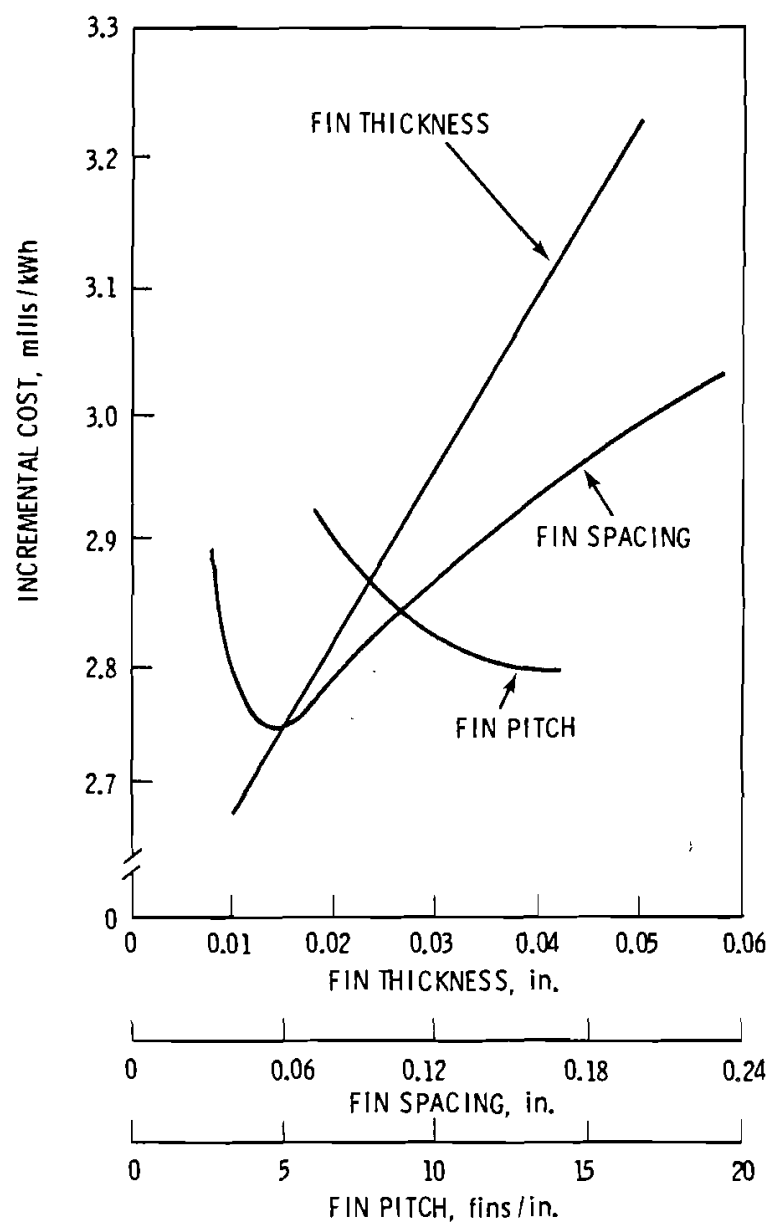

FIGLIRE 6-3. Incremental Cost Versus Fin Parameters

As the fin spacing decreases the air flow path through the heat exchanger becomes increasingly restricted. This causes an increase in the fan power requirements which, at low fin spacings, outweighs the cost advantage obtained by packing the fins closer together. As fin pitch increases, the fin spacing decreases. If values of fin pitch above 14 had been studied, the costs would have turned upward because the fin spacing would be lower. The results indicate that 10 to 14 fins per inch is near optimum. From a durability and maintenance standpoint, a finned tube having more than 14 fins per inch, while also having a high fin, would not be practical. 


\subsubsection{Heat Exchanger Configuration}

The heat exchanger configuration includes specification of the tube rows in depth, the tube length, the tube pitch and the tube arrangement. Some of these parameters are defined in Figure 6-1 where $P_{t}$ is the transverse pitch, $P_{d}$ is the diagonal pitch, and $P_{1}$ is the longitudinal pitch. The tube arrangement refers to whether the tubes are placed in a staggered or inline pattern. The arrangement shown in Figure 6-1 is equilateral staggered. In an equilateral arrangement, $P_{t}=P_{d}$. Any other staggered arrangement is isosceles. The staggered arrangement has been shown to be more cost effective than the inline arrangement. $(18,19)$ Therefore, only the staggered arrangement was considered in this analysis.

\subsubsection{Tube Pitch and Tube Arrangement}

For most of the parametric studies the tubes were modeled in an equilateral staggered arrangement with the transverse and diagonal pitch equal to the fin diameter. This required the fin tips to be in contact. In actual practice some spacing would be provided between fin tips to allow for tube bending and vibration. The results of the tube pitch parametric study revealed that the "in contact" modeling does not significantly affect costs up to a fin tip clearance of about one inch. This result is presented in Figure 6-4. The fin tip clearance is the difference between the diagonal or transverse tube pitch and the fin diameter. However, as fin tip clearance increases in an equilateral arrangement, the optimized value of tube rows in depth increases dramatically. This occurs for two reasons. As the tip clearance increases, the heat exchanger volume must increase to maintain a reasonable heat transfer area. If the heat exchanger becomes wider, the piping costs increase. Therefore, the heat exchanger becomes deeper. This would, in itself, increase the fan power requirements. However, the increased fin tip clearance increases the hydraulic diameter which reduces the friction factor. Taken separately, this would decrease the fan power requirement. Thus, the increased depth is traded off against a reduced friction factor. An actual two-pass heat exchanger would have an even integer number of tube rows. It would have a fin tip clearance of about one quarter inch. The 


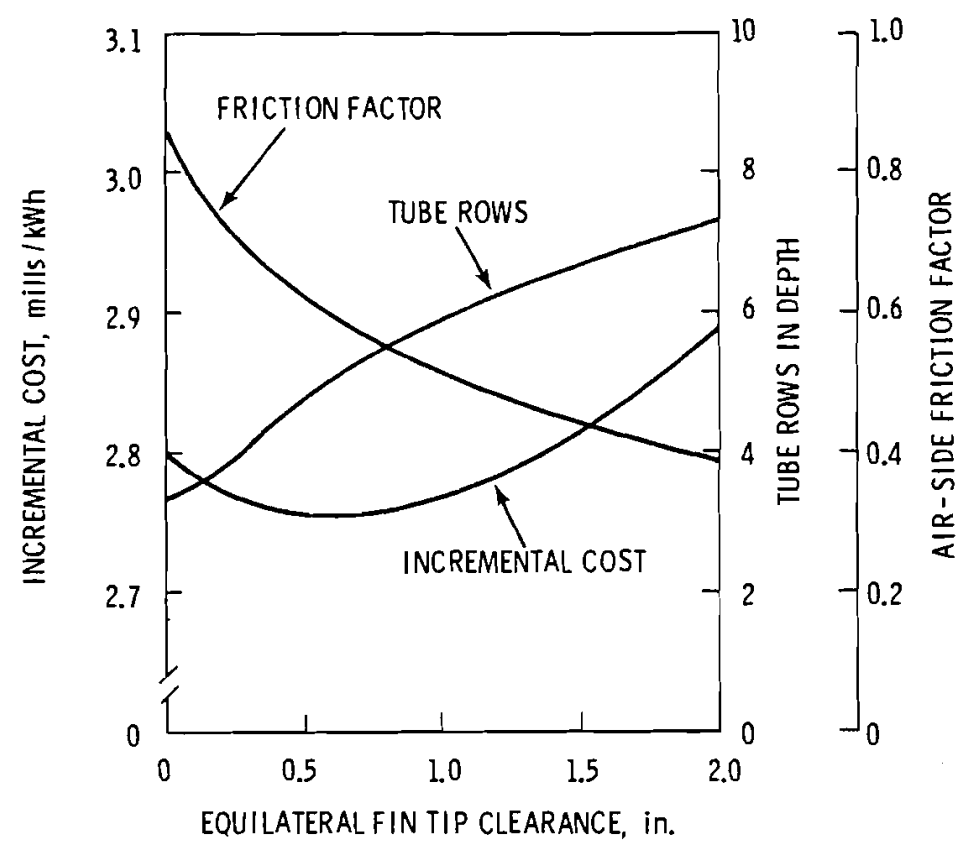

FIGURE 6-4. Incremental Cost, Tube Rows in Depth and Air-Side Friction Factor Versus Equilateral Fin Tip Clearance

difference in results between this condition and zero clearance is not so significant that it would severely distort the analysis of other cooling system parameters.

Two schemes were used to evaluate isosceles tube arrangements. First, the transverse pitch was varied to provide transverse fin tip clearances from zero to one inch while maintaining zero diagonal clearance. Next, the diagonal pitch was varied similarly; that is, to provide diagonal clearances from zero to one inch while maintaining zero transverse clearance. The results indicate no cost incentive for building the heat exchanger in this fashion. The incremental cost variation over the range of parameters studied was about one percent.

\subsubsection{Tube Rows in Depth}

The tube rows in depth refers to the number of heat exchanger tube rows in the direction of air-flow. The tube rows in depth could be externally 
controlled in the optimization code by placing upper and/or lower limits on its value. Results show that for a two-pass counter-crossflow heat exchanger, the optimum even integer number of tube rows in depth will be four. In going to two tube rows, the heat exchanger width becomes very large. This results in increased piping system and tower structural costs. A six-row heat exchanger requires increased fan power and a slightly larger heat exchanger. The fan power increases with heat exchanger depth. To keep the fan power at a reasonable value, the air velocity is reduced. This lowers the fan power but also lowers the heat transfer coefficient. Thus, more surface area is required.

The tube rows in depth is very dependent on the friction factor. Anything causing the friction factor to decrease will cause the tube rows in depth to increase. This was shown in Figure 6-4 where the increased fin tip clearance resulted in optimized designs having deeper exchangers. The friction factor will decrease if the hydraulic diameter is increased. Increasing fin tip clearance, increasing the ratio of the fin diameter to the root diameter, increasing fin spacing and decreasing fin thickness all increase the hydraulic diameter. Any combination of these factors will, therefore, increase the optimized value of tube rows in depth.

\subsubsection{Tube Length}

For the circular tower arrangement the tube length optimizes near 80 feet. For rectilinear towers the optimum length is about 110 feet. An 80-foot length is considered to be a practical manufacturing and shipping limit. The tube length used throughout the parametric analysis was, therefore, 80 feet.

The optimum tube length is less for circular towers than for rectilinear towers because of the constraints on the circular tower fan system. To prevent excessive fan discharge losses from circular towers, the frontal area of the heat exchanger must not be greater than about five times the fan exit area. For a given heat exchanger frontal area, the longer the tubes, the narrower the heat exchanger. This results in a fewer number of 
towers and/or a smalier tower diameter. Either way, the tower roof area is smaller. For a constant fan packing factor this means that the ratio of frontal area to fan exit area will increase. Thus, there is an implicit limit on the tube lengths for circular towers. The fan system constraints are discussed further in Section 6.7.

\subsubsection{Fin Type/Manufacturing Method}

Several types of finned tubes are available. Only two have been quantitatively evaluated in this study: the extruded finned tube and the helical-wound double-footed wrap-on finned tube. Other fin types include continuous plate, serrated or stamped, studded, wire form, and annular. In some cases, these fins can be attached to liners having cross sections other than circular. These other fin types were not evaluated because accurate cost models and air-side performance correlations were not avaitable. The extruded fin was evaluated in conjunction with the one-inch diameter liner only. The fin height used was 5/8-inch, which was considered

to be the maximum by current manufacturing limits. (16) The only fin material considered was aluminum.

If cost were the only consideration for choosing between the wrap-on and extruded finned tube, the wrap-on finned tube would be the first choice. However, experience with the wrap-on fin in other applications shows that air-side corrosion at the fin-liner interface can be a significant threat to the integrity of the surface. Costs associated with surface failures have not been included in the assessment of the various surfaces.

U.S. vendor designs for the Wyodak dry cooled power plant included a wrap-on fin on a stainless steel liner and an extruded fin on a seamless carbon steel liner. Either case provides for corrosion resistance. The extruded fin does not have the crevices at the fin base that are characteristic of the wrap-on fins. The crevices or seams are a result of the overlapping of the footed fin. They provide a location where the buildup of moisture and contaminants can lead to corrosion. However, a stainless 
steel liner would provide protection against corrosion beyond the base of the fin. The extruded fin provides improved corrosion resistance so that a less expensive liner material might be used. The cost models show that the 3/4-inch high wrap-on fin on a one-inch stainless steel liner costs $\$ 1.64 / \mathrm{ft}$ of finned tube. The 5/8-inch high extruded fin on a one-inch seamless carbon steel liner costs $\$ 2.08 / \mathrm{ft}$ of finned tube. If the welded carbon steel liner had been used with the extruded fin the cost would be $\$ 1.40 / \mathrm{ft}$ of finned tube. The cost reduction attained with the extruded fin on a welded carbon steel liner versus the seamless carbon steel liner is reflected in the incremental costs presented in Table 6-2.

TABLE 6-2. Incremental costs for Cooling System Designs Using Different Fin Types and Liner Materials

\begin{tabular}{llc} 
Fin Type & \multicolumn{1}{c}{ Liner Material } & $\begin{array}{c}\text { Incremental Cost } \\
\text { mills/kWh }\end{array}$ \\
Wrap-on & Welded carbon steel & 2.80 \\
& Seamless carbon steel & 2.95 \\
& Stainless Steel & 3.09 \\
& Admiralty & 3.09 \\
& Aluminum & 2.77 \\
Extruded & Welded carbon steel & 3.07 \\
& Seamless carbon steel & 3.44 \\
& Stainless Stee & 3.33 \\
& Admiralty & 3.39 \\
& Aluminum & 3.05
\end{tabular}

\subsubsection{Liner Material}

The liner can represent as much as fifty percent of the cost of the finned tube. Because this is on the order of several million dollars for a 1000-MWe power plant, the liner selection should receive considerable attention. 
In this study, four different materials were considered for the finned tube liner. These are carbon steel (welded and seamless), stainless steel, admiralty and aluminum. The incremental power production costs for optimized cooling system designs using different fin types and liner materials are presented in Table 6-2.

The aluminum liners are competitive, on a cost basis, with the welded carbon steel liner. However, there is some concern regarding the compatibility of admiralty condenser tubes and aluminum liners. With adequate inhibitors in the circulation water it may be possible to overcome this problem. As a result of this potential problem the welded carbon steel liner has been used exclusively in the optimization analysis of other cooling system parameters. The compatibility of the water-side materials in the piping, heat exchanger and any other components in contact with the cooling water must also be taken into account.

\subsubsection{Number of Passes}

The parametric analyses were performed exclusively with the two-pass counter-crossflow heat exchanger modeling. The water side was assumed to be mixed between passes. The effectiveness-NTU data were taken from tabulated information in Reference 20. The economics code optimizes the depth of the heat exchanger such that the number of tube rows in the direction of air flow is not required to be an integer value. In actual practice, however, the use of a two-pass heat exchanger would require an even integer number of tube rows. Sophisticated baffles in the tube bundle headers might be used to create a two-pass arrangement with an odd integer number of tube rows. However, there is currently no cost incentive to investigate such a design because the most economical number of tube rows was four.

A one-pass crossflow heat exchanger was also evaluated. It resulted in incremental costs that were about five percent higher than the incremental cost of the two-pass configuration. The optimum integer number of tube rows in the direction of air flow was four. 


\subsection{TURBINE TYPE}

Dry cooling economic studies have indicated a definite need to expand the present level of turbine-generator technology. Large turbine-generators capable of producing in excess of 500 MWe at operating back pressures substantially above 5 inches Hga are in the early development phase.

Economic incentive to develop turbines capable of operating at increased back pressure results from studies modeling turbine performance characteristics according to preliminary information supplied by potential turbine vendors. Three basic turbines--conventional, modified conventional, and high back pressure--were considered in this analysis. Normalized heat rate as a function of back pressure is shown in Figures $6-5$ and 6-6 for fossil and nuclear turbine-generators. The curves were adapted from Reference 21 and are presented here for illustrative purposes only. The reader should consult the turbine vendor for actual data. Vendors include General Electric, Westinghouse, Allis-Chalmers, Brown Boveri, DeLaval, MAN, and Turbodyne.

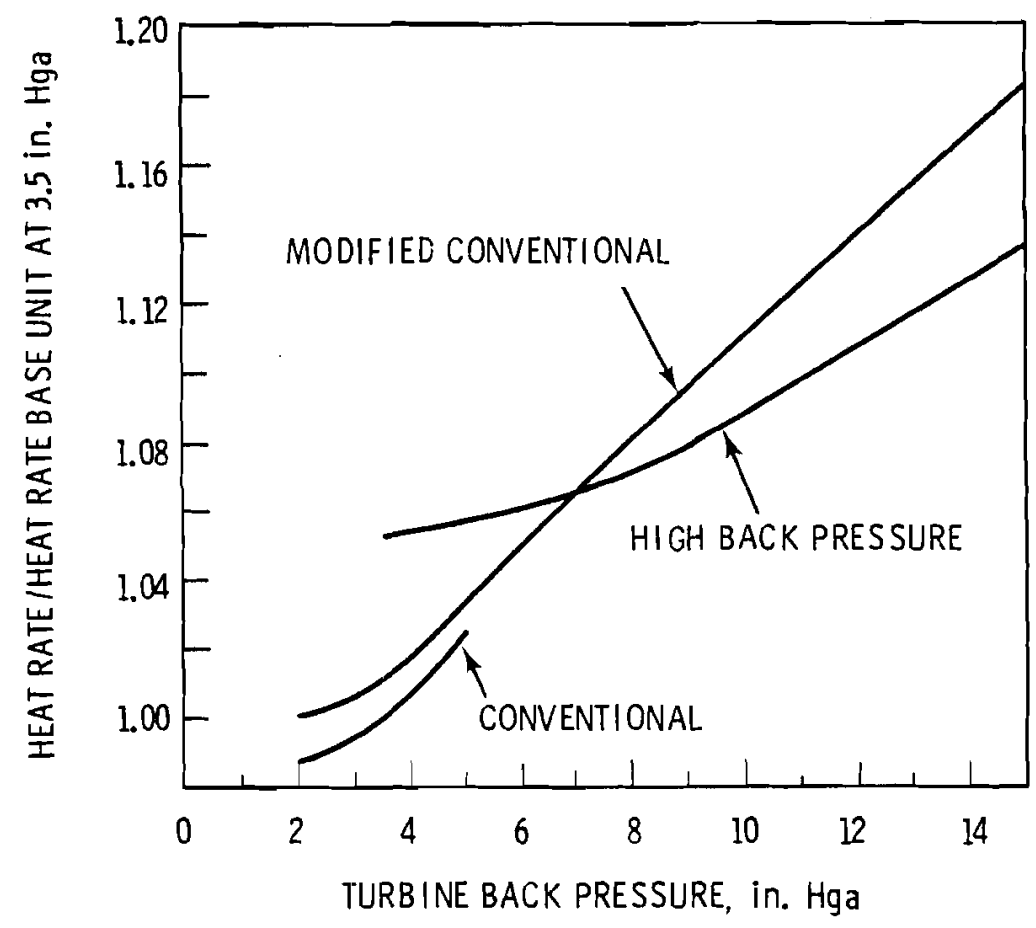

FIGURE 6-5. Normalized Heat Rate Versus Turbine Back Pressure - Fossil 


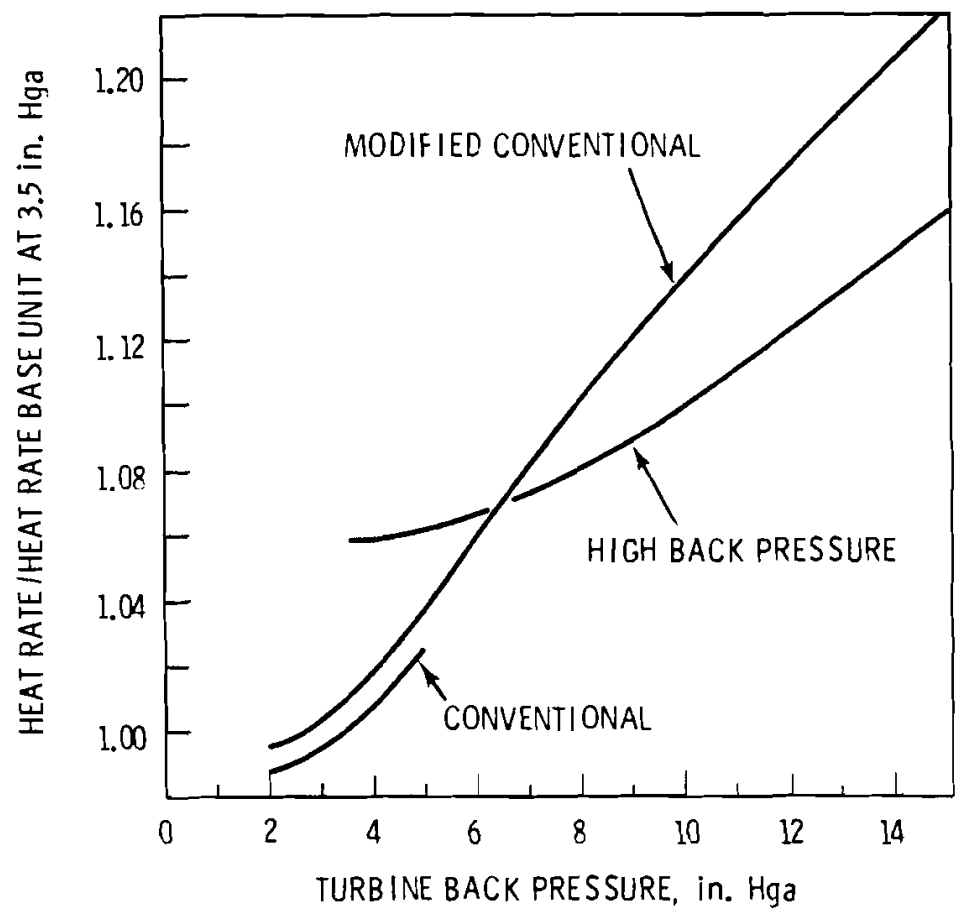

FIGURE 6-6. Normalized Heat Rate Versus Turbine Back Pressure - Nuclear

Allowing a turbine to operate at a higher back pressure for a given ambient temperature results in a higher initial temperature difference (ITD) for the heat exchanger. The ITD is the difference between the inlet water temperature and the inlet air temperature at the heat exchanger. The cooling system size decreases as the ITD increases. Therefore, a high ITD results in a lower cost cooling system in terms of initial capital investment.

As can be seen in Figures 6-5 and 6-6, the performance of the proposed modified conventional and high back pressure turbines is characterized by significantly higher heat rates. Because of this, to achieve a given amount of electric power output at a given ambient temperature, a plant with either of the increased back pressure turbines will have to burn 
more fuel. In general this will be true only when the cooling systems have been optimized for equal design ambient temperatures. In addition to the increased fuel consumption, the increased heat rates result in a requirement for a larger steam supply system.

In deciding which particular turbine to select, the trade-offs between capital costs and energy costs must be considered. Investigations of dry cooling have shown that the trade-offs favor turbines capable of operating at increased back pressures. Where fuel costs are low, the modified conventional and high back pressure turbines are economically more desirable than the conventional turbine. Even in the present fuel market this remains the case. Current fossil fuel (coal) prices are approximately $\$ 1 / 10^{6} \mathrm{Btu}$. The economics code was employed to determine the effect of increasing fuel prices. Even at $\$ 5 / 10^{6}$ Btu there was virtually no decrease in the advantage of increased back pressure turbines when compared to a conventional turbine in an SOA all-dry cooling system. The loss in performance at high back pressures is apparently outweighed by the savings in capital investment achieved by designing the cooling system to a higher ITD.

\subsubsection{Turbine Descriptions}

In this section, the three turbines considered in this analysis will be described in greater detail.

\subsubsection{Conventional Turbine}

The technology of the conventional turbine is relatively well established. These turbines are available to the power industry in sizes up to and exceeding 1000 Mwe for both fossil and nuclear power stations. The operating back pressure range is typically about 2 to 5 inches $\mathrm{Hga}$, although some turbines are designed for slightly higher back pressures. Power output is usually rated at 3.5 inches Hga with 3 percent makeup, but this may also vary with the manufacturer. As can be seen from the performance curves, the conventional turbine has the lowest heat rate. Conventional turbines are typically used where sufficient water is available for oncethrough or evaporative cooling. Under this condition, the back pressure 
can be maintained reasonably constant at low values. Because the steam is allowed to expand as completely as practicable, the maximum energy will have been extracted from the steam. Thus, the heat rate is as low as practicable.

\subsubsection{Modified Conventional Turbine}

It was initially proposed that modifications could be made to existing conventional turbines to allow the back pressure to vary from 2 to 14 inches Hga. The modified conventional turbine would have a heat rate approximately one percent higher than the conventional turbine at the rating back pressure of 3.5 inches $\mathrm{Hga}$. However, potentially destructive problems with offdesign aerodynamics at the low pressure end of the turbine have caused vendors to suggest that upper limits of about 8.0 inches Hga be imposed on the operation of this hypothetical machine. The 8.0-inch Hga limit is not a serious constraint, however, because operation at back pressures above this value would have been required for only the few hours per year when the ambient temperature exceeds about $90^{\circ} \mathrm{F}$. Only warmer sites with climates such as Pheonix would be affected.

When using the performance characteristics for the modified conventional turbine and with no constraint on the back pressure, the economics code optimizes such that the operating back pressure on the hottest day $\left(100^{\circ} \mathrm{F}\right)$ is about 11 inches $\mathrm{Hga}$. By limiting back pressure to 8.0 inches Hga the incremental power production costs increase by only about 5 percent. Thus, this limit is seen to have only a slight effect on the optimized design. However, if the back pressure is limited to 5 inches Hga, the costs increase by about 50 percent.

No modified conventional turbines are currently in operation or planned for delivery in the U.S. However, Westinghouse has indicated that they expect to market a modified conventional turbine for limited operation at 8.0 inches Hga by 1977. This would be suitable for nuclear plants or very large fossil plants (1000- to 1100-MWe range). Allis-Chalmers has disclosed that permission can be obtained to operate their conventiomal units up to 9.0 inches $\mathrm{Hga}$ for fossil and nuclear turbines when the low pressure elements have been properly modified. (18) 


\subsubsection{High Back Pressure Turbine}

Of the proposed new turbines, only one has been declared available for delivery in the U.S. This is a high back pressure turbine for a fossilfueled power station capable of generating 330 MWe at a rating condition of 8.0 inches $\mathrm{Hga}$ with 3 percent makeup required. Its operating back pressure range is about 5.0 to 15.0 inches Hga. Larger turbines-generators for fossil-fueled applications would likely be available upon demand. For nuclear applications, additional problems have yet to be solved. Vendors have not stated when (or if) these nuclear turbines will be available.

\subsubsection{Turbine Optimization Analysis}

The optimization analysis was performed for the three turbine types for fossil and nuclear fuel. Basic differences between the two fuels involves of course, the different heat rate curves for the corresponding fossil and nuclear turbine-generators. In addition, significant differences occur in the parameters listed in Table 6-3.

TABLE 6-3. Differences in Fossil and Nuclear Design and Cost Input

\begin{tabular}{|c|c|c|}
\hline & Fossil & Nuclear \\
\hline Fuel cost, $\phi / 10^{6}$ Btu & 81 & 43 \\
\hline $\begin{array}{l}\text { Overall thermal } \\
\text { efficiency, percent }\end{array}$ & 40 & 33 \\
\hline $\begin{array}{l}\text { Power plant } \\
\text { construction cost, } \$ / k W e\end{array}$ & 440 & 550 \\
\hline
\end{tabular}

It has been assumed that the modified conventional and high back pressure fossil fueled turbine-generators will cost the same as a conventional fossil unit with the same rating. However, the cost of the proposed modified conventional or high back pressure turbines for nuclear applications is expected to be about 15 percent higher than a similarly rated nuclear-fueled conventional turbine. (21) Each one-percent increase in the cost of the turbine-generator results in a nearly two-million dollar increase in the costs attributed to the all-dry cooling system. Consequently, rigorous comparison of cooling system designs for fossil-fueled power 
stations or nuclear plants using the conventional turbine against designs for nuclear-fueled plants using the modified conventional or high back pressure turbine is not recommended until the turbine costs have been firmly established.

Cooling system design and cost summaries are given in Tables 6-4 and 6-5 for fossil and nuclear-fueled turbine-generators. For each fuel the three turbine types are evaluated. Notice that for either fuel the cooling system is less costly with the high back pressure turbine. In Section 6.8 it is shown that this result applies to all five sites investigated in this analysis. It is interesting to note that the only large alldry cooled power station planned for the U.S. has a high back pressure turbine. This 330-MWe power station is located in Wyodak, Wyoming.

The subject of ITD is discussed in detail in Section 6.8. It is apparent from the results presented in Tables 6-4 and 6-5, however, that costs are not too sensitive to ITD when the ITD is above about $45^{\circ} \mathrm{F}$. For an ITD below $45^{\circ} \mathrm{F}$ the costs begin to rise dramatically. At most locations in the U.S., the ITD of cooling systems using the conventional turbine would be 1 imited to $30^{\circ}$ or $35^{\circ} \mathrm{F}$. Thus, the conventional turbine is generally not cost effective for a 11 dry cooling applications. The need for development of alternate turbines is thereby established.

\subsection{CONDENSER}

The parametric analysis of cooling systems using water as the coolant, i.e., state-of-the-art metal finned tube and plastic tube, modeled the condenser as a two-she1l, single-pressure surface condenser. A two-shell condenser model is one that requires the steam and water flow to the low pressure condenser to be divided into two parallel paths. Each identical shell is a essentially a separate condenser. Because the coolant flow through each shell is in a parallel path, each shell is at the same pressure, thus defining the term, single-pressure condenser. The term surface condenser implies that the water flows through tubes normal to the direction of steam flow. The steam and water do not intermix. 
TABLE 6-4. Comparison of Optimized Design and Cost Data for A11-Dry Cooling Systems Using the Three Turbine Types - Fossil

\begin{tabular}{ccc} 
& Turbine Type \\
\hline Modified & High Back \\
Conventional & Conventional & Pressure \\
\end{tabular}

DESIGN PARAMETERS

\begin{tabular}{|c|c|c|c|}
\hline Air Flow Rate, $10^{8} 1 \mathrm{~b} / \mathrm{hr}$ & 11.3 & 8.65 & 5.18 \\
\hline Air Range, ${ }^{\circ} \mathrm{F}$ & 19.3 & 25.2 & 45.6 \\
\hline Air Velocity, $\mathrm{ft} / \mathrm{sec}$ & 15.9 & 17.1 & 15.9 \\
\hline$\Delta P_{\text {air, }} H X, p s i$ & 0.0123 & 0.0113 & 0.0122 \\
\hline$\Delta P_{\text {air, }}$ discharge, psi & 0.0074 & 0.0064 & 0.0069 \\
\hline Fan Power, MWe & 24.1 & 17.2 & 11.2 \\
\hline Fans, Number/Dia, ft & $45 / 60$ & $37 / 60$ & $22 / 60$ \\
\hline Water Flow Rate, $10^{8} 1 \mathrm{~b} / \mathrm{hr}$ & 4.86 & 2.08 & 1.49 \\
\hline Water Range, ${ }^{\circ} \mathrm{F}$ & 10.7 & 25.2 & 38.0 \\
\hline Pump Power, MWe & 16.0 & 6.35 & 4.15 \\
\hline $\mathrm{ITO},{ }^{\circ} \mathrm{F}$ & 27.2 & 45.6 & 71.4 \\
\hline $\mathrm{U}, \mathrm{Btu} / \mathrm{hr} / \mathrm{ft} t^{2}-{ }^{\circ} \mathrm{F}$ & 5.20 & 5.21 & 4.91 \\
\hline H.X. Heat Transfer Area, $10^{6} \mathrm{ft}$ & 90.6 & 52.3 & 42.2 \\
\hline H.X. Width/Length, $f t / f t$ & $7970 / 80$ & $5710 / 80$ & $3770 / 80$ \\
\hline H.X. Depth, Rows & 4.05 & 3.27 & 4.00 \\
\hline Total H.X. Tubes & 151,000 & 87,200 & 70,300 \\
\hline Towers, Number/Dia, ft & $19 / 128$ & $12 / 148$ & $9 / 131$ \\
\hline
\end{tabular}

COST SUMMARY

Cooling System, mills/kWh

3.10

1.95

1.36

Capacity, mills/kWh

0.14

0.27

0.28

Scaling, mills/kWh

0.35

0.22

0.30

Energy, mills/kWh

0.04

0.09

0.09

Base Fuel, mi1ls/kWh

0.18

0.15

0.49

O\&M, mi11s/kWh

0.18

0.11

0.08

Total Incr. Cost, mi1ls/kWh

3.98

2.80

2.60 
TABLE 6-5. Comparison of Optimized Design and Cost Data for A11-Dry Cooling Systems Using the Three Turbine Types - Nuclear

Turbine Type

Conventional Conventional

High Back
Pressure

DESIGN PARAMETERS

Air Flow Rate, $10^{8} 1 \mathrm{~b} / \mathrm{hr}$

11.0

7.47

6.22

Air Range, ${ }^{\circ} \mathrm{F}$

19.8

28.7

38.3

Air Velocity, $\mathrm{ft} / \mathrm{sec}$

15.9

16.2

17.0

$\Delta P_{\text {air, }} H X$, psi

0.0139

0.0133

0.0108

$\Delta P_{\text {air, discharge, }} p s i$

0.0056

0.0068

0.0052

Fan Power, MWe

23.6

16.6

11.6

Fans, Number/Dia, ft

$50 / 60$

$31 / 60$

$30 / 60$

Water Flow Rate, $10^{8} \mathrm{lb} / \mathrm{hr}$

4.64

2.15

1.49

Water Range, ${ }^{\circ} \mathrm{F}$

11.2

23.9

38.3

Pump Power, MWe

14.1

6.36

4.65

ITD, ${ }^{\circ} \mathrm{F}$

27.2

44.6

69.4

U, Btu/hr/ft ${ }^{2}{ }^{\circ} \mathrm{F}$

5.15

5.00

5.16

H.X. Heat Transfer Area, $10^{6} \mathrm{ft}^{2}$

96.8

61.1

37.6

$H . X$. Width/Length, $\mathrm{ft} / \mathrm{ft}$

$7750 / 80$

$5230 / 80$

$4190 / 80$

$H . X$. Depth, rows

4.45

4.16

3.20

Total H.X. Tubes

161,000

Towers, Number/Dia, ft

$16 / 149$

102,000

62,600

$12 / 136$

$8 / 164$

\section{COST SUMMARY}

$\begin{array}{llll}\text { Cooling System, mills/kWh } & 3.12 & 1.94 & 1.43 \\ \text { Capacity, mills } / \mathrm{kWh} & 0.13 & 0.38 & 0.31 \\ \text { Scaling, mills } / \mathrm{kWh} & 0.41 & 0.91 & 1.23 \\ \text { Energy, mills } / \mathrm{kWh} & 0.07 & 0.17 & 0.10 \\ \text { Base Fuel, mills } / \mathrm{kWh} & 0.09 & 0.03 & 0.28 \\ \text { O\&M, mills/kWh } & 0.18 & 0.11 & 0.08 \\ \text { Total Incr. Cost, mills/kWh } & 4.01 & 3.53 & 3.43\end{array}$


If the calculated condenser tube length exceeds 50 feet, the condenser is designed according to a two-pass arrangement. In most cases the optimized cooling system design will have a two-pass condenser with tube lengths of about 35 feet per pass.

\subsubsection{Condenser Design Parameters}

Perhaps the most important condenser design parameter is the TTD, or terminal temperature difference. The TTD is the difference in temperature between the steam saturation temperature and the temperature of the water at the condenser exit. The TTD is analogous to the ITD of the heat exchanger. The ITD represents the initial thermal driving force of the heat exchanger. In contrast, the TTD can be thought of as the final thermal driving force of the condenser. The two parameters are related according to

$$
I T D=T S-T T D-T A
$$

where TS is the steam saturation temperature in the condenser and TA is the ambient air temperature.

For given values of TA and TS, as TTD is increased, the ITD decreases. As discussed in Section 6.8, as ITD decreases, the incremental power production costs increase. Therefore, it would be expected that cooling systems designed with condensers having higher values of TTD would have higher incremental costs. Another observation brought out in Section 6.8 is that costs become a stronger function of ITD as the ITD decreases. Therefore, it would be expected that cooling system designs using the conventional turbine would be influenced more by the TTD than would designs using the other turbines. This is indicated by the slope of the cost versus TTD curves, shown in Figures 6-7 and 6-8, for fossil and nuclear power plants. A lower limit of $5^{\circ} \mathrm{F}$ is recommended for the TTD. This limit has been established by the Heat Exchanger Institute. (21)

The TTD is the only condenser design parameter extensively investigated in this analysis. Another parameter that shouid receive more attention is the conderser tube material. Admiralty was used throughout the analysis. Aluminum tubes would be slightly cheaper but may be subject to 
erosion problems due to steam impingement. Deflector plates could be used but this might negate the cost savings. Stainless steel would be very durable in the condenser application but would be more expensive.

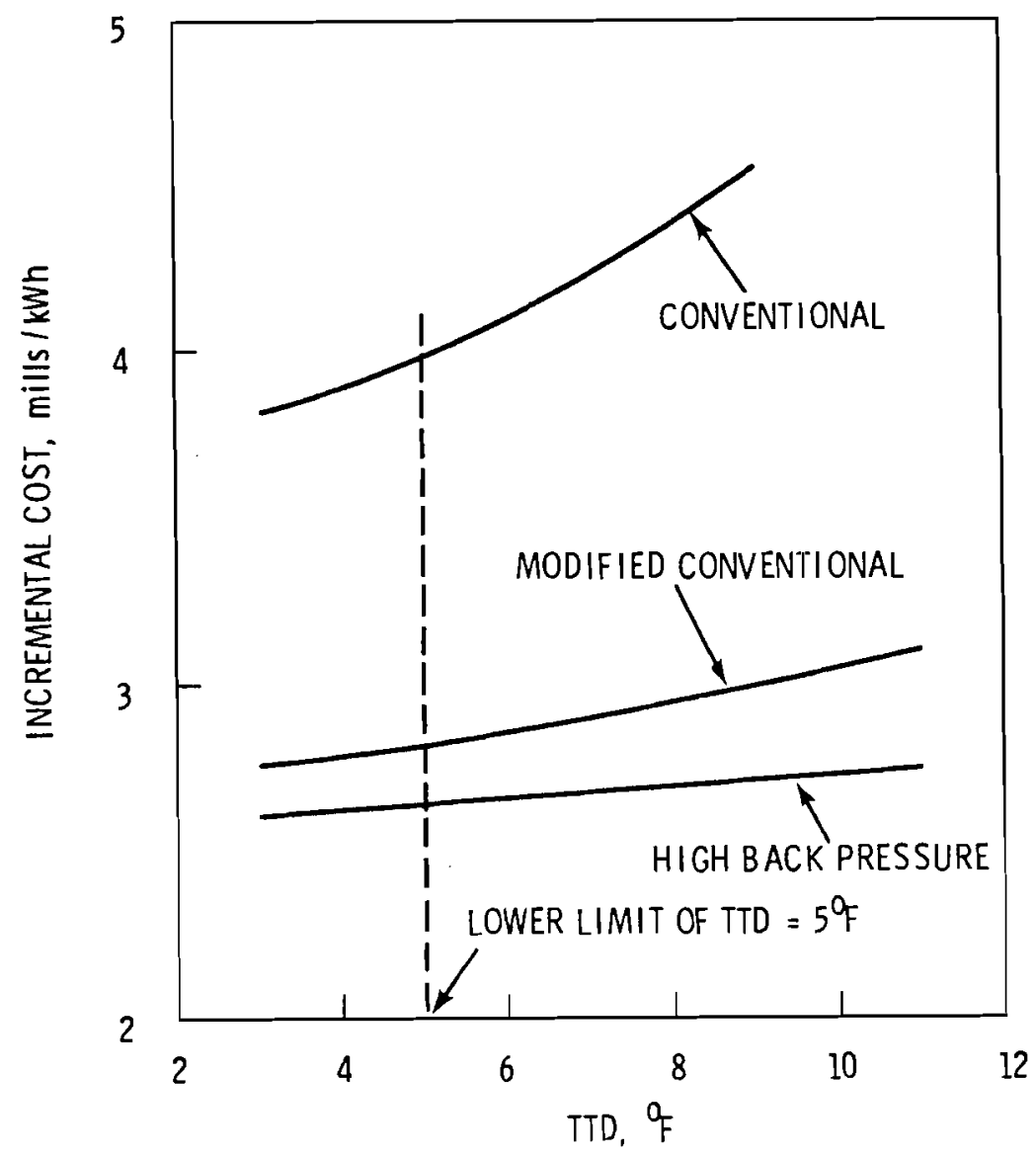

FIGURE 6-7. Incremental Cost Versus Condenser TTD for the Three Turbine Types Fossi]

The design water velocity through the condenser was limited by a corrosion-erosion allowance to a maximum of seven feet per second. (16)

\subsubsection{Parametric Study of TTD}

The TTD was studied over the range of $3^{\circ}$ to $11^{\circ} \mathrm{F}$ for fossil and nuclear power stations. Differences in design and cost information 
for fossil and nuclear power plants are given in Table 6-3. In addition, the turbine heat rate curves are different for the two fuels. The effect of TTD upon the incremental cost of SOA a11-dry cooling systems was presented in Figures 6-7 and 6-8. It is evident that the optimum TTD is the lowest value that can be used, i.e., $5^{\circ} \mathrm{F}$. Regardless of site meteorology or other design conditions, the lower TTD results in a higher ITD and, therefore, the lowest possible cooling system costs.

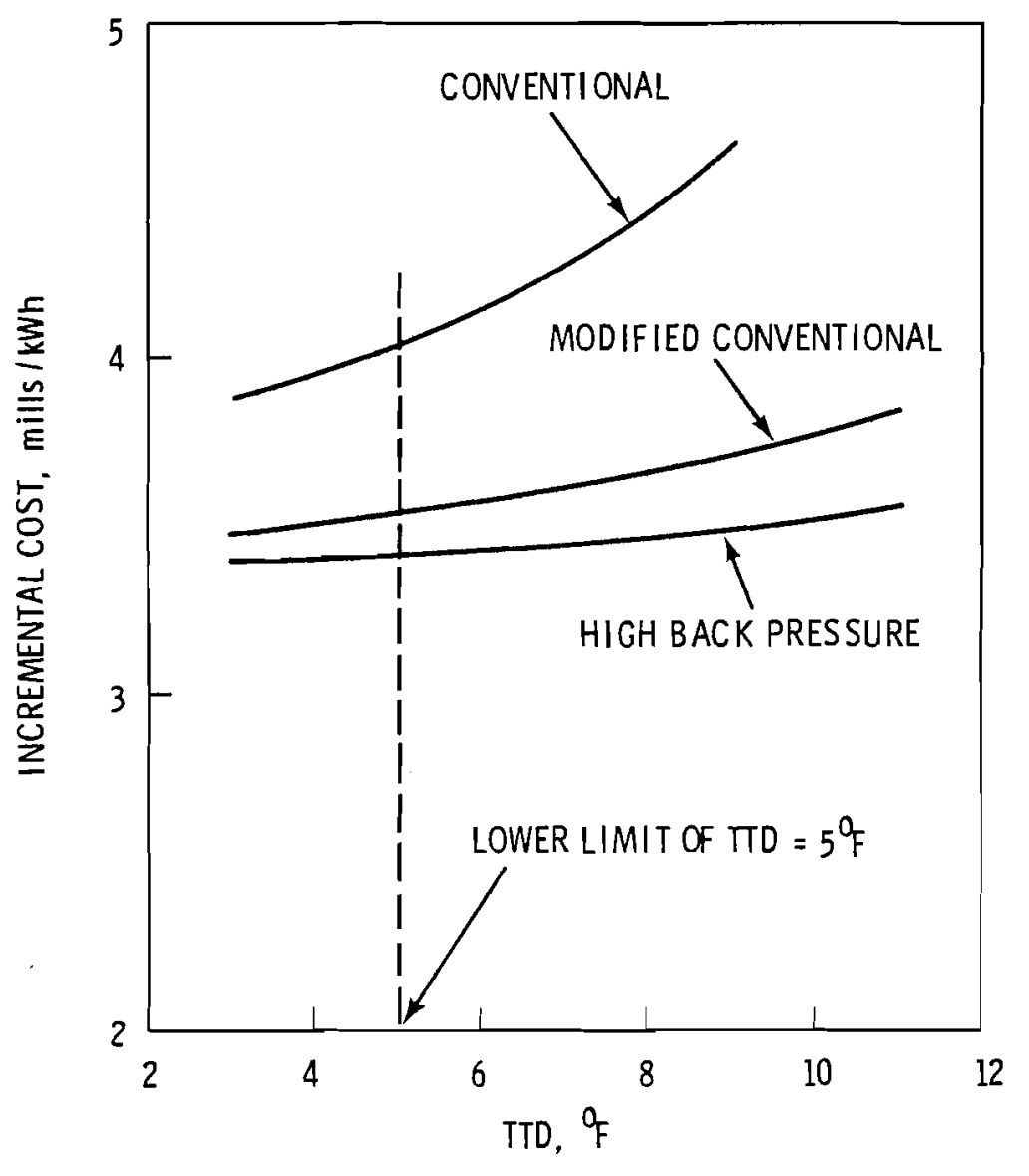

FIGURE 6-8. Incremental Cost Versus Condenser TTD for the Three Turbine Types Nuclear

Optimized cooling system design and cost summaries are presented in Table 6-6 for TTDs of $5^{\circ}$ and $11^{\circ} \mathrm{F}$. The modified conventional fossil turbinegenerator was used in these designs. The key to comparing the designs is the difference in the ITDS. The design having a condenser TTD of $11^{\circ} \mathrm{F}$ has 
a lower ITD. The result is a larger heat exchanger and greater water and air mass flow rates. The larger heat exchanger implies higher costs for such items as structures, louvers and foundation. The increased water flow implies higher costs for piping and for scaling the plant to meet pump power requirements. The increased air flow could have resulted in an increased number of fans. Instead, high performance fans were selected. Either case would have resulted in increased fan power requirements which also adds to plant scaling.

TABLE 6-6. Comparison of Optimized Cooling Designs for Two Condenser TTD Values

\begin{tabular}{|c|c|c|}
\hline \multirow{2}{*}{\multicolumn{3}{|c|}{ DESIGN PARAMETERS }} \\
\hline & & \\
\hline Air Flow Rate, $10^{8} \mathrm{Ib} / \mathrm{hr}$ & 8.65 & 9.20 \\
\hline Air Range, ${ }^{\circ} \mathrm{F}$ & 25.2 & 23.8 \\
\hline Air Velocity, $\mathrm{ft} / \mathrm{sec}$ & 17.1 & 16.8 \\
\hline$\Delta P_{a i r, H X}, p s i$ & 0.0113 & 0.0129 \\
\hline$\Delta P_{a i r}$, discharge, psi & 0.0064 & 0.0071 \\
\hline Fan Power, MWe & 17.2 & 20.0 \\
\hline Fans, Number/Dia, ft & $37 / 60$ & $38 / 60$ \\
\hline Water Flow Rate, $10^{8} \mathrm{~Tb} / \mathrm{hr}$ & 2.08 & 2.39 \\
\hline Water Range, ${ }^{\circ} \mathrm{F}$ & 25.2 & 22.0 \\
\hline Pump Power, MWe & 6.35 & 6.52 \\
\hline ITD, ${ }^{\circ} \mathrm{F}$ & 45.6 & 39.6 \\
\hline $\mathrm{U}, \mathrm{Btu} / \mathrm{hr} / \mathrm{ft}^{2} /{ }^{\circ} \mathrm{F}$ & 5.21 & 5.09 \\
\hline $\begin{array}{l}\text { H. X. Heat Transfer Area, } \\
106 / \mathrm{ft}^{2}\end{array}$ & 52.3 & 66.9 \\
\hline H. $X$. Width/Length, ft/ft & $5710 / 80$ & $6210 / 80$ \\
\hline H. X. Depth, Rows & 3.27 & 3.85 \\
\hline Total H. X. Tubes & 87200 & 112000 \\
\hline Towers, Number/Dia, ft & $12 / 148$ & $14 / 138$ \\
\hline Cond. H.T. Area, $10^{6} / \mathrm{ft}^{2}$ & 0.551 & 0.401 \\
\hline Total Cond. Tubes & 58300 & 34800 \\
\hline \multicolumn{3}{|l|}{ COST SUMMARY } \\
\hline Cooling System, mills/kWh & 1.95 & 2.17 \\
\hline Capacity, mills/kwh & 0.27 & 0.27 \\
\hline Scaling, mills/kWh & 0.22 & 0.26 \\
\hline Energy, mills/kwh & 0.09 & 0.09 \\
\hline Base Fuel, mills/kwh & 0.15 & 0.17 \\
\hline 0\&M, mills/kWh & 0.11 & 0.12 \\
\hline Total Incr. Cost, mills/kwh & 2.80 & 3.09 \\
\hline
\end{tabular}


The only item for which the costs increase significantly by going to a $5^{\circ} \mathrm{F}$ TTD is the condenser. To achieve a lower TTD requires more condenser heat transfer area. This implies a larger, more expensive condenser. However, the heat exchanger is typically about four times as costly as the condenser. Thus, proportional changes in the heat exchanger and condenser sizes results in cost reductions for the heat exchanger which significantly outweigh the cost increases of the condenser.

\subsection{PIPING SYSTEM WATER DESIGN VELOCITY}

In this section the results of the parametric evaluation of the piping system water design velocity are presented. The piping system design and cost model is presented in Reference 16. The water design velocity is one of several variables that determine the piping system costs. However, it is the only significant parameter that could be externally optimized using the optimization code. The results show the optimum water design velocity to be between 12 and 17 feet per second.

A higher water design velocity allows the use of smaller diameter pipe that is less costly if the pipe design pressure does not change. However, the pump power required is proportional to the square of the water velocity. Increasing the power plant size to supply this power costs $\$ 440 / k W$ for fossil plants and $\$ 550 / \mathrm{kWe}$ for nuclear plants in addition to the costs of the increased fuel consumption. Because the power plant is larger, the cooling system must also be scaled up. In addition, pump and motor costs increase with the dynamic head. Therefore, the optimum water design velocity is determined by the tradeoff between the cost of piping system components and the costs to provide pump power.

Piping system component costs were obtained for design pressures of 50, 75, and 125 psi. Optimized designs were developed for each design pressure with design velocities from 4 to 20 feet per second. The maximum allowable water design velocity for neutral pH, high-purity, oxygenated water in carbon steel pipe is about 20 feet per second. (16) This limit is based upon considerations of the combined problem of corrosion and erosion. 
The significant results of the parametric analysis for a design pressure of 125 psi are presented in Figure 6-9. This figure shows the basic trade-off between pump power and piping system costs. The results for the lower design pressures are not shown because they are so similar that the curves could not be distinguished. For example, the incremental cost for the optimized cooling system designs using 50, 75, and 125 psi pipe design pressures with a water velocity of 12 feet per second are 2.69, 2.70, and $2.74 \mathrm{mills} / \mathrm{kWh}$, respectively. To not exceed the pressure limit for pipe designed for 50 psi it would be necessary to maintain the water velocity below 4 feet/second. The incremental cost is so high for this case that the low pressure pipe is not economically competitive. Pipe designed to 75 and 125 psi can be used with design velocities up to about 17 and $32 \mathrm{feet} / \mathrm{second}$, respectively. However, these velocities are above the cost optimum velocities. Therefore, there is no economic incentive for investigating the use of design velocities above the upper limit of 20 feet per second.

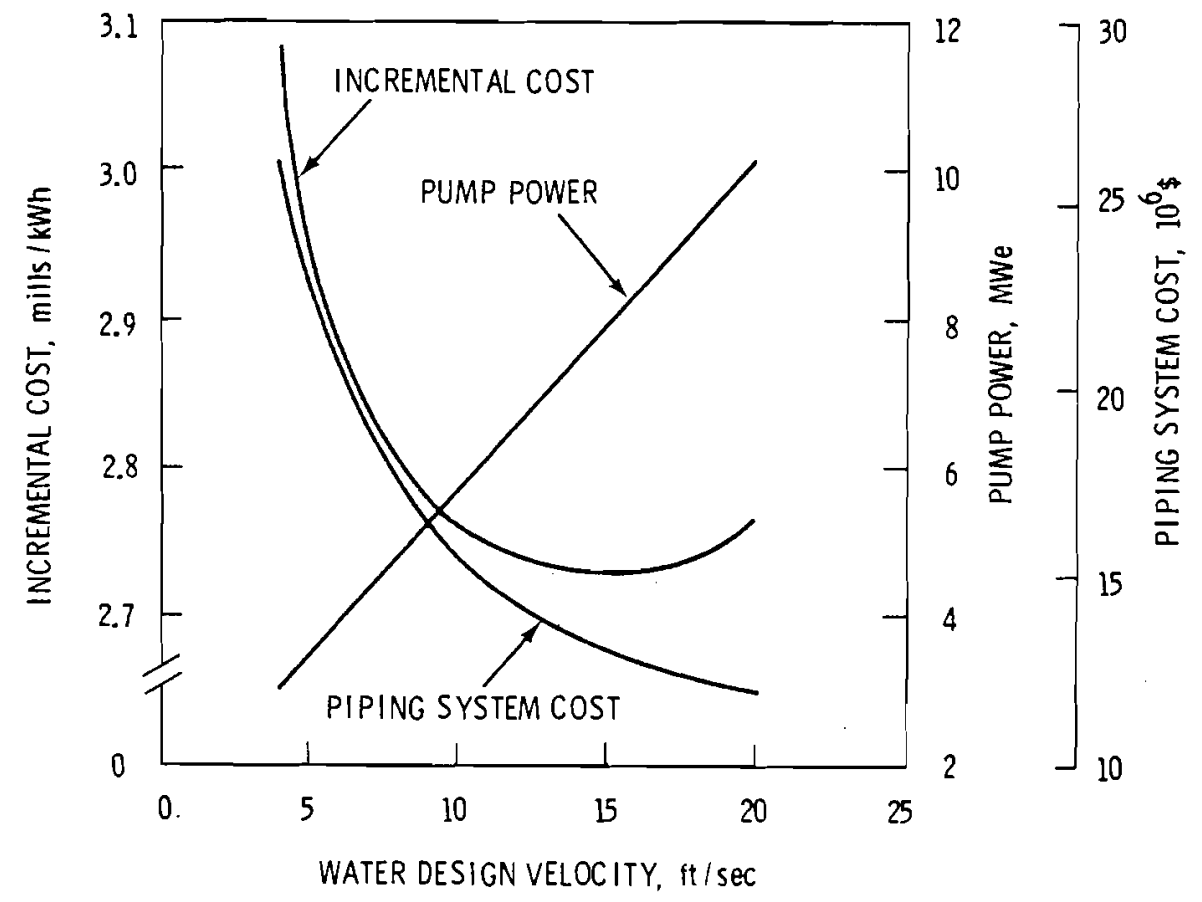

FIGURE 6-9. Incrementa1 Cost, Pump Power, and Piping System Cost Versus Water Design Velocity 
This analysis indicates very little incentive for reducing the pipe design pressure which would reduce the pipe component costs. The pipe having the 125-psi design pressure provides a significant safety factor while having almost no effect upon the cost of electricity.

\subsection{TOWER CONFIGURATION}

An option exists in the economics code to fix the number of circular towers. This option was used to evaluate the effect of the number of towers upon the design and cost of the cooling system.

Several parameters play important roles in the trade-offs determining the design for any particular number of towers. It is difficult to discuss the individual effect that any variable may have because al1 are interrelated. Nevertheless, a brief description will be presented.

The tower diameter is perhaps the key parameter tied to the number of towers. As the number of towers is increased, the tower diameter will decrease. There is a general trend in which the total heat transfer area remains nearly constant. However, as the number of towers increases, the optimized tube rows in depth decreases. The result is that the number of towers and the tower diameter do not vary on a one-to-one basis. The reason for this is that the tower diameter is tied into a tradeoff between structural costs and fan power requirements.

Structural costs are proportional to the square of the tower diameter. For a low number of towers the diameter would be large with corresponding high structural cost, unless the heat exchanger becomes deeper. A deeper heat exchanger results in increased fan power requirements. For a large number of towers with small diameters the total roof area is relatively sma11. For a given packing factor this forces the use of high performance fans unless the tower diameter is increased.

In terms of incremental power production costs, the optimum number of towers for a 1000-Mwe dry cooled power plant is between 8 and 12 although the incremental cost variation over the range from 4 to 16 towers was only about seven percent. In going to less than 8 towers the resultant diameter 
is as small as possible to avoid large structural costs while accepting an increased fan power requirement. In going to more than 12 towers, the resultant diameter is as large as possible. This avoids high fan power costs while accepting increased structural costs.

The incremental cost, tower diameter and tube rows in depth are shown in Figure $6-10$ as a function of the number of towers.

An option having a large impact on the number and design of the cooling towers is whether or not to use a delta heat exchanger arrangement. The use of the delta arrangement significantly reduces the number of towers. The delta option is discussed in detail in Section 6.7.3.

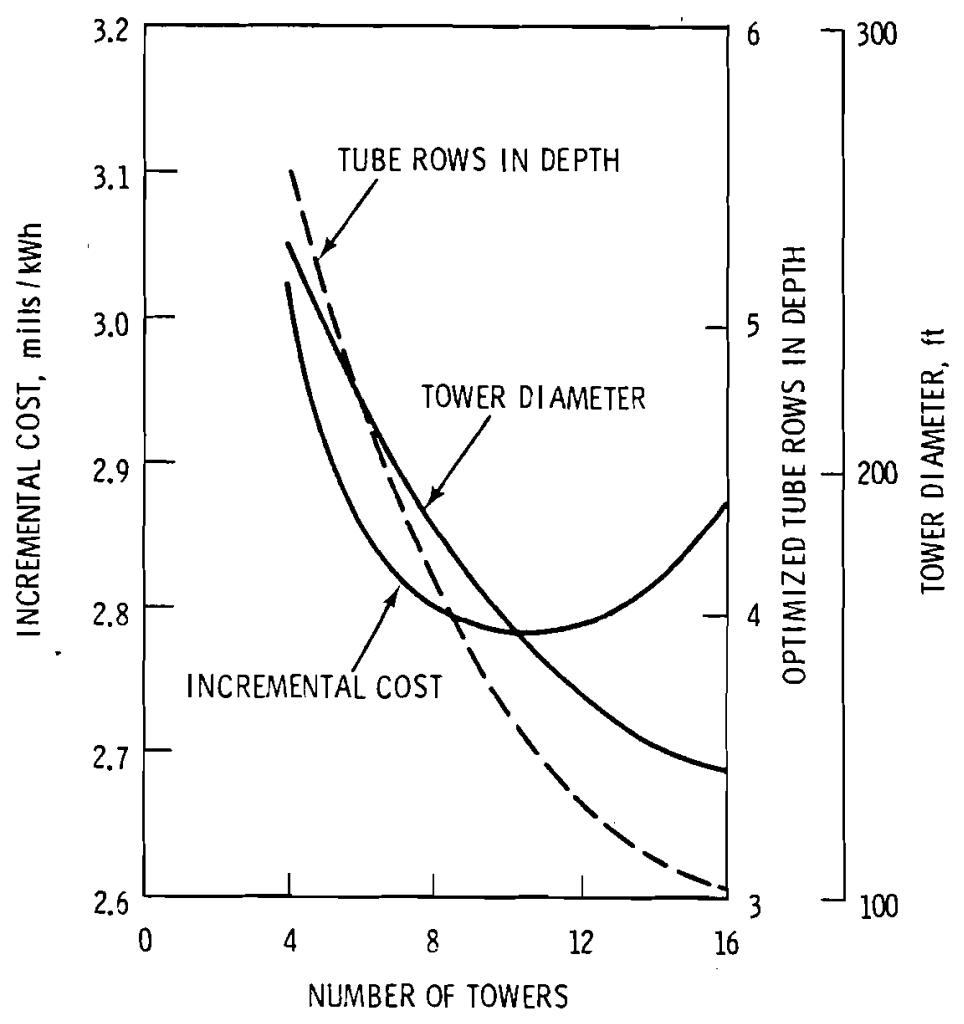

FIGURE 6-10. Incremental cost, Optimized Tube Rows in Depth and Tower Diameter Versus the Number of Circular Towers 
One design aspect that cannot be readily evaluated on a quantitative basis is the cooling system resolution, the extent to which sections of the cooling system can be isolated or controlled. Each tower consists of four quadrants. The coolant flow to each quadrant is controlled by valves in the supply and return piping. Thus, in a four-tower arrangement with sixteen quadrants, one-sixteenth of the cooling system can be isolated. This represents about 60 MWe for a 1000-MWe power plant. With a sixteentower design the cooling system can be controlled to about 15 MWe. The precision of control necessary for freeze protection and back pressure stability would determine the necessary amount of resolution. Other factors involving maintenance and operating experience would also be considered. Increased resolution could also be achieved by dividing the towers into more than four sections, a number chosen rather arbitrarily for this study. In any case, the range of 15 to 60 MWe probably covers values that would be acceptable to the utility industry.

\subsubsection{Circular Versus Rectilinear Towers}

The circular tower is characterized by vertical heat exchanger bundles. The coolant for several towers is supplied through a single header pipe between the condenser and the towers. A rectilinear tower is characterized by horizontal heat exchanger bundles. One tower is supplied from a header pipe connecting the condenser and the tower. A design and cost code was developed for each tower arrangement. Emphasis was placed on the analys is of the circular tower arrangement for state-of-the-art so that comparisons could be made to the advanced system designs which lent themselves to the circular tower model.

The basic differences between the circular tower model and the rectilinear tower model are in the structures and piping models. In addition, the fan packing factor is not a part of the rectilinear model. Because of the horizontal heat exchanger arrangement there is ample roof area for the fans. The problems of relating the fan exit area to the heat exchanger frontal area and the tower roof area in terms of mass continuity are thereby avoided. Although this provides an apparently greater freedom of design, 
the rectilinear arrangement does not prove to be significantly different in design or cost when compared to the circular tower arrangement. While the appearance of the cooling towers is different, design parameters such as total heat transfer surface area, water and air mass flow rates, etc, are about the same for both tower arrangements. External parameters, such as the unit geometry of the finned tube, optimized using the circular tower model will have approximately the same optimum values when analyzed using the rectilinear model.

The structures models are different by virtue of the difference between the vertical and horizontal heat exchangers. The vertical tube bundles are somewhat self-supporting because the lower end rests on the tower foundation. The horizontal tube bundles must be supported about fifty feet above ground level.

The piping system design and cost models for circular and rectilinear towers are presented in Reference 16. Piping system costs can represent as much as 25 percent of the capital costs attributed to the cooling system. While there are some basic differences in the piping layouts, the piping system costs incurred by each tower arrangement are about the same.

\subsection{FAN SYSTEM}

Parameters that are relevant to a discussion of the fan system include the fan type, packing factor and the economic incentives to provide diffuser stacks and/or a delta heat exchanger arrangement. Two other parameters significant in selection of the fan system are the air velocity and fan power requirements.

\subsubsection{Fan Type}

The fan type is described by the fan diameter, number of blades per fan and the blade angle. Within the optimization code, 153 different fan types have been provided. The blade diameters are 24, 26, 28, 30, 40, and 60 feet. There may be 6 to 16 blades per fan. The blade angle may be selected from discrete values between 2 and 22 degrees. 
Each fan type is characterized in the optimization code by a performance curve fit relating pressure drop and fan power requirements to the volumetric flow rate per fan. The pressure drop includes the pressure drop across the heat exchanger plus any discharge losses at the fan exit.

The selection of a particular fan type is based upon a trade-off between the fan system capital costs (including fans, motors, gears, controls, and electrical) and the costs of increasing the power plant size to provide the power requirements incurred by the fan system. High performance fans, that is, fans having high volumetric flow rates per fan, generally require more power than low performance fans.

Two identical cooling towers that have identical air flow rates will require the same fan power to induce the air flow through the heat exchanger. However, if one tower has high performance fans, then the discharge losses for that design would be greater than the discharge losses from the other tower design which uses low performance fans. The discharge losses are higher for the tower design using high performance fans because the same volumetric air flow is induced by fewer fans. The fan exit velocity will be higher. Therefore, the total fan power consumed will be greater. However, because the high performance fan system requires fewer fans the capital cost of the fan system will be lower.

An option in the optimization code allows elimination of any number of fans from consideration by the regular optimization process. This option has been used to investigate the effect of fan diameter upon total incremental power production costs. The results of this parametric analysis are presented in Table 6-7. For each case the design conditions were exactly identical except that the code was restricted to consider only the specific diameter. Based upon the cost models and performance information used in the code it appears that costs are independent of fan diameter. The fan types that were selected are generally in the high performance range. 
TABLE 6-7. Fan Diameter and Incrementa1

Power Production Cost

\begin{tabular}{|c|c|c|c|c|}
\hline $\begin{array}{c}\text { Fan Diameter } \\
\mathrm{ft}\end{array}$ & $\begin{array}{c}\text { Blades/ } \\
\text { Fan } \\
\end{array}$ & $\begin{array}{l}\text { Blade } \\
\text { Angle } \\
\end{array}$ & \# Fans & $\begin{array}{c}\text { Incremental Power } \\
\text { Production Cost } \\
\text { mi11s/kWh } \\
\end{array}$ \\
\hline 24 & 10 & 18 & 159 & 2.80 \\
\hline 26 & 6 & 14 & 193 & 2.85 \\
\hline 28 & 6 & 16 & 173 & 2.84 \\
\hline 30 & 8 & 14 & 145 & 2.84 \\
\hline 40 & 8 & 14 & 85 & 2.84 \\
\hline 60 & 12 & 16 & 37 & 2.80 \\
\hline
\end{tabular}

The selection of a particular type of fan affects the number of fans required for the cooling system. Generally, the larger the fan diameter, the fewer fans required, although fan performance must also be considered. Each fan with motor, gearbox, etc., must receive routine maintenance. For this reason, a large number of small fans may not be acceptable in the utility industry. Because total costs appear to be independent of fan diameter, the utilities may wish to use a smaller number of the large fans. Certainly, a more thorough evaluation of the maintenance costs related to the number and size of fans is necessary.

\subsubsection{Packing Factor}

Preliminary analysis indicated that, for a given heat exchanger width, the structures costs of the circular towers would be minimized by building the maximum number of circular towers. The number of towers is limited by the need to place all the fans in the roof area of the towers. A closer packing arrangement of the fans would, therefore, allow reduction of the structures cost.

The fan packing factor is the ratio of the total roof area of the circular towers to the sum of the swept area of all the fans. To compute the minimum allowable packing factor it is necessary to consider the area required for each fan. If there are no diffuser stacks, the fan diameter 
must be increased by seven feet to compute the fan area. This accounts for the entry section of the fan ring. With no diffuser stacks it may be possible to provide a packing factor as low as 1.7, depending upon the tower diameter, the fan diameter, the packing arrangement, and the number of fans per tower. If diffuser stacks are used, then the actual diameter required for the fans is determined by the size of the diffuser stack rather than the entry section. In this case, the minimum obtainable packing factor is about 2.0 .

Whether or not the cooling system design calls for diffuser stacks and/or a delta heat exchanger arrangement, the incremental costs decrease with decreasing packing factor. These results are presented in Table 6-8.

\section{TABLE 6-8. Incremental Power Production Costs as a Function of Packing Factor and Design Options}

\begin{tabular}{|c|c|c|c|c|}
\hline $\begin{array}{l}\text { Packing } \\
\text { Factor }\end{array}$ & $\begin{array}{l}\text { No Diff. } \\
\text { No Delta }\end{array}$ & $\begin{array}{l}\text { Diff. } \\
\text { Only }\end{array}$ & $\begin{array}{l}\text { Del ta } \\
\text { Only }\end{array}$ & $\begin{array}{l}\text { Diff. W/ } \\
\text { Delta }\end{array}$ \\
\hline 1.5 & 2.78 & -- & 2.57 & -- \\
\hline 1.7 & 2.80 & -- & 2.61 & -- \\
\hline 2.0 & 2.84 & 2.80 & 2.71 & 2.63 \\
\hline 2.5 & 2.89 & 2.82 & 2.73 & 2.69 \\
\hline 3.0 & 2.92 & 2.90 & 2.80 & 2.77 \\
\hline
\end{tabular}

Although costs are not a strong function of packing factor, the packing factor has a noticable affect on the appearance of the cooling system and the trade-offs determining the cooling system design. If packing factor is increased, then more tower roof area is required for each fan. The tower roof area can be increased using a smaller number of larger diameter towers. In this way the frontal area of the heat exchanger, the fan system specifications, and the air velocities through the heat exchanger and fan exits can be maintained. However, because the structures costs go up as the square of the tower diameter, the tower diameter is not increased nor is the number of towers decreased as much as it would have been if it 
were not for this cost relation. If the frontal area is fixed, the result of going to a higher packing factor is to have a fewer number of fans that will operate at higher flow rates with has high discharge losses. Thus, the cooling system design resulting from an increase in packing factor is influenced by the trade-off between energy penalties and structures cost. With fewer fans, a capital cost savings is also a part of the cost trade-offs.

\subsubsection{Diffusers and Delta Arrangements}

The choice of providing diffuser stacks and/or a delta heat exchanger arrangement has been considered. Incremental costs for various design combinations of packing factor, diffusers and delta arrangements are shown in Table 6-8.

For a given heat exchanger width and fan packing factor, consider the effect of using a delta heat exchanger arrangement. With a $60^{\circ}$ included angle in the delta, the effective width of the heat exchanger is halved. That is, instead of having eight towers with a two-hundred foot diameter, for example, there would be four towers with a two-hundred foot diameter. To maintain the heat transfer coefficient the air velocity through the heat exchanger must also be maintained. Although there is half the original number of towers, the same volume of air flow is required. Now, suppose for the nondelta design there were 25 fans per tower with blade diameters of 28 feet. Because of the implications of a fixed packing factor, the design with the delta arrangement must still have 25 fans per tower. However, there are now half as many towers and therefore, only half as many fans. With the same air flow going through half as many fans, the exit velocities from the fans will double. Thus, the fan power requirements attributed to discharge losses would increase by a factor of four.

The delta heat exchanger arrangement reduces the piping costs because the heat exchangers are grouped in a closer arrangement. The length of piping required to distribute the water to the heat exchanger is shortened. However, the delta arrangement forces the fans to operate at very high flow rates with high discharge losses. The designs incorporating 
the delta arrangement will trade off piping cost against the costs incurred through fan power requirements. As a result, the effective or circumferencial heat exchanger width is not generally reduced by half in going to a $60^{\circ}$ delta. Thus, in keeping with the example above, the delta arrangement may result in a design having five towers with 240-foot diameters. This would provide more roof area for more fans which would hold down the fan exit velocities.

Another compromising issue is that the fans are limited to a total pressure of about one inch of water. For a four-row heat exchanger with an air velocity through the minimum cross section of about 18 feet per second, the pressure drop across the heat exchanger is about 0.4 inches of water. This is a typical condition for an optimized design. It follows that the discharge loss cannot exceed about 0.6 inches of water. The discharge velocity is thereby limited to about 50 feet per second. By considering these velocities and the flow areas of the heat exchanger and fan exits, the conditions of mass continuity of the air are established. The result is that there are limitations in the design of the optimized circular tower cooling system that cannot be ignored. The interrelationship between the fan type, flow areas, air velocities, etc., must be considered whether or not the delta arrangement and/or the diffuser stacks are used.

As observed in Table 6-8 there are some cost incentives to use a delta arrangement. However, before the delta arrangement would be recommended it would be necessary to investigate some potential problems. Of primary concern is the maldistribution of air flow through the heat exchanger. This degrades the performance of the cooling system and may lead to freezing problems which could otherwise be avoided. The use of the delta arrangement in the optimization scheme results in designs having as few as two towers. Some of the cost models in this region, e.g., structures and piping, may not be reliable. Because of these concerns, the delta heat exchanger arrangement has not been made a part of the base case for the other parametric analysis. 
The cost trade-offs involved in the selection of the fan type force the use of high performance fans. The high discharge losses mean that energy is being wasted. Diffuser stacks can be added to the fan exit ring to recover some of the velocity pressure. The improvement in the efficiency of the fan system promotes a savings of fuel. However, the diffuser stacks represent a significant capital investment. Also, because of size limitations, they will recover only about 25 percent of the velocity head that would have otherwise been lost. Consequently, only a small cost savings results from the use of diffuser stacks in the optimization analysis.

\subsubsection{Relationships Between Fan and Tower Design Parameters}

This section presents the equations used to assess the interrelationship between the fan system and circular tower design parameters. Nomenclature is presented at the end of this section.

$$
\begin{gathered}
\text { Packing Factor }=\frac{\text { Tower Roof Area }}{\text { Fan Swept Area }} \\
P=\frac{\frac{\pi}{4} D_{T}^{2}}{\frac{\pi}{4} D_{F}^{2} N_{F}}
\end{gathered}
$$

or

$$
D_{F}^{2}=\frac{D_{T}^{2}}{P N_{F}}
$$

The minimum flow area through the heat exchanger tube bundle is typically one-half the frontal area of the tube bundle. For a nondelta arrangement the minimum free flow area is

$$
A_{M}=\frac{\pi D_{T} H}{2}
$$

If a $60^{\circ}$ delta arrangement is used there are twice as many tube bundles around the tower so that

$$
A_{M}=\pi D_{T} H
$$


From continuity, for a nondelta arrangement

$$
\begin{aligned}
& A_{M} V_{M}=A_{F} V_{E} \\
& \frac{\pi D_{T}}{2} H V_{M}=\frac{\pi D_{F}^{2}}{4} N_{F} V_{E} \\
& D_{T} H V_{M}=\frac{D_{F}^{2} N_{F} V_{E}}{2}
\end{aligned}
$$

Substitute the relation for $D_{F}^{2}$ from the packing factor to get

$$
D_{T}=\frac{2 H P V_{M}}{V_{E}} \text {. }
$$

The pressure drop across the heat exchanger is calculated from

$$
\Delta P_{H X}=\frac{f n \rho V_{M}^{2}}{G_{C}}
$$

The discharge loss is

$$
\Delta P_{D}=\frac{\rho V_{E}^{2}}{2 G_{C}}
$$

The relationship between the fan system, tower size and allowable velocities is essentially determined by equations (1) through (4). 
Nomenclature for Section 6.7.4:

$$
\begin{aligned}
P & =\text { packing factor } \\
D_{T} & =\text { tower diameter } \\
D_{F} & =\text { fan blade diameter } \\
N_{F} & =\text { number of fans } \\
A_{M} & =\text { minimum free flow area through heat exchanger } \\
H & =\text { tower height } \\
V_{M} & =\text { air velocity through minimum cross-section } \\
A_{F} & =\text { total swept area of fans } \\
V_{E} & =\text { exit air velocity from fan ring or diffusion stack } \\
f & =\text { air-side friction factor } \\
n & =\text { number of tube rows in direction of air flow } \\
\rho & =\text { air density } \\
G_{C} & =\text { gravitational constant } \\
\Delta P_{H X} & =\text { pressure drop across heat exchanger } \\
\Delta P_{D} & =\text { discharge loss }
\end{aligned}
$$




\subsection{METEOROLOGY}

The meteorology of a particular site is characterized by a maximum temperature and a distribution of temperatures on a yearly average basis. Five sites were selected for this analysis: Wyodak, San Francisco, Chicago, Miami, and Phoenix. Cumulative temperature curves for these five sites are shown in Figure 6-11. The temperature profiles for Wyodak and Chicago have been adjusted so that the cumulative hours below $30^{\circ} \mathrm{F}$ is included in the cumulative hours at $30^{\circ} \mathrm{F}$. This adjustment has no effect on the cooling system designs for these sites. The profiles were adjusted to prevent the prediction of below-freezing water temperatures.

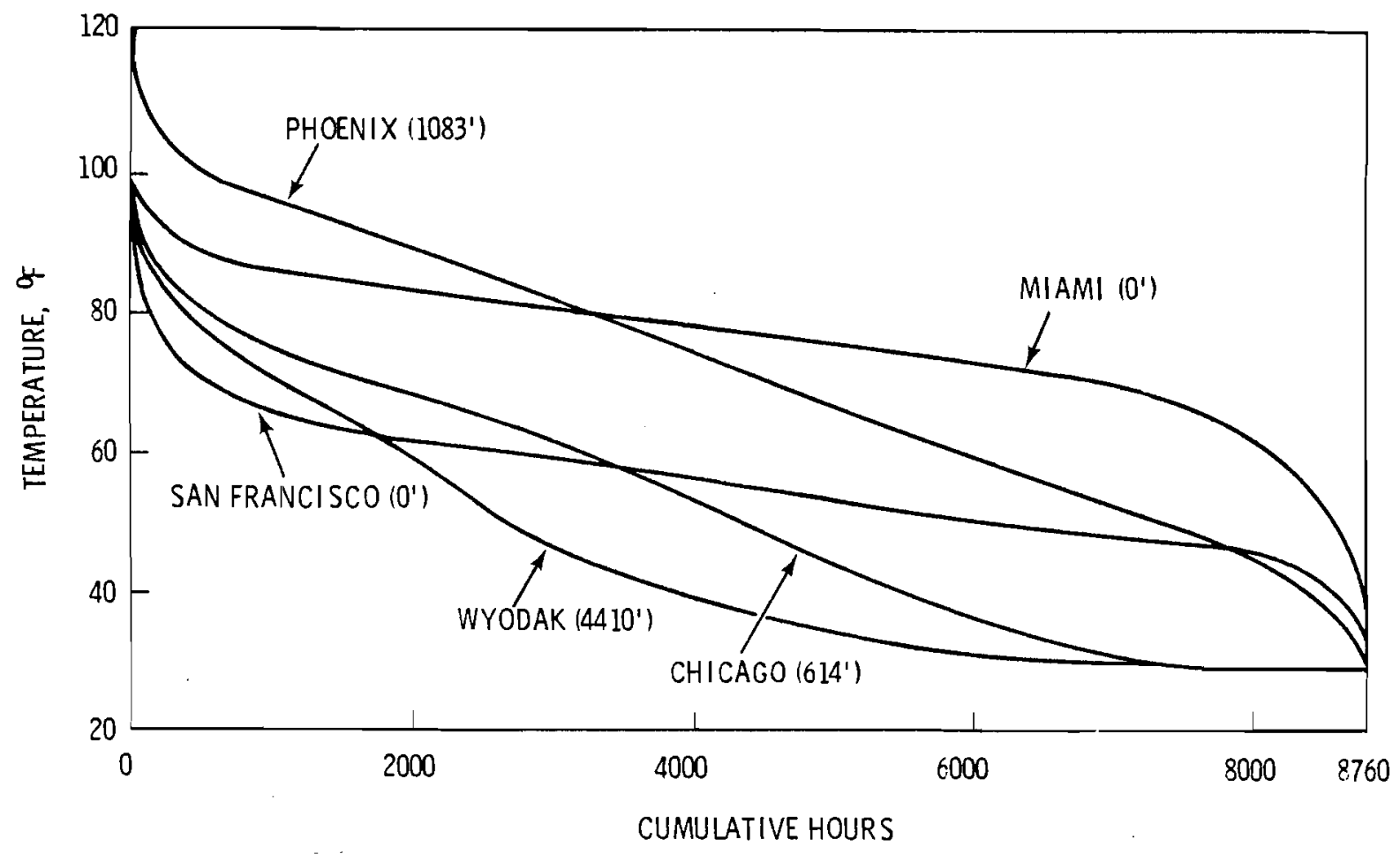

FIGURE 6-11. Cumulative Temperature Distribution Taken from Ten-Year Average for Five Site Meteorologies with Site Elevation in Parentheses

Meteorology influences the design and cost of the cooling system in three ways. The maximum ambient air temperature partly determines the 
maximum ITD of the heat exchanger and the capital cost of the gas turbines required to make up lost performance. The distribution of temperature over the year determines the cost of fuel for the gas turbines.

\section{$6.8 .1 \underline{\text { ITD }}$}

The ITD is the difference between the inlet temperature of the water and the inlet temperature of the air at the heat exchanger. The maximum temperature that the water can assume is limited by turbine back pressure considerations. The difference in temperature between the maximum water temperature and the maximum air temperature is the maximum ITD for which the cooling system can be designed. In general, a cooling system design having a higher ITD will have a smaller cooling system in terms of heat exchanger size and piping system requirements. Thus, the capital expense of these items would be lower. However, the higher ITD also generally implies higher turbine back pressures. Because of poorer heat rates at higher back pressures there are energy penalties associated with increased fuel consumption and the requirement for a larger steam supply system. In spite of this, the trade-offs determining the optimum cooling system design generally favor designs having a higher ITD. The higher the maximum ambient air temperature at a particular site, the lower the potential ITD. Therefore, at sites having higher maximum air temperatures, the costs of the cooling system will be higher than at other sites.

\subsubsection{Capacity Cost}

In this analysis, the cooling system is designed such that the power plant will produce a given net electric output at a given ambient air temperature. At temperatures above this design temperature, the output of the turbine is lowered because of the increase in back pressure. The maximum loss in performance occurs when the back pressure is maximum, a condition occurring when the ambient air temperature is at its maximum. In this analysis the plant is assumed to be a base loaded plant. The difference in output between the base load output and the net output on the hottest day is assumed to be made up by gas turbines. This capital expense is 
referred to as the capacity cost. For a fixed cooling system design, the greater the maximum temperature, the higher this additional cost will be.

\subsubsection{Energy Cost}

Whenever the ambient temperature exceeds the design temperature of the cooling system, the gas turbines are used to maintain the net base load output of the plant. The amount of fuel consumed in making up lost performance is dependent upon the yearly temperature distribution. The sites having the highest average temperatures will, in general, have the highest energy cost associated with the operation of the gas turbines.

While the capacity cost may be similar for two sites, the energy cost may vary considerably. Observe the difference in the temperature profiles between Miami and Wyodak in Figure 6-11. For both sites the maximum temperatures are identical, $100^{\circ} \mathrm{F}$, but Miami is considerably wamer on a yearly average basis. Optimized designs were developed for both sites using identical input conditions except, of course, for the meteorology data. The results showed that the capacity cost for both sites was $0.27 \mathrm{mill} / \mathrm{s} / \mathrm{kWh}$. However, for Miami the cost of operating the gas turbines is $0.49 \mathrm{mills} / \mathrm{kWh}$ while the cost for the Wyodak site is only $0.09 \mathrm{mills} / \mathrm{kWh}$. In comparison, the energy cost attributed to the piping system at the Miami site is $0.43 \mathrm{mills} / \mathrm{kWh}$ for this particular design with the total incremental power production cost being approximately $3.0 \mathrm{mills} / \mathrm{kWh}$. This indicates the effect of site meteorology upon the costs associated with all-dry cooling.

\subsubsection{Evaluation of Five Site Meteorologies}

Optimized designs were developed for each of the five sites using the three turbine types and for fossil and nuclear fuel. A summary of the total incremental power production cost associated with each site and specific turbine is presented in Tables 6-9 and 6-10. A detailed description of some important parameters and costs for some of these designs is given in Tables 6-11 and 6-12 for fossil and nuclear fuel, respectively. The designs presented apply only to the modified conventional turbine. The designs for San Francisco and Chicago were not presented because of the similarity of meteorology for these sites and Wyodak. 
TABLE 6-9. Incremental Power Production Costs for Fossil-Fueled Turbine-Generators for the Five Site Meteorologies and the Three Turbine Types

\begin{tabular}{|c|c|c|c|}
\hline Site & Conventional & $\begin{array}{c}\text { Modified } \\
\text { Conventional }\end{array}$ & $\begin{array}{l}\text { High Back } \\
\text { Pressure }\end{array}$ \\
\hline Wyodak & 3.98 & 2.80 & 2.60 \\
\hline San Francisco & 3.70 & 2.63 & 2.49 \\
\hline Chicago & 3.73 & 2.73 & 2.58 \\
\hline Miami & 3.82 & 3.03 & 2.80 \\
\hline Phoenix & -- & 4.43 & 3.18 \\
\hline
\end{tabular}

TABLE 6-10. Incremental Power Production Costs for Nuclear-Fueled Turbine-Generators for the Five Site Meteorologies and the Three Turbine Types

\begin{tabular}{|c|c|c|c|}
\hline Site & Conventiona 1 & $\begin{array}{c}\text { Modified } \\
\text { Conventional } \\
\end{array}$ & $\begin{array}{l}\text { High Back } \\
\text { Pressure }\end{array}$ \\
\hline Wyodak & 4.01 & 3.53 & 3.43 \\
\hline San Francisco & 3.72 & 3.42 & 3.26 \\
\hline Chicago & 3.81 & 3.50 & 3.36 \\
\hline Miami & 3.81 & 4.11 & 3.57 \\
\hline Phoenix & -- & 5.24 & 4.00 \\
\hline
\end{tabular}

\subsubsection{ITD}

The maximum allowable back pressure for the modified conventional turbine corresponds to a temperature of about $153^{\circ} \mathrm{F}$. The maximum ambient air temperature at Phoenix is $120^{\circ} \mathrm{F}$ while at Wyodak and Miami it is $100^{\circ} \mathrm{F}$. Allowing $5^{\circ} \mathrm{F}$ for the condenser TTD, the maximum ITD for which the cooling system can be designed is $28^{\circ} \mathrm{F}$ (153-5-120) for Phoenix and $48^{\circ} \mathrm{F}$ (153-5-100) for the other sites. As a result, the Phoenix site has much higher water and air flow rates and a larger heat exchanger. The capital cost of the the cooling system, which includes the condenser, the piping system and a 11 the cooling tower components, is therefore much greater for the Phoenix site. 
TABLE 6-11. Parameters and Costs for Wyodak, Miami, and Phoenix for the Modified Conventional Turbine - Fossil

Site

Wyodak

Miami

Phoenix

DESIGN PARAMETERS

Air Flow Rate, $10^{8} 1 \mathrm{~b} / \mathrm{hr}$

8.65

8.64

11.5

Air Range, ${ }^{\circ} \mathrm{F}$

25.2

25.3

19.2

Air Velocity, ft/sec

17.1

18.5

14.4

$\Delta P_{\text {air, }} H x$, psi

0.0113

0.0162

0.0124

$\Delta P_{\text {air, discharge, }} \mathrm{ps} i$

0.0064

0.0065

0.0062

Fan Power, MWe

17.2

18.5

21.2

Fans, Number/Dia, ft

$37 / 60$

$34 / 60$

$47 / 60$

Water Flow Rate, $10^{8} \mathrm{lb} / \mathrm{hr}$

2.08

2.07

5.19

Water Range, ${ }^{\circ} \mathrm{F}$

25.2

25.3

10.2

Pump Power, MWe

6.35

6.65

17.1

ITD, ${ }^{\circ} \mathrm{F}$

45.6

45.6

26.4

$\mathrm{U}, \mathrm{Btu} / \mathrm{hr} / \mathrm{ft} \mathrm{t}^{2}-^{\circ} \mathrm{F}$

5.21

5.90

5.28

H. X. Heat Transfer Area, $106 \mathrm{ft} 2$

52.3

46.5

96.1

H. X. Width/Length, ft/ft

$5710 / 80$

$4460 / 80$

$7900 / 80$

H. X. Depth, Rows

3.27

3.73

4.34

Total H. X. Tubes

87,200

77,600

160,000

Towers, Number/Dia, ft

$12 / 748$

$8 / 173$

$18 / 135$

COST SUMMARY

Cooling System, mi11s/kWh

1.95

1.76

3.16

Capacity, mills/kWh

0.27

0.27

0.28

Scaling, mills/kWh

0.22

0.24

0.38

Energy, mills/kWh

0.09

0.49

0.18

Base Fue1, mi11s/kWh

0.15

0.17

0.25

$0 \& M$, mi11s/kWh

0.11

0.10

0.18

Total Incr. Cost, mills/kWh

2.80

3.03

4.43 
TABLE 6-12. Parameters and Costs for Wyodak, Miami and Phoenix for the Modified Conventional Turbine - Nuclear

Site

Wyodak Miami

DESIGN PARAMETERS

$\begin{array}{lccc}\text { Air Flow Rate, } 10^{8} \mathrm{Ib} / \mathrm{hr} & 7.47 & 9.51 & 11.5 \\ \text { Air Range, }{ }^{\circ} \mathrm{F} & 28.7 & 22.5 & 18.7 \\ \text { Air Velocity, ft/sec } & 16.2 & 16.0 & 15.2 \\ \Delta \mathrm{P}_{\text {air, HX }} \text {, psi } & 0.0133 & 0.0117 & 0.0142 \\ \Delta \mathrm{P}_{\text {air, discharge, psi }} & 0.0068 & 0.0068 & 0.0069 \\ \text { Fan Power, MWe } & 16.6 & 16.8 & 23.6 \\ \text { Fans, Number/Dia, ft } & 31 / 60 & 36 / 60 & 44 / 60 \\ \text { Water Flow Rate, } 10^{8} \mathrm{Ib} / \mathrm{hr} & 2.15 & 2.28 & 5.07 \\ \text { Water Range, }{ }^{\circ} \mathrm{F} & 23.9 & 22.5 & 10.2 \\ \text { Pump Power, MWe } & 6.36 & 7.68 & 16.8 \\ \text { ITD, }{ }^{\circ} \mathrm{F} & 44.6 & 40.8 & 25.6 \\ \mathrm{U}, \text { Btu/hr/ft }{ }^{2}{ }^{\circ} \mathrm{F} & 5.00 & 5.50 & 5.39 \\ \text { H. X. Heat Transfer Area, } & & & \\ \text { 106 ft2 } & 61.1 & 54.0 & 96.2 \\ \text { H. X. Width/Length, ft/ft } & 5230 / 80 & 5660 / 80 & 7500 / 80 \\ \text { H. X. Depth, Rows } & 4.16 & 3.40 & 4.58 \\ \text { Total H. X. Tubes } & 102,000 & 89,800 & 160,000 \\ \text { Towers, Number/Dia, ft } & 12 / 136 & 12 / 147 & 17 / 135\end{array}$

COST SUMMARY

Cooling System, mills/kWh

1.94

1.99

3.10

Capacity, mills/kWh

0.38

0.33

0.42

Scaling, mills/kWh

0.91

0.89

1.03

Energy, mills/kWh

0.17

0.74

0.44

Base Fuel, mi1ls/kWh

0.03

0.04

0.07

O\&M, mi11s/kWh

0.11

0.10

0.18

Total Incr. Cost, mills/kWh

3.53

4.11

5.24 


\subsubsection{Capacity}

It was stated previously that for a fixed cooling system design a higher maximum ambient temperature would result in a larger capacity cost. As seen in the design comparisons, the capacity costs are nearly equal for all three sites. However, the cooling system designs are not identical. If the design developed for the Wyodak site were to be used at a site having a higher maximum ambient temperature, the steam flow to the turbine would have to be decreased for the ambient temperatures exceeding $100^{\circ} \mathrm{F}$. This would be necessary to maintain back pressure below the maximum allowable value. As a result, the output of the turbine-generator would decrease. To keep the plant capacity at its base load value the capacity of the gas turbines would have to be increased. The optimized designs shown in the summaries are developed on the basis that the maximum allowable back pressure will not be exceeded on the hottest day. Consequently, the design for the Phoenix site performs as we 11 at $120^{\circ} \mathrm{F}$ as do the other designs at $100^{\circ} \mathrm{F}$. The capital expense for the gas turbines required to make up lost capacity is, therefore, about the same for the three sites.

In addition to meteorology, the capacity cost is also influenced by the design ambient temperature, i.e., the ambient air temperature at which the turbine generator produces the base load plant output. If the design temperature equaled the maximum ambient temperature, there would be no capacity or energy costs because the plant would produce rated capacity on the hottest day. At all lower ambient temperatures the plant could produce excess power. However, if the utility system were summer peaking, then there would not likely be a market for the excess power. For a further discussion of design teniperature, see Section 6.8.5.

\subsubsection{Energy}

The Miami and Wyodak meterologies are significantly different but the cooling system designs are quite similar because both sites are designed according to the same input conditions except for the temperature profiles. The difference in meteorologies shows up in the energy requirements for the gas turbines. The Miami site is consistently associated with the highest energy cost. Wyodak, the coldest site, shows the lowest energy cost. 


\subsubsection{Site Elevation}

In addition to temperature data, a significant characteristic of any site is its elevation above sea level. Two designs for the Wyodak meteorology are given in Table 6-13. The elevations have been artificially set at 0 and 8000 feet. The differences in the designs appear in the size of the heat exchanger. The lower air density at higher elevations results in a lower overall heat transfer coefficient. To compensate for this, the design at the higher elevation requires a larger heat exchanger. Notice that the overall costs increase by about 10 percent with the increase in elevation from 0 to 8000 feet.

\subsubsection{Design Temperature}

Optimized cooling system designs were developed for design temperatures between 40 and $100^{\circ} \mathrm{F}$. The results are shown in Figure 6-12. A design and cost summary for design temperatures of 50 and $100^{\circ} \mathrm{F}$ is presented in Table 6-14. The curve of incremental cost shows that a design temperature of $50^{\circ} \mathrm{F}$ is optimum. This result applies to the Wyodak meteorology. For warmer sites where more gas turbine fuel is consumed, the optimum design temperature may be somewhat higher. Thus, a design temperature of $50^{\circ} \mathrm{F}$ was used as the design basis. The effect of design temperature upon the capacity and energy cost is also presented.

The factor having the most impact upon the increase in incremental cost as the design temperature is increased is the plant scaling cost. Figure $6-13$ is presented to explain the reason for this result. Regardless of the design temperature, the turbine back pressure must be the maximum allowable on the hottest day so that the maximum ITD can be achieved. As turbine back pressure decreases from the maximum, in this case 8 inches $\mathrm{Hga}$, the heat rate improves and, therefore, the plant output increases. At the design temperature the output of the turbine-generator is 1000 MWe for this study. When the design temperature is $100^{\circ} \mathrm{F}$ the plant output is 1000 MWe on the hottest day, i.e., when the turbine back pressure is 8 inches Hga. When the design temperature is $50^{\circ} \mathrm{F}$ the plant output is 1000 MWe when the 
TABLE 6-13. Two Designs for the Wyodak Meteorology With Different Elevation Above Sea Level

$\frac{\text { Elevation, } \mathrm{ft}}{8,000}$

DESIGN PARAMETERS

Air Flow Rate, $10^{8} \mathrm{lb} / \mathrm{hr}$

Air Range, ${ }^{\circ} \mathrm{F}$

Air Velocity, ft/sec

$\Delta P_{\text {air, }} H X$, psi

$\Delta P_{\text {air, discharge, }} p{ }^{i}$

Fan Power, MWe

Fans, Number/Dia, ft

Water Flow Rate, $10^{8} \mathrm{lb} / \mathrm{hr}$

Water Range, ${ }^{\circ} \mathrm{F}$

Pump Power, MWe

ITD, ${ }^{\circ} \mathrm{F}$

$\mathrm{U}, \mathrm{Btu} / \mathrm{hr} / \mathrm{ft} \mathrm{t}^{2}-{ }^{\circ} \mathrm{F}$

H. X. Heat Transfer Area $106 \mathrm{ft}^{2}$

H. X. Width/Length, $\mathrm{ft} / \mathrm{ft}$

$H . X$. Depth, rows

Total H. X. Tubes

Towers, Number/Dia, ft

\section{COST SUMMARY}

Cooling System mills/kWh

Capacity, mi11s/kWh

Scaling, mills/kWh

Energy, mills/kWh

Base Fuel, mills/kWh

0\&M, mi11s/kWh

Total Incr. Cost, mil1s/kWh
8.54

25.6

18.4

.0165

.0064

18.5

$34 / 60$

2.05

25.6

6.36

45.6

5.85

47.9

54.1

$4450 / 80$

$6142 / 80$

3.85

3.14

79,800

$8 / 173$

90,000

$13 / 147$

1.77

2.07

0.27

0.27

0.23

0.23

0.09

0.09

0.16

0.16

0.10

0.11

2.63

2.94 
turbine back pressure is about 2 inches Hga. The turbine is purchased on the basis of its output at the rating back pressure. This is 3.5 inches $\mathrm{Hga}$ for the modified conventional turbine. Therefore, for the design using a $50^{\circ} \mathrm{F}$ design temperature, a turbine with a rated output of about 990 MWe would be satisfactory. The design using a $100^{\circ} \mathrm{F}$ design temperature requires a turbine with a rated output of about 1070 MWe. The entire base plant and steam supply system must be scaled up to correspond to the rated output of the turbine. The cost, about $\$ 440,000 /$ MWe for the output above 1000 MWe, is included in the scaling cost. For rated output below 1000 MWe this represents a cost reduction. Additional scaling to provide auxiliary power for fans and pumps does not change significantly with design temperature.

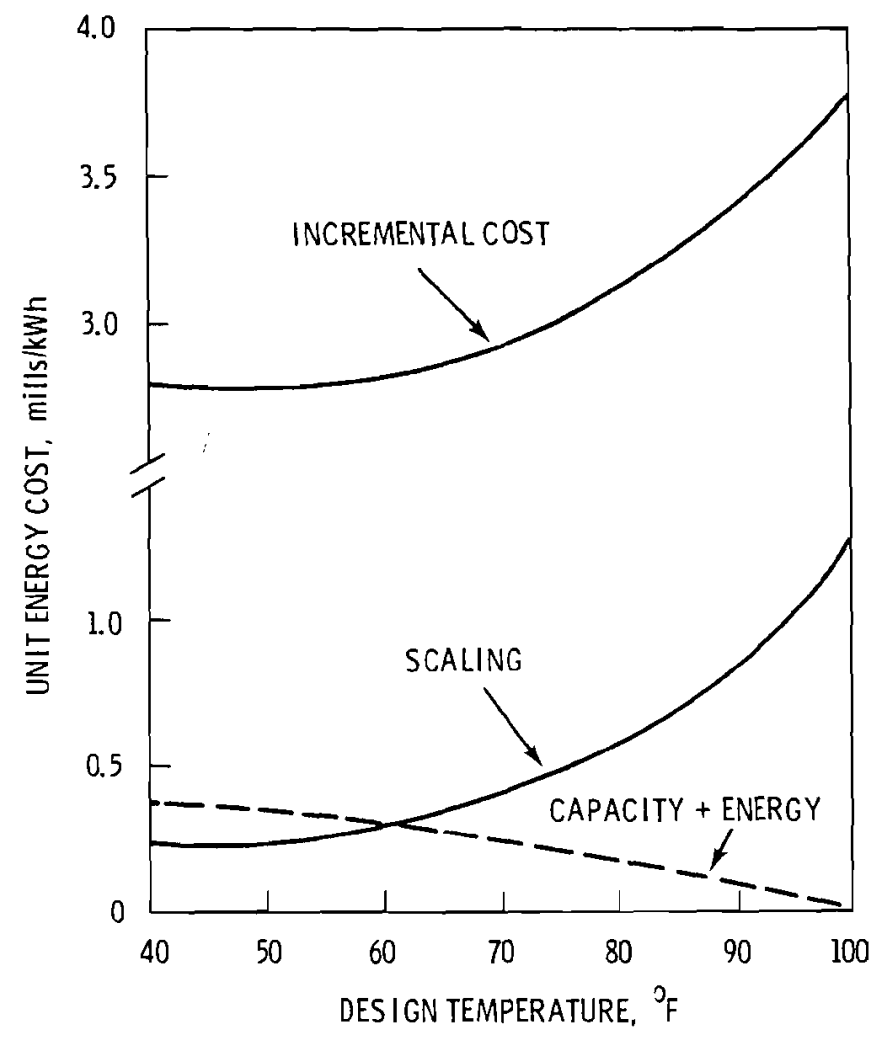

FIGURE 6-12. Cost Parameters Versus Design Temperature 
TABLE 6-14. Comparison of Optimized Designs for

Two Design Temperature

$\frac{\text { Design Temperature, }{ }^{\circ} \mathrm{F}}{50}-\frac{100}{10}$

\section{DESIGN PARAMETERS}

Air Flow Rate, $10^{8} \mathrm{lb} / \mathrm{hr}$

Air Range, ${ }^{\circ} \mathrm{F}$

Air Velocity, ft/sec

$\Delta P_{\text {air, H. X. }}$ psi

$\Delta P_{\text {air, discharge, psi }}$

Fan Power, MWe

Fans, Number/Dia, ft

Water Flow Rate, $10^{8} \mathrm{1b} / \mathrm{hr}$

Water Range, ${ }^{\circ} \mathrm{F}$

Pump Power, MWe

ITD, ${ }^{\circ} \mathrm{F}$

U, Btu $/ \mathrm{hr} / \mathrm{ft}^{2}{ }^{\circ}{ }^{\circ} \mathrm{F}$

H. X. Heat Transfer Area $106 \mathrm{ft}^{2}$

H. X. Width/Length, ft/ft

$H$. $X$. Depth, rows

Total H. X. Tubes

Towers, Number/Dia, ft

\section{COST SUMMARY}

Cooling System mills/kWh

Capacity, mills/kWh

Scaling, mills/kWh

Energy, mills/kWh

Base Fuel, mills/kWh

0\&M, mills/kWh

Total Incr. Cost, mills/kWh
8.65

25.2

17.1

0.0113

0.0064

17.2

$37 / 60$

2.08

25.2

6.35

45.6

5.21

52.3

57.2

$5710 / 80$

3.27

87200

$12 / 148$

$6150 / 80$

$13 / 147$

8.88

27.8

17.9

19.3

$40 / 60$

2.39

24.8

7.28

45.4

5.12

\subsection{2 \\ .2}

95300

0.0117

0.0065

.

1.95

2.15

0.27

0

0.22

1.30

0.09

0

0.15

0.20

0.11

0.12

2.80

3.77 


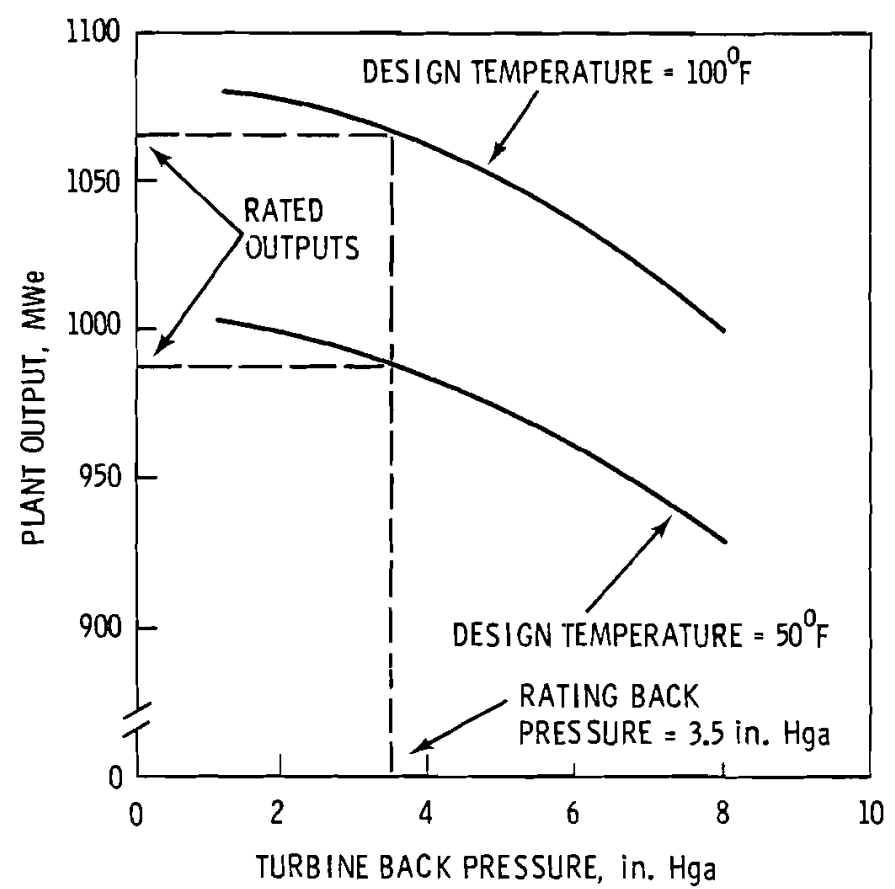

FIGURE 6-13. Plant Output Versus Turbine Back Pressure for Two Design Temperatures 


\subsection{PARAMETRIC STUDIES OF PLASTIC TUBE HEAT EXCHANGER DRY COOLING SYSTEMS}

The dry cooling tower PLASTIC system proposed by PNL is an americanized version of an Italian concept for heat rejection from major power plants. Italimpianti of Italy is a commercial firm promoting the sale of a natural draft heat rejection system using plastic tubes as the heat transfer surface. A 75-MWe natural draft PLASTIC system is being built by Italimpianti as a demonstration plant, scheduled for startup up in 1978. The system proposed by PNL is a forced draft version of this concept.

Because the system proposed by PNL is an original concept, basic knowledge of system optima was nonexistent. Therefore the parametric studies described in this section were conducted to provide that information. Most of the studies described in this section deal with parameters which are external to the optimization routine of the computer code. Some parameters which are a part of the internal optimization routine of the code have been varied to determine their effect on the cost of the system.

\subsection{GENERAL CONS.IDERATIONS}

The PLASTIC system differs from $\mathrm{SOA}$ and $\mathrm{NH}_{3}$ systems in two respects: heat transfer surface area and physical size. The heat transfer surface area consists of bare tube bundles. Plastic tubes exhibit no corrosion problems as do metal finned tubes. The failure mechanisms of both polyethylene and polypropylene which are used in this study are primarly related to chemical degradation due to ultraviolet light and to chemical reactions. This is usually described as "weathering" or "aging". In addition, these plastics can fail in creep if excessive stress levels occur for long periods of time.

The physical size of some of the components of the PLASTIC system is significantly larger than that of $\mathrm{SOA}$ and $\mathrm{NH}_{3}$ system components. This becomes evident when comparing the frontal area of the heat exchanger of each system. The PLASTIC system is from $1-1 / 2$ to two times larger than the other systems in this respect. 
In addition, the total volume of water in the PLASTIC system is about twice that of the SOA system. Because of this extra size, configurations not effective in reducing the cost of dry cooling for $\mathrm{SOA}$ and $\mathrm{NH}_{3}$ systems are effective in reducing the incremental cost of the PLASTIC system. These configurations are explored in the parametric studies explained in this section.

The PLASTIC system was optimized according to constraints listed in Section 4.1. The parametric studies described here are compared on the basis of these constraints. Some constraints 1 isted in Section 4.1 were varied to determine their effect on the cost and physical dimensions of the PLASTIC system. Additional parameters requiring specification to completely define the base case for the PLASTIC system are:

- tube arrangement - staggered (equilateral spacing)

- tube outside diameter -0.250 in.

- tube wall thickness - 0.10 of outside diameter

- tube pitch - 0.50 in.

- $\quad$ tube material - polyethylene

- $\quad$ piping design velocity - $12.0 \mathrm{ft} / \mathrm{sec}$

- heat exchanger arrangement - delta

- maximum allowable back pressure of the turbine - 8.0 in. Hga.

Unless otherwise specified, all parametric studies were made using the general design basis outlined in Section 4.1 and the restrictions listed above.

The following PLASTIC system parameters were varied to determine their effect on the cost of the system.

- Heat exchanger configuration - delta versus nondelta

- Fan discharge - with and without recovery stacks

- Fan spacing - packing factor 
- Towers - number of towers

- Tube arrangement - inline and staggered

- $\quad$ Outside diameter of plastic tube

- Transverse and longitudinal pitch

- Tube materiat

- Turbine back pressure - conventional and modified conventional turbines

- Piping system design velocity.

Each parametric variation is discussed in the following sections.

\subsection{TOWER ARRANGEMENTS}

In determining the optimum tower arrangements for the PLASTIC system, three parameters were varied to minimize the incremental cost of the system:

- Fan spacing - packing factor

- Heat exchanger configuration - delta and nondelta

- Fan discharge - diffused and nondiffused.

The packing factor is the ratio of the total surface area on top of the circular tower over the total fan swept area per tower. Restricting the fan system design to 28-foot diameter fans, the packing factor was varied from 3.0 to 1.5 for four different combinations of heat exchanger configuration and fan discharge method.

The results of three of the combinations are given in Figure $7-1$. As shown, the curves representing data with a delta heat exchanger arrangement show a significant reduction in cost over that of the nondelta heat exchanger arrangement. Only a slight decrease in incremental costs is shown in the cases where velocity recovery stacks are used with the fan system. The results of the nondelta heat exchanger configuration without velocity recovery stacks were not included in Figure 7-1 due to their close proximity to the nondelta curve with velocity recovery stacks. 


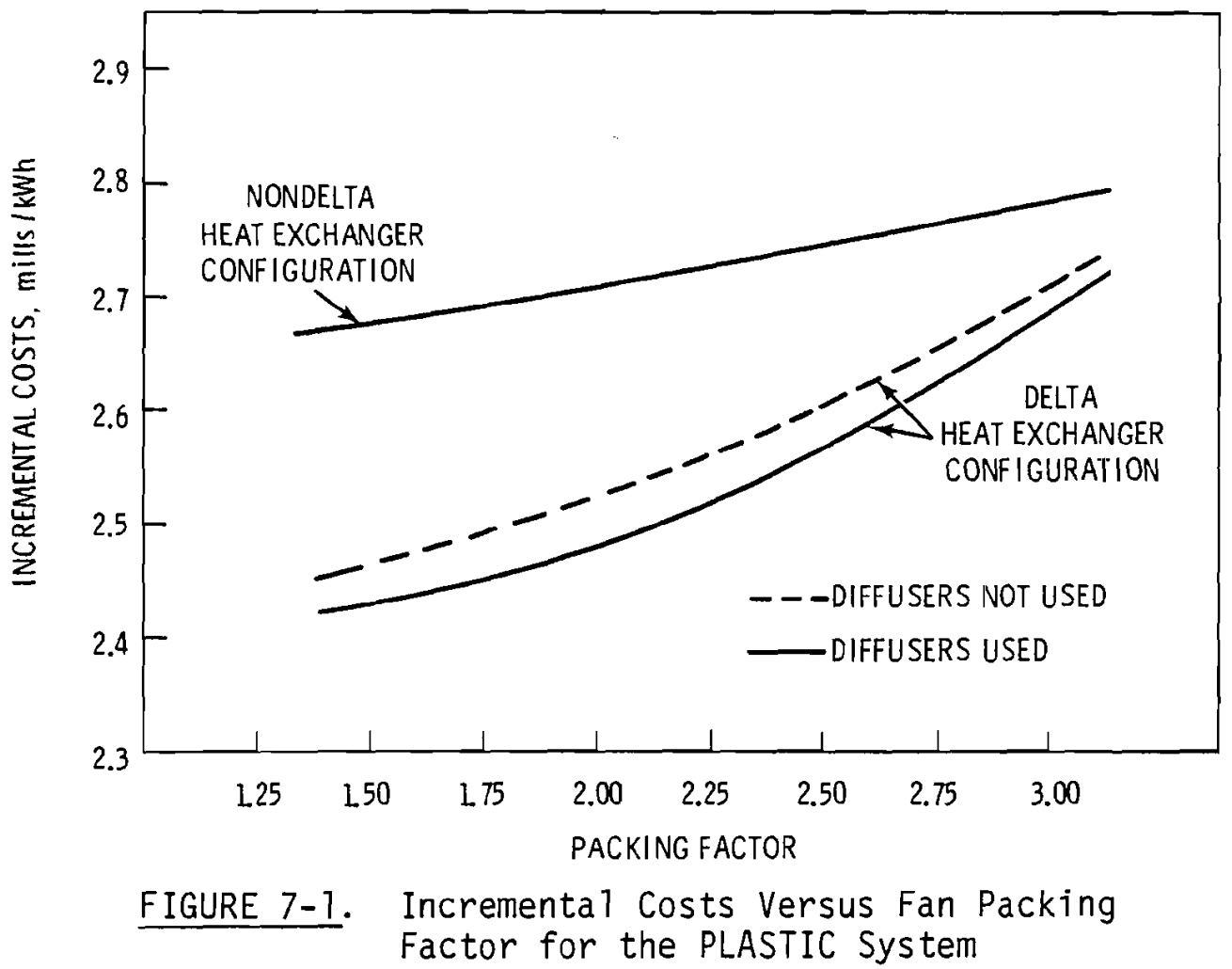

The maximum number of fans that can be placed on a circular tower is limited by geometric constraints such as fan and tower diameter. Several fan arrangements are possible for each set of geometric constraints. The optimimum fan arrangement dictates the minimum packing factor.

When using velocity recovery stacks on a fan system, the diameter of the fans must be increased to allow for the overhang of the stacks. The entry bell of the fan must also be accounted for by increasing the effective fan diameter when determining the optimum fan arrangement.

The optimum packing factor was determined to be 2.0 , based on the following method.

The optimum fan arrangement was determined for each case on the bas is of fan and tower diameters from the computer code. From this arrangement the maximum number of fans for each tower system design was determined. This was in turn compared against the number of fans found as the optimum by the 
computer code. If the total from the optimization code was less than the maximum number of fans allowed by geometric constraints, then the run was considered to be valid.

The optimum heat exchanger configuration for the PLASTIC system is shown to be the delta arrangement according to Figure 7-1. The optimization procedure does not account for the maldistribution of air flow through the cooling deltas. Its effect on the results is not presently known.

The difference in cost between the diffused and nondiffused cases is very small when compared to the total cost of dry cooling; the decision was made somewhat arbitrarily in favor of velocity recovery stacks because they do conserve energy.

An additional parametric study of the effect of the number of towers on the incremental cost of the PLASTIC system was made. The tower number parameter is internally optimized by the code but an external option is available for limiting the allowable number of towers in the design. For this study, the number of towers was limited to values either less or greater than the optimum number of towers. The fan system design was not limited to a specific fan diameter as in the previous parametric studies.

In the region in which the number of towers was limited to less than the optimum, the incremental costs increase at a faster rate than for those cases where the number of towers was greater than the optimum. In the region of a small number of large diameter towers, the structural costs increase significantly over the optimum case. For a large number of smal1 diameter towers, the piping cost of the system becomes large.

The optimum tower arrangement was found to be four 243-foot diameter towers with 60-foot diameter fans. If the fan system design was restricted to 28-foot diameter fans, the optimum arrangement was found to be six 196-foot diameter towers. The difference in incremental costs between the two designs was less than one percent. As seen in Figure 7-2, there is a region of four to six towers over which the incremental costs are fairly constant. 


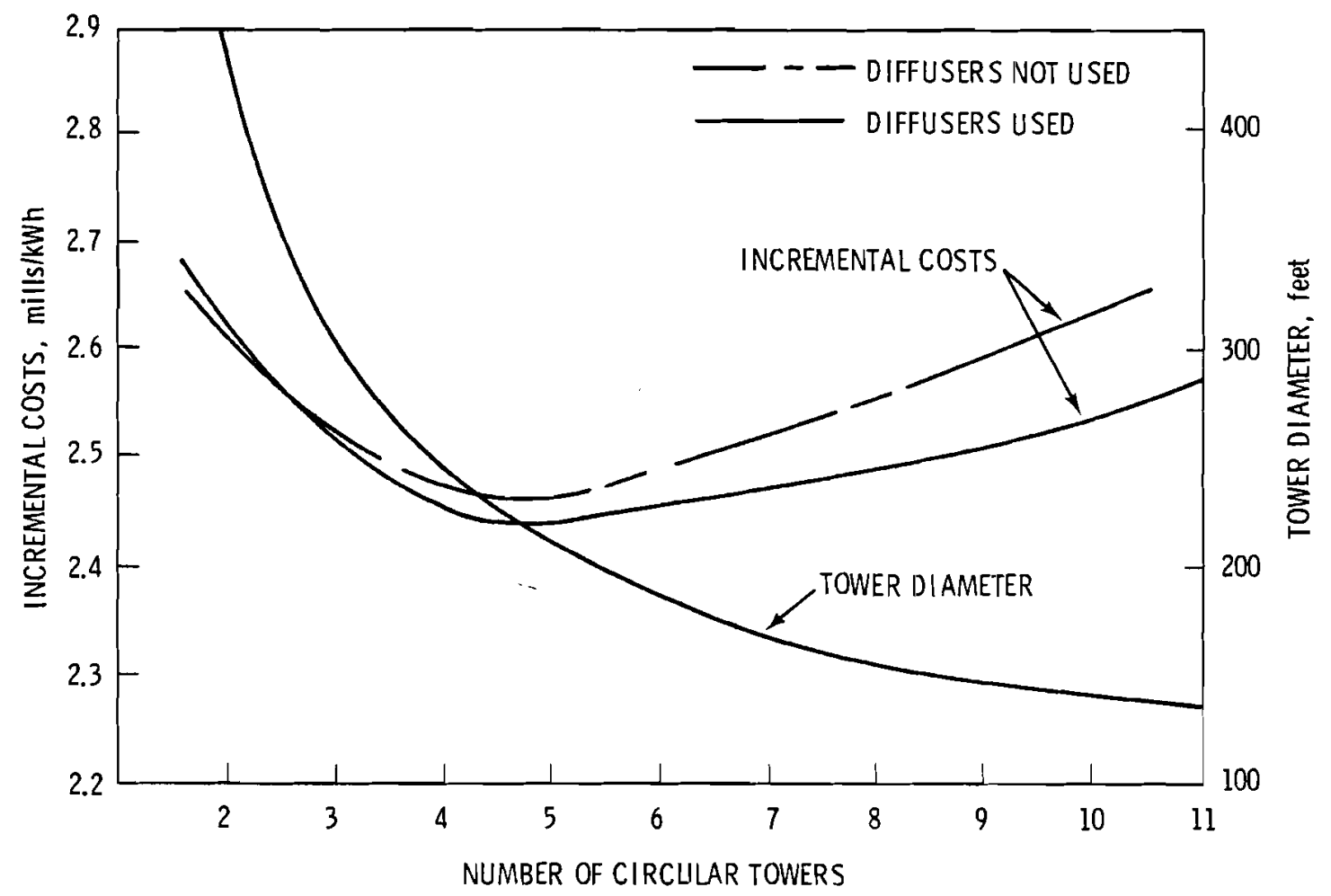

FIGURE 7-2. Incremental Costs and Tower Diameter Versus Number of Circular Towers for the PLASTIC System

In summary, the optimum tower arrangement values obtained from these parametric studies were:

- fan spacing - packing factor 2.0

- heat exchanger configuration - delta

- fan discharge - velocity recovery

- number of towers - 4 to 6 .

\subsection{HEAT EXCHANGER}

The parametric studies of heat exchanger geometry and tube material were performed for two distinct heat exchanger tube arrangements. For the inline and staggered tube arrangements, the parameters varied were: 
- $\quad$ tube outside diameter

- transverse and longitudinal pitch

- $\quad$ tube material

The transverse pitch is the centerline-to-centerline distance of adjacent tubes normal to the air flow through the heat exchanger bundle. The longitudinal pitch is the centerline-to-centerline spacing of adjacent tube rows in the direction of air flow.

\subsubsection{Staggered Tube Arrangement}

For the staggered tube arrangement, the outside diameter of the plastic tubes was varied from $0.125 \mathrm{in}$. to $1.000 \mathrm{in}$. with a transverse pitch equa 1 to twice the outside diameter. The tube wal1 thickness was set equal to one-tenth the outside diameter based upon long-term strength requirements. The tube arrangement of adjacent rows was set equal to an equilateral spacing. This sequence of runs considered two different tube materials: polyethylene and polypropylene.

The results of these parametric variations are presented in Figure 7-3. As indicated, the polyethylene material gives the minimum cost for a particular outside diameter. Both materials have a greater than 30-year 1 ife expectancy at the temperatures and pressures common to this system. The polyethylene has a lower creep temperature, higher thermal conductivity, and costs the least of the two materials. Polypropylene was found to give higher incremental costs in comparison with the polyethylene cases.

The optimum outside tube diameter is shown to be 0.1875 in. according to the cost studies made. A tube diameter of $0.250 \mathrm{in}$. was selected though as the optimum due to the following reasons. The total number of tubes for the PLASTIC system having tube outside diameter of $0.250 \mathrm{in}$. is significantly less than for the 0.1875-in. diameter tube system. Due to the uncertainty of the heat exchanger cost model for a large number of smal1 tubes, the larger diameter tube was selected. Also, for the small diameter tube the drain time of such a system might be too long, resulting in a freezing problem during the winter at shutdown. 


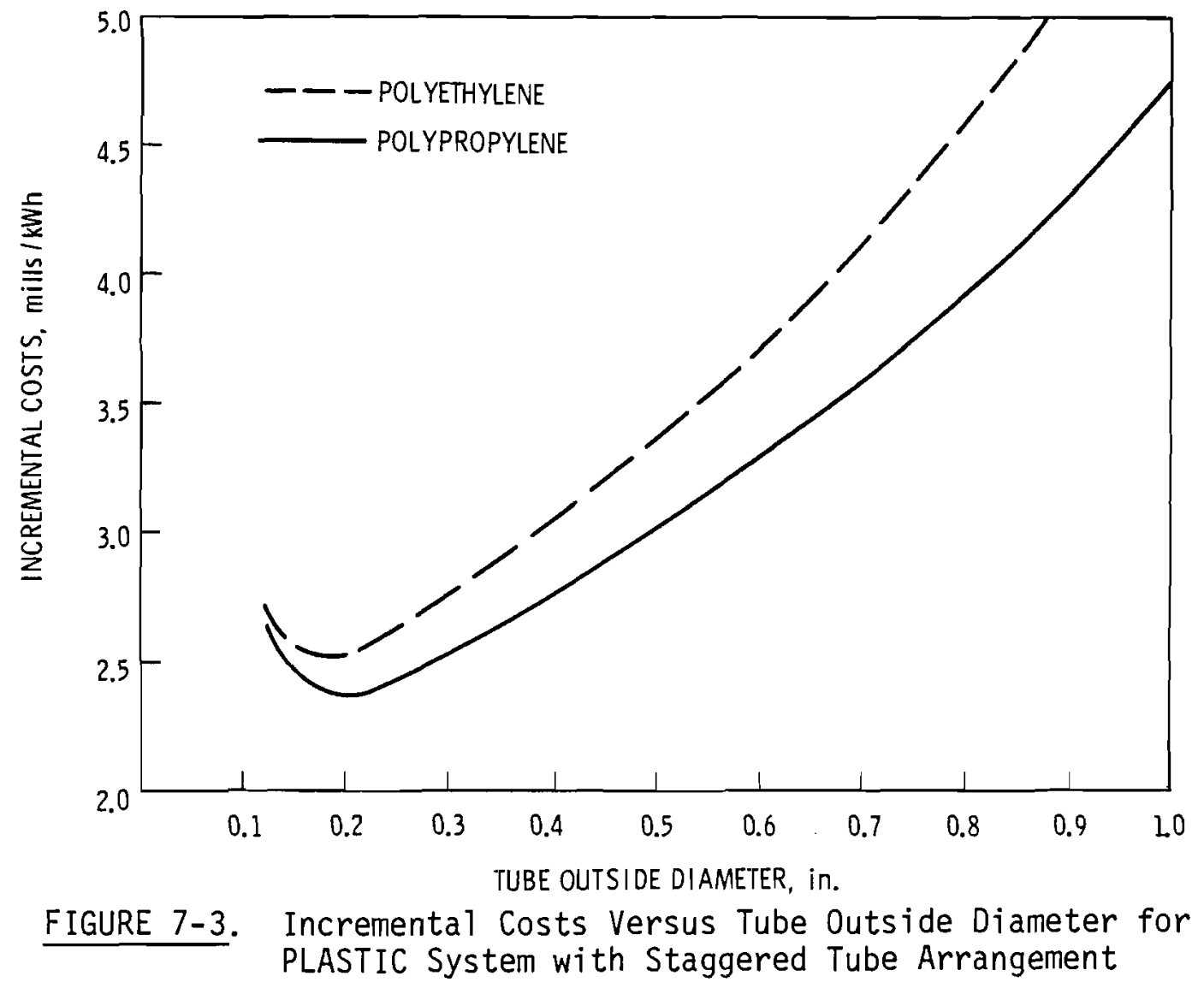

The ratio of tube transverse pitch to outside diameter was also varied for the staggered tube arrangement using polyethylene tube material only. The tube arrangement of adjacent rows was held to an equilateral tube spacing. As shown in Figure $7-4$, the ratio was varied from 1.5 to 4.0 for three different tube diameters ( $0.375 \mathrm{in.}, 0.250 \mathrm{in.,} 0.1875 \mathrm{in.})$. The optimum tube transverse pitch-to-outside diameter ratio is two.

In summary, the optimum values obtained from these staggered tube parametric studies are:

- tube outside diameter -0.250 in.

- tube transverse pitch -0.500 in.

\subsubsection{Inl ine Tube Arrangement}

For the inline tube arrangement, the outside diameter of the plastic tube was varied from $0.125 \mathrm{in}$. to $1.000 \mathrm{in}$. The transverse and longitudinal 


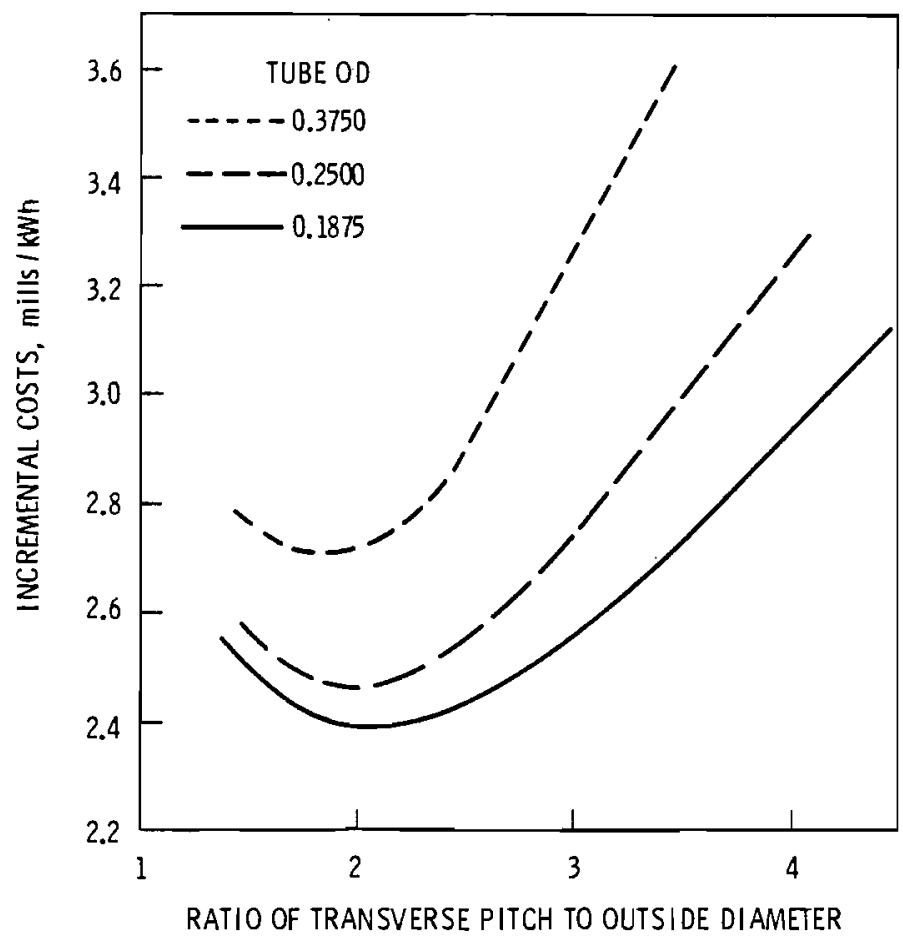

FIGURE 7-4. Incremental Costs Versus Transverse Pitch for PLASTIC System with Staggered Tube Arrangement

tube pitch was set equal to twice the outside diameter. The tube wall thickness was set equal to one-tenth the tube outside diameter. Again, these computer runs were made with polyethylene and polypropylene as the heat exchanger material.

The results of these parametric studies are presented in Figure 7-5. The relative position of polyethylene versus polypropylene is unchanged from that of the staggered tube arrangement. The optimum diameter of the inline tubes was found to be the same as that of the staggered tube arrangement: $0.1875 \mathrm{in}$. An outside tube diameter of $0.250 \mathrm{in}$. would be chosen as the most practical on the basis of arguments presented for the staggered tube arrangement.

The ratio of tube transverse pitch to tube outside diameter was varied for the inline tube arrangement. In this run sequence, the longitudinal pitch was set equal to the tube transverse pitch so that tubes in adjacent rows formed a square arrangement. The ratio of tube transverse pitch to 


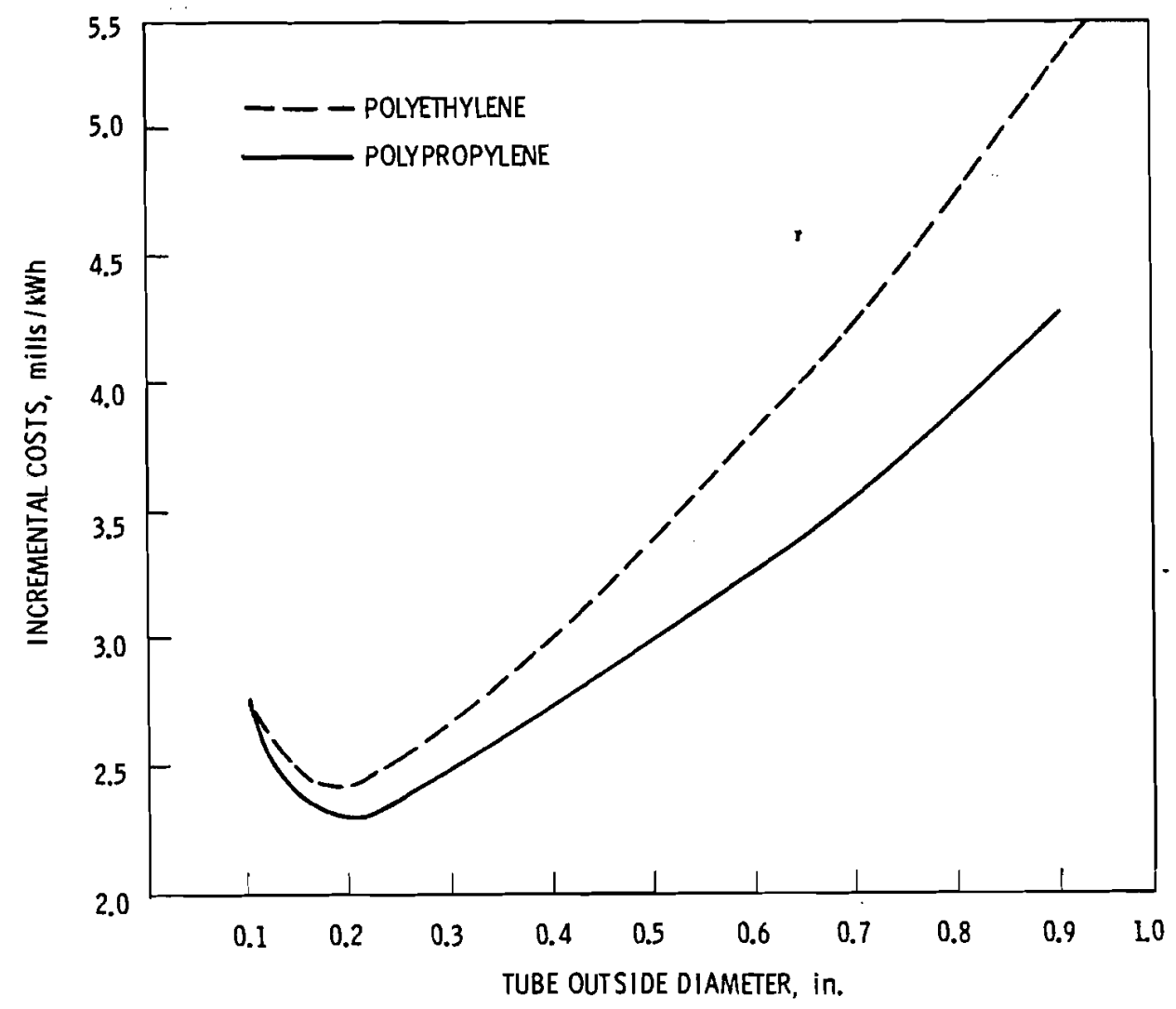

FIGURE 7-5. Incremental Costs Versus Tube Outside Diameter for PLASTIC System with Inl ine Tube Arrangement

outside diameter was varied from a value of 1.5 to 4.0 for three different tube outside diameters ( 0.375 in., 0.250 in., 0.1875 in.).

The results are given in Figure 7-6. The optimum tube transverse pitch lies between 1.5 and 2.0 times the tube outside diameter.

The ratio of tube longitudinal pitch to tube outside diameter was also varied for the inline tube arrangement. In this sequence of runs, the tube transverse pitch was set equal to twice the tube outside diameter.

Again, the range of values over which the ratio of tube longitudinal pitch to tube outside diameter was varied was 1.5 to 4.0 for the tube outside diameters of $0.375 \mathrm{in.}, 0.250 \mathrm{in.}$, and $0.1875 \mathrm{in}$.

The results are presented in Figure 7-7. In the region to the left of the vertical line, correlations for the friction factor through banks of inline bare tubes (see Appendix) were not verified by experimental data. The 


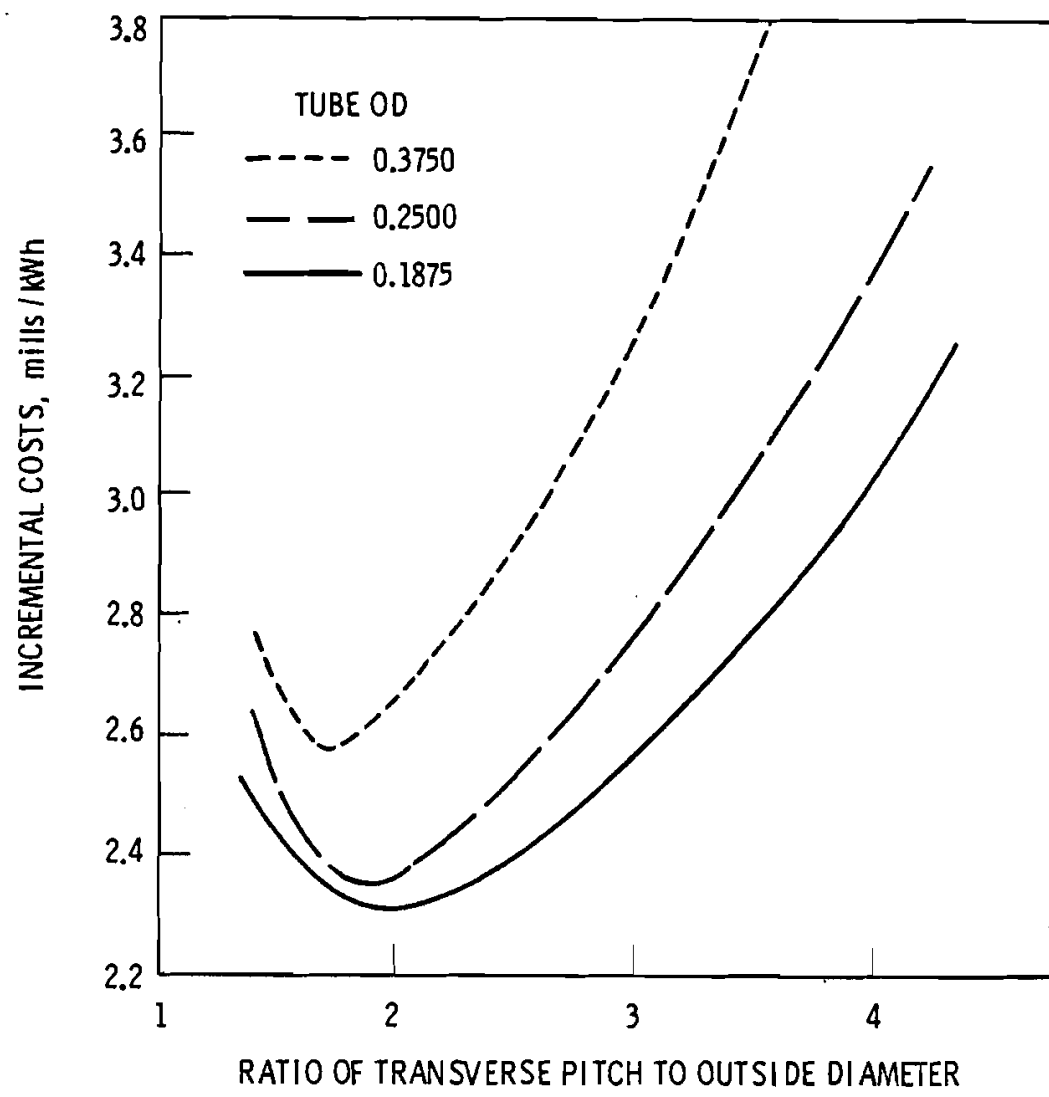

FIGURE 7-6. Incremental Costs Versus Transverse Pitch for PLASTIC System with Inl ine Tube Arrangement

curves to the left of this line do not represent the results of computer optimization runs. Instead, this portion of the curves is given to show the general trend that is expected in this region. The vertical line corresponds to a value of 1.5 for the ratio of longitudinal pitch to tube outside diameter. The minimum cost for each sequence of runs corresponds to this limit.

The spacers for the plastic tube heat exchanger are positioned at intervals along the tube for the purpose of tube alignment and support. However, because of the flexibility of the plastic tubing there is an uncertainty as to the position of the tubes between the spacers. The tubes are therefore capable of meandering between an inline to staggered tube arrangement no matter what arrangement is selected. As a result, the pressure drop and air-side heat transfer coefficients cannot be calculated 


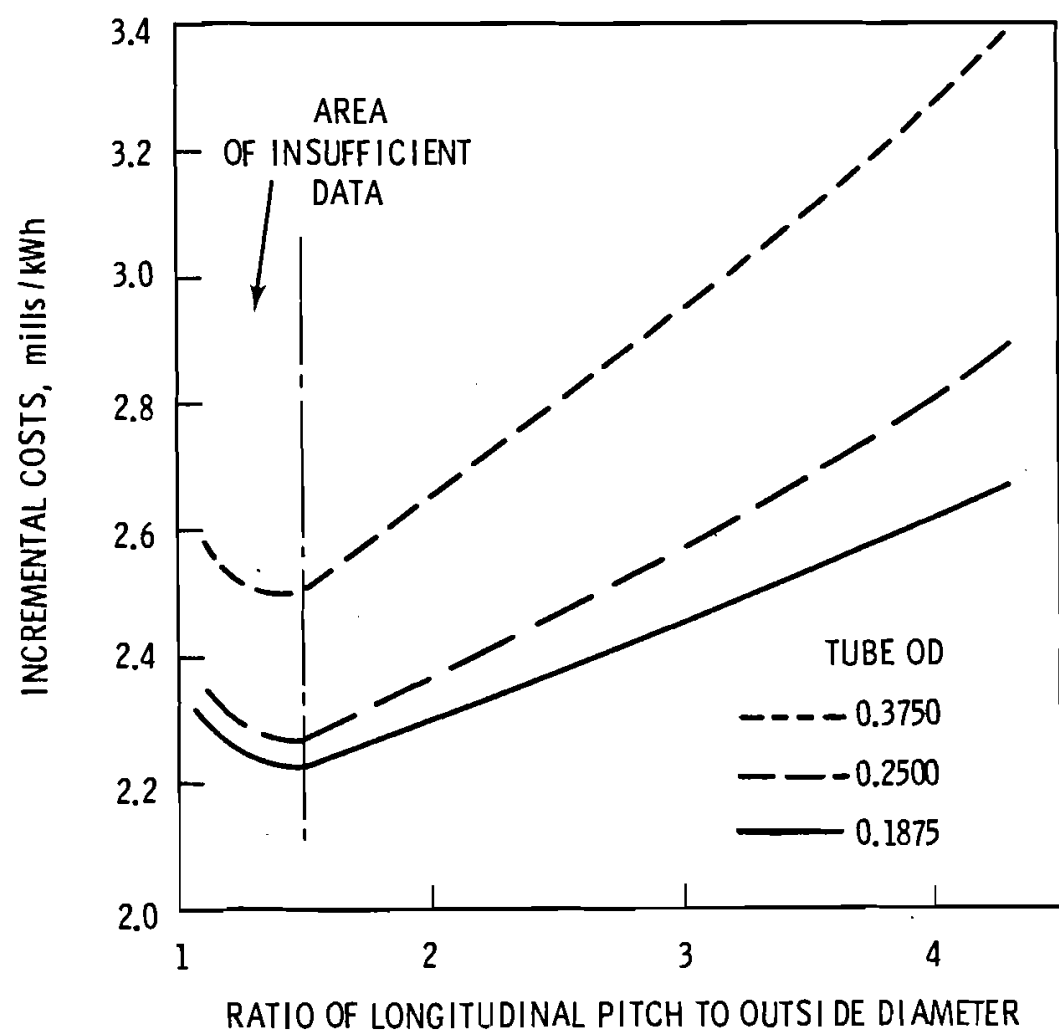

FIGURE 7-7. Incremental Costs Versus Longitudinal Pitch for PLASTIC System with Inl ine Tube Arrangement

with enough accuracy to justify the selection of one arrangement over another. Therefore the staggered tube arrangement was arbitrarily selected over the inline tube arrangement.

In summary, the optimum values obtained from these inline tube parametric studies are:

- tube outside tube diameter - 0.250 in.

- tube transverse pitch - 0.500 in.

- tube longitudinal tube pitch -0.375 in.

\subsection{TURBINE}

The three turbine types presently under development or in operation are described in Section 6.3. Trade-offs between the various turbine types and the SOA dry cooling system are also discussed in that section. The 
general conclusions and relationships between turbine type and cooling system outlined there apply to the PLASTIC dry cooling system as well.

In this parametric study, emphasis was placed on determining the effect of the maximum yearly turbine back pressure on the incremental cost of the PLASTIC system. This was done for a fossil-fueled turbine generator.

A sequence of computer runs was made in which the maximum turbine back pressure of the year was varied over a range of values for conventional (5.0 to $6.0 \mathrm{in.} \mathrm{Hga)}$ and modified conventional $(5.0$ to $11.0 \mathrm{in}$. Hga) turbines. The data from these computer runs are presented in Figure 7-8 in the form of incremental costs versus maximum yearly turbine back pressure curves.

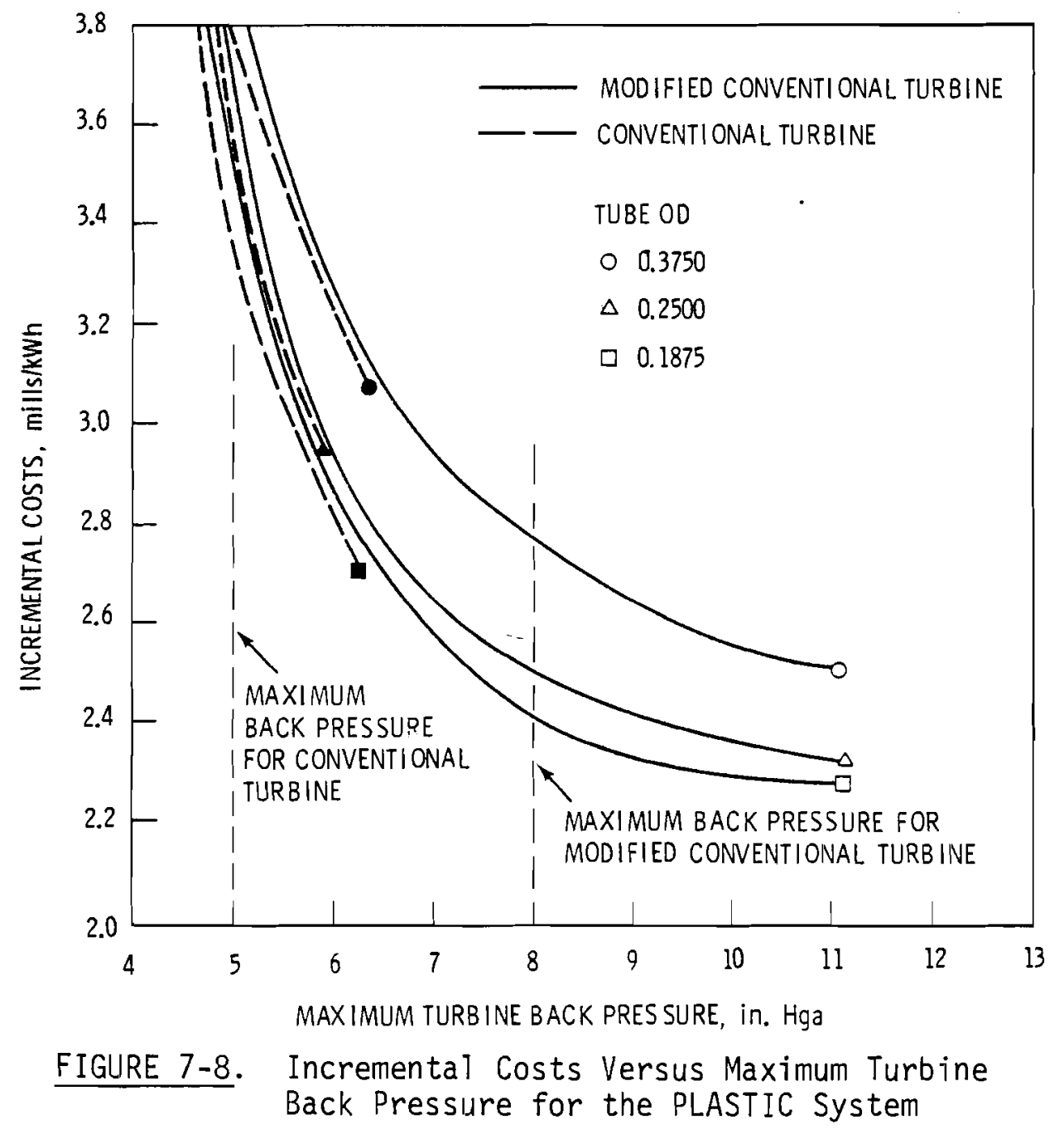


For the modified conventional turbine there is a large reduction in incremental costs up to a maximum back pressure of $8.0 \mathrm{in.} \mathrm{Hga.} \mathrm{For} \mathrm{the}$ near optimum tube diameters ( $0.1875 \mathrm{in}$. and $0.250 \mathrm{in.})$ there is only a slight decrease in incremental cost beyond this point. The system using the $0.375 \mathrm{in}$. tube diameter does show a larger savings in this area.

In the region of low back pressures ( 4.0 to $6.0 \mathrm{in.} \mathrm{Hga.)} \mathrm{the} \mathrm{system}$ using the conventional turbine has only a slight advantage over the system using the modified conventional turbine.

A cooling system design and cost summary is given in Table 7-1 for PLASTIC systems using conventional, modified conventional, and high back pressure turbines. The cost summary terms are defined in Section 6.1. The maximum yearly turbine back pressure was limited according to the particular turbine used:

- Conventional turbine - 5.0 in. Hga.

- Modified conventional turbine $-8.0 \mathrm{in}$. Hga.

- High back pressure turbine -8.0 in. Hga

The high back pressure turbine was limited to $8.0 \mathrm{in}$. Hga. due to the temperature limitation on the polyethylene heat exchanger tubes. If the maximum yearly turbine back pressure is raised to the 15.0 in. Hga. limit for the high back pressure turbine, then the incremental cost of the PLASTIC system drops to $2.41 \mathrm{mi} 11 \mathrm{~s} / \mathrm{kWh}$.

The effect of heat exchanger ITD on the size and cost of an SOA dry cooling system was discussed in Section 6.8. The size of the plastic tube heat exchanger is inversely dependent upon the ITD. Without any constraints on the maximum turbine back pressure the optimum ITD of the PLASTIC system is found to be 5 to $10^{\circ} \mathrm{F}$ higher than for the SOA system. This is dependent upon the type of turbine and the site meteorology used.

The conclusions also arrived at in Section 6.8 on the combined effect of ITD and turbine type hold true for the PLASTIC system. One disadvantage of the PLASTIC system is the limit on the maximum turbine back pressure due to the yield strength of the plastic tubing. The ITD of the heat exchanger 
TABLE 7-1. Comparison of Optimized Design and Cost Data for PLASTIC A1l-Dry Cooling Systems Using the Three Turbine Types - Fossil

\begin{tabular}{|c|c|c|}
\hline & מ & High Back \\
\hline Conventi & Conventional & Pressure \\
\hline
\end{tabular}

DESIGN PARAMETERS

Air Flow Rate, $10^{8} 1 \mathrm{bm} / \mathrm{hr}$

9.22

7.02

7.22

Air Range, ${ }^{\circ} \mathrm{F}$

23.3

31.1

32.9

Air Velocity, $\mathrm{ft} / \mathrm{sec}$

9.0

12.2

10.6

$\Delta P_{\text {air, }} H X, P s i$

0.0930

0.0140

0.0105

$\Delta P_{\text {discharge, }} p{ } i$

0.0059

0.0053

0.0065

Fan Power, MW

15.8

15.3

14.0

Fans, number/dia

Water Flow Rate, $10^{8} 1 \mathrm{bm} / \mathrm{hr}$

$4.1 / 60$

$33 / 60$

$31 / 60$

Water Range, ${ }^{\circ} \mathrm{F}$

4.78

2.02

2.15

10.8

25.9

26.6

Pump Power, MW

15.3

6.7

6.0

ITD, ${ }^{\circ} \mathrm{F}$

28.0

45.6

47.4

U, Btu/hr/ft ${ }^{2}-^{\circ} \mathrm{F}$

12.8

14.9

13.8

Heat Transfer Area, $10^{6} \mathrm{ft}^{2}$

46.2

22.7

26.2

Width/Length, $\mathrm{ft} / \mathrm{ft}$

$11020 / 80$

$6244 / 80$

$7413 / 80$

Tube Depth, rows

33.4

28.9

28.1

Total Tubes, $10^{6}$

8.820

4.335

5.008

Towers, number/dia, ft

$10 / 170$

$4 / 243$

$6 / 193$

\section{COST SUMMARY}

$\begin{array}{llll}\text { Cooling System, mills/kWh } & 2.83 & 1.66 & 1.82 \\ \text { Capacity, mills/kWh } & 0.14 & 0.27 & 0.06 \\ \text { Scaling, mills/kWh } & 0.23 & 0.20 & 0.39 \\ \text { Energy, mills/kWh } & 0.04 & 0.09 & 0.05 \\ \text { Base Fuel, mills/kWh } & 0.12 & 0.14 & 0.53 \\ \text { O\&M, mills/kWh } & 0.16 & 0.10 & 0.10 \\ \text { Total Incr. Cost, mills/kWh } & 3.52 & 2.46 & 2.95\end{array}$


is therefore limited for a particular site meteorology. With an upper limit on the ITD a dry cooling system of increased size is required to handle the heat load.

Further definition of the temperature limits of high density polyethylene and other candidate materials is needed to determine if the incremental cost of the PLASTIC dry cooling system can be reduced.

\subsection{PIPING SYSTEM WATER DESIGN VELOCITY}

In this section the results of the parametric evaluation of the piping system water design velocity are presented. The piping system design and cost model is presented in Reference 16. The water design velocity is one of several variables that determine the piping system costs. However, it is the only significant parameter that could be externally optimized using the optimization code.

Section 6.5 discusses the trade-offs of water design velocities versus pump power and capital cost of the piping system. For the PLASTIC system this trade-off is shown in Figure 7-9. The effect of piping design pressures on the incremental cost of a dry cooling system was also discussed in Section 6.5. A comparable study was made for the PLASTIC system. In this study the piping system was designed using three different design pressures: 50 psi, 75 psi, and 125 psi.

Summing up the dynamic head across the pump system and static head of the circular towers, a total pressure of the optimum PLASTIC system was found to be $66.7 \mathrm{psi}$. This gives a safety factor of approximately 2.0 for the steel pipes and is well within the allowable stress of the plastic tubing.

The piping design velocity was varied from 4.0 to $20.0 \mathrm{ft} / \mathrm{sec}$ for three different heat exchanger tube diameters. The results of the parametric evaluation of the piping system water design velocity are presented in Figure 7-10. No significant decrease in cost of the PLASTIC system is gained 


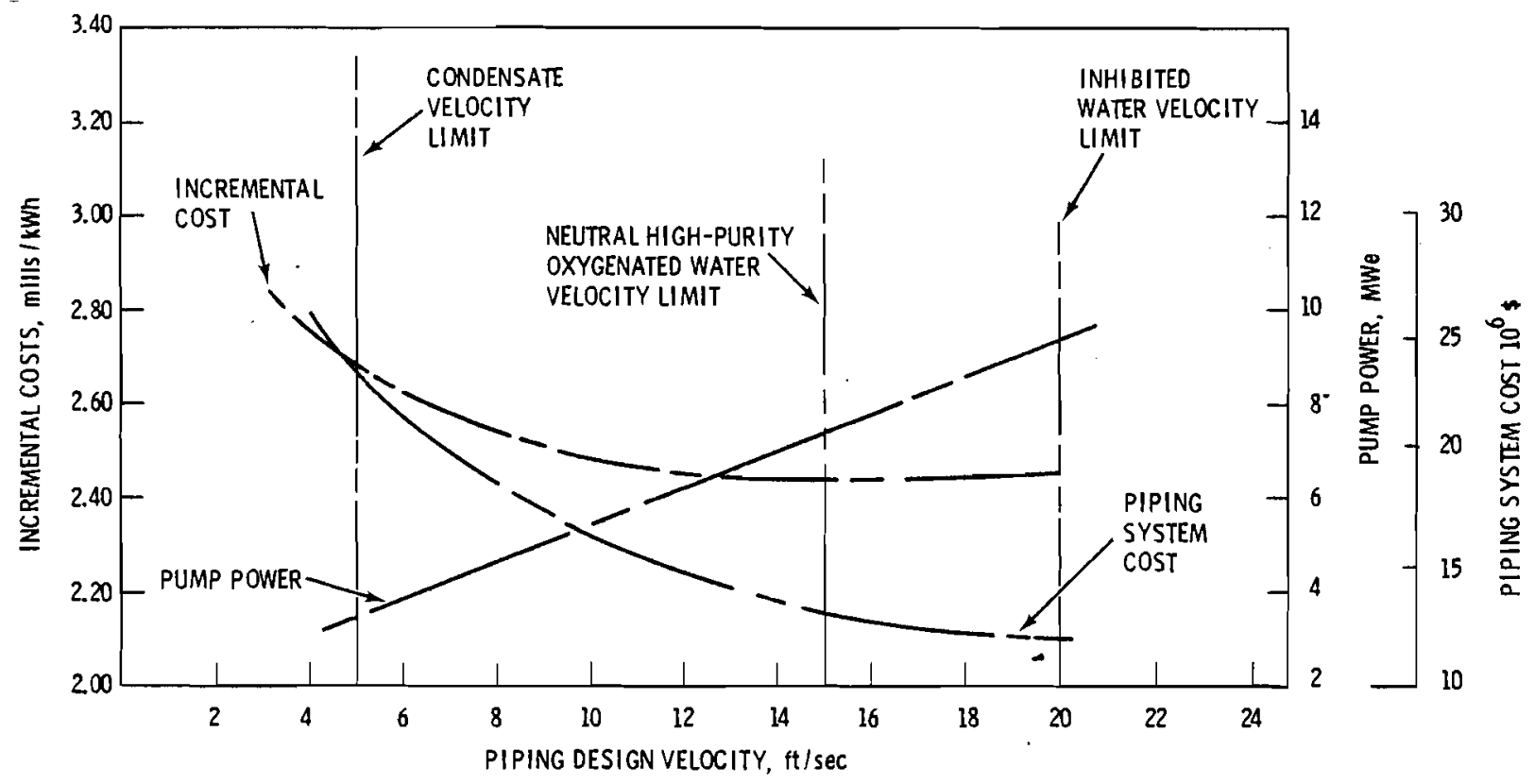

FIGURE 7-9. Incremental Costs, Pump Power, and Piping System Cost Versus Piping Design Velocity for the PLASTIC System

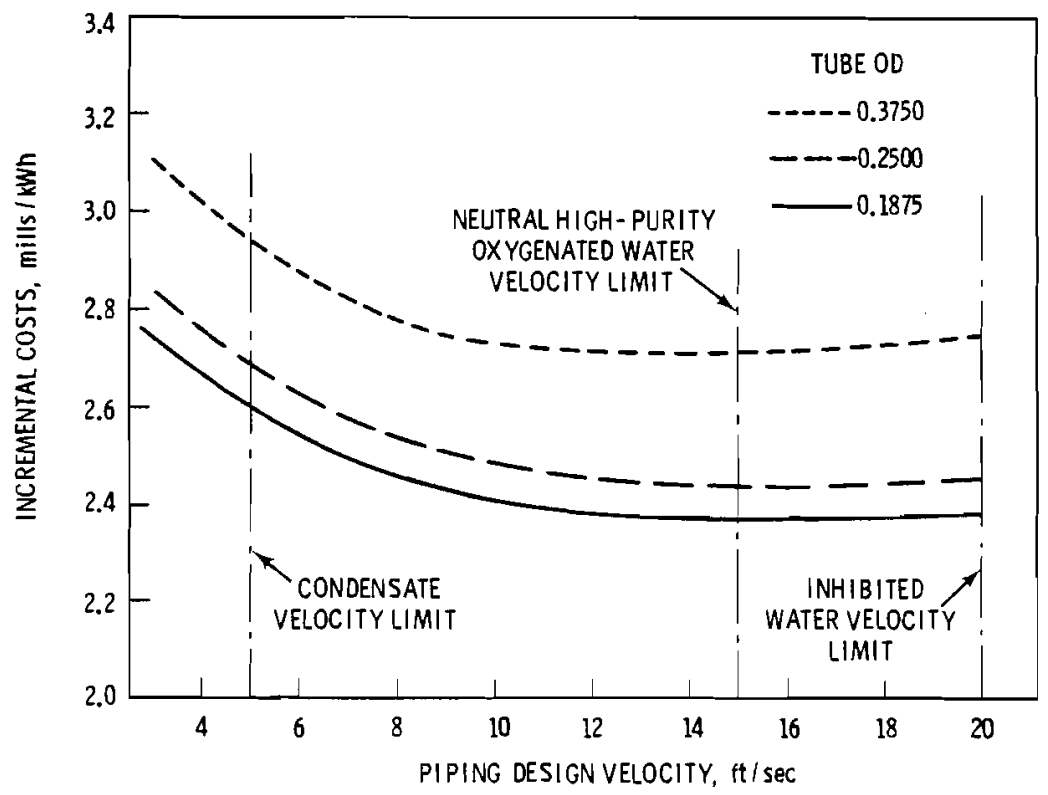

FIGURE 7-10. Incremental Costs Versus Piping Design Velocity for the PLASTIC System 
for a piping design velocity greater than $12.0 \mathrm{ft} / \mathrm{sec}$. Between 12 and $20 \mathrm{ft} / \mathrm{sec}$, incremental cost remains unchanged as there is an even trade-off between the capital cost of the piping system and the cost of the pumping power.

\subsection{CONDENSER}

The type of condenser used in the PLASTIC system analysis was the two-pass, two-she11, single pressure surface condenser. Admiralty was used as the condenser tubing. Additional savings may be achieved by using a cheaper tubing in the condenser for the PLASTIC system. Materials compatibility concerns are greatly reduced with the use of plastics.

The terminal temperature difference (TTD) for the condenser has not been optimized for the PLASTIC system. A11 cases were run with a TTD of $5^{\circ} \mathrm{F}$ which is probably near optimum. For a discussion of the effect of TTD on the incremental power production costs, the reader is referred to Section 6.4.

\subsection{GENERAL COMMENTS}

Several other subsystems of the PLASTIC system are not directly related to the type of heat exchange surface used. These subsystems have been covered thoroughiy in Section 6.0 as part of the SOA system.

One such subsystem is the fan system. This is an internally optimized system of the computer code. The fan type selected can be limited to various fan diameters depending on the input to the code.

Another subsystem is the tower configuration. An optimization of the number and size of towers is made internaity in the code. This internat optimization accounts for the size of the fan, the packing factor, and tower diameter. Sections 6.6 and 6.7 .4 contain a more complete discussion.

\subsubsection{Circular versus Rectilinear Towers}

A comparison was made between circular and rectilinear towers on the basis of incremental costs. The circular tower arrangement was found to give significantly lower costs than the rectilinear tower arrangement. Because of this, further study of the rectilinear tower arrangement was not done and cost comparisons are not available for this arrangement. 


\subsection{PARAMETRIC STUDIES OF AMMONIA LOOP COOLING SYSTEM}

The $\mathrm{NH}_{3}$ cooling system is an advanced dry cooling system which uses $\mathrm{NH}_{3}$ instead of water as the intermediate fluid. Its advantages are a high heat of vaporization and low vapor specific volume for the transporting fluid which cut the cost of piping when compared to other heat rejection systems. The isothermal heat rejection in the tower also gives cost advantages over the other systems because of the larger average temperature difference in the heat exchanger. The one disadvantage the system has is in the condenser/reboiler where enhanced heat transfer surfaces are required to keep the temperature difference sufficiently smaller than the temperature difference required for standard condenser tubing.

The two advantages mentioned above give the $\mathrm{NH}_{3}$ system a cost advantage over the SOA and PLASTIC systems if the enhanced tubing is used in the condenser/reboiler. Smaller decreases in cost can be obtained by performing a parametric study of the parameters affecting the design and cost of the cooling system.

The parametric studies performed on the $\mathrm{NH}_{3}$ system were done on the basis of the constraints listed in Section 4.0. The additional parameters that required specification to completely define the base case of the ammonia system are:

- Supply piping design velocity (vapor) - $150 \mathrm{ft} / \mathrm{sec}$

- Return piping design velocity (1iquid) - $15 \mathrm{ft} / \mathrm{sec}$

- Condenser/reboiler tube type - enhanced

- Condenser/reboiler tube material - aluminum

- Heat exchanger tube - aluminum wrap-on fin, carbon steel liner

- Heat exchanger unit geometry - optimum for SOA (Section 6.2.1)

- Heat exchanger configuration - nondelta

- Fan recovery - with recovery stacks. 
The following parameters were varied to determine their effect on the ammonia system.

- Heat exchanger configuration - delta versus nondelta

- Fan discharge - with and without velocity recovery stacks

- Fan spacing - packing factor

- Towers - number of towers

- Turbine types - conventional, modified conventional, and high back pressure

- Supply piping design velocity (vapor)

- Return piping design velocity (1iquid)

Each of the parametric variations is discussed in the following sections.

\subsection{GENERAL CONSIDERATIONS}

The $\mathrm{NH}_{3}$ dry cooling system condenser, piping system, and heat exchanger are different from those in the SOA system. In the $\mathrm{NH}_{3}$ system condenser, isothermal heat transfer occurs between condensing steam and boiling ammonia. This contrasts to the SOA system in which the heat transfer in the condenser occurs between nonisothermal heating of liquid water and condensing of steam. The design of the SOA condenser is based on the initial temperature difference (RANGE ${ }_{\text {water }}+$ TTD) and final temperature differences (TTD) between the water and the saturated steam and the velocity of the water inside the tubes. The condenser for the ammonia system is designed on the basis of the temperature difference between the steam and ammonia as well as the exit quality of the $\mathrm{NH}_{3}$ leaving the tubes.

The SOA system piping includes supply and return lines which feed and collect water to and from the heat exchanger in the tower. The piping diameter is based on a design velocity. 
The piping for the $\mathrm{NH}_{3}$ system also includes supply and return 1 ines. The supply piping feeds $\mathrm{NH}_{3}$ vapor to the tower; the return piping returns $\mathrm{NH}_{3}$ liquid to the condenser/reboiler. The supply piping diameter is determined by a vapor design velocity. The return piping is determined by a liquid design velocity.

Because vapor in the $\mathrm{NH}_{3}$ system piping undergoes a pressure drop, the vapor temperature decreases from the condenser/reboiler to the tower. This temperature drop decreases the ITD, increasing the cost of the heat exchanger. The SOA system does not exhibit this decrease in heat exchanger ITD.

The SOA system has two-pass vertical heat exchangers situated in circular towers. The $\mathrm{NH}_{3}$ system heat exchanger is a one-pass vertical arrangement, also situated in a circular configuration. The fluid flowing through the heat exchanger is a two-phase mixture caused by condensation of $\mathrm{NH}_{3}$ vapor on the inside of the tube walls.

The SOA system heat exchanger is designed on the basis of the initial temperature difference between the water and the air; the temperature ranges of the water (RANGE water $_{\text {) }}$ ) and the air (RANGE $a$ ir $)$, the mass flow rates of air and water, and the frontal area of the heat exchanger. For the $\mathrm{NH}_{3}$ system, the heat exchanger design is based on the initial temperatuer difference between the $\mathrm{NH}_{3}$ and the air in the tower, the temperature range of the air, the mass flow rates of the air and the $\mathrm{NH}_{3}$ through the tower, and the frontal area of the heat exchanger.

\subsection{HEAT EXCHANGER}

The four areas of variation in the heat exchanger are the unit geometry, the configuration, fin type or manufacturing method, and the materials. The unit geometry used in the tower heat exchanger is the same optimum used for the SOA system (Section 6.2.1). This unit geometry was used because it appears to be near or at optimum. To verify this choice for the $\mathrm{NH}_{3}$ system, further investigation would have to be done. 


\subsubsection{Heat Exchanger Configuration}

The vertical heat exchanger configuration for the $\mathrm{NH}_{3}$ system is determined by the number of tubes in depth and the length of the tubes in the heat exchanger. The number of tubes in depth is internally optimized by the code. The tube depth found by the code varies from three to four with very little difference in incremental cost within that range. Tube length was maintained at the highest practical length, $80 \mathrm{ft}$, so that the inside coefficient could be maintained at a high value.

\subsubsection{Fin Type or Manufacturing Method and Liner Materials}

Two types of finned tubes were studied; the wrap-on finned tube and the extruded finned tube. Aluminum was used for both types of fins. The materials used for the tube liners with the wrap-on fins were aluminum and carbon stee 1 .

Shown in Table 8-1 are the cooling system design and cost summaries for the three different tube types and materials. The two wrap-on fins gave nearly identical incremental costs; the extruded fin tube gave a ten percent higher incremental cost.

\subsection{TURBINE TYPE}

The discussion and description of turbine types is in Section 6.3. The turbine types used in the optimization analysis are the conventionat turbine, the modified conventional turbine and the high back pressure turbine. The analysis was done only for fossil fuel.

Cooling system design and cost summaries are given in Table 8-2. The lowest cost cooling system is the system with the modified conventional turbine. This result is in contrast to the results for the SOA system and for the PLASTIC system where the lowest cost is obtained with the high back pressure turbine.

Moreover, the cost of the cooling system given in Table 8-2 for the high back pressure turbine is lower than it really would be. The reason is that 
TABLE 8-1. Comparison of Optimized Design and Cost Data for A17-Dry Cooling Systems Using Three

Different Tubes in the Tower

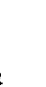

Aluminum Wrap-on Fin Aluminum Liner
Aluminum Extruded Finned Tube

\section{DESIGN PARAMETERS}

Air Flow Rate, $10^{6} \mathrm{lb} / \mathrm{hr}$

Air Range, ${ }^{\circ} \mathrm{F}$

Air Velocity, ft/sec

$\Delta P_{\text {air, }} H X, P s i$

$\Delta P_{\text {discharge }}$ psi

Fan Power, MW

Fans, Number/Dia

$\mathrm{NH}_{3}$ Flow Rate, $10^{6} \mathrm{lb} / \mathrm{hr}$

TTDI

Pump Power, MW

ITD, ${ }^{\circ} \mathrm{F}$

U, Btu/hr/ft ${ }^{2}-{ }^{\circ} \mathrm{F}$

Heat Transfer Area, $10^{6} \mathrm{ft}^{2}$

Width/Length, $\mathrm{ft} / \mathrm{ft}$

Tube Depth, rows

Total Tubes

Towers, number/dia

\section{COST SUMMARY}

Capital, mills/kWh

Capacity, mi11s/kWh

Scaling, mills/kWh

Energy, mills/kWh

Base Fuel, mills/kWh

$0 \& M, m i 11 \mathrm{~s} / \mathrm{kWh}$

Total Incr. Cost, mi11s/kWh
723

29.9

17.6

.0101

.0056

12.9

$34 / 60$

10.8

4.96

.49

43.4

5.51

36.7

$4674 / 80$

2.8

61060

$9 / 165$

1.482

.255

.088

.090

.085

.085

2.085
714

30.2

17.5

.0100

.0056

12.8

$33 / 60$

10.8

4.80

.48

43.6

5.51

36.8

$4648 / 80$

2.8

61370

$9 / 164$
719

30.0

17.1

.0094

.0058

12.5

$32 / 60$

10.8

4.24

.49

44.0

6.38

31.0

$4343 / 80$

3.8

76190

$8 / 173$
1.591

.254

.083

.089

.082

.091

2.190 
TABI.F 8-2. Comparison of Optimized Design and Cost Data for A11-Dry Cooling Systems Using the Three Turbine Types - Fossil

\begin{tabular}{ccc} 
Turbine Type & \\
\hline Modified & High Back \\
Conventional & Conventional &
\end{tabular}

DESIGN PARAMETERS

\begin{tabular}{|c|c|c|c|}
\hline Air Flow Rate, $10^{6} 1 \mathrm{~b} / \mathrm{hr}$ & 1073 & 700 & 513 \\
\hline Air Range, ${ }^{\circ} \mathrm{F}$ & 19.7 & 30.8 & 45.8 \\
\hline Air Velocity, $\mathrm{ft} / \mathrm{sec}$ & 14.9 & 17.1 & 18.9 \\
\hline$\Delta P_{\text {air, }} H X, p s i$ & .0076 & .0098 & .0123 \\
\hline$\Delta P_{\text {discharge, }}$ psi & .0066 & .0056 & .0068 \\
\hline Fan Power, MW & 17.0 & 12.4 & 11.2 \\
\hline Fans, Number/Dia & $45 / 60$ & $32 / 60$ & $22 / 60$ \\
\hline $\mathrm{NH}_{3}$ Flow Rate, $10^{6} 1 \mathrm{~b} / \mathrm{hr}$ & 10.2 & 10.8 & 12.4 \\
\hline TTDI & 3.04 & 4.84 & 6.24 \\
\hline Pump Power, MW & .42 & .48 & .53 \\
\hline ITD, ${ }^{\circ} \mathrm{F}$ & 28.3 & 44.2 & 61.4 \\
\hline$U, B t u / h r / f t^{2}-{ }^{\circ} F$ & 4.96 & 5.45 & 5.79 \\
\hline Heat Transfer Area, $10^{6} \mathrm{ft}^{2}$ & 62.0 & 36.9 & 26.9 \\
\hline Width/Length, $\mathrm{ft} / \mathrm{ft}$ & $8098 / 80$ & $4646 / 80$ & $3123 / 80$ \\
\hline Tube Depth, rows & 2.7 & 2.8 & 3.1 \\
\hline Total Tubes & 103,150 & 61,570 & 44,740 \\
\hline Towers, number/dia & $20 / 129$ & $9 / 164$ & $6 / 166$ \\
\hline \multicolumn{4}{|l|}{ COST SUMMARY } \\
\hline Capital, mil1s/kWh & 2.185 & 1.473 & 1.151 \\
\hline Capacity, mills/kWh & .141 & .262 & .226 \\
\hline Scaling, mills/kWh & .048 & .083 & .252 \\
\hline Energy, mi11s/kWh & .036 & .093 & .072 \\
\hline Base Fuel, mills/kWh & .025 & .082 & .460 \\
\hline $0 \& M, m i 11 s / k W h$ & .126 & .085 & .066 \\
\hline Total Incr. Cost mills/kWh & 2.561 & 2.078 & 2.227 \\
\hline
\end{tabular}


the ammonia pressure on the hottest day with a high back pressure turbine is higher than the design pressure limit for the ammonia piping (450 psi) upon which the piping cost algorithms were based. Because of this, the piping should be thicker and more expensive. This was not taken into account in the total incremental cost (estimated increase of three percent in the incremental cost).

\subsection{CONDENSER/REBOILER}

Because the design of the condenser/reboiler is not controlled by any external parameters except tube length and ammonia vapor exit quality, the major amount of investigation was done in terms of the tube type and tube material. The tube length was not investigated because the maximum tube length allowable $(50 \mathrm{ft})$ gives the best inside coefficient and any lower tube length gives higher cost. The exit quality of the armmonia has small effect on the cost of the condenser when enhanced tubing is used. When conventional tubing is used the exit quality must be kept below 0.5 to keep the heat transfer coefficient sufficiently high.

The tubing types investigated were enhanced and conventional. Aluminum and stainless steel, the only materials used because of constraints imposed by the ammonia and the steam, were used for both types of tubing. The cooling system design and cost summaries for the four cases are shown in Table 8-3. Substitution of enhanced tubing for conventional tubing reduces the incremental cost by about $0.32 \mathrm{mills} / \mathrm{kWh}$. Substitution of aluminum for stainless steel reduces the incremental cost by about $0.25 \mathrm{mills} / \mathrm{kWh}$.

Table 8-4 compares incremental costs of the optimum SOA and PLASTIC systems and the four cases for the $\mathrm{NH}_{3}$ system from Table 8-2. If the enhanced stainless steel or the conventional aluminum must be used, the price differential between the $\mathrm{NH}_{3}$ and PLASTIC systems is greatly reduced. If conventional stainless steel has to be used the PLASTIC system will hold an advantage in cost over the $\mathrm{NH}_{3}$ system. In no instance does the cost of the SOA system become less than the $\mathrm{NH}_{3}$ system. 
TABLE 8-3. Comparison of Optimized Design and Cost Data for All-Dry Cooling Systems Using Four Different Materials in the Condenser/Reboiler

\begin{tabular}{|c|c|c|c|}
\hline Aluminum & $\begin{array}{l}\text { Stainless } \\
\text { Steel }\end{array}$ & Alumi num & $\begin{array}{l}\text { Stainless } \\
\text { Steel }\end{array}$ \\
\hline Enhanced & Enhanced & Conventiona 1 & Conventional \\
\hline
\end{tabular}

DESIGN PARAMETER

\begin{tabular}{|c|c|c|c|c|}
\hline Air Flow Rate, $10^{6} 1 \mathrm{~b} / \mathrm{hr}$ & 723 & 745 & 859 & 886 \\
\hline Air Range, ${ }^{\circ} \mathrm{F}$ & 29.9 & 29.0 & 25.2 & 24.4 \\
\hline Air Velocity, ft/sec & 17.6 & 16.9 & 15.8 & 16.0 \\
\hline$\Delta P_{\text {air }, ~} H X, p s i$ & .0101 & .0101 & .0080 & .0084 \\
\hline$\Delta P_{\text {discharge }}$ psi & .0055 & .0056 & .0063 & .0062 \\
\hline Fan Power, MW & 12.9 & 13.4 & 13.9 & 14.6 \\
\hline Fans, Number/Dia & $34 / 60$ & $35 / 60$ & $37 / 60$ & $39 / 60$ \\
\hline $\mathrm{NH}_{3}$ Flow Rate, $10^{6} \mathrm{lb} / \mathrm{hr}$ & 10.8 & 10.7 & 10.7 & 10.7 \\
\hline TTDI & 4.96 & 7.88 & 10.8 & 12.2 \\
\hline Pump Power, MW & .49 & .38 & .55 & .51 \\
\hline ITD, ${ }^{\circ} \mathrm{F}$ & 43.4 & 40.6 & 37.0 & 35.5 \\
\hline $\mathrm{U}, \mathrm{Btu} / \mathrm{hr} / \mathrm{ft}^{2}-{ }^{\circ} \mathrm{F}$ & 5.51 & 5.38 & 5.20 & 5.22 \\
\hline Heat Transfer Area, $10^{6} \mathrm{ft}^{2}$ & 36.7 & 41.7 & 45.3 & 47.4 \\
\hline Width/Length, $\mathrm{ft} / \mathrm{ft}$ & $4674 / 80$ & $4990 / 80$ & $6137 / 80$ & $6253 / 80$ \\
\hline Tube Depth, rows & 2.8 & 3.0 & 2.6 & 2.7 \\
\hline Total Tubes & 61060 & 69380 & 75310 & 79060 \\
\hline Towers, number/dia & $9 / 165$ & $10 / 159$ & $14 / 140$ & $14 / 142$ \\
\hline \multicolumn{5}{|l|}{ COST SUMMARY } \\
\hline Capital, mills/kWh & 1.482 & 1.735 & 1.780 & 2.019 \\
\hline Capacity, mil1s/kWh & .255 & .256 & .255 & .254 \\
\hline Scaling, mills/kWh & .088 & .093 & .108 & .116 \\
\hline Energy, mil1s/kWh & .090 & .090 & .091 & .091 \\
\hline Base Fuel, mills/kWh & .085 & .087 & .094 & .099 \\
\hline $0 \& M, \mathrm{mi} l 1 \mathrm{~s} / \mathrm{kWh}$ & .085 & .100 & .102 & .116 \\
\hline Total Incr. Cost mills/kWh & 2.085 & 2.361 & 2.430 & 2.695 \\
\hline
\end{tabular}


TABLE 8-4. Comparison of Incremental Costs of SOA, PLASTIC, and Ammonia Systems

Cooling System

SOA

PLASTIC

$\mathrm{NH}_{3}$ Enhanced Aluminum

$\mathrm{NH}_{3}$ Enhanced Stainless Steel

$\mathrm{NH}_{3}$ Conventional Aluminum

$\mathrm{NH}_{3}$ Conventional Stainless Steel
Incremental Cost

2.82

2.49

2.10

2.36

2.43

2.69

From the above comparisons it can be concluded that the cost advantage of the $\mathrm{NH}_{3}$ over the PLASTIC system vanishes or becomes quite small if conventional tubing is used in the condenser/reboiler. The cost comparison between the SOA and $\mathrm{NH}_{3}$ systems shows that, no matter which of the four condenser tubes is used, the ammonia cooling system is of lower cost.

\subsection{PIPING SYSTEM DESIGN VELOCITIES}

The design of the piping system for the $\mathrm{NH}_{3}$ cooling loop is done on the basis of design velocities (the average velocity in the pipe) for the supply and return lines. The supply line carries $\mathrm{NH}_{3}$ vapor; the return line carries $\mathrm{NH}_{3}$ liquid.

The design of the vapor line is a trade-off between the cost of the piping and the cost of the heat exchanger and the condenser/reboiler. The piping costs decrease with increasing $\mathrm{NH}_{3}$ velocity. However, the temperature drop in the $\mathrm{NH}_{3}$ being transported increases with $\mathrm{NH}_{3}$ velocity because of a larger pressure drop in the vapor. This temperature drop reduces the temperature difference available to the heat exchanger and to the condenser/reboiler which results in increased costs for these components. Therefore, by varying the vapor design velocity over a range of values, a minimum total cost for the cooling system can be obtained. 
The minimum total cost for the return system can also be found as a function of the liquid design velocity by varying the design velocity over a range of values. In this case piping cost is traded off with pumping power. In addition, erosion considerations limit the design velocity to $15 \mathrm{ft} / \mathrm{sec}$ maximum.

The incremental cost of the $\mathrm{NH}_{3}$ cooling system versus the vapor supply velocity is shown in Figure 8-1. The optimum vapor supply velocity is in the vicinity of $150 \mathrm{ft} / \mathrm{sec}$. The incremental cost does not begin to rise significantly until the design vapor velocity is below $100 \mathrm{ft} / \mathrm{sec}$.

As seen from Figure 8-1, the incremental cost does not change much above a return design velocity of $10 \mathrm{ft} / \mathrm{sec}$. For return velocities above $15 \mathrm{ft} / \mathrm{sec}$, the decrease in the incremental cost is insignificant. This places the optimum liquid design velocity at $15 \mathrm{ft} / \mathrm{sec}$ (the limit imposed by erosion considerations).

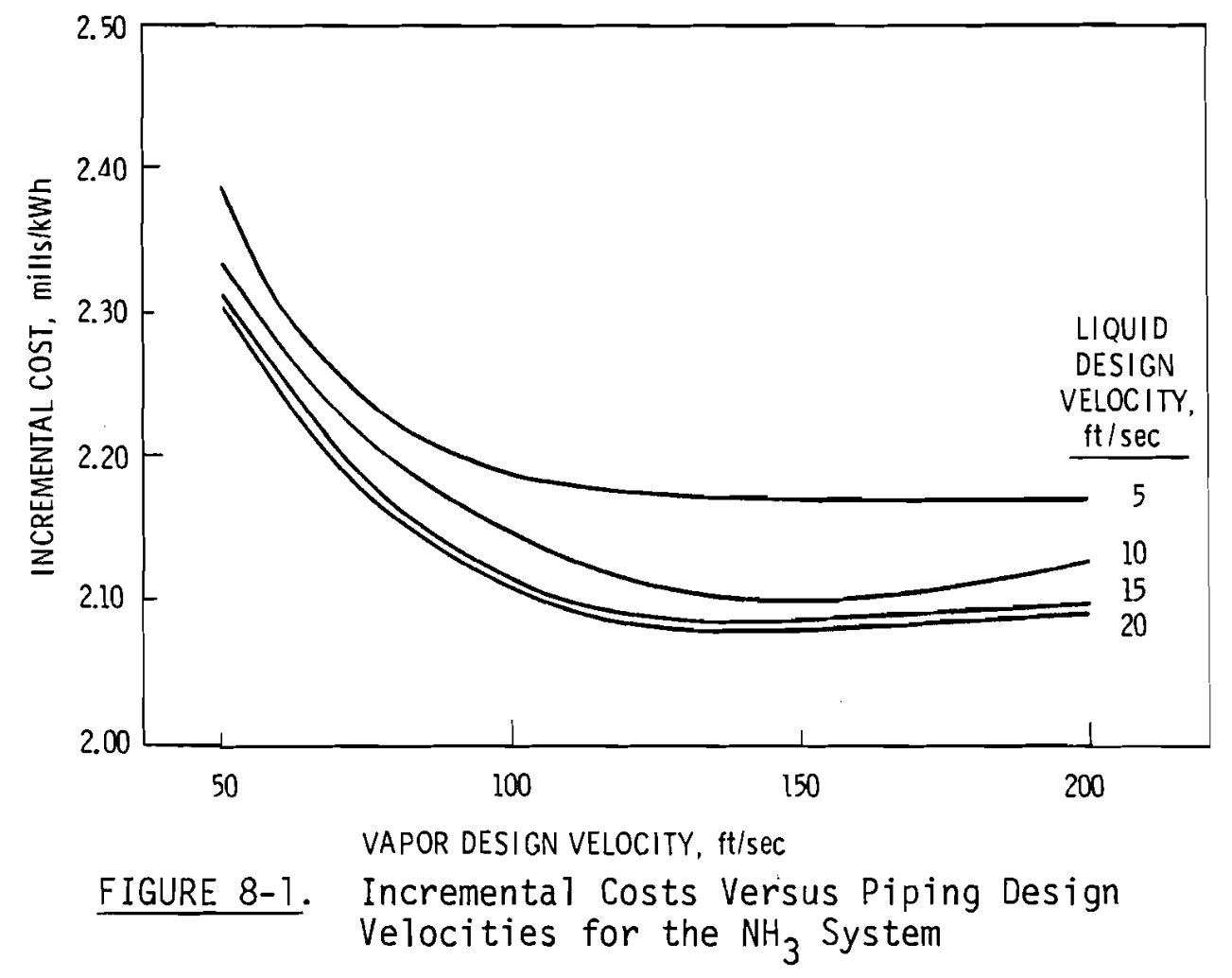




\subsection{TOWER CONFIGURATION}

The configuration of the circular towers depends on the number of towers, the number of fans on the tower roofs, whether diffusers are used, and whether the delta heat exchanger arrangement is used. The optimum number of towers is found by the code while the optimum packing factor can be found by externally varying it. The other two variables are "yes or no" answers on whether cheaper costs are obtained.

The velocity recovery stacks used on the fans of the tower were designed by one method. The angles of the sides were chosen so that the maximum diffuser diameter would be 12 percent greater than the fan diameter. The height of the stack was chosen to be one-half the fan diameter. The dimensions given are used in industry and give reasonable accuracy in predicting velocity recovery.

The use of velocity recovery stacks resulted in insignificant cost changes although the diameter of the fans became larger and the tower diameters became smaller. The recovery stacks were used in the comparisons among the three systems.

When delta heat exchanger configurations are used in the circular towers, the number of towers is reduced and higher air flow through each tower is required. Because the heat exchangers are not tangential to the circumference of the towers, the air flowing into the sides of the towers might enter nonperpendicularly into the face of the heat exchangers. This could alter the air-side heat transfer and pressure drop of the heat exchangers.

When the code was run with the delta heat exchangers, the incremental cost was reduced by about two percent. With the uncertainty of the air-side processes in mind it was decided that the delta arrangements would not be used in the optimum configuration.

The packing factor determines the number of fans of given diameter that can be placed on the roof of a tower. The minimum packing factor (Section 6.7.4) for any size tower varies for any fan size because each 
size fan can only be packed into certain configurations. Figure 8-2 plots the incremental cost of the $\mathrm{NH}_{3}$ system versus packing factor, obtained by using the code to find the optimum designs of the $\mathrm{NH}_{3}$ cooling system for different packing factors. The line drawn at the packing factor of 2.0 is the geometric limit of the packing factors. Below this limit, the number of fans required in each tower cannot be geometrically put into the towers. For this reason the optimum packing factor was chosen as 2.0 because it gave the lowest incremental cost.

Figure $8-3$ is a plot of the incremental cost versus the number of towers in the cooling system. Although the optimum number of towers is nine, the cost of the $\mathrm{NH}_{3}$ cooling system does not increase significantly until the system is designed with five towers or less. 


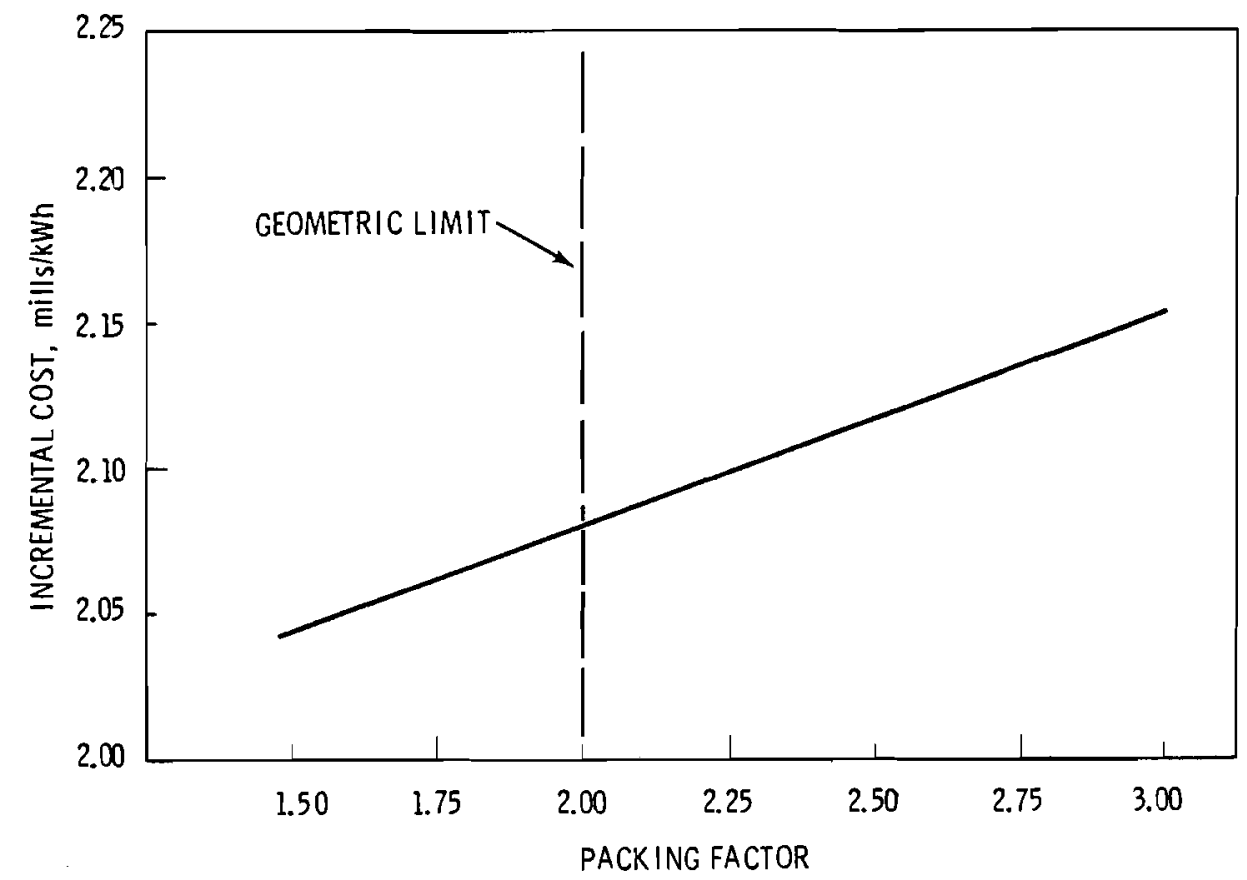

FIGURE 8-2. Incremental Costs Versus Packing Factor for the $\mathrm{NH}_{3}$ System

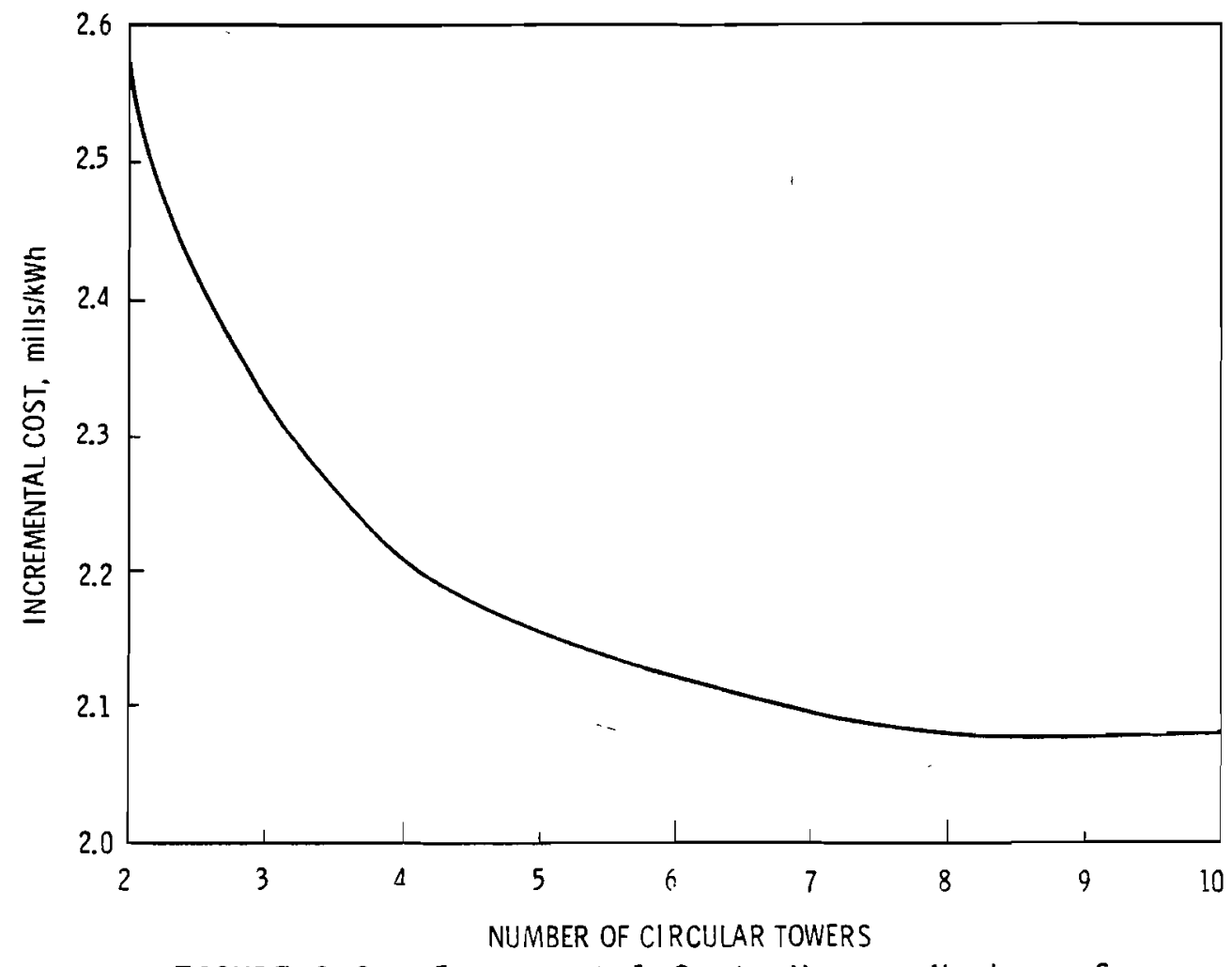

FIGURE 8-3. Incremental Costs Versus Number of Circular Towers for the $\mathrm{NH}_{3}$ System 


\section{REFERENCES}

1. R. C. Norton, W. J. Westre and G. L. Larsen, Dry Cooling Design Characteristics of a Large Power Plant. Wyodak Resources and Development Corporation, Gillette, WY.

2. Dry Cooling Tower Program: Results of Industrial Contacts Through August 1974. BNWL-1878, Battelle, Pacific Northwest Laboratories, Richland, WA, November $1,1974$.

3. C. H. Armstrong and R. S. Schermerhorn, "Dry Cooler Saves Water Dollars and Environmental Headaches." Electric Light and Power, E/G Edition, pp. 22-23, February 1974.

4. U.S. AEC Dry Cooling Tower Development Program Plan - Initial Issue. BNWL-B-393, Battelle, Pacific Northwest Laboratories, Richland, WA, December 1974.

5. B. C. Fryer, A Review and Assessment of Engineering Economic Studies of Dry Cooled Electrical Generating Plants. BNWL-1976, Battelle, Pacific Northwest Laboratories, Richland, WA, March 1976.

6. W. V. Loscutoff, Preliminary Evaluation of Wet/Dry Cooling Concepts for Power Plants. BNWL-1969, Battelle, Pacific Northwest Laboratories, Richland, WA, January 1976.

7. Y. Onishi, Mathematical and Experimental Investigations on Dispersion and Recirculation of Plumes from Dry Cooling Towers at Wyodak Power Plant in Wyoming. BNWL-1982, Battelle, Pacific Northwest Laboratories, Richland, WA, February 1976.

8. A. B. Johnson, Jr., D. R. Pratt and G. E. Zima, A Survey of Materials and Corrosion Performance in Dry Cooling Applications. BNWL-1958, Battelle, Pacific Northwest Laboratories, Richland, WA, March 1976.

9. D. R. Pratt, Compatibility of Ammonia with Candidate Dry Cooling System Materials. BNWL-1992, Battelle, Pacific Northwest Laboratories, Richland, WA, April 1976.

10. D. R. Pratt, Scale Formation in Deluged Dry Cooling Systems. BNWL-2060, Battelle, Pacific Northwest Laboratories, Richland, WA, May 1976.

11. J. W. Currie, Costing Electric Power: Implications for Dry Cooling Technology. BNWL-1998, Battelle, Pacific Northwest Laboratories, Richland, WA, July 1976. 
12. J. G. DeSteese, European Dry Cooling Tower Operating Experience. BNWL-1995, Battelle, Pacific Northwest Laboratories, Richland, WA, March 1976.

13. B. R. Andeen and L. R. Glicksman, Dry Cooling Towers for Cooling Plants. DSR 73047-1, Massachusetts Institute of Technology, Cambridge, MA, February 1972.

14. L. R. Glicksman and B. R. Andeen, "Sensitivity of Power Generating Costs with Dry Cooling Towers." 9th Intersociety Energy Conversion Engineering Conference Proceedings, 1974. American Society of Mechanical Engineers, New York, NY, pp. 566-571, 1974.

15. B. R. Andeen, L. R. Glicksman and W. M. Rohsenow, Improvement of the Environmental and Economic Characteristics of Cooling Towers, Part I: Optimized Design Program, Fluidized Beds, and Non-Metallic Heat Exchangers. Massachusetts Institute of Technology, Cambridge, MA, June $30,1973$.

16. P. A. Ard, C. H. Henager, D. R. Pratt and L. E. Wiles, Costs and

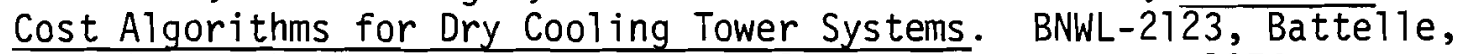
Pacific Northwest Laboratories, Richland, WA, September 1976.

17. F. R. Zaloudek, A Study of the Comparative Costs of Five Wet/Dry Cooling Tower Concepts. BNWL-2122, Battelle, Pacific Northwest Laboratories, Richland, WA, September 1976.

18. Heat Transfer and Pressure Drop Characteristics of Dry Tower Extended Surfaces. Part II: Data Analys is and Correlation. PFR Engineering Systems, Inc., Marina del Rey, CA, June 15, 1976.

19. C. Weierman, J. Taborek and W. J. Marner, Comparison of the Performance of Inline and Staggered Banks of Tubes with Segmented Fins. Heat Transfer Research, Inc., Alhambra, CA, August 1975.

20. R. A. Stevens, Mean Temperature Difference in Counter Crossflow Heat Exchangers. MS Thesis, Southern Methodist University, Dallas, TX, June 1956.

21. J. P. Rossie, R. D. Mitchel1 and R. 0. Young, Economics of the Use of Surface Condensers with Dry Cooling Systems For Fossil-Fueled and Nuclear Generating Plants. R. W. Beck and Associates, Denver, CO, December 1973. 
APPENDIX

HEAT TRANSFER AND PRESSURE DROP CORRELATIONS AND DATA BASE 


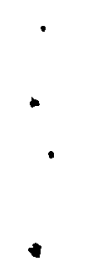


APPENDIX

\author{
HEAT TRANSFER AND PRESSURE DROP \\ CORRELATIONS AND DATA BA.SE
}

\title{
HEAT TRANSFER COEFFICIENT AND FRICTION FACTOR FOR METAL FINNED TUBE HEAT EXCHANGERS
}

The performance of the metal finned tube heat exchanger is determined by the water-side and air-side heat transfer coefficients and friction factors. The performance is also influenced by the thermal resistance of the tube wall and fin, air-side and water-side fouling, and contact resistance at the liner-fin interface. For given values of the water and air flow rates and heat exchanger size, the prediction of the heat transfer coefficients and friction factors establishes the pumping power, fan power, and total heat load of the heat exchanger.

\section{WATER-SIDE}

The water-side performance parameters are calculated from established correlations discussed below.

\section{Friction Factor}

The friction factor is predicted from the Blasius equation for flow in a circular conduit. The Blasius equation generally applies to the turbulent flow regime for Reynolds numbers up to $10^{5}$. The range of Reynolds numbers observed in the parametric studies was $3 \times 10^{4}$ to $7 \times 10^{4}$, wel1 within the limits of the Blasius equation. Other correlations were programmed for Reynolds numbers below 2000 and above $10^{5}$, but such conditions are not economically attractive.

To evaluate the Reynolds numbers, the range of tube inside diameters was 0.680 to 1.908 inches. The optimized water velocity in the tubes ranged between 1.0 and 7.0 feet per second with the lower velocities characteristic of the larger diameter tubes. 


\section{Heat Transfer Coefficient}

The water-side heat transfer coefficient is predicted with the DittusBoelter correlation for turbulent flow in tubes. This correlation is applicable to Reynolds numbers greater than $10^{4}$, a condition that was met for all observed cases in the parametric studies.

\section{$\underline{\text { AIR-SIDE }}$}

The air-side performance parameters are not as well established as their water-side counterparts. The performance of a particular firned tube may vary significantly from the performance that would be predicted from any of the available correlations. This causes substantial concern because the performance of the heat exchanger, and thus, the accuracy of the economic analysis, is dominated by the air-side conditions.

It is the purpose of this section to present the two sets of correlations that were available for the optimization studies. The correlations will be evaluated by comparing them against each other and by comparing the performance predictions against actual finned tube experimental data. One set of correlations uses a friction factor developed by Briggs \& Robinson (1) and a heat transfer coefficient developed by Briggs \& Young. (2) The other set of correlations was developed by PFR Engineering Systems, Inc., (3) at the request of PNL. The PFR correlations were used exclusively in the parametric studies of SOA and ammonia loop all-dry cooling systems using the metal finned tube heat exchanger. Both sets of air-side performance correlations apply only to staggered rows of finned tubes. Emphasis has been given to the analysis of the staggered tube arrangement because it has been shown to be economically more acceptable than the inline arrangement.

In addition to developing the correlations, the PFR study was commissioned to collect performance data and to develop a figure of merit for the selection of finned tubes. The collection and review of finned tube airside performance data is possibly the most thorough work of its kind available. (5) The PFR correlation was developed in consideration of all of this data. 
The meaning of a "figure-of-merit" is that one could determine the economically optimum or near optimum finned tube unit geometry by considering only the performance of the finned tube, that is, without consideration of the economics of the entire cooling system. The attempt at PNL to develop a reliable and meaningful figure-of-merit has been unsuccessful. It is now evident that it is difficuit, if not impossible, to successfully disassociate the economics of any one component from the remainder of the cooling system.

\section{Friction Factor}

Briggs and Robinson Correlation (1)

The friction factor correlation developed by Briggs and Robinson is

$f=18.93\left(\frac{P_{t}}{D_{r}}\right)^{-.927}\left(\frac{P_{t}}{P_{d}}\right)^{.515} \operatorname{Re}_{r}-.316$

where

$P_{t}=$ tube pitch normal to air flow

$D_{r}=$ root diameter

$P_{d}=$ tube pitch measured on diagonal between staggered tubes

$\operatorname{Re}_{r}=$ Reynolds number based on root diameter and the velocity at minimum cross section.

See Figure A-1 for a pictorial definition of these terms.

The friction factor was defined according to

$$
f=\frac{\rho G_{C} \Delta P}{N G_{m}^{2}}
$$

where

$$
\begin{aligned}
P= & \text { air density } \\
G_{C}= & \text { gravitationa } 1 \text { constant } \\
\Delta P= & \text { pressure drop across heat exchanger } \\
N= & \text { tube rows in direction of air flow } \\
G_{m}= & \text { air mass velocity at minimum cross section normal to direction of } \\
& \text { flow. }
\end{aligned}
$$



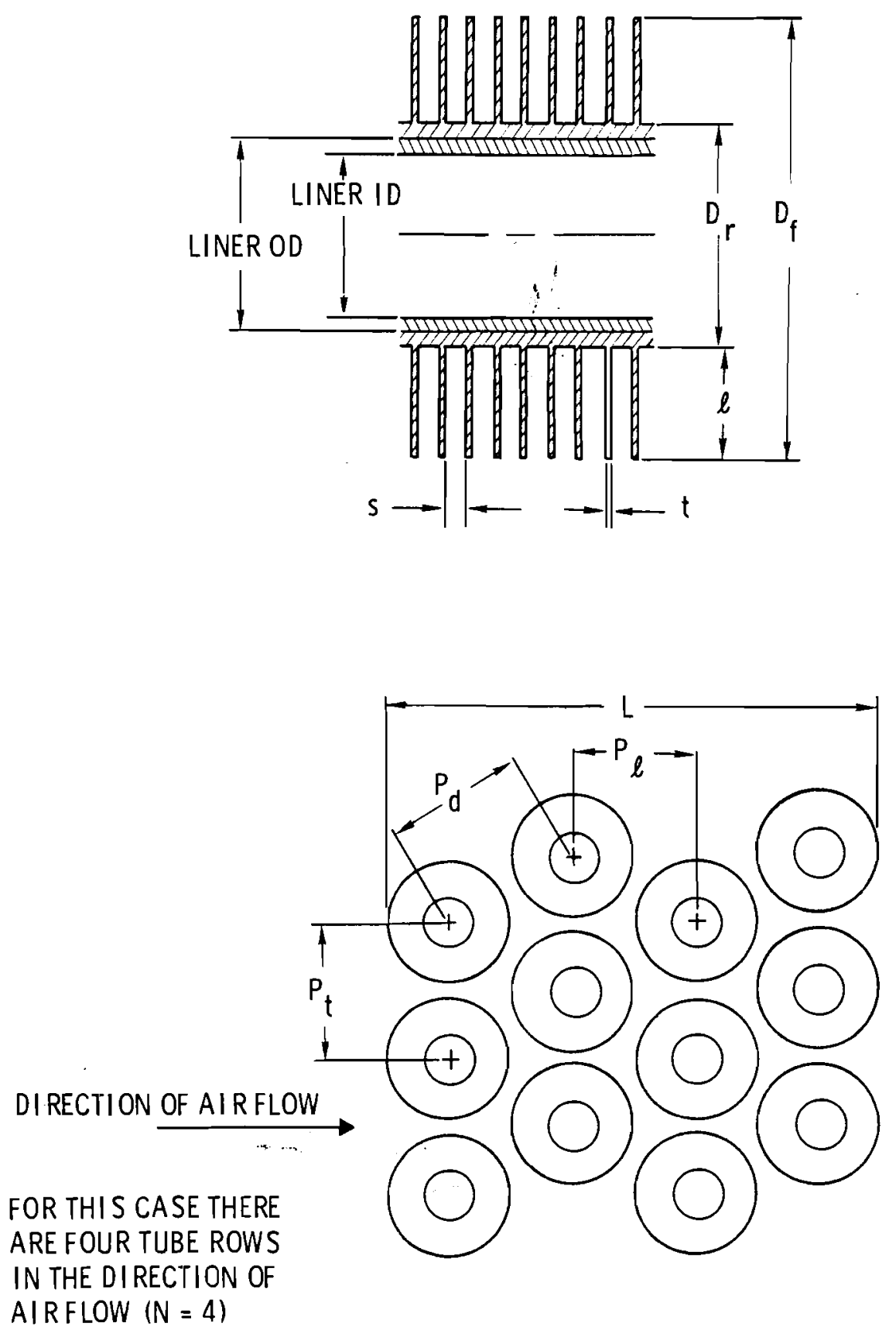

FIGURE A-1. Finned Tube Unit Geometry and Tube Pitch Parameters 
The correlation, equation (1), applies to staggered tube arrangements. For equilaterally spaced tubes, the ratio of $\mathrm{P}_{t} / \mathrm{P}_{d}$ is unity.

The range and variety of unit geometry variables for which the correlation was developed are relatively smal1. The range of the unit geometry variables was: root diameter (0.734 in. to $1.610 \mathrm{in.}$ ); fin diameter (1.561 in. to $2.750 \mathrm{in.})$; fin height $(0.414 \mathrm{in}$. to $0.570 \mathrm{in.})$; fin thickness $(0.0158 \mathrm{in}$. to $0.0235 \mathrm{in.})$; fin spacing (0.0729 in. to $0.1086 \mathrm{in.})$; and fins per inch (7.90 to 10.94). The tube pitch was varied between 1.687 inches and 4.500 inches with equilateral and isosceles arrangements being considered. Although the range of values is considered somewhat restricted, the near optimum unit geometry, as determined by the parametric studies, is bracketed by these values.

\section{PFR Correlation}

The friction factor correlations developed by PFR Engineering Systems, Inc., are:

$$
f=\left(\frac{150}{R e_{h}}+\frac{1.8}{R e_{h} \cdot 2}\right)\left(\frac{P_{1}}{D_{h}}\right)^{.35} \text { for } \frac{P_{1}}{D_{h}}>4,
$$

and

$$
f=13.6 \operatorname{Re}_{h}^{-.3}\left(\frac{P_{1}}{D_{h}}\right)^{-.42} \text { for } \frac{P_{1}}{D_{h}} \leq 4,
$$

where

$$
\begin{aligned}
R e_{h}= & \text { Reynolds number based on hydraulic diameter and the } \\
& \text { velocity at minimum cross section } \\
P_{1}= & \text { tube pitch in direction of air flow } \\
D_{h}= & \text { hydraulic diameter }
\end{aligned}
$$

PFR used the following equation to define friction factor:

$$
f=\frac{2 G_{c} \Delta P}{N \rho G_{m}^{2}}
$$


The terms in the equation (5) were defined with equation (2). The correlations developed by PFR were multiplied by one-half so that they would be defined on a basis identical to that of the Briggs and Robinson correlation; that is $f=\rho G_{c} \Delta P / N G_{m}{ }^{2}$. This allowed the comparison of the correlations.

The hydraulic diameter is defined as

$$
D_{h}=\frac{4 L}{N} \frac{A_{c}}{A_{t}}
$$

where

$L=$ depth of heat exchanger from leading edge of the first row of tubes to trailing edge of last row of tubes

$A_{C}=$ minimum flow area between tubes normal to direction of air flow

$A_{t}=$ heat transfer area per foot of finned tube

$\mathrm{N}$ = tube rows in direction of flow.

The PFR correlation was developed in order to include a large amount of data from many sources into a comprehensive, accurate correlation. An extensive quantity of data was reviewed to filter out the data that was considered to have been taken under questionable conditions. For example, friction factor data obtained from any module having less than five transverse tube rows was considered to have unacceptable edge effects. Some of the data was reanalyzed so that all the data could be reported on a common basis. A11 unit geometries were given equal weighting in the development of the correlation. The range of unit geometry variables was: root diameter (0.188 in. to 2.000 in.); fin diameter ( 0.375 in. to 3.250 in.); fin height ( $0.094 \mathrm{in.}$ to $0.875 \mathrm{in.})$; fin thickness (0.008 in. to $0.080 \mathrm{in.})$; fin spacing (0.025 in. to $0.200 \mathrm{in.})$; and fins per inch (4.0 to 30.0).

\section{Comparison of Friction Factor Correlations}

The basic difference between the two friction factor correlations is the defining length for the Reynolds number. The PFR correlation uses hydraulic diameter. The hydraulic diameter is based upon the root diameter and the fin geometry parameters including fin thickness, fins per inch, and 
fin height. Briggs and Robinson use the root diameter which is the only unit geometry variable that appears explicitly in their correlation. While the Briggs and Robinson correlation does not explicitly include the effects of the fin geometry, changes in these parameters will cause a change in the friction factor predicted by the correlation. For example, if the fin thickness were increased and all other variables were unchanged, the air velocity through the minimum cross section would increase because of the increased restriction of the flow path. The velocity increase would result in a higher Reynolds number and, therefore, a slightly lower friction factor. The velocity increase would show up most dramatically as an increase in the air-side pressure drop.

While the use of the hydraulic diameter yields a correlation that is more explicitiy sensitive to changes in some unit geometry variables, it is not certain that it yields a superior correlation. This may be especially true when the correlation is applied to near optimum unit geometries. Recall that the range of unit geometry variables which were used to develop the Briggs and Robinson correlation encompassed the near optimum values. The interest here is primarily in the near optimum unit geometries. In view of this emphasis, it is possible that the Briggs and Robinson correlation could be, in fact, the better correlation to use in this analysis. In other words, it could be postulated that in order to achieve general applicability, the PFR correlation was developed with a sacrifice in accuracy for specific unit geometries. Therefore, one should not draw conclusions regarding the applicability of either correlation based solely on the functional form.

To evaluate how the correlations compare, friction factors have been calculated for the near optimum unit geometry (NOUG) and for several other surfaces. These are compared in Table A-1 for a root diameter Reynolds number of $10^{4}$, which is near optimum. (The PFR correlation can be converted to a root diameter Reynolds number form by replacing $\operatorname{Re}_{h}$ by $\operatorname{Re}_{r} D_{h} / D_{r}$.)

These surfaces were selected from the PFR report on the basis of their approach to the near optimum unit geometry. The surfaces and the corresponding data are from several sources, including Briggs and Robinson (surfaces 75B 
TABLE A-1. Comparison of Friction Factors Calculated from the Two Available Correlations Against Actua 1

Finned Tube Data from Reference 5

\begin{tabular}{|c|c|c|c|}
\hline Surface* & Briggs \& Robinson & PFR & Actual Data \\
\hline NOUG & .458 & .771 & -- \\
\hline $75 \mathrm{~B}$ & .363 & .403 & .331 \\
\hline $78 E$ & .512 & .581 & .430 \\
\hline 80 & .454 & .558 & .473 \\
\hline 83 & .513 & .611 & .704 \\
\hline 84 & .614 & .803 & .775 \\
\hline 85 & .509 & .597 & .743 \\
\hline 86 & .428 & .620 & .494 \\
\hline 97 & .400 & .422 & .395 \\
\hline 1080 & .542 & .866 & .613 \\
\hline $109 \mathrm{C}$ & .404 & .562 & .394 \\
\hline $120 \mathrm{~A}$ & .518 & .572 & .840 \\
\hline $143 \mathrm{~A}$ & .456 & .620 & .467 \\
\hline 144 & .441 & .855 & .612 \\
\hline $145 \mathrm{~A}$ & .462 & .689 & .685 \\
\hline 201 & .513 & .606 & .756 \\
\hline
\end{tabular}


and $78 \mathrm{E})$. Surface 97 is the only surface that is not equilateral; the tube pitch in the direction of air flow $\left(P_{1}\right)$ is 1.75 inches while the tube pitch normal to air flow $\left(P_{t}\right)$ is 1.56 inches. Surfaces 144 and $145 \mathrm{~A}$ are the closest available to an optimum unit geometry, while surface $143 \mathrm{~A}$ is also very close.

The PFR friction factor exceeds the data for eleven of the fifteen observed cases. The Briggs and Robinson friction factor exceeds the data only four times. On this basis and by observing the result for the near optimum unit geometry one can conclude that the PFR correlation is significantly more conservative in terms of friction factor. If one were to develop a cooling system design using air flow characteristics predicted by a correlation, then the PFR correlation would be the likely choice. But, with the significant variation between the data and the correlations it can be concluded that the only way to obtain a reliable performance prediction, such as would be required in the actual design of a power plant cooling system, is to test the candidate finned tube under conditions similar to that of the proposed application.

Even though the friction factors are considerably different, the differences in the cooling system designs using either correlation are very subtle. Table A-2 presents optimized designs using either correlation with a near optimium set of input variables. The fan power is proportional to the triple product of the friction factor, tube rows in depth and the cube of the air velocity. Since the PFR friction factor is relatively high, the fan power must be kept down by reducing the tube rows in depth and the velocity. Reducing the velocity by only 15 percent reduces the cube of the velocity by nearly 40 percent. Both designs presented in Table A-2 require about the same heat transfer area. Therefore, the reduced heat exchanger depth for the PFR design results in a greater overall heat exchanger width which is reflected as an increase in the number of towers while the tower diameter remained nearly constant. 
TABLE A-2. Comparison of Cooling System Designs Developed from the PFR Correlations and the Correlations of Briggs and Robinson and Briggs and Young

Tube Description: Liner $O D=1.00 \mathrm{in}$.

Fin $O D=2.57$ in.

Fins $/$ Inch $=10.0$

Fin Thickness $=0.018 \mathrm{in}$.

Wrap-On Aluminum Fins

Carbon Steel Liner

Air-Side Performance Correlation

PFR Briggs \& Robinson

DESIGN PARAMETERS

\begin{tabular}{|c|c|c|}
\hline Air Flow Rate, $10^{8} \mathrm{lb} / \mathrm{hr}$ & 8.65 & 7.54 \\
\hline Air Range, ${ }^{\circ} \mathrm{F}$ & 25.2 & 28.9 \\
\hline Air Velocity, $\mathrm{ft} / \mathrm{sec}$ & 17.1 & 20.1 \\
\hline Friction Factor & 0.850 & 0.473 \\
\hline$\Delta P_{a i r, H X}, p s i$ & 0.0113 & 0.0126 \\
\hline$\Delta P_{\text {air, discharge, }}$ psi & 0.0064 & 0.0071 \\
\hline Fan Power, MWe & 17.2 & 16.3 \\
\hline Fans Number/Dia, $\mathrm{ft}$ & $37 / 60$ & $31 / 60$ \\
\hline Water Flow Rate, $10^{8} 1 \mathrm{~b} / \mathrm{hr}$ & 2.08 & 2.10 \\
\hline Water Range, ${ }^{\circ} \mathrm{F}$ & 25.2 & 24.9 \\
\hline Pump Power, MWe & 6.35 & 6.15 \\
\hline LMTD, ${ }^{\circ} \mathrm{F}$ & 20.4 & 18.6 \\
\hline ITO, ${ }^{\circ} \mathrm{F}$ & 45.6 & 45.6 \\
\hline $\mathrm{h}, \mathrm{Btu} / \mathrm{hr} / \mathrm{ft}^{2} /{ }^{\circ} \mathrm{F}$ & 7.23 & 7.62 \\
\hline$U, B t u / h r / f t^{2} /{ }^{\circ} \mathrm{F}$ & 5.21 & 5.36 \\
\hline $\mathrm{HX}$ Heat Transfer Area, $10^{6} / \mathrm{ft}^{2}$ & 52.3 & 56.6 \\
\hline$H X$ Width/Length, $\mathrm{ft} / \mathrm{ft}$ & $5710 / 80$ & $4260 / 80$ \\
\hline HX Depth Rows & 3.27 & 4.74 \\
\hline Total HX Tubes & 87200 & 94100 \\
\hline Towers Number/Dia, ft & $12 / 148$ & $8 / 166$ \\
\hline \multicolumn{3}{|l|}{ ST SUMMARY } \\
\hline Cooling System, mills $/ \mathrm{kWh}$ & 1.95 & 1.80 \\
\hline Capacity, mills/kwh & 0.27 & 0.27 \\
\hline Scaling, mills/kWh & 0.22 & 0.20 \\
\hline Energy, mills/kWh & 0.09 & 0.09 \\
\hline Base Fuel, mills/kwh & 0.15 & 0.15 \\
\hline O\&M, mills/kWh & 0.11 & 0.10 \\
\hline Total Incr. Cost, mills $/ \mathrm{kWh}$ & 2.80 & 2.61 \\
\hline
\end{tabular}


The difference in air velocities and tower configuration between designs using the different correlations results in different fan system requirements. As a consequence of these basic differences in the tradeoffs that determine the optimum designs, the incremental power production cost for a design developed with the PFR correlation is calculated to be about seven percent higher than when the Briggs and Robinson correlation is used. When comparing the metal finned tube systems (SOA and ammonia) to the plastic systems, this cost difference should be kept in mind. Use of the Briggs and Robinson correlation would widen the gap between the costs of the ammonia system and the plastic system.

Heat Transfer Coefficient

\section{Briggs and Young Correlation}

The correlation for the heat transfer coefficient developed by Briggs and Young is

$$
h=0.134 \frac{k}{D_{r}} \operatorname{Pr}^{.333}\left(\frac{s}{T}\right)^{.200}\left(\frac{s}{t}\right)^{.1134} \operatorname{Re}_{r} .681
$$

where

$$
\begin{aligned}
& k=\text { thermal conductivity of air } \\
& D_{r}=\text { root diameter } \\
& \mathrm{Pr}=\text { Prandt } 1 \text { number of air } \\
& s \text { = spacing between fins } \\
& 1 \text { = fin height } \\
& t=\text { fin thickness } \\
& R e_{r}=\text { Reynolds number based on root diameter and air velocity at }
\end{aligned}
$$

This correlation applies to both equilateral and isosceles staggered tube arrangements as it was concluded by Briggs and Young that tube pitch had a negligible effect upon heat transfer.

As with the Briggs and Robinson correlation for friction factor, this correlation was developed from an investigation of a relatively narrow range of unit geometry variables. However, the ranges include the near 
optimum unit geometry. The range of the unit geometry variables was: root diameter (.438 in. to $1.610 \mathrm{in.}$ ); fin diameter (.737 in. to $2.750 \mathrm{in.}$ ); fin height ( 0 in. to .656 in.); fin thickness $(0.13 \mathrm{in.}$ to $.080 \mathrm{in.})$; fin spacing (.035 in. to $.117 \mathrm{in.}$ ); and fins per inch (6.3 to 19.5). The tube pitch was varied between .964 inches and 4.370 inches.

\section{PFR Correlation}

The heat transfer correlation developed by PFR is

$$
h=0.290 \frac{k}{D_{r}} \operatorname{Pr} .333\left(\frac{A_{0}}{A_{r}}\right)^{-.17} \operatorname{Re}_{r} .633
$$

where

$$
\begin{aligned}
k= & \text { thermal conductivity of air } \\
D_{r}= & \text { root diameter } \\
P_{r}= & \text { Prandt } 1 \text { number of air } \\
A_{0} / A_{r}= & \text { ratio of total finned tube area to base tube area } \\
R_{r}= & \text { Reynolds number based on root diameter and air velocity at } \\
& \text { minimum cross section. }
\end{aligned}
$$

This correlation applies to both equilateral and isosceles staggered tube arrangements. Notice that the Reynolds number is defined here with the root diameter whereas the friction factor correlation of PFR uses a Reynolds number based on hydraulic diameter.

The data used in the development of the heat transfer correlation was screened in a fashion similar to that for the friction factor correlation. For example, all the tubes in the tube bank must have been heated in order to obtain usable heat transfer data. Any other heating arrangement was considered to be unacceptable.

The range of unit geometry variables used to develop this correlation is about the same as is presented for the PFR friction factor. It may be slightly different in some cases since some finned tube data collected by PFR was lacking in either heat transfer data or friction factor data. Regardless, the range of unit geometry is significantly broader here than for the Briggs and Young heat transfer work. Similar arguments apply as to 
whether or not this is actually an improvement. That is, to achieve a correlation applicable to such a wide range of conditions, there may be a sacrifice of accuracy for specific unit geometries.

\section{Comparison of Heat Transfer Correlations}

An indication of the acceptability of either correlation is how they compare against each other and against actual data. Both correlations include the effects of fin thickness, fin pitch, and fin height, as well as the other pertinent variables. This was not the case with the friction factor correlations as the Briggs and Robinson correlation did not explicitly include the effect of these unit geometry variables.

Table A-3 compares heat transfer coefficients for a Reynolds number of $10^{4}$ for the same surfaces as were compared for friction factor. In this case, surfaces have been excluded because heat transfer data was not available. These surfaces were chosen for comparison on the basis of their approach to the near optimum unit geometry (NOUG).

The agreement between the correlations and the data is obviously quite good. It appears that either correlation would be highly adequate for a generalized parametric study of this kind.

TABLE A-3. Comparison of Heat Transfer Coefficients Calculations Against Actual Finned Tube Data from Reference 5

\begin{tabular}{|c|c|c|c|}
\hline Surface & $B \& Y$ & PFR & Actual Data \\
\hline NOUG & 8.54 & 8.16 & -- \\
\hline 80 & 10.01 & 10.66 & 9.43 \\
\hline 83 & 9.80 & 9.70 & 9.13 \\
\hline 84 & 6.30 & 6.40 & 6.75 \\
\hline 85 & 8.85 & 8.82 & 7.92 \\
\hline 86 & 9.32 & 9.94 & 8.88 \\
\hline 97 & 16.23 & 16.41 & 21.11 \\
\hline $143 \mathrm{~A}$ & 10.75 & 11.34 & 11.45 \\
\hline 144 & 6.57 & 7.05 & 7.79 \\
\hline $145 \mathrm{~A}$ & 9.27 & 9.37 & 9.98 \\
\hline 201 & 8.85 & 8.82 & 9.19 \\
\hline
\end{tabular}


Notice the relatively high heat transfer coefficient of surface 97 . Referring to Table A-1, one observes that this surface also has one of the lowest friction factors. This would seem to make surface 97 an ideal surface. However, surface 97 has the smallest root diameter (.630 in.) and shortest fins (.404 in.) of all the surfaces used in the comparison. This makes the heat transfer area per foot of finned tube relatively small. The cost of a unit of finned tube surface area is, therefore, relatively high. The trade-offs that determine the optimum unit geometry are far more complex than the trade-off between the unit cost and the performance of the surface. The trade-offs are dealt with more thoroughly in Section 6.2 of this report. As a result of considerations of unit cost and performance, as well as considerations of a 11 other economic trade-offs, surface 97 is not necessarily superior to the others on an economic basis.

\section{DISCUSSION}

The parametric optimization studies indicate which value of a certain parameter results in the economically optimum cooling system design. By studying this parameter over a range of values on either side of the optimum it is possible to determine the sensitivity of costs and cooling system design to changes in this parameter. Determination of the optimum and the design and cost trends about the optimum of each independent parameter form the results of this study. It is generally true that similar trends and optimums are observed regardless of which set of airside performance correlations has been used. This holds as long as each correlation is applied within the ranges of the variables for which it was developed.

For the purposes of this study, it was difficult to assess which set of correlations would be more acceptable. If the attempt was to design a cooling system that was guaranteed to have a minimum heat rate capability, then one would certainly use actual data after scoping the problem using the more conservative PFR correlations. However, it is the purpose of this study to evaluate the relative economics of different designs. To do this most effectively, it would be necessary to have the same degree of 
conservatism in all the cost models, physical models, assumptions, and correlations. This same conservatism would have to be applied to the descriptions of the advanced systems also. It is not realistic to expect that this could be done. The best available models were used with the hope that the conservatism in any one model was not so unbalanced that it would prevent an accurate identification of the true optimum. In this regard, either set of air-side performance correlations is probably acceptable. 


\section{HEAT TRANSFER COEFFICIENT AND FRICTION FACTOR CORRELATIONS} FOR PLASTIC TUBE HEAT EXCHANGERS

Heat transfer coefficient and friction factor correlations used in the optimization of a plastic tube dry cooling tower system for an electric generation plant are presented in this section. In the optimization procedure used for this system, the correlations presented here were the basis for determining the size of the cooling tower system and the mode in which it operated. The total cost of the system is highly dependent upon the values obtained from these correlations.

The heat transfer and pressure drop correlations presented here fall into two categories: air-side and water-side. The air-side is further subdivided into inline or staggered tube spacing (pitch) categories.

WATER-S.IDE

Friction Factor

The water-side pressure drop is determined through the use of a Fanning friction factor relationship for smooth tubes. The Fanning pressure drop equation is used in the following form:

$$
\Delta p=4 f \frac{L}{D}\left(\rho v^{2} / 2 g_{C}\right)
$$

The friction factor is provided by three separate correlations covering three different Reynolds number ranges:

- Laminar Range, $(0<\operatorname{Re}<2000)$ :

$$
f=16 / \operatorname{Re}
$$

- Transitional $\left(2000<\operatorname{Re}<1 \times 10^{5}\right)$ :

$$
f=0.0791 /(\operatorname{Re})^{0.25}
$$

- Turbulent $\left(\operatorname{Re}>1 \times 10^{5}\right)$ :

$$
f=0.046 /(\operatorname{Re})^{0.20}
$$

The water flow rate for the optimum plastic tubed system is in the transitional flow regime. 


\section{Heat Transfer Coefficient}

The water-side heat transfer coefficient is estimated through the use of the Dittus-Boelter correlation ${ }^{(7)}$ or the laminar flow relationship of W. Nusselt ${ }^{(8)}$ depending on the flow regime of the cooling water.

Those relationships are expressed in the following form:

- Dittus-Boelter correlation (transitional-turbulent, $\operatorname{Re}>2400$ ):

$$
h=0.023(\operatorname{Re})^{0.80}(\operatorname{Pr})^{0.40} \mathrm{k} / \mathrm{D}
$$

- Nusselt Relationship (laminar, Re $<2400$ ):

$$
h=3.66 \mathrm{k} / \mathrm{D}
$$

For the range of parameters selected, the Reynolds number and velocities through the tubes vary from 3000 to 5000 and 1.00 to $4.00 \mathrm{ft} / \mathrm{sec}$, respectively. This is in the region of transitional flow. The heat transfer coefficient is highly dependent upon the state of turbulence of the cooling water in the tube. The turbulent flow is preferred because it gives a higher heat transfer coefficient for only a slight increase in pressure drop. This is the case which is most likely to exist due to the high amount of turbulence which will exist in the headers. Only when the Reynolds number of the tube flow is below 2400 is Equation (11b) used.

\section{$\underline{\text { AIR-SIDE }}$}

A literature search on the subject of air side heat transfer coefficient and friction factor through banks of bare tubes was provided to the Dry Cooling Tower Program at PNL by Dr. Knudson of Oregon State University. Reference 9 provided the most complete information. Prior to this literature search, correlations provided in Reference 10 had been used as the basis for the analysis.

Pressure Drop

The air-side pressure drop through a bank of tubes is determined through the use of a Fanning friction factor relationship,

$$
\Delta p=4 f N\left(\rho v_{\max }^{2} / 2 g_{c}\right)
$$


The friction factor for both the inline and staggered tube arrangement were obtained from McAdams. (10)

Incorporation of information from Reference 9 into the optimization code would have required converting friction factor data from graphic to tabular form. Because this would have introduced an additional error into the computation scheme, the decision was made to use McAdams' information in the optimization code.

Staggered Tube Arrangement

The friction factor relationship provided by McAdams for a staggered tube arrangement is

$$
f=\left(0.25+\frac{0.1175}{\left(X_{T}-1\right)^{1.08}}\right)\left(\operatorname{Re}_{\max }\right)^{-0.16} .
$$

\section{Inline Tube Arrangement}

Inline tube arrangement friction factor is provided by

$$
f=\left(0.044+\frac{0.08 X_{L}}{\left(X_{T}-1\right)^{N}}\right)\left(R e_{\max }\right)^{-0.15}
$$

in which $N=0.43+\left(1.13 / X_{L}\right)$.

In the above relationships, $X_{L}$ is the ratio of the longitudinal pitch to the tube outside diameter. $X_{T}$ is the ratio of the transverse pitch to tube outside diameter. All pitches are measured from centerline to centerline.

Equations (13a) and (13b) are based on data which cover a Reynolds number range of 2000 to $4 \times 10^{4}$.

For the range of parameters selected in the optimization of the plastic tube advanced concept, the air-side Reynolds number varied from 500 to 5000 . The air velocity at the minimum cross-sectional flow area ranged from 7.0 to 15.0 feet per second. The Reynolds number range lies within the laminar and transitional flow regimes. 
The Reynolds number range straddles the lower limit of the friction factor relationships for both staggered and inline tube arrangements. To verify that these relationships give friction factors within a reasonable 1 imit of actual data in the region less than 2000, they were compared against Zukauskas' data. (9) It was found that down to a Reynolds number of 500, friction factors calculated by equations (13a) and (13b) were within acceptable limits of actual data.

Heat Transfer Coefficient

The air-side heat transfer correlations for a bank of bare tubes are taken from McAdams $(10)$ and Zukauskas. (9) The Zukauskas correlations appearto be based on more complete data than those of McAdams. Although both sets of correlations are provided in the optimization code, only Zukauskas' correlations were used in the optimization of the plastic tube advanced concept.

Staggered Tube Arrangement

McAdams recommends the relationship below for gases flowing normal to banks of staggered tubes for a Reynolds number from 2000 to 32000:

$$
\mathrm{h}=0.33(\mathrm{Pr})^{0.33}(\mathrm{Re})^{0.60 \mathrm{k} / \mathrm{D}}
$$

Zukauska recommends the following set of relationships for determining the heat transfer rates in banks of tubes:

- Laminar, $10<\operatorname{Re}<100$ :

$$
h=0.90(\operatorname{Re})^{0.40}(\operatorname{Pr})^{0.36} \mathrm{k} / \mathrm{D}
$$

- Transitional, $1000<\operatorname{Re}<2 \times 10^{5}$ :

For $a / b<2$,

$$
h=0.35(a / b)^{0.2}(\operatorname{Re})^{0.60}(P r)^{0.36} \mathrm{k} / \mathrm{D}
$$

For $a / b>2$,

$$
h=0.40(R e)^{0.60}(P r)^{0.36} \mathrm{k} / 0
$$


- $\quad$ Turbulent, $\operatorname{Re}>2 \times 10^{5}$ :

$$
h=0.022(\operatorname{Re})^{0.84}(\mathrm{Pr})^{0.36} \mathrm{k} / \mathrm{D}
$$

The Reynolds number region from 100 to 1000 is a transitional flow regime from laminar to turbulent, which is not covered by any correlation in Zukauskas' article. For completeness, correlations were derived for this region through use of an equation of the following form:

$$
h=c(\operatorname{Re})^{m}(P r)^{0.36} \mathrm{k} / 0
$$

The constants $c$ and $m$ were determined by forcing this equation to fit values obtained at $\operatorname{Re}$ of 100 and 1000 by equations $(15 a-c)$. The resulting equations are:

- $100<\operatorname{Re}<1000$

For $a / b<2$,

$$
h=c(R e)^{m}(P r)^{0.36} k / D .
$$

where

$$
\begin{aligned}
& c=0.3755(100)^{\left(-0.02 \log _{10}(a / b)\right)} \\
& m=0.58983+0.2 \log _{10}(a / b)
\end{aligned}
$$

For $a / b \geq 2$,

$$
h=0.28(\operatorname{Re})^{0.65}(\mathrm{Pr})^{0.36} \mathrm{k} / \mathrm{D}
$$

Inline Tube Arrangement

Only one set of correlations is used for the heat transfer in an inline tube bundle. These were taken from Zukauskas. (9) Again, the region from a Reynolds number of 100 to 1000 was not covered by a specific relationship. A relationship was derived from data obtained from adjacent correlations.

- Laminar, $10<\operatorname{Re}<100$ :

$$
h=0.80(\operatorname{Re})^{0.40}(\mathrm{Pr})^{0.36} \mathrm{k} / \mathrm{D}
$$


- Transitiona 1:

For $100<\operatorname{Re}<1000$,

$$
h=0.293(R e)^{0.618}(P r)^{0.36} \mathrm{k} / \mathrm{D}
$$

For $1000<\operatorname{Re}<2 \times 10^{5}$,

$$
\mathrm{h}=0.27(\mathrm{Re})^{0.63}(\mathrm{Pr})^{0.36} \mathrm{k} / \mathrm{D}
$$

- Turbulent, $\operatorname{Re}>2 \times 10^{5}$,

$$
h=0.021(\operatorname{Re})^{0.84}(\operatorname{Pr})^{0.36} \mathrm{k} / \mathrm{D} \text {. }
$$

The range of Reynolds numbers found to be optimum for the plastic tube advanced concept is from 500 to 5000 . This range includes the region in which heat transfer correlations were not available from Zukauskas. As described earlier, this region was accommodated by relationships derived from data obtained from adjacent correlations. 
NOMENCLATURE

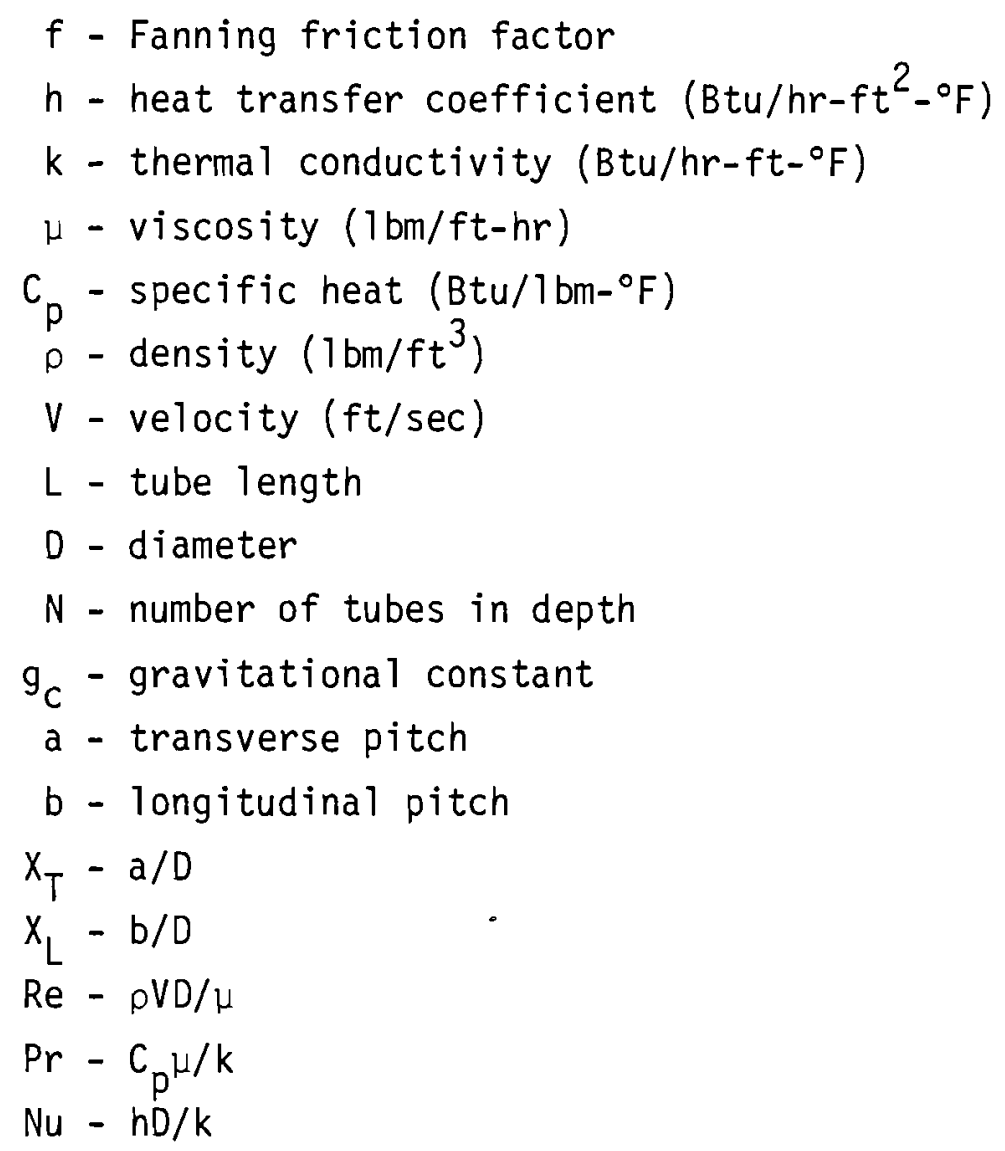




\section{HEAT TRANSFER COEFFICIENT AND FRICTION FACTOR CORRELATIONS FOR THE AMMONIA COOLING LOOP}

\section{CONDENSER/REBOILER}

The condenser/reboiler is similar in design to that of a conventional water shell and tube condenser. The differences are:

- ammonia instead of water passes through the tubes, and

- header wall thickness is increased to provide sufficient strength to withstand the pressure of the ammonia.

Condenser designs were considered with the smooth tubing used in commercial condensers built and used today and with enhanced tubing. The enhanced tubes have better heat transfer coefficients obtained by use of sintered metal on the inside surface and by use of a proprietary outside surface developed by LINDE Division of Union Carbide.

\section{Heat Transfer Correlations}

\section{Smooth Tubing}

The design of the condenser/reboiler with smooth tubing is accomplished by determining the number and length of tubes in the condenser. This is done by finding the average overall coefficient for a specific temperature difference, heat load, and tube length. To find the overall coefficient the average inside and outside heat transfer coefficients of the horizontal tubes must be determined. The outside coefficient must take into account steam velocity, condensate $f i l m$ thickness, and condensate film buildup and removal due to splashing down from one tube to the next in a bank of tubes. The following correlation, used to handle these effects, was derived by Nusseit ${ }^{(11)}$ and modified by Kern.

$$
h_{S}=.728\left(\frac{g \rho_{L}\left(\rho_{L}-\rho_{V}\right) k_{L}^{3} h_{f g}}{D_{0} \mu_{L} \Delta T_{S}}\right)^{1 / 4}\left(\frac{1}{N}\right)^{1 / 6}
$$

The original equation by Nusselt was derived with the number of tubes in depth $(N)$ in the tube bank taken to the $1 / 4$ power. Kern later modified the equation by changing it to the $1 / 6$ power so that conditions in the condenser could be better predicted. 
The steam-side coefficient obtained from equation (11) by the optimization code typically ranges from 1000 to $1500 \mathrm{Btu} / \mathrm{hr}-{ }^{\circ} \mathrm{F}-\mathrm{ft}^{2}$ for the smooth tubing.

The inside heat transfer coefficient of the smooth tubing is composed of the sum of nucleate boiling and forced convection heat transfer:

$$
h_{i}=h_{f C}+h_{B}
$$

The forced convection coefficient in equation (19) is found by the correlation developed by Dittus-Boelter: ${ }^{(7)}$

$$
h_{f C}=.023 \operatorname{Re}_{L}^{.8} \operatorname{Pr}_{L}^{.4} k_{L} / D_{i}
$$

The range of values obtained from this correlation by the optimization code is from 200 to $500 \mathrm{Btu} / \mathrm{hr}-{ }^{\circ} \mathrm{F}-\mathrm{ft}^{2}$ with liquid inlet velocities into the tubes varying from $0.5 \mathrm{ft} / \mathrm{sec}$ to $1.5 \mathrm{ft} / \mathrm{sec}$. The boiling coefficient is obtained from the correlation. developed by Rohsenow:

$$
h_{B}=\left(C p_{L} / h_{f g}(.015) \operatorname{Pr}_{L}{ }^{1.7}\right)^{3} \frac{\mu_{L} h_{f g} \Delta T_{a}^{2}}{\sqrt{\frac{\sigma}{\rho_{L}-\rho_{v}}}}
$$

The boiling coefficient ranges from 800 to $1200 \mathrm{Btu} / \mathrm{hr}-{ }^{\circ} \mathrm{F}-\mathrm{ft}^{2}$ in the optimization code.

\section{Enhanced Tubing}

Design of the condenser/reboiler with enhanced tubing is done by the same method as for smooth tubing. Different heat transfer correlations are used to obtain the inside and outside coefficients of the horizontal tubes. The correlations used for the enhanced surfaces are derived from experimental data obtained from Union Carbide Corporation, LINDE Division. The correlations are derived from two data points of heat flux versus temperature difference.

The steam-side correlation is derived from experimental data ${ }^{(13)}$ for steam condensing at one atmosphere on the outside of a single horizontal tube. The correlation is used for pressures below one atmosphere with the 
assumption that the effect of pressure does not have a large influence on the condensation coefficient. The influence of condensate film buildup due to the film of one tube falling on another tube in a tube bank is taken care of by adding to the experimental correlation the relationship for the tube bank depth (N) from equation (18). The following correlation is used to describe the condensation process.

$$
h_{s}=16700 \Delta T_{s}^{-.572}\left(\frac{l}{N}\right)^{1 / 6}
$$

The steam-side coefficients obtained by the code from equation (22) range in values from 3000 to $6000 \mathrm{Btu} / \mathrm{hr}-{ }^{\circ} \mathrm{F}-\mathrm{ft}^{2}$.

The heat transfer correlation for the ammonia-side of the enhanced tubing includes, as before, the effect of two processes; nucleate boiling and forced convection heat transfer. It is assumed that the forced convection correlation does not change from equation (21). The boiling correlation does change with the change in the tubing. The boiling correlation used was developed from experimental data ${ }^{(13)}$ for a piece of the enhanced surface heated in a pool of ammonia so that boiling occurred at different temperatures of the surface. The correlation takes the form of a constant multiplying the temperature difference between the surface and the bulk fluid temperature:

$$
h_{B}=18000 \Delta T_{a}^{1.72} \text {. }
$$

The boiling coefficients obtained from equation (23) by the optimization code range in values from 14,000 to $20,000 \mathrm{Btu} / \mathrm{hr}-{ }^{\circ} \mathrm{F}-\mathrm{ft}^{2}$.

\section{Pressure Drop Correlations}

Smooth Tubing

The correlation used to determine the pressure drop in the smooth tubes of the condenser/reboiler was developed by Lockhart and Martine 11 ${ }^{(14)}$ for two-phase flow:

$$
\Delta P=\phi_{L}^{2} f_{L} \frac{L}{D_{j}} \frac{G_{L}^{2}}{\rho_{L}}
$$


The Martinelli function $\left(\phi_{L}\right)$ is provided by a curve fit of the LockhartMartinelli parameter $(X)$ :

$$
x=f_{L} G_{L}^{2} \rho_{v} / f_{v} G_{v}^{2} \rho_{L}
$$

The Fanning friction factor ( $f$ ) is provided by four separate correlations covering three different regimes of flow. The regimes are differentiated by four ranges of Reynolds numbers.

- Laminar Regime $(0<\operatorname{Re} \leq 1600)$

$$
f=16 / \operatorname{Re}
$$

- Transition Regime $(1600<\operatorname{Re} \leq 3950)$

$$
f=.01
$$

- Turbulent Regime $(3950<\operatorname{Re} \leq 52,000)$

$$
f=.0791 / R e^{.25}
$$

- Turbulent Regime $(52,000 \leq R e)$

$$
f=.046 / \operatorname{Re}^{.20}
$$

The flow regime usually found by the code is the turbulent flow regime. The pressure drops are within one-half to two pounds per square inch.

Enhanced Tubing

The method used to determine the pressure drop through the enhanced tubes of the condenser/reboiler is the same as for the smooth tubes.

\section{TOWER}

\section{Arrangements}

The arrangements of the tower depend on the type of flow inside the tube of the tower. The type of flow also affects the cost of the heat exchangers, the tower structure, and the piping to and in the towers. The two types of flow in the tubes are countercurrent and cocurrent.

\section{Countercurrent Flow}

The flow arrangement in the dry cooling tower in the inside of the tubes is irnportant in terms of cost. If a counterflow arrangement as 
shown in Figure A-2 could be used, the cost associated with the structure and the piping could be greatly reduced as shown by a probable structural and piping arrangement in Figure A-3. One problem with counterflow situations is that entrainment of liquid (flooding) at the liquid-vapor interface can occur if certain conditions are present. For ammonia with its low surface tension and high vapor density, the condition of flooding does occur at low superficial vapor velocities $(2-3 \mathrm{ft} / \mathrm{sec})$ which requires that the length of a one-inch diameter tube be not above 17 feet in the tower if flooding is not to occur. Because the tubing in the tower would be longer than the minimum nonflooding length and because of the uncertainty of what happens to the inside heat transfer coefficient (enhancement or degregation) when flooding occurs, the countercurrent flow scheme was not pursued any further.

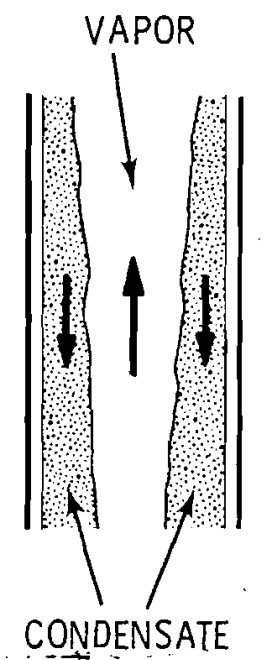

FIGURE A-2. Countercurrent Flow

\section{Cocurrent Flow}

The three cocurrent flow conditions possible in a condensation process are shown in Figures $A-4$ through $A-6$. The stratified flow condition in Figure A-4 results when low vapor velocities occur in the tubes which are either sloped or horizontal. Figure A-5 shows annular flow which occurs when high vapor velocities are prevalent in horizontal tubes and low and high vapor velocities in vertical tubes. Figure A-6 shows annular flow with mist in the vapor core which occurs at very high vapor velocities in 
both horizontal and vertical tubes. The last situation does not occur in an air-cooled condensation process because of the high heat transfer rate needed to obtain high vapor velocities.

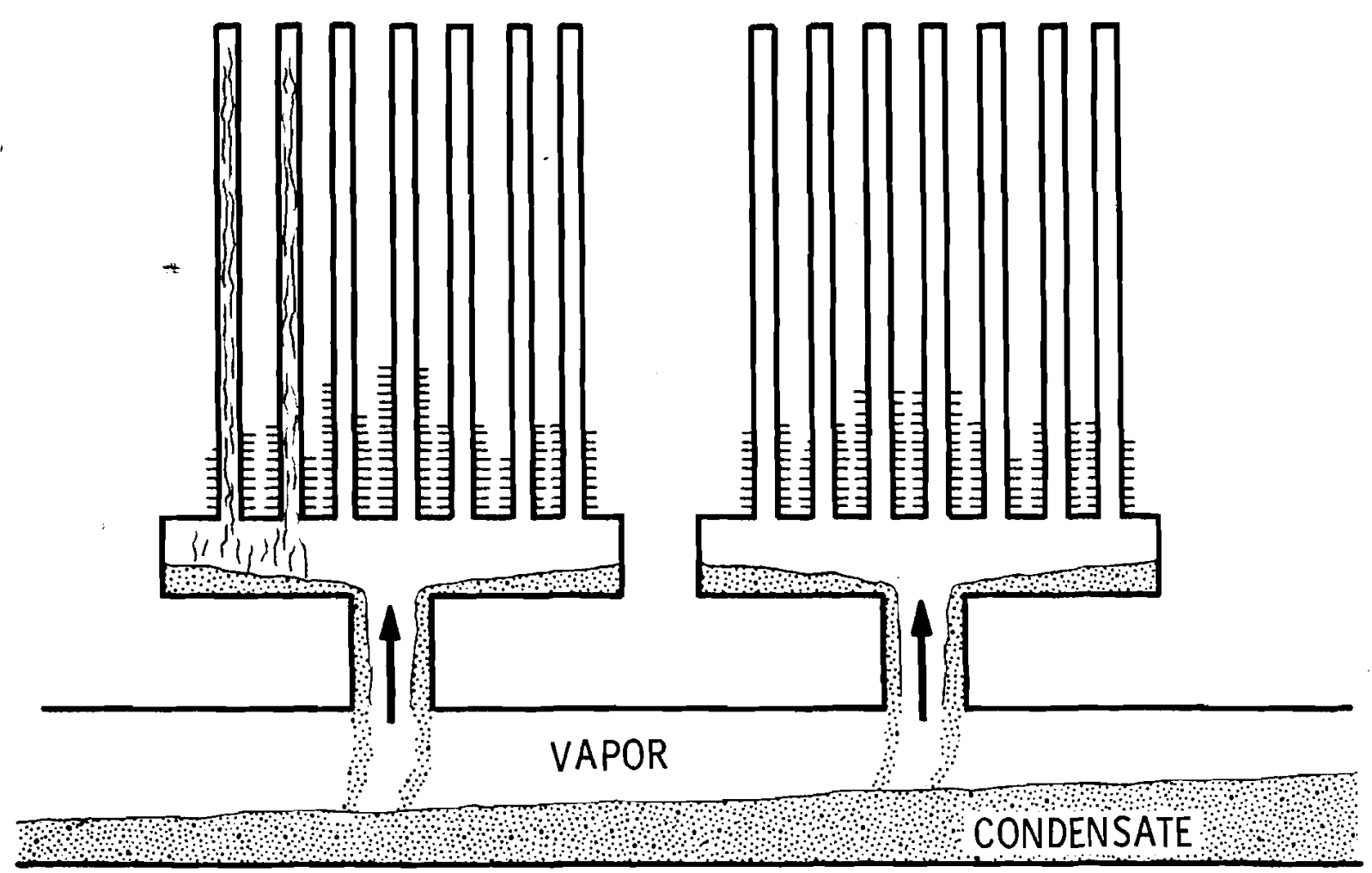

FIGURE A-3. Probable Structural and Piping Arrangement for Countercurrent Flow

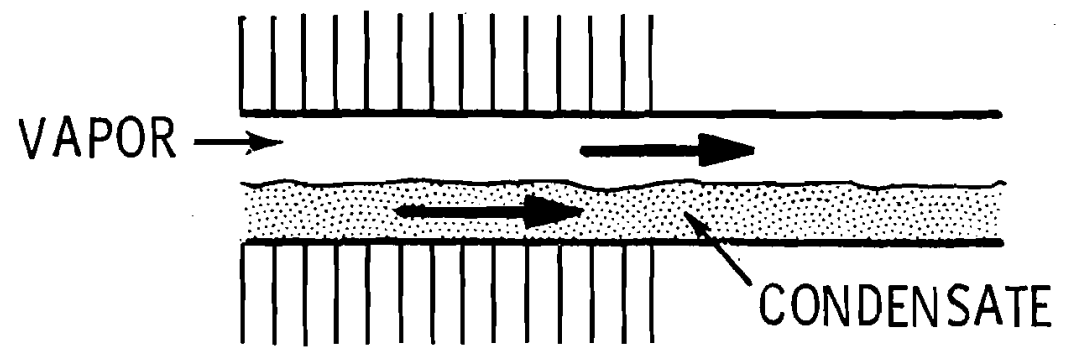

FIGURE A-4. Stratified Flow 


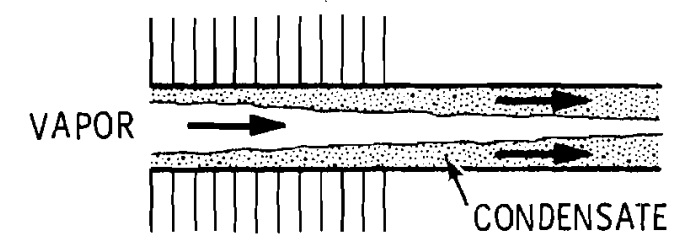

FIGURE A-5. Annular Flow

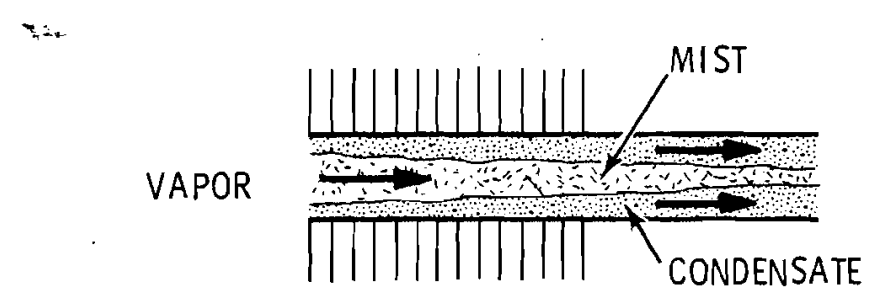

FIGURE A-6. Annular Flow with Mist

\section{Tower Configuration}

Two types of towers can be used when cocurrent flow is on the inside of the tubes. One is the rectilinear tower, shown in Figure A-7, which can handle both horizontal and sloped tubing. Because all or some of the weight of the heat exchanger plus the coolant must be supported by the structure of the tower, the structural cost for the rectilinear towers is greater than for the round tower. As shown in Figure $A-8$, the round tower supports the heat exchanger along the tower periphery, decreasing the structural cost.

When the rectiliner tower was investigated for the SOA system, it was found slightly more costly than the circular tower. So the analysis for the SOA system was mainly done with circular towers. When the difference between the circular and the rectilinear towers for the PLASTIC system was evaluated, a definite savings with the circular towers was realized. 


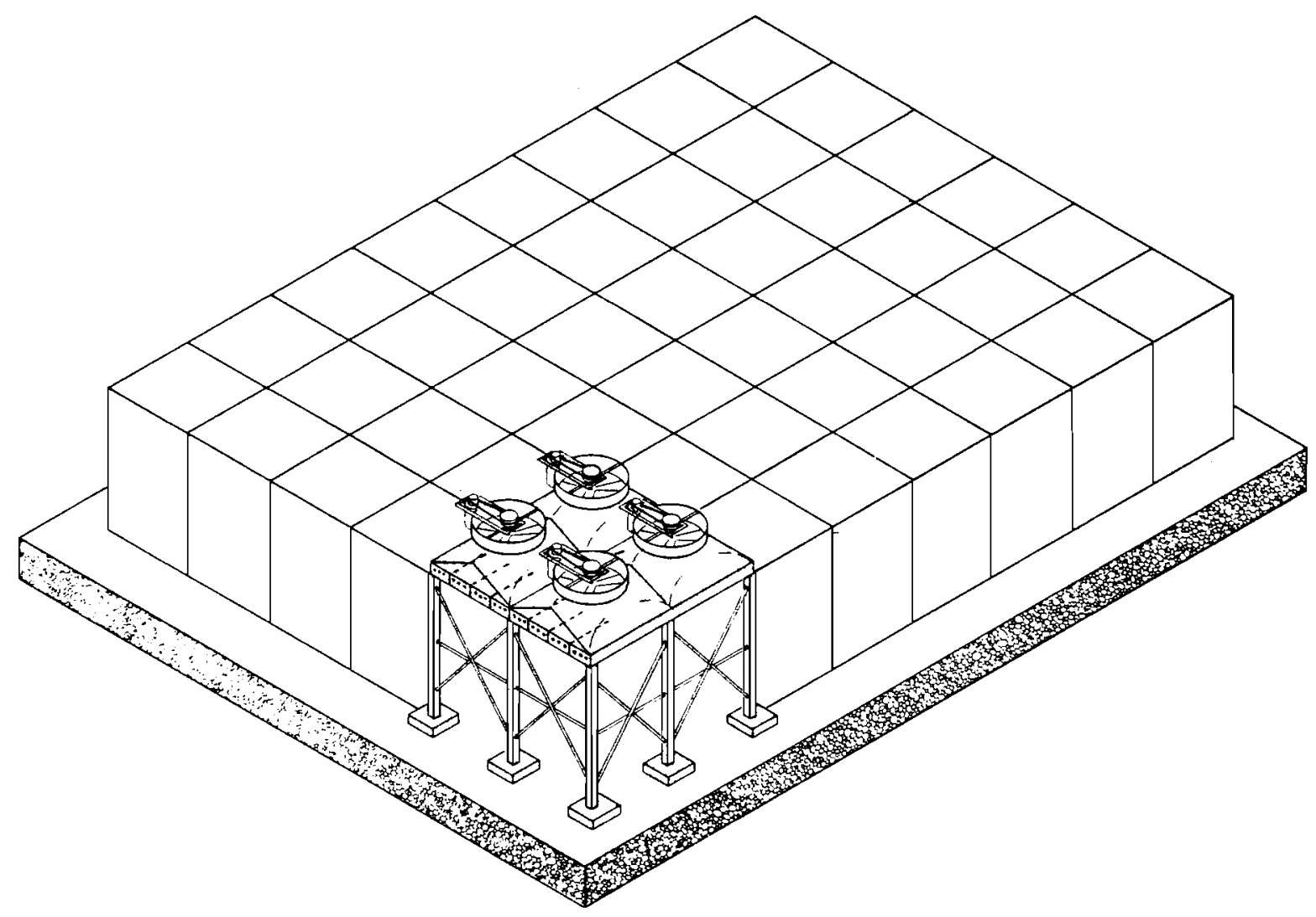

FIGURE A-7. Rectangular Tower

Because the major part of the analysis for the SOA and the PLASTIC systems was done with the circular tower, it was decided to analyze the $\mathrm{NH}_{3}$ system with circular towers. The $\mathrm{NH}_{3}$ system was not analyzed with rectilinear towers.

\section{Heat Transfer Correlations - Tower Heat Exchanger}

\section{Air-Side}

The air-side heat transfer correlations are the same as those described for the metal finned tube system.

\section{Ammonia-Side}

Because the condensation of ammonia only takes place in the vertical section of the tubes of the heat exchanger, three flow regimes must be modeled to find the correct heat transfer coefficient. All the regimes 
depend on the thickness of the average condensate layer and the velocity of the vapor entering the tube. This depends on whether the gravity force or the vapor shear force is the predominating force.

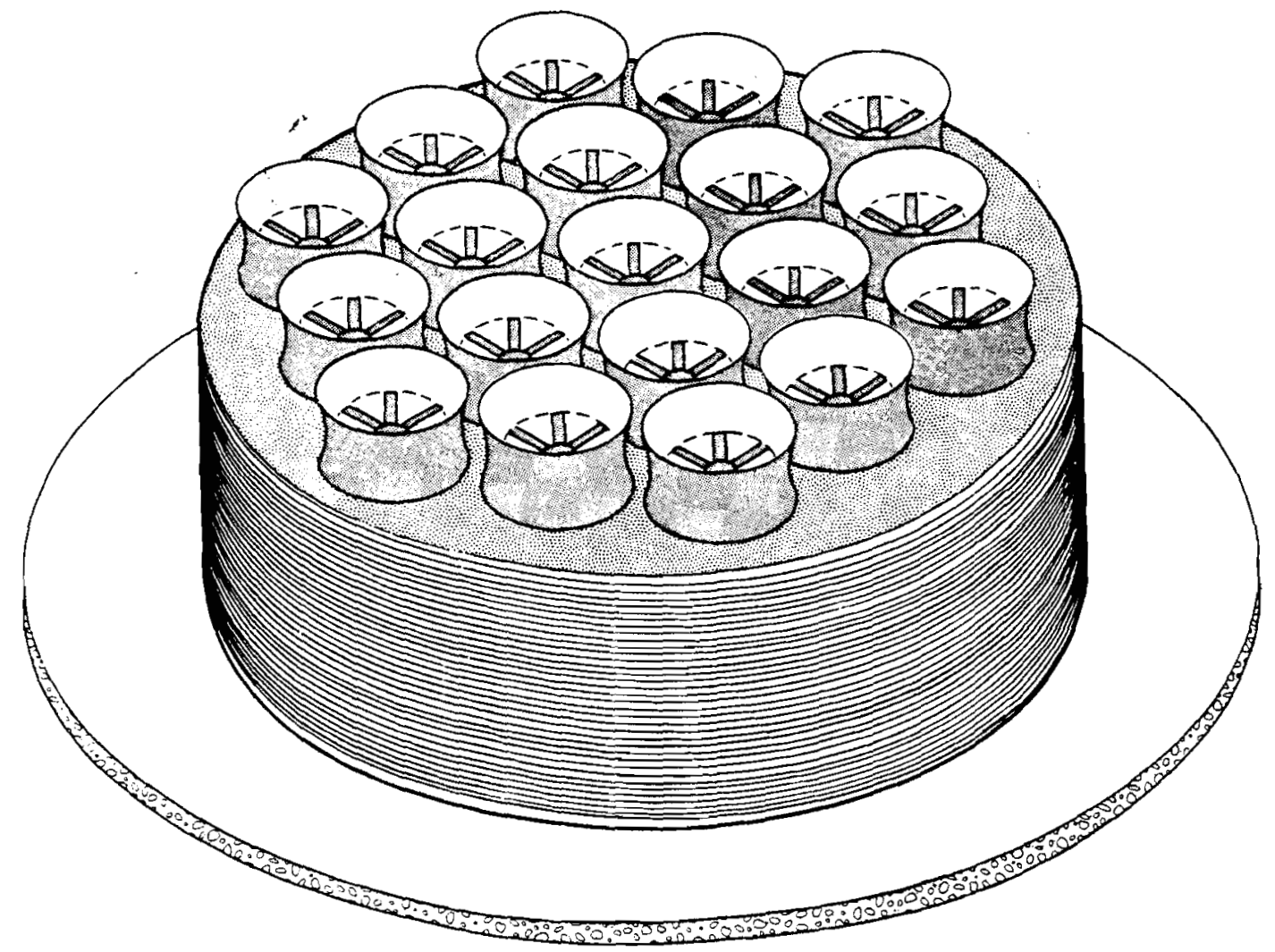

FIGURE A-8. Circular Tower

When the average condensate thickness is small and the velocity of the vapor is low (gravity force predominates over the vapor shear force) the resulting laminar film condensation can be predicted with the classical analysis of Nusselt as embodied in the following equation.

$$
h_{i}=1.47 K_{L}\left(g \sin \theta \rho_{L}\left(\rho_{L}-\rho_{V}\right) / \mu_{L}^{2}\right)^{1 / 3} /\left(\operatorname{Re}_{L}\left(1-x_{0}\right)\right)^{1 / 3}
$$

If the condensate thickness is large or the velocity of the vapor is of medium velocity (gravity force still predominates over the vapor shear 
force) the resulting turbulent film condensation can be predicted by the correlation developed by Kirkbride: $(15,16)$

$$
h_{i}=.0077 K_{L}\left(g \sin \theta \rho_{L}\left(\rho_{L}-\rho_{V}\right) / \mu_{L}^{2}\right)^{1 / 3}\left(\operatorname{Re}_{L}\left(1-x_{0}\right)\right)^{.4} .
$$

When the arnular ring of condensate is mainly controlled by the vapor shear force (predominating over the gravity force), the correlation by Boyko and kruzhilin (17) was used for the turbulent liquid flim heat transfer coefficient:

$$
h_{i}=.024 K_{L} \operatorname{Re}_{L} .8 \operatorname{Pr}_{L} .43 / D_{i} \frac{\sqrt{1+\left(\rho_{L} / \rho_{V}-1\right) x_{i}}+\sqrt{1+\left(\rho_{L} / \rho_{V}-1\right) x_{0}}}{2}
$$

The range of values found by the optimization code for the inside coefficient is from 1000 to $1600 \mathrm{Btu} / \mathrm{hr}-{ }^{\circ} \mathrm{F}-\mathrm{ft}^{2}$. The Reynolds number based on the liquid varies from 5000 to 15,000 with the entering vapor velocity ranging from 10 to 20 feet per second. The correlation most often used by the code to define the inside coefficient is equation (31).

\section{Pressure Drop Correlation - Tower Heat Exchanger}

The two-phase pressure drop in the tubes of the heat exchanger is found by the same set of equations as for the pressure drop in the condenser/ reboiler. The only difference is that the Martinelli function $\left(\phi_{L}\right)$ is provided by a functional relationship of the Lockhart-Martinelli parameter $(X)$ and not as a curve fit of the parameter.

\section{$\underline{\text { PIPING }}$}

\section{Pressure Drop Correlations}

The pressure drop correlations in the optimization code are used to calculate the pressure drops for the supply and return piping. The supply piping transports vapor while the return line transports liquid.

The pressure drop in the vapor line is found on an incremental basis where each length of pipe of a particular diameter is divided into ten sections. The pressure drop across each section is calculated; then new vapor properties are found to be used to find the pressure drop in the next section. 
The pressure drop in the liquid line is calculated for the whole length of pipe of one specific diameter.

Supply Piping

The pressure drop in the supply piping of the cooling loop is calculated by using the Fanning equation:

$$
\Delta P=4 f_{v} \frac{L}{D_{i}} \frac{G_{v}^{2}}{2 p_{v}}
$$

The pressure drops found by the optimization code vary from approximately 10 to 20 pounds per square inch.

\section{Return Piping}

The pressure drop in the return piping is also calculated by using the Fanning equation.

$$
\Delta P=4 f_{L} \frac{L}{D_{i}} \frac{G_{L}^{2}}{2 \rho_{L}}
$$

The pressure drops for the return piping vary from about 2 to 6 pounds per square inch.

\section{Temperature Drop Correlation}

Shown in Figure A-9 is a pressure-enthalpy diagram of the vapor dome for ammonia and a typical cycle ammonia passes through when it goes around the cooling loop. The diagram shows five important points of the cycle. Point $A$ to Point $B$ shows what happens to the ammonia in the condenser/ reboiler. Point $C$ to Point $D$ shows the condensation of ammonia in the tower.

Point $B$ to Point $C$ is what occurs in the piping from the condenser/ reboiler to the dry tower. The process is controlled by the pressure drop in the pipeline. Since the transfer of heat through the pipe walls is negligible and no pumping is done on the vapor the process through the pipe is isenthalpic. With the flow being isenthalpic and having a pressure drop the ammonia encounters a temperature drop from the beginning to the end of the supply piping. 


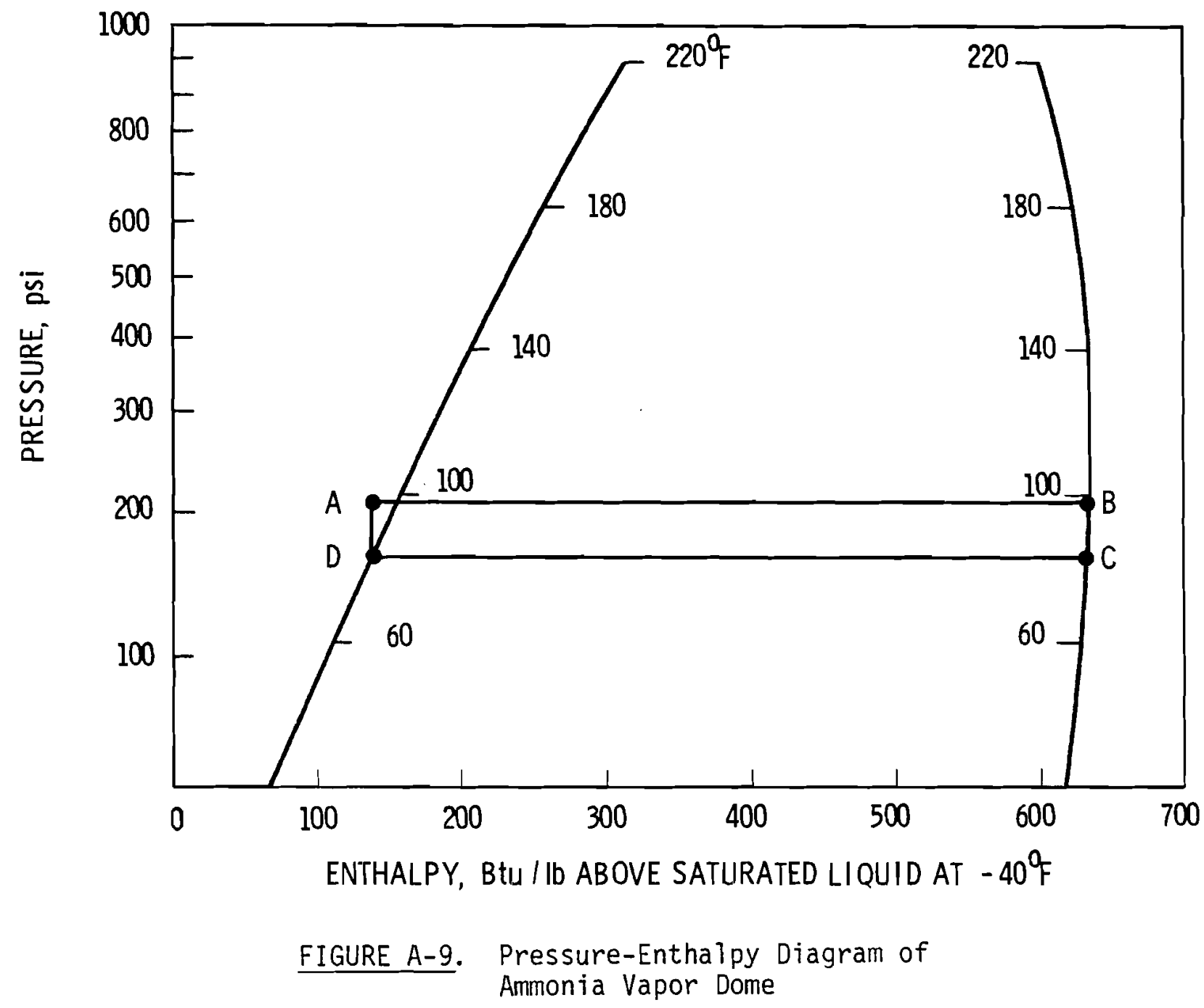


The pressure and temperature drops are calculated along the main piping and the quadrant supply runs by dividing the pipes into ten sections and calculating the pressure drop for each section. The temperature drop is calculated for each section of pipe by using the new pressure at the end of each section and a curve fit of the saturation line of pressure versus temperature.

$$
P=a+b T+c T^{2}
$$

The optimization code typically calculates a temperature drop of the vapor from 3 to $5^{\circ} \mathrm{F}$. 


\section{NOMENCLATURE}

g - acceleration of gravity $\left(\mathrm{ft} / \mathrm{hr}^{2}\right)$

$\rho_{L}$ - density of riquid $\left(1 \mathrm{bm} / \mathrm{ft}^{3}\right)$

$p_{V}$ - density of vapor $\left(1 \mathrm{bm} / \mathrm{ft}^{3}\right)$

$K_{L}$ - thermal conductivity of 1 iquid $\left(B t u / h r-{ }^{\circ} \mathrm{F}-\mathrm{ft}\right.$ )

$h_{f g}$ - heat of vaporization (Btu/ibm)

$D_{0}$ - outside diameter of tube (in)

$D_{i}$ - inside diameter of tube (in)

$\mu_{L}$ - viscosity of liquid $(1 \mathrm{bm} / \mathrm{ft}-\mathrm{hr})$

$\mathrm{N}$ - number of tubes in depth

$\Delta T_{S}$ - temperature difference between saturated steam and tube surface $\left({ }^{\circ} \mathrm{F}\right)$

$h_{i}$ - inside heat transfer coefficient of tube (Btu/hr- ${ }^{\circ} \mathrm{F}-\mathrm{ft}$ )

$h_{f c}$ - inside heat transfer coefficient of tube due to forced convection (Btu/hr- ${ }^{\circ} \mathrm{F}-\mathrm{ft}^{2}$ )

$h_{B}$ - inside heat transfer coefficient of tube due to boiling (Btu/hr- ${ }^{\circ} \mathrm{F}-\mathrm{ft} \mathrm{t}^{2}$ )

$\operatorname{Re}_{L}$ - liquid Reynolds number

$\mathrm{Pr}_{L}$ - liquid Prandtl number

$C \mathrm{P}_{L}$ - liquid specific heat (Btu/lbm- ${ }^{\circ} \mathrm{F}$ )

$\Delta T_{a}$ - temperature difference between saturated ammonia and inside tube surface, $\left({ }^{\circ} \mathrm{F}\right)$

$\sigma$ - surface tension of 1 iquid $(1 \mathrm{~b} / \mathrm{ft})$

$\Delta P$ - pressure drop $\left(1 \mathrm{~b} / \mathrm{ft}^{2}\right)$

$\phi_{L}$ - Martinelli function

$X$ - Lockhart-Martine 11 i parameter

$f_{L}$ - liquid friction factor 


$$
\begin{aligned}
& f_{v} \text { - vapor friction factor } \\
& L \text { - length of pipe (ft) } \\
& G_{L} \text { - mass flux of liquid }\left(1 \mathrm{bm} / \mathrm{ft}^{2}-\mathrm{hr}\right) \\
& G_{v} \text { - mass flux of vapor }\left(1 \mathrm{bm} / \mathrm{ft}^{2}-\mathrm{hr}\right) \\
& \theta \text { - angle of tubes from the horizontal } \\
& X_{0} \text { - quality of fluid leaving tubes } \\
& X_{i} \text { - quality of fluid entering tubes }
\end{aligned}
$$




\section{APPENDIX REFERENCES}

1. K. K. Robinson and D. E. Briggs, "Pressure Drop of Air Flowing Across Triangular Pitch Banks of Finned Tubes." Chemical Engineering Progress Symposium Series. 62(64): 1966.

2. D. E. Briggs and E. H. Young, "Convection Heat Transfer and Pressure Drop of Air Flowing Across Triangular Pitch Banks of Finned Tubes." Chemical Engineering Progress Symposium Series. 59(41): 1963.

3. Heat Transfer and Pressure Drop Characteristics of Dry Tower Extended Surfaces, Part II: Data Analys is and Correlation. PFR Engineering Systems Inc., Marina del Rey, CA, June 15, 1976.

4. C. Weierman, J. Taborek and W. J. Marner, Comparison of the Performance of Inline and Staggered Banks of Tubes with Segmented Fins. Heat Transfer Research, Inc., Alhambra, CA, August 1975.

5. Heat Transfer and Pressure Drop Characteristics of Dry Tower Extended Surfaces, Part I: Heat Transfer and Pressure Drop Data. PFR Engineering Systems, Inc., Marina del Rey, CA, March 1, 1976.

6. P. A. Ard, C. H. Henager, D. R. Pratt and L. E. Wiles, Cost Analysis and Algorithms for Dry Cooling Tower Systemis. BNWL-2123, Battelle, Pacific Northwest Laboratories, Richland, WA 99352, November 1976.

7. F. W. Dittus and L. M. K. Boelter, Univ. Calif., Pubs. Eng. 2: 443, 1930.

8. W. Z. Nusse1t, "Die Abhangigkeit der Wärmeïbergangszahl Von der Rohrlänge." Zeitschr. V.D.I. 54: 1910.

9. A. Zukauskas, "Heat Transfer from Tubes in Crossflow." Academy of Sciences of the Lithuanian SSR, republished in Advances in Heat Transfer, Volume 8. The Academic Press, 1972.

10. W. A. McAdams, Heat Transmission. McGraw-Hil1 Book Co., New York, NY, 1954.

11. W. Z. Nusse1t, Ver. Dent. Ing. 60: 541, 569, 1916.

12. W. M. Rohsenow, "Heat Transfer with Boiling." Modern Developments in Heat Transfer. Pp. 85-158, 1963.

13. Heat Rejection by Dry Cooling in Steam Electric Power Stations. LINDE Division, Union Carbide, New York, NY, April 1976.

14. R. W. Lockhart and R. C. Martinelli, "Proposed Correlations for Isothermal Two-Phase, Two-Component Flow in Pipes." Chem. Eng. Prog. 45: $39,1949$. 
15. C. G. Kirkbride, Trans. Am Inst. Chem. Engrs. 30: 170-186, 1933-1934.

16. C. G. Kirkbride, Ind. Eng. Chem. 26: 425-428, 1934.

17. L. D. Boyko and G. N. Kruzhilin, Int. Jour. Heat and Mass Transfer. 10: $361-373,1967$. 



\section{DISTRIBUTION}

No. of

Copies

\section{OFFSITE}

A. A. Churm

Chicago Patent Group

Energy Research and

Development Administration

9800 South Cass Avenue

Argonne, IL 60439

Office of Assistant General Counsel for Patents

Energy Research and

Development Administration

Washington, DC 20545

27 ERDA Technical Information Center

10 I. Helms

Advanced Concepts Evaluation

Branch - F-309

ERDA Division of Nuclear

Research and Application

Washington, DC 20545

W. F. Savage

Chief, Advanced Concepts Evaluation Branch

ERDA Division of Nuclear Research and Application

Washington, DC 20545

D. C. Bauer

Director, Division of Nuclear Research and Application

Energy Research and Development Administration

Washington, DC 20545

W. E. Mott

Director, Energy Control Technology

ERDA Division of Biomedical and Environmental Research

Washington, DC 20545
No. of

Copies
B. R. Dickey

Allied Chemical Company

550 2nd Street

Idaho Falls, ID 83401

J. S. Joyce

All is-Chalmers Power

Systems, Inc.

1135 South 70th Street

West Allis, WI 53214

E. T. Wanderer

A luminum Company of America

Algoa Technical Center

Alcoa Center, OH 45069

H. J. Janzon

American Electric Power

2 Broadway

New York, NY 10004

T. Woods

Arizona Public Service Co.

2121 W. Cheryl Drive

Phoenix, AZ 85021

M. W. Peterson

Babcock \& Wilcox

Fossil Power Division

20 South Van Buren

Barberton, OH 44203

G. C. Cree1

Baltimore Gas \& Electric Co.

Gas \& Electric Building

Baltimore, MD 21203

E. Schinner

Baltimore Aircoil Co., Inc.

P.0. Box 7322

Bàltimore, MD 21227 
No. of

Copies

J. P. Budliger

Battelle-Geneva

7 Route De Drizi

1227 Geneva, SWITZERLAND

$P$. Leung

Bechtel Corporation

P.0. Box 60860

Terminal Annex

Los Angeles, CA 90060

G. R. Retti

Bechtel Corporation

P.0. Box 3965

San Francisco, CA 94119

J. P. Rossie

R. W. Beck and Associates

400 Prudential Plaza

Denver, C0 80202

B. Westre

Black Hills Power and Light Company

P.0. Box 1400

Rapid City, SD 57701

L. E. Stamets

California State Energy

Resources Conservation and

Development Commission

1111 Howe Avenue

Sacramento, CA 95825

J. Sell

Carolina Power \& Light Co. 336 Fayettesville Street

Raleigh, NC 27602

$\mathrm{J}$. Morse

Catalytic Construction Corp.

P.0. Box 11402

Charlotte, NC 28029
No. of

Copies

H. H. Osborn

Combustion Engineering

Air Preheater Company

Wellsville, NY 14895

R. H. Holyoak

Commonwealth Edison

One First Plaza

P.0. Box 767

Chicago, IL 60690

C. L. Newman

Consolidated Edison Co. of New York, Inc.

4 Irving Place

New York, NY 10003

W. A. Messner

Consolidated Edison Co. of New York, Inc.

4 Irving Place

New York, NY 10003

F. K. Moore

Cornell University

I thaca, NY 14850

R. J. Haberski

Curtiss-Wright Corp.

One Passaic Street

Wood Ridge, NJ 07075

S. K. Blackley

Duke Power Company

P.0. Box 2178

Charlotte, NC 28201

E. Guyer

Dynatech Company

99 Erie Street

Cambridge, MA 02139 
No. of

Copies

J. K. Swindt

Ecodyne Cooling Products Co.

San Rosa, CA 95403

J. Maulbetsch

Electric Power Research

Institute

3412 Hillview Avenue

P.0. Box 10412

Pa10 Alto, CA 94304

L. Geller

Empire State Electric Energy Research Corp.

1250 Broadway

New York, NY 10001

M. Maxwe11 (MD-61)

IERL-RTP

Environmental Protection Agency

Research Triangle Park, NC 27711

F. H. Rainwater

Environmental Protection Agency

Pacific Northwest Water Laboratory

200 S.W. 35th Street

Corvallis, OR 97330

W. Hoydisch

Environmental Sciences and Services

44-43 37th Street

Long Island City, NY 11101

E. L. Damon

Fostor Wheeler Energy Co.

110 S. Orange Avenue

Livingston, NJ 07039

A. M. Rubin

Franklin Institute

Twentieth \& Parkway

Philadelphia, PA 19103
No. of

Copies

B. Davis

GEA Airexchangers, Inc.

46 Worthington Drive

Maryland Heights, MD 63043

A. C. Eulberg

General Atomic

P.0. Box 81608

San Diego, CA 92138

E. H. Miller

General Electric Co.

Large Steam Turbine Division

300 Nott Street

Schenectady, NY 12301

R. K. Shah

Harrison Radiator Division

General Motors Corp.

Lockport, NY 14094

J. F. Sebald

Gilbert Associates, Inc.

525 Lancaster Avenue

Reading, PA 19603

J. E. Taboric

Heat Transfer Research Inc.

1000 S. Fremont Avenue

Alhambra, CA 91802

E. C. Smith

Hudson Products

6855 Horwin Drive

Houston, TX 77036

M. W. Larinoff

Hudson Products

6855 Horwin Drive

Houston, TX 77036

W. R. Scott, Jr.

Ingersol1-Rand

Phillipsburg, NJ 08865 
No. of

Copies

C. Rocco

Italimpianti - Societa

Italiana Impianti p.a.

Piazza, Piccapietra 9

18121 Genoa, ITALY

J. L. Mulloy

Los Angeles Department of Water and Power

$111 \mathrm{~N}$. Hope Street

Los Angeles, CA 90012

R. J. Meyer

Louisiana Power \& Light Co.

142 Delaronde Street

New Orleans, LA 70174

E. S. Miliaras

The Charles T. Main Co.

Southeast Tower

Prudential Center

Boston, MA 02199

R. Landon

Marley Co.

5800 Fox Ridge Drive

Mission, KS 66202

L. R. Glicksman

Massachusetts Institute of Technology

77 Massachusetts Avenue

Cambridge, MA 02139

M. W. Golay

Massachusetts Institute of Technology

77 Massachusetts Avenue

Cambridge, MA 02139

R. Harleman

Department of Civil Engineering

Massachusetts Institute of

Technology

77 Massachusetts Avenue

Cambridge, MA 02139
No. of

Copies

A. J. Vander Weyden

McDonnel Douglas Astronautics Co.

5301 Bols Avenue

Huntington Beach, CA 92647

R. Hofacher

Montana Power Co.

40 E. Broadway

Butte, MT 59701

W. G. Hoydysn

New York University

University Heights

New York, NY 10453

W. Kals

Niagara Blower

405 Lexington Avenue

New York, NY 10017

R. H. Meyer

Northeast Utilities

P.0. Box 270

Hartford, CT 06101

L. P. Davis

Department of Mechanical

Engineering

Oregon State University

Corvalitis, OR 97330

C. E. Wicks

Department of Chemical

Eng ineering

Oregon State University

Corvallis, OR 97330

J. G. Knudson

Engineering Experiment Station

Oregon State University

Corvallis, OR 97330

J. W. Miche 1

OTEC Heat Exchange Project

Activity

Oak Ridge National Laboratory

Box Y

Oak Ridge, TN 37830 
No. of

Copies

A. A. Ariey

Pacific Gas \& Electric

77 Beale Street

San Francisco, CA 94106

F. F. Mautz

Pacific Gas \& Electric

77 Beale Street

San Francisco, CA 94106

P. G. Humphries

Pacific Power \& Light Co.

Public Service Bldg.

Portland, OR 97204

D. G. Pfeiffer

Pennsylvania Power \& Light

2 North Ninth Street

Allentown, PA 18101

T. Rozenmann

PFR Engineering Systems, Inc.

Suite 832

4676 Admiralty Way

Marina del Rey, CA 90291

Prof. Ing. Carlo Roma

Piazza delle Muse 8

Rome, ITALY

G. L. Henderson

Power Generation Cooling Systems

4714 - 52nd Street S.

Seattle, WA 98118

R. F. Walker

Public Service of Colorado

5900 E. 39th Avenue

Denver, CO 80207

J. D. Maddox

Public Service of New Mexico

Corporate Planning Dept.

Albuquerque, NM 87103
No. of

Copies

G. E. Collins

Research Cottrell

Hamon Cooling Tower Division

Box 750

Bound Brook, NJ 08805

R. Lindberg

Reynolds Aluminum Co.

Reynolds Metallurgical

Research Laboratory

Richmond, VA 23261

R. G. Lacy

San Diego Gas \& Electric

101 Ash Street

San Diego, CA 92107

R. L. Skone

Seattle City Light

1015 Third Ave.

Seattle, WA 98104

F. A. McCracken

Southern California Edison

2244 Walnut Grove Avenue

Rosemead, CA 91770

P. Sporn

Consultant Engineer

74 Trinity P1., Suite 511

New York, NY 10006

A. L. London

Department of Mechanica 1

Engineering

Stanford University

Stanford, CA 94305

J. Y. Parce

Stearns and Rogers

$700 \mathrm{~S}$. Ash Street

Denver, CO 80222

D. H. Guild

Stone \& Webster Engineering Corp.

225 Franklin Street

Boston, MA 02107 
No. of

Copies

H. I. Wilson

Tampa Electric Co. P.0. Box 111

Tampa, FL 33601

W. Keel

Texas Electric Service Co.

115 W. Seventh Street

Fort Worth, TX 76102

A. A. Ward

Tucson Gas \& Electric

220 W. 6th Street

Tucson, AZ 85701

J. Bartz

Union Carbide Corp.

Linde Division

61 East Park Drive

Tonawanda, NY 14150

G. J. Kidd

Union Carbide Corp.

ORGDP - K-25

P.0. Box D

Oak Ridge, TN 37803

F. Notaro

Union Carbide Corp.

Linde Division

61 East Park Drive

Tonawanda, NY 14150

G. A. Englesson

United Engineers \&

Constructors

1401 Arch Street

Philadelphia, PA 19105

K. Simhan

University of Bremen

Bremen, WEST GERMAIVY

J. F. Kennedy

University of Iowa

Hydraulic Research Institute

Iowa City, IA 52240
No. of

Copies

J. H. Hutchinson

Utah Power \& Light

1407 W. N. Temple

Salt Lake City, UT 84103

S. Ragone

Virginia Electric \& Power Co. 700 E. Franklin Street

Richmond, VA 23261

J. T. Kimball

Washington State University

College of Engineering

Pullman, WA 99163

D. L. 01 son

Washington Water Power Co.

E. 1411 Mission Avenue

Spokane, WA 99202

G. H. Soule

West Associates

Sierra Pacific Power Co.

100 E. Moana Lane

Reno, NV 89510

J. A. Barnett

Executive Director

Western States Water Council

220 South 2nd East

Suite 200

Salt Lake City, UT 84111

G. J. Silvestri

Westinghouse Electric Corp.

Steam Turbines Division

Lester Branch

Box 9175

Philadelphia, PA 19113

K. A. Oleson

Westinghouse Electric Corp.

Steam Turbines Division

Lester Branch

Box 9175

Philadelphia, PA 19113 
No. of

Copies

L. E. Wilkinson

Consultant

6582 Ganon Street, S.E.

Salem, OR 97301.

\section{ONSITE}

ERDA Richland Operations Office Energy Programs Division

H. E. Ransom

Westinghouse Hanford Company Hanford Engineering Development Laboratory

J. Fletcher

\section{Battelle-Northwest}

R. T. Allemann

P. A. Ard

D. J. Braun

D. J. Braun

J. W. Currie

D. E. Deonigi

R. L. Dillon

D. W. Dragnich

R. L. Drake

D. W. Faletti

J. W. Finnigan

B. C. Fryer

J. J. Hauth

A. J. Haverfield

C. H. Henager

A. B. Johnson

W. S. Kelly

R. S. Kemper

C. J. Knoll

W. V. Loscutoff

R. P. Marshall

D. E. Olesen

Y. Onishi

L. T. Pedersen

H. C. Riches

J. B. Schuette
No. of

Copies 
